\title{
品程口 . 回跓
}

TÓPICOS EM CIÊNCIAS DA SAÚDE

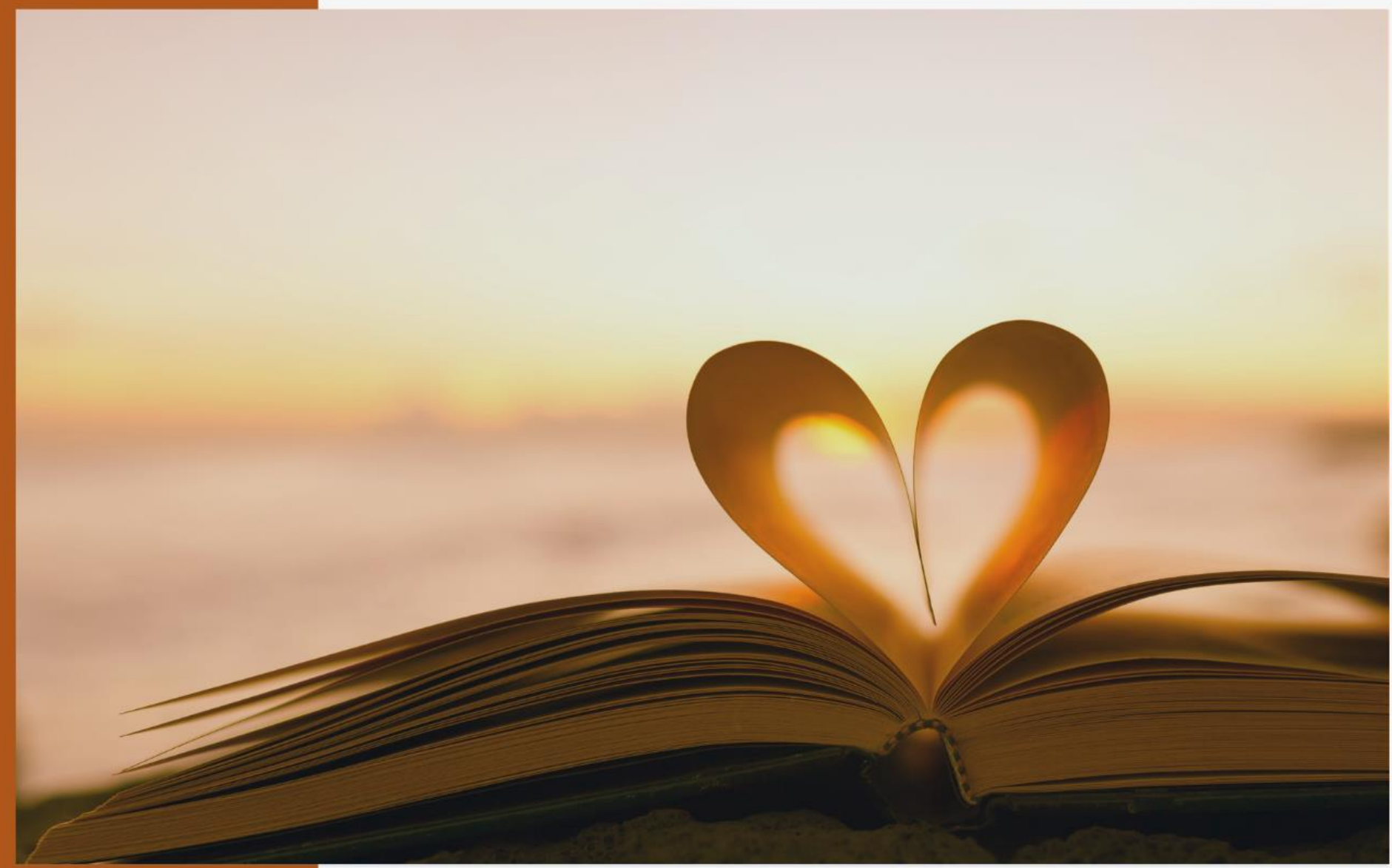

$\frac{q}{\underline{g}}$

Gleica Soyan Barbosa Alves

Eliene de Oliveira

(Organizadoras)

Ano 2021

Editora Poisson 
Gleica Soyan Barbosa Alves

Eliene de Oliveira

(Organizadoras)

Tópicos em Ciências da Saúde Volume 25

1a Edição

Belo Horizonte

Poisson

2021 
Editor Chefe: Dr. Darly Fernando Andrade

\section{Conselho Editorial}

Dr. Antônio Artur de Souza - Universidade Federal de Minas Gerais

Msc. Davilson Eduardo Andrade

Dra. Elizângela de Jesus Oliveira - Universidade Federal do Amazonas

Msc. Fabiane dos Santos

Dr. José Eduardo Ferreira Lopes - Universidade Federal de Uberlândia

Dr. Otaviano Francisco Neves - Pontifícia Universidade Católica de Minas Gerais

Dr. Luiz Cláudio de Lima - Universidade FUMEC

Dr. Nelson Ferreira Filho - Faculdades Kennedy

Msc. Valdiney Alves de Oliveira - Universidade Federal de Uberlândia
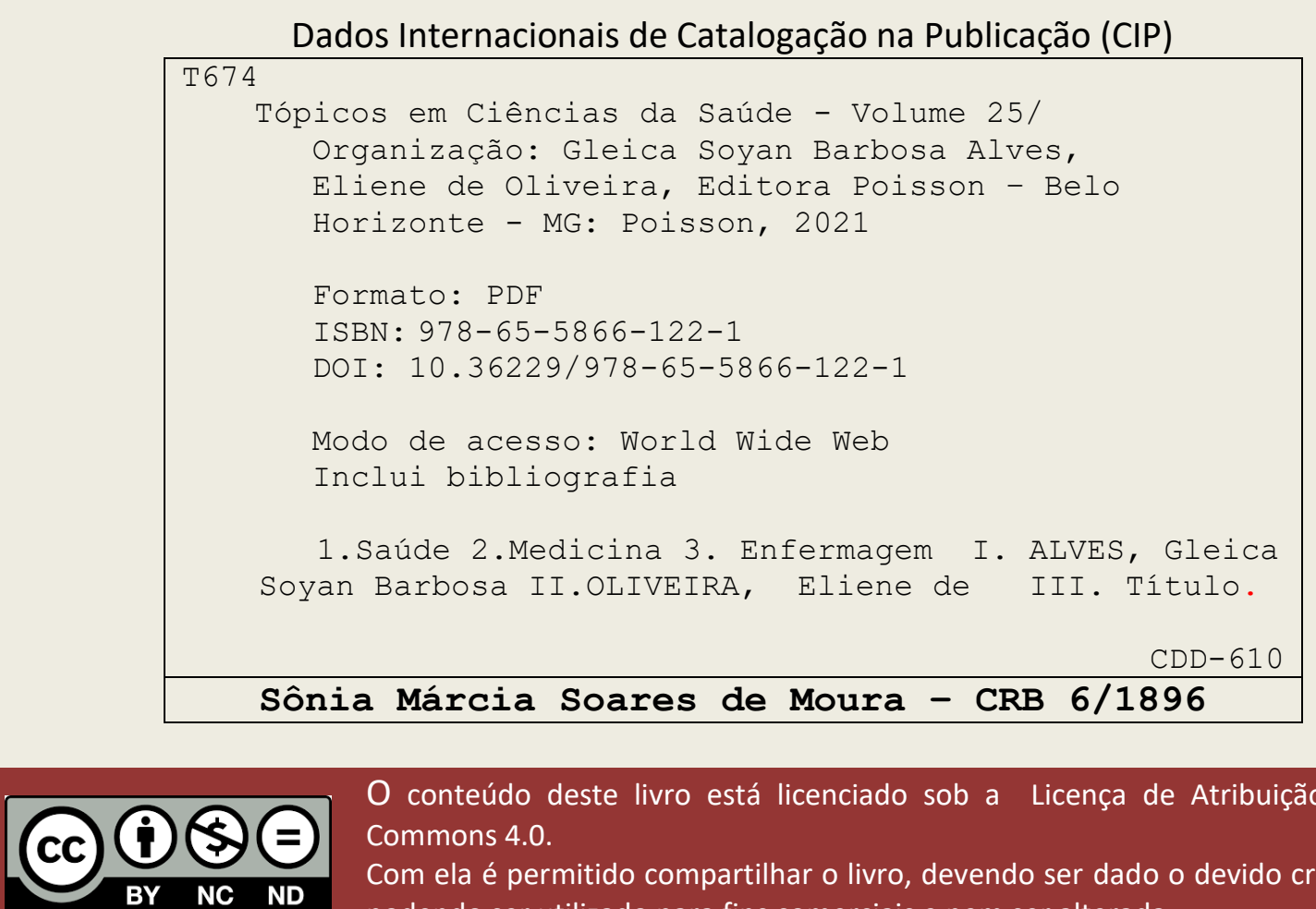

O conteúdo deste livro está licenciado sob a Licença de Atribuição Creative Commons 4.0.

Com ela é permitido compartilhar o livro, devendo ser dado o devido crédito, não podendo ser utilizado para fins comerciais e nem ser alterada.

O conteúdo dos artigos e seus dados em sua forma, correção e confiabilidade são de responsabilidade exclusiva dos seus respectivos autores.

Esse e outros títulos podem ser baixados gratuitamente em www.poisson.com.br Entre em contato pelo contato@poisson.com.br 


\section{SUMÁRIO}

Capítulo 1: 0 desenvolvimento da linguagem na primeira infância e a audição na orelha média. 07

Elizabeth Matilda Oliveira Williams, Moniki Aguiar Mozzer Denucci, Ilma Alessandra Lima Cabral Rodrigues, Patrícia Helena Ribeiro Caixão de Siqueira Barreto

DOI: 10.36229/978-65-5866-122-1.CAP.01

Capítulo 2: Exposição ao ruído: Influência do motor de alta rotação em dentistas.... 14

Ilma Alessandra Lima Cabral Rodrigues, Milla Ferreira Couri Sternberg, Elizabeth Matilda Oliveira Williams, Tânia Machado de Carvalho, Moniki Aguiar Mozzer Denucci

DOI: 10.36229/978-65-5866-122-1.CAP.02

Capítulo 3: Fluxo de pacientes nas clínicas de atendimento odontológico após a centralização dos encaminhamentos pela Central de Recepção e Triagem 30

Ana Caroline Santos Mariano, Daniela Huller, Leomar Emanuel Almeida Mecca, Lauro Taques Neto, Flávia Gomes Matos, Fábio André dos Santos

DOI: 10.36229/978-65-5866-122-1.CAP.03

Capítulo 4: Análise das necessidades de tratamento de pacientes cadastrados no Sistema Dental Office $®$

Marianne Grollmann, Eduarda Cristina Santos, Laura Cristina Andrade Bubna, Dominique Ellen Carneiro, Lourdes Zeballos López, Fábio André dos Santos

DoI: 10.36229/978-65-5866-122-1.CAP.04

Capítulo 5: Integração entre as escolas municipais de Ponta Grossa e o Banco de Dentes Humanos da Universidade Estadual de Ponta Grossa 42

Thais Regina Kummer Ferraz, Luiz Ricardo Marafigo Zander, Mariane Aparecida Sanson Wayar, Maria Eduarda Schimanski, Tamara Cristina Alves, Stella Kossatz

DOI: 10.36229/978-65-5866-122-1.CAP.05

Capítulo 6: Prevalência de mucosite oral em pacientes portadores de câncer de cabeça e pescoço atendidos na Unidade de Alta Complexidade em Oncologia, Feira de Santana, Bahia 52

Vinicius Silva Bastos de Jesus, Ana Paula Eufrázio do Nascimento, Leonardo de Jesus Costa Santos, Márcio Campos Oliveira, Ágda Braga Teixeira

DOI: 10.36229/978-65-5866-122-1.CAP.06 


\section{SUMÁRIO}

Capítulo 7: Atenção à saúde da mulher na prevenção do câncer cervicouterino: Possibilidades e desafios 60

Ana Flávia de Lima Rocha Cruz, Alexandre Bezerra Silva, Brenda Helen Freire Barbosa, José Deusvando Freire Campos, Josivan Felix da Silva

DOI: $10.36229 / 978-65-5866-122-1 . C A P .07$

Capítulo 8: 0 uso de óleo essencial de lavanda pela fisioterapia no tratamento de mulheres no climatério 68

Ruth Barin, Jeronimo Costa Branco, Sheila Spohr Nedel, Larissa Santos Nunes, Quelen Carpes Grützmacher DOI: $10.36229 / 978-65-5866-122-1 . C A P .08$

Capítulo 9: Violência por parceiro íntimo em mulheres atendidas em uma maternidade de referência: Prevalência, repercussões na saúde e acompanhamento pré-natal...... 74

Luciana Maia Santos, Benvinda Matias Dantas Neta, Iandra Sara dos Santos Ferreira, Ana Karoline Brito dos Santos, Luzimara Gomes Melo, Rosely Cabral de Carvalho

DOI: 10.36229/978-65-5866-122-1.CAP.09

Capítulo 10: Sepse: Desafios e perspectivas para o enfrentamento no contexto hospitalar 87

Alisson Junior dos Santos

DOI: $10.36229 / 978-65-5866-122-1 . C A P .10$

Capítulo 11: Saúde mental das enfermeiras: Diferenciais de gênero e saúde 95

Iracema Lua, Paloma de Sousa Pinho, Tânia Maria de Araújo

DOI: $10.36229 / 978-65-5866-122-1 . C A P .11$

Capítulo 12: Prevalência de distúrbios psíquicos menores em fisioterapeutas intensivistas de uma grande cidade do estado da Bahia 103

Cleide Lucilla Carneiro Santos, Núbia Samara Caribé de Aragão, Lorena Pacheco Cordeiro Lisboa, Eder Pereira Rodrigues, Gabriella Bené Barbosa, Davi Félix Martins Júnior, Mônica de Andrade Nascimento, Carlito Lopes Nascimento Sobrinho

DOI: 10.36229/978-65-5866-122-1.CAP.12 


\section{SUMÁRIO}

Capítulo 13: Distúrbios psíquicos menores e qualidade de vida de enfermeiros intensivistas em uma grande cidade do interior da Bahia.

Núbia Samara Caribé de Aragão, Cleide Lucilla Carneiro Santos, Deise dos Santos Silva Nascimento, Eder Pereira Rodrigues, Gabriella Bené Barbosa, Davi Félix Martins Júnior, Mônica de Andrade Nascimento, Carlito Lopes Nascimento Sobrinho

DOI: $10.36229 / 978-65-5866-122-1 . C A P .13$

Capítulo 14: Metodologia ativa incorporada ao ensino médico: Contribuições da monitoria em laboratório de habilidades

Ádria Rodrigues da Silva, David José Oliveira Tozetto, Cláudia Dizioli Franco Bueno, Maria Alice Alves Fernandes de Souza, Andressa Costa de Sousa

DOI: 10.36229/978-65-5866-122-1.CAP.14

Autores: 


\section{Capítulo 1}

\section{O desenvolvimento da linguagem na primeira infância e a audição na orelha média}

\section{Elizabeth Matilda Oliveira Williams \\ Moniki Aguiar Mozzer Denucci \\ Ilma Alessandra Lima Cabral Rodrigues \\ Patrícia Helena Ribeiro Caixão de Siqueira Barreto}

Resumo: 0 artigo trata-se de um estudo que mostra o comprometimento da audição decorrente da otite média interferindo na linguagem na primeira infância. Destacamos, tendo por base um referencial que aborda de forma ampliada o problema e suas implicações na aprendizagem do indivíduo, justificando a realização deste trabalho. 0 objetivo geral tem como base oportunizar um aprofundamento na doença otológica, e os objetivos específicos, observar as consequências que a privação auditiva altera na aquisição da linguagem e da fala em crianças na fase pré-escolar e ressaltar a importância da avaliação auditiva precocemente. A metodologia trata-se de uma revisão bibliográfica, onde diversos autores renomados foram pesquisados em sites, livros, artigos e revistas acadêmicas. Concluímos que, esta doença otológica é considerada na população pediátrica de maior prevalência e sem a devida atenção e tratamento das áreas de saúde e afins poderá complicar-se levando a criança a surdez e o seu comprometimento com a aprendizagem, sociabilidade e comunicação. Isto serve de alerta para reforçarmos a importância de realizar precocemente a avaliação auditiva.

Palavras-chave: Otite média, Linguagem, Primeira infância, Aprendizagem. 


\section{INTRODUÇÃO}

A audição constitui uma das principais habilidades humanas, sendo o principal meio de ligação do ser humano com o ambiente. A audibilidade, ou capacidade de ouvir interfere de forma determinante no processo de desenvolvimento cognitivo, emocional e social da criança. (NORTHERN, DOWNS, 2005).

Efeitos da privação sensorial auditiva refletem-se no desenvolvimento global da criança, comprometendo de forma mais acentuada as esferas educacional, emocional, social e, sobretudo, a linguagem. 0 desenvolvimento da linguagem depende do funcionamento normal dos processos auditivos, tanto periférico como central, para receber e transmitir, perceber, relembrar os sons e integrar as experiências sonoras, o que permite a comunicação e interação social. (KAMINSKI, TOCHETTO, 2006).

Sendo assim, a detecção precoce e a intervenção imediata em crianças com perda auditiva aumentam a probabilidade de otimizar o potencial de linguagem receptiva e expressiva de alfabetização (leitura e escrita), desempenho acadêmico e desenvolvimento emocional e social. (MUSIEK, RINTELMAN, 2006).

Segundo Campos (2004), a otite média é a inflamação da cavidade da orelha média que resulta da interação de vários fatores. Os fatores mais importantes são a infecção e a disfunção da tuba auditiva. Em crianças a otite média pode ser explicada pela imaturidade do sistema imunológico e também pela imaturidade estrutural e funcional da tuba auditiva, é considerada doença altamente prevalente na infância, com maior pico de incidência entre seis e 24 meses de idade, e com segundo pico de incidência entre quatro e sete anos de idade.

Estima-se que $90 \%$ das crianças desenvolverão otite média na idade escolar (AMERICAN ACADEMY OF PEDIATRICS, 2004).

Em crianças, a otite média, vem desencadear um quadro de perda auditiva do tipo condutiva, geralmente leve a moderada que pode produzir uma sensação de abafamento do som, baixo rendimento escolar, podendo ser rotulada como distraída, pedir para repetir o que os outros falam, além de ouvir televisão em volume alto. (WECKX, 2004).

É bem provável que praticamente todas as crianças apresentarão algum grau de perda auditiva relacionada à otite média em alguma fase da primeira infância. (NORTHERN, DOWNS, 2005).

Para Katz, Tillerey (1997), esta alteração na qualidade da audição da criança faz com que ela, além de sentir dificuldade para ouvir, tenha dificuldade para perceber a riqueza dos detalhes que uma informação sonora pode trazer. Embora a otite média seja uma condição flutuante, que afeta frequentemente uma orelha e geralmente ocasiona uma perda auditiva leve, ela está claramente associada a limitações importantes na comunicação e na aprendizagem. 0 caráter flutuante leva a uma inconsistência na detecção dos sons. Isto é uma desvantagem para o sistema auditivo central que se encontra em processo de desenvolvimento, pois representa uma situação de inconsistência de estimulação auditiva dificultando a formação de engramas adequados para os sons da fala. Além disso, é interessante ressaltar que há uma probabilidade da otite média ser uma condição ruidosa, pois o fluido na orelha média próximo à cóclea produz ruído que tende a interferir na percepção da fala podendo causar uma distorção na percepção de imagens acústicas e redução da velocidade e precisão da decodificação de mensagens verbais.

A privação sensorial decorrente de secreção na orelha média, agravada pelo número e pela duração dos episódios da doença, pode afetar a percepção da fala e dificultar a compreensão, principalmente em ambiente ruidoso, prejudicando o desenvolvimento da linguagem da criança, do aprendizado escolar e do processamento auditivo (SAES, GOLDBERG, MONTOVANI, 2005).

Do ponto de vista auditivo, segundo Chermak, Musiek, Phillps (2002), a otite média tem sido considerada como uma das principais causas de perdas auditivas periféricas e alterações do processamento auditivo.

A triagem das habilidades auditivas tem grande importância devido à estreita relação entre audição, fala, leitura e escrita. Se a primeira não se desenvolve adequadamente, sendo a otite um dos fatores prejudiciais, o desenvolvimento das demais habilidades podem ser influenciado, já que estão intimamente ligadas ao processamento auditivo. Assim, justifica-se acompanhar os processos da audição de uma criança em desenvolvimento, principalmente em idade escolar (MUSIEK, RINTELMAN, KATZ, TILLERY, 1997). A pesquisa metodológica trata-se de uma revisão bibliográfica, onde diversos autores renomados foram pesquisados em sites, livros, artigos e revistas acadêmicas. O objetivo geral deste estudo foi oportunizar um aprofundamento na doença otológica, tendo como objetivos específicos, observar as consequências que a surdez altera na aquisição da linguagem e da fala em crianças na primeira infância, e a importância da avaliação auditiva precocemente. 


\section{DESENVOLVIMENTO}

\subsection{ANATOMIA E FISIOLOGIA DA AUDIÇÃO}

0 ouvido humano é o órgão responsável pela audição e o equilíbrio, localizado no osso temporal do cérebro. É capaz de captar e interpretar as ondas sonoras mecânicas oriundas do ambiente, transformá-las em sinais elétricos e conduzi-las até o córtex cerebral, pelo nervo auditivo, onde serão interpretadas. 0 sistema auditivo humano é divido em central e periférico, o sistema central compreende o nervo e o córtex cerebral e o periférico o ouvido externo, médio e interno.

Segundo Zemlin (2005), o ouvido externo é uma parte do sistema auditivo periférico, tem a função de proteção contra danos mecânicos, captar e conduzir a onda sonora até o ouvido médio, é constituído pelo pavilhão auricular e pelo meato acústico externo. 0 meato acústico externo estende do pavilhão auricular até a membrana timpânica, localizada no ouvido médio. As ondas sonoras captadas pelo pavilhão auricular são conduzidas pelo meato acústico externo até ao tímpano.

O ouvido médio é uma parte do sistema auditivo periférico responsável pelo acoplamento da impedância entre o meio aéreo da orelha média e o líquido da orelha interna, proporcionando reflexão mínima e a transmissão máxima de energia sonora para a orelha interna (BONALDIET, 2003).

Para Bonaldiet (2003), a membrana timpânica é constituída por uma cavidade timpânica preenchida por ar, constituída pelos ossículos da audição, martelo, bigorna e estribo, músculo estapédio, músculo tensor do tímpano e ligamentos.

A membrana timpânica forma um septo entre o meato acústico externo e a orelha média. É uma membrana fina, semitransparente, cuja forma é elíptica e levemente côncava, devido à tração exercida pelos ossículos do ouvido médio. Os ossículos do ouvido médio, martelo, bigorna e estribo, constituem uma cadeia móvel e são limitados pela membrana timpânica e pela janela oval (ANSON, DONALDSON, 1973).

Zemlin (2005), diz que, a principal função deles é transmitir as vibrações sonoras para o meio líquido da orelha interna e protegê-la da entrada de vibrações sonoras excessivas.

O martelo é um dos ossículos que encontra fixado a membrana timpânica, anatomicamente, constitui de cabeça, colo, cabo ou manúbrio de dois processos, o lateral e o anterior, que atuam como uma alavanca juntamente com o cabo, o qual está fixado na membrana timpânica. A bigorna é um dos ossículos situado entre o martelo e o estribo constituído por um corpo e dois ramos, o corpo articula com a cabeça do martelo, o ramo longo com o estribo e o ramo curto está unido por um ligamento à parede posterior da cavidade timpânica. $\mathrm{O}$ estribo é o menor ossículo e é formado por uma cabeça, dois ramos, anterior e posterior, e uma base. A cabeça articula com a bigorna e a base se fixa a janela oval (ANSON E DONALDSON, 1973).

Conforme diz Anson e Donaldson (1973), o ouvido interno é uma parte do sistema auditivo periférico relacionada à recepção do som e à manutenção do equilíbrio. Está envolvida por uma cápsula óssea labiríntica e é dividida em duas partes: labirinto ósseo e labirinto membranáceo. 0 labirinto ósseo é um espaço com líquido circundado pela cápsula óssea labiríntica, é formado pela cóclea, vestíbulo e canais semicirculares. O labirinto membranáceo é preenchido por um líquido, a endolinfa e é formado pelos ductos semicirculares, sáculo, utrículo e ducto coclear.

O caminho percorrido pela energia sonora inicia no pavilhão auricular, em seguida é conduzida pelo canal auditivo externo até a membrana timpânica e cadeia ossicular, depois segue para o ouvido interno, nervo auditivo até o nível do córtex cerebral (MENEZES E MOTTA, 2005).

\subsection{OTITE}

Otite é o termo usado para toda infecção do ouvido, que pode ocorrer no ouvido externo ou médio e pode ser aguda ou crônica. Dessa forma, otite média é a inflamação do ouvido médio, sendo a mais frequente das doenças do ouvido. 0 mau funcionamento da tuba auditiva é o fator mais importante na patogênese das doenças do ouvido médio. Assim, grande parte dos doentes com otite média apresentam função anormal da tuba auditiva, representada por inflamação com sinais e sintomas bem característicos (MINITI, 2001).

Segundo Golz (1998), as consequências das otites médias sobre o equilíbrio e o comportamento das crianças principalmente são instigantes, tendo se tornado objeto de vários estudos clínicos e psicológicos 
ao longo dos últimos anos, complementa dizendo que o período mais curto de aleitamento materno, o ingresso precoce em creches e a convivência com grande número de crianças na mesma creche/escola são fatores que aumentarão a incidência de otites médias na infância.

\subsection{OTITE MÉDIA}

A otite média é uma infecção da orelha média observada primariamente entre crianças na fase préescolar, ocasionalmente em adultos. Moraxellacatarrbalis, Stre-ptococcuspneumoniae e Haemophilusinfluenzae são os patógenos mais comuns, e infecção viral com otite serosa pode predispor à otite média aguda. A infecção causada por patógenos das vias aéreas superiores é favorecida pela obstrução da drenagem através das tubas auditivas edemaciadas e congestionadas, ou seja, vírus e bactéria, normalmente infectando o nariz e faringe, ascendem pela tuba auditiva e causam acúmulo de pus dentro do ouvido médio. Perfuração de membrana timpânica e secreção purulenta podem ocorrer (ANDREOLI, 2005).

Conforme descreve Andreoli (2005), sinais e sintomas básicos da otite média são: dor e secreção no ouvido, perda da audição, febre, letargia, vertigens, tinido.

O diagnóstico pode ser feito por: otoscopia (que mostra perda da nitidez ou distorção das marcas ósseas na membrana do tímpano), pneumatoscopia (pode mostrar a diminuição da mobilidade da membrana do tímpano) e também cultura da secreção para identificação de agente causador (BIRNEY, 2007).

Segundo Andreoli (2005), em crianças, entretanto, sintomas localizados podem não estar presentes. A membrana timpânica pode parecer inflamada, porém para diagnosticar a otite média, devemos observar líquidos atrás da membrana. Às complicações da otite média são raras, mas incluem infecções nas células aéreas da mastoide, meningite bacteriana, abscesso cerebral e empiemasubdural.

\subsection{OTITE MÉDIA E O DESENVOLVIMENTO DA LINGUAGEM NA INFÂNCIA}

Segundo Nunes (2015), a audição é um sentido complexo que envolve uma porção periférica responsável pela sensação de som e uma porção central que se refere ao "caminho" percorrido pelo som ao longo do Sistema Nervoso Central até ao córtex auditivo, é neste caminho que a mensagem auditiva é processada e interpretada. As dificuldades neste caminho são visíveis em tarefas como localização sonora, lateralização e discriminação auditiva, reconhecimento dos padrões auditivos e percepção dos aspectos temporais, a estas dificuldades damos o nome de Perturbação do Processamento Auditivo (PPA). Nestes casos, há uma série de fatores que podem estar associados à sua etiologia, como é o caso das otites médias.

A otite média é uma inflamação ou infecção do ouvido médio e pode ocorrer por vários fatores etiológicos, como a disfunção da trompa de Eustáquio, alergias, infecções respiratórias das vias superiores ou o crescimento excessivo de tecido que constitui uma obstrução da trompa de Eustáquio, o que resulta num abaulamento do tímpano (VAN RIPER E EMERCK, 1990).

Para Nunes (2015), quando ocorre uma otite, a criança tem uma perda auditiva temporária. Sabendo que é através da exposição sonora que a criança desenvolve competências auditivas, de processamento e identificação dos sons da fala, a ocorrência de otites recorrentes irá fazer com que a criança não consiga apreender o estímulo auditivo durante esses momentos, dificultando a percepção da fala e consequentemente a sua aprendizagem, posto isto, e tendo em conta que é através da audição que também processamos os sons da fala que compõem as palavras e frases que produzimos, a entonação e as intenções comunicativas associadas (ex.: repreensão ou carinho), esta perda momentânea pode interferir com a capacidade de compreensão do que ouvimos, deste modo, podem surgir alterações na fala como substituições e/ou omissões dos sons, mas também dificuldades no desenvolvimento da linguagem ao nível da expressão e compreensão, nomeação, produção de frases, compreensão de ordens.

O desenvolvimento da linguagem se inicia precocemente, e mesmo no período pré-natal a criança já é capaz de reconhecer vozes e sons da fala, sabendo-se que existe um padrão universal para a aquisição da linguagem, ou seja, os fonemas, sílabas e a prosódia (pronúncia das palavras) parecem surgir na mesma sequencia e na mesma idade em todas as línguas já estudadas. Porém, esse desenvolvimento se torna paulatinamente mais específico, adquirindo as características da língua pátria de cada criança (PETINOU, 2001).

Petinou (2001) destaca que, no primeiro ano de vida, a comunicação baseia-se na silabação. Quando a criança descobre que sua voz provoca reações dos que a rodeiam, seu comportamento vocal torna-se mais 
variado, incorporando fonemas como "ba", "pa" e "da". As primeiras palavras geralmente não soam da mesma forma como pronunciadas pelos adultos, mas são inteligíveis. Na medida que a criança pratica a produção de sons e palavras, gradativamente, percebe e incorpora o vocabulário, sintaxe e pronúncia. 0 nível de compreensão da linguagem comumente está acima do seu nível de produção, isto é, a criança entende mais palavras e frases do que consegue emitir.

Para Paradise (1998), o tratamento adequado das otites médias nos três primeiros anos de vida é importantíssimo, pois essa é a fase de maior desenvolvimento da linguagem. Por volta dos 18 meses, o vocabulário da criança tem, em média, 50 palavras. Aos três anos, já atinge 1.000 palavras.

No entanto, Petinou (2001), ressalta que essa expansão obviamente depende não só da integridade do sistema auditivo, mas também da comunicação com as outras crianças e os adultos que vivem no mesmo ambiente, destaca que, crianças com perda auditiva na faixa etária de um a três anos têm maior dificuldade para aquisição da linguagem, menor percepção dos sons da fala que contenham consoantes mudas ou fricativas como /s/ e /z/, e incorrem frequentemente em erros fonéticos na pronúncia de /l/e $/ \mathrm{r} /$. A causa mais comum para isso é a hipoacusia condutiva leve - ainda que unilateral - provocada pelas otites médias. Durante essas infecções, a criança recebe estímulos sonoros distorcidos, o que explica os erros fonéticos.

Por ser uma doença bastante comum em crianças, o principal sintoma da otite em geral é a diminuição da audição, esta pode acabar causando um mau aproveitamento escolar e comprometendo também a aquisição e o desenvolvimento das linguagens no período pré-escolar e escolar (BALBANI, MONTOVANI, 2003).

\subsection{HABILIDADES AUDITIVAS}

Pereira (1997), enumera as habilidades auditivas necessárias para a compreensão da mensagem sonora, assim definidas:

a) Detecção: capacidade de identificar presença ou ausência de som;

b) Discriminação: capacidade que o indivíduo tem de perceber diferenças sutis mediante estímulos sonoros a que estão expostos;

c) Localização: capacidade de identificar o sítio gerador do estímulo sonoro, mesmo variando a distância, direção e intensidade;

d) Figura-fundo: capacidade que o indivíduo tem de distinguir os sons da fala na presença de outros sons de fala semelhante;

e) Fechamento auditivo: capacidade de identificar os sons da fala quando apresentados de forma incompleta acusticamente;

f) Reconhecimento: capacidade de reconhecer sons previamente apresentados;

g) Compreensão: capacidade de interpretar o estímulo sonoro, ou seja, dar significado à informação auditiva captada;

h) Memória: capacidade de armazenar e recuperar os estímulos sonoros, assim, o funcionamento correto de todas habilidades poderá determinar como indivíduo receberá a informação sonora.

As perdas condutivas, mesmo as mais leves, podem levar ao abafamento do som prejudicando a qualidade auditiva da criança, onde ela tem dificuldade para ouvir e perceber a riqueza dos detalhes que a informação sonora pode trazer.

Relata Longone e colaboradores (1998), uma série de dificuldades que uma criança em fase de aprendizado da linguagem pode apresentar quando é portadora de deficiência auditiva leve:

a) Perda da constância das pistas auditivas quando a informação acústica flutua;

b) Confusão dos parâmetros acústicos na fala rápida;

c) Confusão na segmentação e na prosódia;

d) Mascaramento em ambiente ruidoso:

e) Quebra na habilidade em perceber os sons da fala;

f) Quebra na habilidade de perceber, de forma precoce, os agudos fonoaudiológicos;

g) Abstração errônea das regras gramaticais;

h) Perda dos padrões de entonação subliminares. 
Esses dados comprovam o quanto de pista auditiva a criança perde e que essas alterações afetam o desenvolvimento da linguagem e fala da mesma, afirma (LONGONE, 1998).

\section{CONSIDERAÇÕES FINAIS}

No processo do desenvolvimento infantil, a audição é fundamental, principalmente por estar ligada a linguagem e a fala. Isso depende de boa audição e do bom funcionamento normal dos processos auditivos.

A aquisição da linguagem é um processo gradual e dinâmico, isso se procede através do feedback estabelecido entre a audição e a fala, a criança estabelece e adquire suas referências auditivas que irão ajudar na estruturação dos conceitos básicos para a construção da linguagem e futuras aprendizagens.

Neste processo, o estudo mostra um dos aspectos a ser levado em consideração que é o comprometimento da audição por interferência de inflamação auricular, em meio a mais comum, encontramos a otite média. Verificou-se que o efeito de privação auditiva reflete bruscamente de forma muito acentuada no individuo, nas esferas educacionais, emocionais, sociais e, sobretudo na linguagem e na fala.

Frente às reflexões, verificou-se que a otite média é considerada na população pediátrica uma doença de maior prevalência e sem a devida atenção e tratamento das áreas de saúde e afins poderá complicar-se levando a criança a surdez e o seu comprometimento com a aprendizagem, sociabilidade e comunicação.

Como observamos, os dados apresentados, servem de alerta para os profissionais da área de saúde, cuidadores e professores, onde muitas crianças, possivelmente necessitarão de acompanhamento pedagógico e fonoaudiológico.

No entanto, reforçamos a importância em realizar precocemente a avaliação auditiva sendo fundamental, para identificar, diagnosticar e tratar, proporcionando aos indivíduos uma ampliação na qualidade de vida neste universo de sons.

\section{REFERÊNCIAS}

[1] American Academy of Pediatrics, Subcommitteeon Otitis Media With Effusion, American Academy of Otolaryngology-Head and Neck Surgery. Otitis media witheffusion. Pediatrics. 2004;113:1412-29.

[2] ANDREOLI, T. E., CARPENTEr, C. C. J., GRIGGS, R. C., LOSCALZO, J. Medicina Interna Básica. 6ํa edição, Editora Elsevier, Rio de Janeiro, pg 887, 2005.

[3] ANSON, B. J., DONALDSON, J. A. Surgical anatomy of the temporal boneandear. 2nd ed. Philadelphia: WB Saunders; 1973.

[4] BALBANI, A. P. S., MONTOVANI, J. C. Impacto das otites médias na aquisição da linguagem em crianças J. Pediatr. Porto Alegre, v. 79, n.5,2003.

[5] BIRNEY, M.H. Fisiopatologia. Editora Guanabara Koogan, Rio de Janeiro, pg 71, 2007.

[6] BONALDI, L.V., DE ANGELIS, M. A., SMITH, R. L. Anatomia funcional do sistema vestibulococlear. In: Frota, S. Fundamentos em Fonoaudiologia: Audiologia. 2ª edição. Rio de Janeiro: Koogan, 2003; 1-17p.

[7] CAMPOS, C. A.H. Tradado de otorrinolaringologia. São Paulo: Roca;2004.

[8] CHERMAK, G. D., MUSIEK, F. E. Auditory training principlesand approaches for remediatingandmanagingauditoryprocessingdisorders. Sem Hear. 2002; 23(4): 297-308.

[9] GOLZ, A., ANGEL, Y. B., PARUSH, S. Evaluationof balance disturbances in childrenwithmiddleeareffusion. Int J PediatrOtorhinolaryngol, v. 43, n.6. 1998.

[10] KAMINSKI, J.M., TOCHETTO, T. M., MOTA, H.B. Maturação da função auditiva e desevolvimento de linguagem. RevSocBrasFonoaudiol. 2006; 11(1):17-21.

[11] KATZ, J., TILLERY, K. L. Anintroducingtoauditoryprocessing. In: Lichtig, I., Carvallo, R. M. Audição abordagens atuais. Carapicuíba: Pró-Fono; 1997.p.119-43.

[12] LONGONE, E., FÁVERO, S. R., SANTOS, S. R., FILHO, C. N. A., BORGES, A. C. C., COSTA, G. R. Perfil audiológico de pacientes com queixas nasais - Revista da Sociedade Brasileira de Fonoaudiologia. Nov.1998.p.51-4.

[13] MENEZES, P.L., GRIZ, S., MOTTA, M.A. Psicoacústica. In: MENEZES, P. L., NETO, S. C., MOTTA, M. A. Biofísica da audição. 1a edição. São Paulo: Lovise, 2005, capítulo 3, 65-67p.

[14] MINITI, A., BENTO, R. F., BUTUGAN, O. Otorrinolaringologia: clínica e cirúrgica. 2. Ed. São Paulo: Atheneu, 487 p, 2001. 
[15] Musiek, F. E., Rintelmann, W.F. Perspectivas atuais em avaliação auditiva. São Paulo: Manole; 2001.

[16] NORTHERN, J. L., DOWNS, M.P. Audição na infância. Rio de Janeiro: Guanabara Koogan; 2005.

[17] NUNES, C. L.(2015). Processamento Auditivo. Conhecer, avaliar e intervir. Lisboa. Papa-Letras.

[18] PARADISE, J. L. Otitis media andchilddevelopment: shouldweworry?Pediatr InfectDis J 1998; 17:1076-83.

[19] PEREIRA, L. D., SCHOCHAT, E. Processamento Auditivo Central: manual de avaliação. São Paulo; Lovise; 1997.

[20] PETINOU, K. C., SCHWARTZ, R.G., GRAVEL, J. S., RAPHAEL, L. J. A

preminaryaccountofphonologicalandmorphophonologicalperception in youngchildrenwithandwithoutotitismedia. Int J Lang CommunDisord 2001; 36:21-42.

[21] PHILLIPS, D.P. Central auditory system and central auditoryprocessingdisorders. Sem Hear. 2002; 23(4):251-61.

[22] SAES, S.O., GOLDBERG, T.B. L., MONTOVANI, J.C. Secreção na orelha média em lactentes: ocorrência, recorrência e aspectos relacionados. J. Pediatr. 2005; 81(2);133-8.

[23] VAN RIPER, C. \& EMERICK, L. (1990) Correção da Linguagem. Uma introdução à patologia da fala e à audiologia. São Paulo. Artes Médicas Sul.

[24] WECKX, L. L. M. Presença ou ausência de bactérias na otite média com efusão. J. Pediatr. 2004; 80(1): 5-6.

[25] ZEMLIN, W. R. Princípios de anatomia e fisiologia em fonoaudiologia. Artmed. 4a edição. São Paulo, 2005. 


\title{
Capítulo 2
}

\section{Exposição ao ruído: Influência do motor de alta rotação em dentistas}

\author{
Ilma Alessandra Lima Cabral Rodrigues \\ Milla Ferreira Couri Sternberg \\ Elizabeth Matilda Oliveira Williams \\ Tânia Machado de Carvalho \\ Moniki Aguiar Mozzer Denucci
}

Resumo: Introdução: os equipamentos de alta tecnologia trazem ganhos para a área a que se destinam; porém, desencadeiam também uma série de questionamentos sobre a saúde do trabalhador que os manipulam. Em 1945, surgiram as turbinas de alta rotação, equipamento que dava rapidez e qualidade ao trabalho dos dentistas, mas em contrapartida, poderia trazer riscos auditivos por emitir alto nível de ruído. Objetivo: verificar a influência do ruído do motor de alta rotação na audição dos dentistas, considerando a distância da fonte geradora de som, tempo e freqüência de exposição e, comparar com os achados da literatura. Metodologia: foram avaliados 40 cirurgiõesdentistas de ambos os sexos, na faixa etária de 25 a 40 anos, através de questionário objetivo, meatoscopia, audiometria tonal (V.A. e V.O.), IRF e SRT. Utilizou-se o audiômetro MAICO MA 41, em cabina acústica e em consultório particular. Resultados: foi encontrada curva audiométrica característica de perda auditiva em 22,5\% dos exames e curva audiométrica dentro dos padrões aceitáveis, porém, com tendência a perda auditiva em $20 \%$ dos exames. Os outros 57,5\% estavam dentro dos padrões aceitáveis. Conclusão: 0 ruído do motor de alta rotação não é o único fator a desencadear a perda auditiva nos dentistas. Verificamos na literatura que, as condições gerais do ambiente e a suscetibilidade individual são peças fundamentais para levarem o indivíduo a desenvolver ou não a perda auditiva induzida por ruído.

Palavras-chave: ruído, Audiologia, dentista, odontologia, perda auditiva. 


\section{INTRODUÇÃO}

Os avanços tecnológicos são frutos e geradores de pesquisa ao mesmo tempo. Isto significa que quanto mais se pesquisa, mais surge a necessidade de pesquisar. Equipamentos com alta tecnologia trazem muitos ganhos para a área a que se destinam, porém desencadeiam também uma série de questionamentos sobre a saúde e segurança do trabalhador que os manipula.

Desde a revolução industrial, o ruído tem acompanhado o homem em várias atividades. Cresceu o número de indústrias de materiais pesados, empresas de aviação se tornaram mais representativas e surgiram equipamentos, como a turbina de alta rotação (1945), que emitia alto nível de ruído ao ser usada. Tal equipamento surgiu como um grande aliado dos dentistas, dando qualidade e rapidez ao trabalho dos mesmos; porém, trouxe também a preocupação e o risco de estar prejudicando a audição de seus usuários.

Ao final da década de 50, antes mesmo da preocupação por parte do governo em preservar a audição dos trabalhadores, pesquisadores do mundo todo já desconfiavam que as turbinas de alta rotação poderiam estar prejudicando a audição de dentistas, já que o ruído era de aproximadamente $100 \mathrm{~dB}$ em frequência acima de $6000 \mathrm{~Hz}$ (SHINOHARA, 1998). Na década de 90, o Governo Federal, ao avaliar trabalhadores expostos a ruídos acentuados por longo período de tempo e comprovar que alguns já tinham sofrido danos auditivos irreversíveis, começou a incentivar programas de conservação auditiva (BORGES E SALES, 2015).

De acordo com a NR7 (MINISTÉRIO DO TRABALHO, 1996), Norma Regulamentadora da Legislação Trabalhista de 1996, ficou estabelecido o tempo máximo permitido de exposição aos diversos níveis de intensidade de ruído. Caso os limites propostos fossem ultrapassados, o trabalhador ficaria sujeito a dano auditivo. Um ambiente de trabalho será considerado de risco para o desenvolvimento de perdas auditivas quando ultrapassar 85dBA para uma jornada de 8 horas de trabalho. Já na Norma Regulamentadora 17 NR17, que é baseada na Norma Brasileira - NBR número 10152, está estabelecido que para fins de conforto acústico, os níveis máximos de ruído em consultórios odontológicos devem ser de $45 \mathrm{dBA}$ a 50dBA (BORGES E SALES, 2015); (ABNT, 2000). Sabendo que os consultórios e clínicas odontológicas apresentam elevados níveis de pressão sonora, os profissionais podem, com o tempo, apresentar comprometimentos na saúde auditiva (GONÇALVES et. al., 2010); (LELO et. al., 2009).

Surgiu o termo PAIR (perda auditiva induzida por ruído) que começou a ser amplamente usado e pesquisado em todas as áreas profissionais. 0 que antes era tido como suspeita, agora era aceito como uma ameaça real. Restava saber até que ponto havia risco, quem estaria no grupo de risco e quem já estaria atingido. PAIR foi definido como "uma doença crônica e irreversível" resultante da agressão às células ciliadas do órgão auditivo de Corti, que decorre da exposição sistemática e prolongada a ruídos, cujos níveis de pressão sonora (NPS) são elevados (FERREIRA, 1998). Borges e Sales (2015) caracterizam a perda auditiva induzida por ruído como sensorioneural, quase sempre bilateral e irreversível.

Este artigo faz uma revisão da literatura das principais pesquisas realizadas nos últimos anos, relacionando o motor de alta rotação com os níveis de audição dos dentistas. Escolhemos o motor de alta rotação como alvo, por ter sido citado por vários autores como o instrumento mais nocivo, em termo de ruídos, em consultório odontológico (VAIDYANATHAN, 1990); (TAIRA E FERRAZ, 1997); (RUSSO E SANTOS, 1988). Fator também a ser considerado é a distância do ruído ao ouvido dos dentistas, pois cirurgiões-dentistas podem apresentar perdas unilaterais relacionadas à proximidade com a fonte ruidosa (FROTA, 1998).

O cirurgião-dentista está na sociedade como um profissional liberal, autônomo, não vinculado a empresas que seguem programas de conservação auditiva; desta forma, quando o profissional percebe as consequências da perda auditiva induzida por ruído, certamente a patologia já se encontra instalada. Queremos visualizar, nesta pesquisa, qual a influência do ruído da turbina de alta rotação na audição dos dentistas e se a curva audiométrica obtida realmente é compatível com a PAIR.

Este estudo vem preencher esta lacuna, despertando o profissional dentista para os cuidados que deve ter em sua rotina de trabalho. Se o resultado encontrado for positivo, quem sabe mais pesquisas estarão sendo incentivadas no intuito de informar e prevenir os cirurgiões-dentistas e muitos outros profissionais dos riscos auditivos a que estão expostos e ignoram. 


\section{REVISÃO DE LITERATURA}

\subsection{A AUDIÇÃO E CONSIDERAÇÕES SOBRE A PAIR}

A onda sonora audível é periódica e regular compreendida entre 20 a $20000 \mathrm{~Hz}$. A cóclea, com seus 30.000 cílios que vibram, transforma a onda mecânica em impulso elétrico que é decodificado no cérebro como som. O Sistema Auditivo é responsável pela detecção das ondas sonoras. Quando ocorre a surdez, o indivíduo fica socialmente prejudicado devido à incapacidade de interagir, ou seja, ouvir e reagir. A audição é o mais social dos sentidos humanos, e a sua deficiência priva o homem da comunicação (CAMPIOTTO, 2005).

O órgão responsável pela audição é a orelha, que está contido no osso temporal e é dividido em orelha externa, média e interna. 0 ouvido externo desempenha a função de proteger a membrana timpânica e favorecer a ressonância sonora e é composto pelo pavilhão auricular e meato acústico externo (FROTA, 1998).

0 ouvido médio tem a função de transmissão sonora. Nele estão localizadas as seguintes estruturas: a) sistema tímpano ossicular: é constituído pela membrana timpânica, martelo, bigorna e estribo; é um transformador de energia com finalidade de igualar as impedâncias do ouvido médio e interno, para transmissão sonora efetiva. b) Trompa de Eustáquio ou tuba auditiva: estrutura que deixa a membrana timpânica livre para vibrar, pois iguala as pressões externa e interna; c) Músculo tensor do tímpano: é um músculo propulsor e mediador, pois, na sua contração, ajuda a movimentação dos ossículos e, ao mesmo tempo, diante de sons muito elevados, tem a função de proteger o ouvido interno e as células do Órgão de Corti contra lesões (CAMPIOTTO, 2005). A orelha média é um sistema pneumático e funciona como um transformador de energia sonora em energia mecânica e controla também a impedância do meio aéreo ao líquido intralabiríntico (KATZ, 1989).

O ouvido interno é a parte essencial do sistema auditivo, pois nele se encontram as células sensoriais da audição, ou seja, a cóclea, também conhecida como labirinto devido a sua complexidade e forma. É na cóclea que se encontra o Órgão de Corti, órgão constituído por células de sustentação e por células ciliadas sensoriais, que são as células ciliadas internas e células ciliadas externas (HUNGRIA, 1988).

O ouvido humano é capaz de detectar sons pouco intensos e ainda possui mecanismo de proteção para manter a integridade orgânica e funcional das células sensoriais quando estas se encontram expostas a ruídos de alta intensidade. Podemos considerar que há, no sistema auditivo, um sistema regulador de intensidades sonoras; porém, este sistema regulador possui suas limitações; ruídos extremamente intensos (acima de 120dB) podem gerar lesões mecânicas nas células ciliadas e ruídos não tão intensos podem gerar lesões metabólicas (FROTA, 1998).

0 ruído pode produzir uma redução inicial da capacidade auditiva, mudando temporariamente o limiar nas frequências de 3000 a $6000 \mathrm{~Hz}$; porém, a audição volta ao normal após cessar a exposição. Sons de $85 \mathrm{~dB}$ ou mais, por longo período de tempo, podem danificar as células ciliadas da cóclea de forma permanente, provocando zumbidos, perda auditiva em frequência específica ou até surdez. Com a degeneração das células ciliadas, toda a cóclea pode ser atingida. A exposição a sons intensos pode afetar o nível de oxigênio na cóclea, implicando em mudanças no seu suprimento sanguíneo, portanto uma degeneração da mesma (HUNGRIA, 1988).

As perdas auditivas induzidas pelo ruído (PAIR) têm características específicas, como ser sempre uma perda neurossensorial, maior nas frequências agudas, quase sempre bilateral, geralmente apresentando melhora na frequência de $8000 \mathrm{~Hz}$. É conhecida também com a denominação de "Surdez Ocupacional" ou "Perda Auditiva Ocupacional"; tem grande prevalência nas comunidades urbanas industrializadas e é decorrente da exposição contínua a níveis elevados de pressão sonora.

Atualmente o ruído é considerado o terceiro maior agente causador de doenças ocupacionais. Ele pode causar danos à saúde humana de diversas formas, comprometendo, além do sistema auditivo, as atividades físicas, fisiológicas, mentais e sociais do indivíduo que permanece exposto a ele (PENNA, 2003).

As Normas Regulamentadoras (NR) sobre os diferentes aspectos da rotina de trabalho foram a maneira encontrada pela Legislação Nacional para tratar da segurança e saúde do trabalhador. Ainda em 1978, o Ministério do Trabalho aprovou a Norma Regulamentadora NR15 que trata dos limites de tolerância para cada tipo de agente, como, por exemplo, o ruído, de acordo com a tabela a seguir: 


\begin{tabular}{|c|c|}
\hline Nível de ruído em Hz & Máxima exposição diária \\
\hline 85 & 8 horas \\
\hline 86 & 7 horas \\
\hline 87 & 6 horas \\
\hline 88 & 5 horas \\
\hline 89 & 4 horas \\
\hline 100 & 15 minutos \\
\hline 115 & 7 minutos \\
\hline
\end{tabular}

Na década de 80, a realização de exames audiométricos tornou-se obrigatória nas empresas com índice de ruído considerado alto. A obrigatoriedade dos exames, devido à Norma Regulamentadora NR7 da portaria 3217/78 do Ministério do Trabalho, não tinha um caráter prevencionista. A execução da audiometria era apenas para determinação dos limiares auditivos (MINISTÉRIO DO TRABALHO, 1996).

Somente em 1988, a Constituição da República Federativa do Brasil determinou, em seu artigo 196, que "A saúde é direito de todos e dever do Estado". Com isso, a atuação tornou-se eminentemente preventiva, com o objetivo de minimizar e evitar danos à saúde do trabalhador. Em 1994, a NR7 que se chamava Exames Médicos, passou a se chamar Programa de Controle Médico de Saúde Ocupacional (PCMSO), apresentando um enfoque clínico - epidemiológico.

Cabe ressaltar que, mesmo dentro das normas estabelecidas na forma acima, existe um fator não mensurável que é a suscetibilidade individual à exposição ao ruído. Isto significa que o ruído pode provocar lesões em um indivíduo e em outro não, embora estejam ambos no mesmo ambiente (PENNA, 2003); (ROESER, 2001). Os dentistas despertaram seu interesse para a perda auditiva induzida por ruído por volta de 1945, devido ao surgimento de equipamentos como turbina de alta rotação, que emite alto nível de ruído ao ser usada.

A seguir, teremos uma breve revisão da literatura de pesquisadores do mundo inteiro que dedicaram grande parte de suas vidas a buscar verdades que pudessem ajudar as próximas gerações de dentistas a se prevenirem da perda auditiva em seu ambiente de trabalho.

\subsection{ESTUDOS SOBRE A SAÚDE AUDITIVA DO DENTISTA}

A preocupação com a saúde do trabalhador começou na década de 50 e a relação da Fonoaudiologia com a Odontologia, hoje aqui discutida, é a favor da saúde do dentista em termos auditivos. Estudos realizados em vários países que, um dia, também se preocuparam e questionaram a saúde auditiva de dentistas que se expõem diariamente a ruídos, serão revistos neste trabalho.

A evolução do motor de pé para a turbina elétrica foi um grande avanço tecnológico para a área da Odontologia. Em 1914, conseguia-se uma rotação de 300 rpm.; aperfeiçoamentos vieram e, em 1957, a SS White Company colocou no mercado o Borden Airotor, o primeiro motor de mão com aproximadamente $300.000 \mathrm{rpm}$. Este instrumento foi o percursor da nova geração de turbinas de alta rotação (HYSON, 2002).

O ruído emitido por estes instrumentos era intenso e, em 1959, este problema despertou a reflexão do Dr. Jerome S. Mittelman, dentista de Nova York, que, desconfiado que a vibração das turbinas poderia causar danos auditivos, orientou a todos que agissem com cuidado e bom-senso ao usá-las. No mesmo ano, o U.S. Public Health Service pesquisou o ruído das turbinas e encontrou valores de intensidade do ruído em torno de $84 \mathrm{~dB}$, nas freqüências de 4.800 a $9.600 \mathrm{~Hz}$. Já nesta época, considerou-se que os dentistas que trabalhassem 8 horas por dia com instrumentos estariam no grupo de risco.

Em 1960, um ativo pesquisador e dentista de Cleveland, o Dr. Howard E. Kessler, recomenda que se façam audiometrias periódicas e que os dentistas usem protetores auriculares, pois os danos não seriam só auditivos mas também comportamentais (HYSON, 2002). Houve quem discordasse das orientações e estudos controversos começam também a aparecer. Resultados não conclusivos ao associarem o ruído da turbina de alta rotação com a queda de audição dos dentistas foram encontrados (SHINOHARA, 1998). 
Cantwell (1960) relata que a limitada exposição ao ruído produzia uma perda auditiva temporária sem maiores riscos à audição; o mesmo vemos em Hopp (1962), que, avaliando acadêmicos, nega a ocorrência do trauma acústico após a exposição à turbina. Em 1963, Shubert e Glorig também não encontraram perda auditiva numa exposição diária de 12 minutos (SHINOHARA, 1998). Podemos observar que estes últimos autores consideraram pouco tempo de exposição ao ruído em suas pesquisas, o que foi visto, mais tarde, como uma variável importante.

Weatherton, em 1972, encontrou valores diferentes de nível de audição dos estudantes para os profissionais e atribuiu isso ao fator idade e tempo de exposição. Foi uma desconfiança que Taylor, em 1965, já havia colocado como fator determinante, quando observou que uma média de 3,7 anos de exposição diária ao ruído geraria uma perda de 5 a $7 \mathrm{~dB}$ numa faixa frequência de 4000 a $6000 \mathrm{~Hz}$, com maior perda no ouvido esquerdo onde a turbina estaria mais próxima (SHINOHARA, 1998); (HYSON, 2002).

Muitas pesquisas foram realizadas e uma das mais extensas e marcantes desta época foi a de 1974 feita pela American Dental Association's Council e Dental Materials and Devices, orientando que, para se chegar à conclusão se o dano auditivo advinha do ruído da turbina, deviam-se associar vários fatores como: a idade do sujeito, a condição física individual, a frequência de exposição, a intensidade do som, a relação de exposição e intervalo entre outros. Recomendou-se também o tratamento acústico para o consultório odontológico e uso de protetores auriculares.

Em 1978, o Long Island Medical Center deixou um questionamento a ser esclarecido. Eles observaram que a perda de audição nos dentistas ia aparecendo com a idade e que nas pessoas fora deste grupo isto também ocorria. Concluíram que a perda de audição é, em primeiro lugar, um fator relacionado com a idade (HYSON, 2002).

0 ano de 1985 foi um marco mundial no que se diz respeito à preocupação por parte dos governantes e Ministério da Saúde com relação à saúde do trabalhador. Uma lei inglesa admitiu que o limite de $90 \mathrm{~dB}$ por 8 horas diárias seria um limite seguro (COLES E HOARE, 1990).

No Brasil, somente na década de 90, o Ministério da Saúde teve olhos para seus trabalhadores. O termo PAIR (perda auditiva induzida por ruído) foi amplamente divulgado e normas e portarias foram instituídas para proteger o trabalhador (RUSSO E SANTOS, 1988); (FROTA, 1998).

Em 1990, Scully alerta para mais um item ainda não questionado. Com o passar dos anos, os equipamentos de alta rotação foram se modernizando e se tornando mais silenciosos: desta forma, deverse-ia considerar que as primeiras turbinas realmente apresentavam ruído acima de $85 \mathrm{~dB}$ e que as turbinas modernas apresentavam ruído abaixo de 85dB. Lopes e Genovese (1991) concordaram e acrescentaram que a variação das medidas de intensidade dos aparelhos dependia não só do seu ano de fabricação, mas também das marcas existentes no mercado, do modelo e do estado de conservação do equipamento.

Lehto (1990) faz um extenso estudo comparativo do ruído existente em turbinas de modelos mais antigos (1973) com mais modernos (1988). No audiograma de homens e mulheres, nos anos de 1973 e 1988, o autor encontrou leve queda na frequência de $6000 \mathrm{~Hz}$, mas o mesmo afirma isso não ter valor estatístico. 0 autor conclui que não há dano para a audição com uso de equipamentos mais modernos, que são muito mais silenciosos, como no caso da turbina, onde encontrou ruído na faixa de 65 a $75 \mathrm{~dB}$. Na realidade, o ruído desta intensidade seria incapaz de provocar perdas auditivas e/ou zumbidos (LEHTO, 1990). O mesmo acredita que os sintomas que os dentistas sentem podem até ser fruto de um fator psicofisiológico, quando o profissional potencializa o estresse do dia-a-dia achando que tem perda auditiva.

No mesmo ano (1990), em um estudo desenvolvido na Universidade de New Jersey (VAIDYANATHAN, 1990), foi relatado que, como as variáveis são muitas em relação ao tempo de exposição, tipo de turbina e distância da mesma do ouvido do dentista, seria difícil definir quem seria afetado por prejuízos auditivos. 0 risco existe e, durante o uso da turbina, tanto o profissional como seu auxiliar e paciente são afetados no que diz respeito à dificuldade de compreensão do que é dito, com o ruído de fundo. Este foi o único estudo encontrado que considerou a "comunicação" mais um prejuízo desencadeado pelo ruído da turbina de alta rotação durante o atendimento odontológico (VAIDYANATHAN, 1990).

Por volta dos anos 90, estudos mais específicos foram valorizados, já que considerar amostras não homogêneas ou situações não semelhantes trazia dados estatísticos não conclusivos.

Kam (1990) demonstra isto quando avalia o uso do motor de alta rotação durante um dia normal de trabalho do dentista (8 horas), com a turbina ficando a aproximadamente 18 centímetros de distância do pavilhão auricular e com intervalo de 1 hora de almoço. Foram usadas várias brocas com pontas 
diferentes e, em média, o uso contínuo foi de 16 segundos em freqüências de 4.000 a $10.000 \mathrm{~Hz}$. 0 ruído médio ficou em $91 \mathrm{~dB}$ e, em 8 horas, calcula-se que a turbina foi usada por 110 minutos.

De acordo com a NR15, o risco aumenta conforme aumenta a intensidade de exposição. Mesmo que os 110 minutos fossem usados sem intervalo, não estariam na faixa limite de risco, e o uso contínuo era de somente 16 segundos. De acordo com a NR15, um ruído de $91 \mathrm{~dB}$ poderia ser usado por aproximadamente 3 horas, ou seja, 180 minutos, o que faz com que a amostra pesquisada seja considerada sem risco para danos auditivos (KAM, 1990).

A Faculdade de Odontologia de Dresden, na Alemanha (1990), aplicou um tipo de avaliação mais completa entre os dentistas. Com base em análises dos principais instrumentos emissores de ruído usados pelos dentistas, verificou-se que muitos emitiam sons de alta frequência e decidiu-se complementar a avaliação audiológica convencional com a audiometria de alta frequência. A amostra compunha-se de dentistas com aproximadamente 10 anos de profissão e estudantes de odontologia (REITEMEIER E FRITSCHE, 1990).

Foi encontrada diferença significativa entre a audição de dentistas e estudantes; esta queda abrangia também os sons de alta frequência, mas sem prejuízo social. 0 autor esclarece que as leis alemãs não consideram quedas em altas freqüências como doença ocupacional, porém o uso de protetores auriculares é essencial e que as indústrias fabricantes destes equipamentos devem estar mais atentas (REITEMEIER E FRITSCHE, 1990).

Na França, em 1991, foi realizado um estudo semelhante na La Fondation A. de Rotschild - Paris, intitulado "Sons de Alta Frequência, os efeitos negativos na audição dos dentistas". Os autores observam que nos sons de alta freqüência os ruídos ultrapassam $110 \mathrm{~dB}$ e que nos equipamentos mais modernos os ruídos são mais baixos. Orientam ao uso de protetores auriculares com caráter preventivo (FAIN E ELBAZ, 1991).

Alguns autores ocasionalmente discordam do ruído da turbina como vilão nas perdas auditivas dos dentistas; porém, aqueles pesquisadores que selecionaram mais suas amostras enfatizam que a prevenção deve ser um bom caminho. Após 1995 não encontramos quem relatasse ou pelo menos colocasse em dúvida a relação do ruído provocado pela turbina de alta rotação e a queda na audição de dentistas que a usavam por longo período de tempo e por muitos anos. Entretanto é evidente que se precisa levar em consideração a predisposição genética individual (TRAVAGLINI, 2003).

Uma amostra de 380 exames foi o alvo de uma pesquisa realizada no Brasil, durante o Congresso Internacional de Odontologia do Estado de Goiás, em 1996. Deste grupo 228, eram dentistas e, apesar da maioria $(38,16 \%)$ ter apresentado exame audiométrico normal, um número significativo $(31,58 \%)$ apresentou exame compatível com a PAIR. As especialidades em que se encontraram mais alterações foi a de clínico geral, o dentista especialista em dentística, o odontopediatra e o periodontista. As especialidades em que se encontraram menos casos de PAIR foi a ortodontia. Os acadêmicos tiveram baixíssimos índices de PAIR, o que condiz com a literatura sobre o desenvolvimento de PAIR, ou seja, uma perda progressiva que depende da exposição diária ao ruído por longos períodos ou anos ( SANTANA, 1996)

Torna-se relevante expor que, além do que os exames comprovam, que o índice de PAIR em dentistas é grande, alguns dos que apresentam audiometrias normais podem ter quadro clínico de zumbido, cefaléia, fadiga e tontura; e que a sintomatologia pode aparecer antes mesmo da perda auditiva (BERBARE, 1997).

Ao longo dos anos foi verificado que Scully (1990) não tinha razão ao relatar que as turbinas modernas não traziam prejuízos; mesmo dentre as turbinas mais modernas, algumas marcas conseguiam alcançar padrões ideais de ruído, enquanto outras, não. Este foi um diferencial pouco considerado, talvez pela dificuldade de se formar amostras homogêneas neste sentido.

Das turbinas estudadas por Saquy (1994), encontraram médias de valores abaixo de $85 \mathrm{~dB}$ para as marcas Dabi-atlante e Kavo, enquanto as da marca Rucca apresentaram valores acima de $85 \mathrm{~dB}$. Devemos considerar que dentro do consultório odontológico existem outros ruídos e que, dependendo do material usado no dente e da rigidez do dente, os valores de ruído provocado pelas turbinas sofrem alterações.

Em torno do ano 2000, artigos publicados no Brasil e no exterior, tanto em revistas e periódicos da área odontológica e fonoaudiológica, dão ênfase ao caráter informativo dos danos irreversíveis provocados por ruídos e citam a prevenção como ideal a ser alcançado ao longo dos anos (HINZI, DE LEON E MITCHELL, 1999); (BERBARE, 1997). A perda auditiva provocada por ruído é uma das únicas perdas auditivas que pode ser totalmente prevenida. 
Foi constatado em algumas pesquisas que tanto acadêmicos de Odontologia como profissionais não estavam sendo definitivamente informados de que o ruído provocado por seus instrumentos de trabalho poderia trazer danos de audição. Apenas $26 \%$ dos entrevistados sabiam quais as sequelas da exposição ao ruído (BOACNIN, 1999).

Encontramos estudos com resultados semelhantes realizados no Japão (2001) e no Brasil (2002), em que os pesquisadores fizeram a medição do ruído durante o trabalho dos dentistas. Os valores dos ruídos nos consultórios variaram de 74,4 dB a 95,7 dB e os valores máximos sempre estavam associados a turbinas (SOUZA E MATTOS, 2002). Em oito condições diferentes de trabalho (variando materiais e dentes), o resultado indicou que em todas as situações o ruído poderia causar baixa de audição (ALTINOZ, et. al., 2001), fato que havia sido citado por Saquy em 1994.

Morarasu (2001) confirma que, pela intensidade do som medido nos consultórios odontológicos, este pode ser considerado uma poluição sonora para os ouvidos humanos.

É fato que o ruído pode causar problemas auditivos. A perda auditiva decorrente da exposição ao ruído é neurossensorial permanente progressiva, variando de grau leve a severo. Os problemas não auditivos são, entre outros, a irritabilidade, nervosismo, ansiedade, zumbido, taquicardia, dores de cabeça, dores no estômago e insônia. 0 risco em consultório odontológico existe, o perigo auditivo presente é importante e exige medidas preventivas como a adoção de um Programa de Conservação Auditiva (PCA), que é um conjunto de medidas profiláticas com o objetivo de impedir que determinadas condições de trabalho provoquem a deteriorização da audição.

Além da audiometria, o PCA inclui a redução do ruído ambiental, o uso de equipamentos de proteção individual e campanhas de educação e informação. Essas medidas podem ser adotadas em unidades de ensino odontológico, prefeituras, sindicatos e associações de classe.

Considerando a dificuldade de mensurar quem é mais ou menos predisposto, indica-se que cada profissional procure manter sua boa saúde auditiva, identificando e minimizando todos os riscos do seu ambiente de trabalho (TRAVAGLINI, 2003); (BERBARE, 2002); (SINGI, et. al. 2002).

\section{METODOLOGIA}

Para a realização deste estudo, foram avaliados 40 cirurgiões-dentistas de ambos os sexos e de faixa etária variando de 25 a 40 anos. Todos os participantes assinaram um termo de consentimento livre e esclarecido (anexo 1).

As avaliações foram efetuadas no Centro de Otorrinolaringologia - Dr. Róger Abdo Mendes, situado na cidade de Muriaé - MG. As etapas da avaliação consistiram em responder a um questionário objetivo, avaliação otoscópica e audiometria.

A presente pesquisa foi avaliada e aprovada pelo comitê de Ética do Centro de Especialização em Fonoaudiologia (CEFAC), sob o número 119/04, tendo sido aprovado sem risco com necessidade de Termo de Consentimento livre e esclarecido. Os dentistas foram convidados a participar desta pesquisa através de carta-convite (anexo 2). Os mesmos receberam orientação de ficarem em repouso auditivo de 14 horas antes da audiometria. Todos passaram previamente por avaliação otológica.

A otoscopia foi realizada por médico otorrinolaringologista, no intuito de detectar alterações em orelha externa e média. Foram eliminados casos de patologias crônicas e inflamatórias e observando-se presença de rolha de cera no conduto auditivo externo, a mesma foi retirada, antes da audiometria, pelo médico otorrinolaringologista.

Os participantes responderam a um breve questionário acompanhados pela fonoaudióloga. No questionário, foram respondidas questões referentes à sensação auditiva dos dentistas e sua rotina de trabalho. As perguntas 1,2,3,4 foram consideradas fatores de exclusão do paciente desta pesquisa, já que, isoladamente ou em conjunto, poderiam desencadear perdas auditivas que não somente induzidas pelo ruído do motor de alta rotação. Estas questões 1, 2, 3, 4 representam respectivamente: fatores hereditários, riscos auditivos por trauma ou por tempo excessivo (fora da fonte sonora desta pesquisa), ototoxidade, sequela de patologias (Anexo 3). A pergunta 5, quando respondida com NÃO, também foi fator de exclusão, já que o indivíduo não tinha o perfil buscado nesta pesquisa.

Na avaliação audiométrica, foi usado o audiômetro MA-41 da Maico, devidamente calibrado em cabina dentro de padrões acústicos aceitáveis, segundo Russo (1988). Realizou-se a pesquisa do limiar tonal por via aérea nas freqüências de $250 \mathrm{~Hz}, 500 \mathrm{~Hz}, 1000 \mathrm{~Hz}, 2000 \mathrm{~Hz}, 3000 \mathrm{~Hz}, 4000 \mathrm{~Hz}, 6000 \mathrm{~Hz}$ e $8000 \mathrm{~Hz}$; e, por 
via óssea, nas freqüências de $500 \mathrm{~Hz}, 1000 \mathrm{~Hz}, 2000 \mathrm{~Hz}, 3000 \mathrm{~Hz}, 4000 \mathrm{~Hz}$, em método ascendente, como descrito por Frota (1998); logoaudiometria com IRF e SRT.

Foram considerados padrões aceitáveis as audiometrias cujos limiares se mantiveram até $25 \mathrm{~dB}$. Limiares acima de $25 \mathrm{db}$ caracterizam a perda auditiva e, aqui buscamos a perda induzida por ruído (PAIR), ou seja , limiares acima de $25 \mathrm{~dB}$ em frequências agudas $(3000 \mathrm{~Hz}$ a $6000 \mathrm{~Hz})$. As audiometrias dentro dos padrões aceitáveis, mas com tendência a perda foram aquelas que os limiares se mantiveram até $25 \mathrm{~dB}$ porém, com queda nas freqüências de $3000 \mathrm{~Hz}$ a $6000 \mathrm{~Hz}$ (SANTANA, 1996).

Os resultados obtidos foram comparados com achados da literatura.

\section{RESULTADOS}

Apresentaremos a seguir os resultados referentes às respostas obtidas no questionário objetivo (anexo 3). Quando questionados sobre o tempo em que tem contato ccom o motor de alta rotação (Pergunta 6) 40\% dos entrevistados possui entre 10 e 20 anos, 25\% apresentavam mais de 20 anos, 20\% de 05 a 10 anos e $15 \%$ apresentavam até 05 anos de contato com o motor de alta rotação. Na questão 7 foi perguntado quanto tempo por semana os profissionais utilizam o motor de alta rotação. A maior parte dos profissionais, $70 \%$ do total, utilizam o motor de alta rotação de 10 a 20 horas semanais.

Outro resultado pertinente, diz respeito a posição da orelha que fica mais próxima do motor de alta rotação durante o uso (Pergunta 8), 65\% dos profissioinais relataram que a orelha direita é a que fica mais exposta ao ruído do motor de alta rotação. A distância que o motor fica da orelha do profissional (Pergunta 9), em 55\% dos entrevistados é de $30 \mathrm{~cm}$. Somente $20 \%$ dos profissionais trabalham com o motor de alta rotação a uma distância de mais de $30 \mathrm{~cm}$ da orelha. $80 \%$ dos dentistas que participaram da pesquisa acreditam que o ruído do motor de alta rotação pode prejudicar a sua audição (Pergunta 10).

Com relação a ocorrência de queixas auditivas por parte dos entrevistados (Pergunta 11), 60\% dos profissionais relataram a presença de queixas e somente $65 \%$ dos entrevistados já realizaram uma audiometria (Pergunta 12). Um dado importante é que 100\% dos dentistas entrevistados não utilizam protetores auriculares (equipamento de proteção individual) durante a utilização do motor de alta rotação.

Veremos à seguir o resultado dos exames da audiometria. (Fig. 1)

Figura 1: Resultado das audiometrias

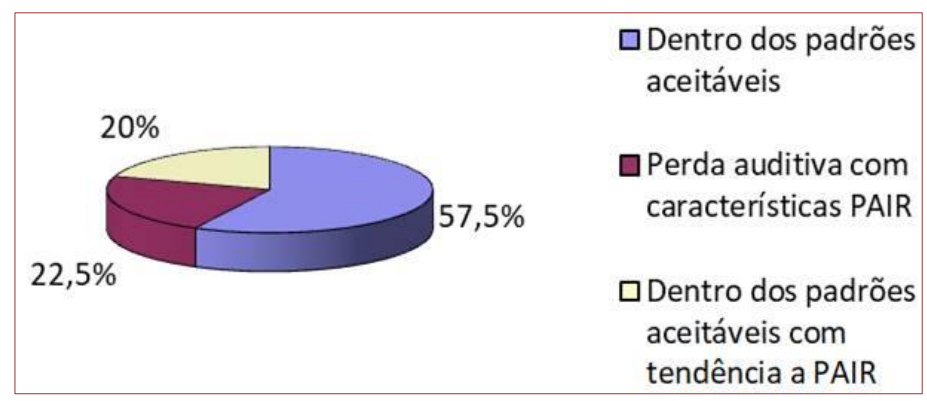

\section{DISCUSSÃO}

Os resultados encontrados na primeira parte deste estudo demonstram que o fator "tempo de uso" parece não ser o único a desencadear a perda auditiva já que a mesma apareceu em percentuais iguais (5\%) em cada faixa de tempo (até 5 anos, 5 a 10 e mais de 20 anos). 0 número um pouco maior de perdas (7,5\%) apareceu de 10 a 20 anos, e consideramos que isto aconteceu uma vez que a amostra (40\%) concentravase mais nesta faixa de tempo.

Apesar de alguns autores afirmarem que o número de anos seria um fator importante a ser considerados, pois, ao compararem estudantes e profissionais sempre achavam diferença significativa nos limiares dos profissionais (SHINOHARA, 1998); (HYSON, 2002); (REITEMEIER E FRISTSCHE, 1990); um estudo feito 
pela American Dental Association's (1974) havia orientado que avaliar somente um fator não seria um bom caminho; já que o profissional sofre influências de fatores associados (HYSON, 2002).

Outro dado que nossa pesquisa discorda de alguns autores é que os mesmos relatam que a exposição limitada ao motor de alta rotação não levaria a perda (HOPP, 1962), mas vimos em nossos resultados que dos dentistas que trabalhavam até 5 anos na profissão, $5 \%$ do total apresentam perda; $5 \%$ apresentam tendência a perda e $5 \%$ audiometria normal. Isto pode ser explicado ao verificar que outros ruídos dentro do consultório odontológico podem favorecer o desencadear da perda; como foi relatado por Souza (2002), ao analisar ruídos diversos em consultório odontológico.

Altinöz (2001) avaliando 8 condições diferentes de trabalho, verifica que em todas as situações o ruído pode provocar baixa de audição (TRAVAGLINI, 2003); isto também pode ser confirmado nesta pesquisa ao constatarmos que o número de horas semanais (frequência de uso) em contato com o motor de alta rotação demonstrou não ser relevante na ocorrência da perda auditiva. Enquanto nos que ficam até 10 horas semanais em contato com o motor de alta rotação encontramos a presença de perda auditiva em $15 \%$ da amostra, naqueles que ficam até 30 horas semanais não houve resultados fora da normalidade.

Acreditamos que chegamos a estes resultados principalmente por ser a fonte sonora um ruído intermitente. Os intervalos entre silêncio e ruído, feitos durante o manuseio/preparo do material odontológico, podem ter sido o fator atenuador das lesões auditivas. Isto foi detalhadamente descrito por Kam (1990).

Outra questão a ser lembrada é a suscetibilidade individual, já que encontramos pessoas que o usam há muitos anos e sem alterações nos limiares. Como citado pela Dra. Mariene Hidoka (TRAVAGLINI, 2003), existe o que chamamos de "ouvido de cristal e ouvido de pedra" - ou seja, alguns indivíduos desenvolvem mais facilmente as perdas, outros não.

Não encontramos na literatura relatos de realização de exames de audiometria periódicos pelos dentistas; assim como em nossa pesquisa, eles só faziam este exame em quadros clínicos já instalados, ou seja, a pedido médico (35\%). Alguns já se queixavam de perda auditiva ou sintomas associados (40\%), e mesmo assim $5 \%$ destes nunca fizeram audiometria.

Em nossa pesquisa, aqueles que não tinham queixa e apresentaram resultados alterados, demonstraram muita surpresa. Eles nunca tinham feito audiometria e verificamos que $10 \%$ tinham perda e $20 \%$ tendência a perda. Por isso a recomendação para que se faça audiometrias periódicas é bem antiga, autores em 1960 (HYSON, 2002) já alertavam os profissionais e avisavam que os danos não seriam só auditivos (LETHO, 1990). Boacnin constatou que tanto acadêmicos de odontologia como profissionais, não estavam bem informados dos riscos do ruído à audição. Apenas $26 \%$ sabiam das sequelas (BOACNIN, 1999).

Por volta do ano 2000 muitos artigos publicados no Brasil e no exterior, tanto na área fonoaudiológica como odontológica, dão ênfase ao caráter informativo dos danos provocados pelo ruído. A prevenção aparece como um ideal a ser buscado ao longo dos anos; já que a perda auditiva provocada por ruído é uma das únicas perdas auditivas que podem ser totalmente evitadas (HINZI, LEON E MITCHELL, 1999); (BERBARE, 1997). Soares (2020) aloca o ruído no grupo de riscos físicos a que os profissionais da Odontologia estão sujeitos e complementa que a perda auditiva induzida por ruído (PAIR) provoca um comprometimento nas esferas física, mental e social.

O uso efetivo de EPI (equipamento de proteção individual) ainda não é uma realidade, apesar de estudos datados de 1974 (HYSON, 2002) e outros mais recentes como na Alemanha (1990) (REITEMEIER, 1990), na França (1991) (TRAVAGLINI, 2003) e no Brasil (2002) (BERBARE, 1997), terem recomendado o uso de protetores auditivos, em nossa pesquisa verificamos que $100 \%$ ainda não tem este hábito.

Avaliando os resultados do exame de audiometria, tivemos 57,5\% da amostra com resultados dentro dos limiares normais, $22,5 \%$ com perda auditiva característica de PAIR e $20 \%$ com limiares normais, porém, com tendência a PAIR. Esta característica de tendência a perda ou entalhe em frequências agudas, mesmo com limiares normais também foi considerada por Santana (1996) (SANTANA, 1996), em estudo que a autora encontrou $31,58 \%$ de sua amostra nesta condição, enquanto que $21 \%$ tinha audiometria característica de PAIR.

Boacnin (1999) teve 18,75\% de sua amostra apresentando perda auditiva característica de PAIR e 12,5\% apresentando limiares normais com indícios de queda que configuram a PAIR.

Não encontramos autores que discordassem que o contato frequente com o ruído do motor de alta rotação pudesse levar a perda auditiva, porém, a predisposição individual e as condições gerais do ambiente são 
fatores que influenciam significativamente $\mathrm{o}$ aparecimento e desenvolvimento destas perdas (TRAVAGLINI, 2003); (SOUZA E MATTOS, 2002); (BERBARE, 2002); (SOARES, 2020); (BORGES E SALES, (2015).

\section{CONCLUSÃO}

Avaliando os resultados das audiometrias dos dentistas que usam o motor de alta rotação e, considerando tempo de uso, distância e freqüência de exposição, não podemos afirmar que somente o ruído do motor de alta rotação possa deteriorar efetivamente a audição dos mesmos.

Não queremos afirmar que o motor de alta rotação não seja o grande "vilão" dos consultórios odontológicos, mas, temos que associar o seu ruído às condições gerais do ambiente e à suscetibilidade individual para se chegar ao desenvolvimento de uma perda auditiva.

Como não podemos determinar quem está mais predisposto, o caminho deve ser a informação e prevenção de todos que se encontram em contato com o ruído e as indústrias que fornecem as turbinas e os protetores assumindo o papel de manter seus usuários esclarecidos dos riscos e formas de proteção.

\section{REFERÊNCIAS}

[1] ALTINÖZ, H. C.; GÖKBUDO, K. R.; BAYRAKTAR, A.; BELLI, S. A pilot study of measurement of the frequency of sounds emitted by high-speed dental air turbines. Journal of Oral Science sep.; v. 43, no 3, 189-92, 2001.

[2] ASSOCIAÇÃO BRASILEIRA DE NORMAS TÉCNICAS (ABNT). NBR 10152: Níveis de ruído para conforto acústico em ambientes diversos. Rio de Janeiro. 2000.

[3] BERBARE, G.M. Efeitos dos ruídos nas práticas de atendimento odontológico. Portal APCD; 1997.

[4] BERBARE, G. M. (2002). O ruído produzido pelo motor de alta rotação pode provocar algum prejuízo auditivo? Portal APCD, 2002.

[5] BOACNIN, S.B.O. O ruído ocupacional e suas sequelas. Portal APCD, 1999.

[6] BORGES, S. S.; SALES, R. A influência do ruído na saúde auditiva dos dentistas da cidade de Patrocínio/MG. Revista Saúde e Meio Ambiente, vol. 4. Patrocínio, Minas Gerais, 2015.

[7] CAMPIOTTO, A.R.; Levy, C. et al. Tratado de Fonoaudiologia. Ed. Tecmed. 2005

[8] CANTWELLI, K.R, TUNTURI, A.R, MANNY, V.R. Noise from high-speed dental handpieces. J Am Dent Assoc;61(5):571-7, 1960.

[9] COLES, R. R. A.; HOARE, N.W. Noise-induced hearing loss and the dentist. Br Dent. J. ; v. 159, p. 209. 1985.

[10] FAIN, G.; ELBAZ, P. Les sons Hautes Frequences-Leurs effects néfastes sur l'oreille interne du praticien. Inf Dent may; 73(18): 1373-9. 1991.

[11] FERREIRA JR, M. PAIR - perda auditiva induzida por ruído - bom senso e consenso. São Paulo: VK, 1998.

[12] FROTA, S. Fundamentos em Fonoaudiologia - Audiologia. Rio de Janeiro: Editora Guanabara Koogan S.A. 1998.

[13] GONÇALVES, C.G.O.; RIBAS, A.; LACERDA, A.B.M.; GONÇALVES, G.A.; ALBIZU, E. A exposição ao ruído na prática da odontologia. In: Morata, T.C.; Zucki, F.M. (org). Saúde Auditiva: Avaliação de Riscos e Prevenção. São Paulo: Plexus, 2010.

[14] HINZI, H.F.; DE LEON, C.; MITCHELLI, W.C. Dentists at high risk for hearing loss: protection with custom earplugs. Gen Dent nov-dec 1999; 47 (6): 600-3; quiz 604-5, 1999.

[15] HOPP, E.S. Acoustic trauma in high-speed dental drills. Layngoscope; v.72, p.821-7. 1962.

[16] HUNGRIA, H. Otorrinolaringologia. Ed. Guanabara. 1988.

[17] HYSON, J.M. The air turbine and hearing loss: are dentists at risk? J. Am Dent Assoc; 133(12): 1639 - 42; Dec. 2002.

[18] KAM, J.K. Occupational noise exposures among dentists during the use of high- speed dental drills. Am Ind Hyg Assoc J. april; 51(4): A 255, 1990.

[19] KATZ, J. Tratado de Audiologia Clínica. Ed. Manole. 1989.

[20] LELO, N.M.V.; RICCO, F.F.; SABO, V.A.; NETTO, M.P.; RICCO, R.A.P.O. Avaliação do Limiar Auditivo em Profissionais de Odontologia. Colloquium Vitae, v. 1, n. 1, p. 271-274. 2009. 
[21] LETHO, T. Dentists' hearing and exposure to high speed turbine dental drill noise. Proc. Finn Dent Soc; 86(34): 115-25. 1990.

[22] LOPES, A.; GENOVESE, W.J. Doenças profissionais do cirurgião-dentista. São Paulo (SP): Pancast; 68-75 p. 1991.

[23] MINISTÉRIO DO TRABALHO. Normas Regulamentadoras em Segurança e Medicina do Trabalho. São Paulo: Atlas, 1996.

[24] MORARASU, C.; BURBRI, V.; BORTA, C.; IGNAT, L.; BORTA, B.; MORARASU, G. (2001). The evaluation of sound level in dental practice. Rev. Med. Chir Sec. Med Nat lasi oct-dec; 105 (4); 785-9, 2001.

[25] PENNA, A. Audiologia Ocupacional. Ed. Pulso. 2003.

[26] REITEMEIER, B.; FRITSCHE, F. Untersuchugen zur Langzeitwirkung von Lärm bei Zahnärzten. Zahn Mund Kieferheilkd Zentralbl; 78 (8): 735-8. 1990.

[27] ROESER, R.J. Manual de consulta rápida em Audiologia. Ed. Revinter. 2001.

[28] RUSSO, I.P; SANTOS, T.M. A Prática da Audiologia Clínica. São Paulo: Cortez Editora. 1988.

[29] SANTANA, K.D. Pair em dentistas: atuação odontológica e sua relação com a perda auditiva induzida por ruído. Revista Fono Atual set.; no 13 p.9. 1996.

[30] SAQUY, P.C et. al. Intensidade de ruído produzido pelas canetas de alta rotação. Revista Gaúcha de Odontologia (RGO) jun.; v. 42, n.3, p.131-3.1994.

[31] SCULLY, C. et al. Occupational hazards to dental staff. Londres. Br Dent J Ed. 1990.

[32] SHINOHARA, E. H; MITSUDA, S.T. Trauma acústico em odontologia. Rev. do CROMG 1998; 4(1): 42-5, jan-jun, 1998.

[33] SINGI, A.O.; SINGI, L.M.; FEHR, J.; MONTEIRO, M.; MELANI, R. F. H. Doença Ocupacional do Cirurgião Dentista - Perda auditiva por indução de ruídos (PAIR). Anais Tema Livre apresentado no Congresso de Odontologia Legal; Fundecto - USP - São Paulo. 2002.

[34] SOARES, M. S. Doenças ocupacionais na prática odontológica: saúde dos cirurgiões-dentistas da rede Sistema Único de Saúde -SUS. Dissertação de mestrado apresentada ao Programa de Pós-graduação Mestrado Profissional em Saúde do Trabalhador da Universidade Federal de Uberlândia. Minas Gerais. 2020.

[35] SOUZA, H. M. R.; MATTOS, U. A. O. Nível de ruído produzido por turbina de alta rotação em consultório odontológico. Rev. Bras. Odontol. maio-jun. ; 59(3):169-72. 2002.

[36] TAIRA, A.; FERRAZ, N.M. Fonoaudiologia e o ambiente odontológico: percepção dos ruídos existentes e grau de conscientização do Cirurgião-dentista em relação à perda auditiva induzida por ruído. Cadernos - Centro Universitário São Camilo, São Paulo, v.3, n.2, p.102-112. jul. / dez. 1997.

[37] TRAVAGLINI, F. Ruído nos consultórios pode comprometer a audição do cirurgião dentista. Portal APCD; 2003.

[38] VAIYANATHAN, T.K; CINOTTI, W.R; COHEN, S.M, WANG. Hearing-damage risk and communication interference in dental pratice. J Dent Res 69(2): 489-93, February. 1990. 
ANEXO 1

CARTA PARA OBTENÇÃO DO CONSENTIMENTO LIVRE E ESCLARECIDO:

\section{Caro(a) Senhor(a)}

Eu, Milla Ferreira Couri, fonoaudióloga, portadora do CIC 865449266-04, RG M-6.201.116 SSP-MG, estabelecida na Rua Dr Alves Pequeno no 237, sl 201, CEP 36880-000 na cidade de Muriaé, cujo telefone de contato é (32) 3722-4371, vou desenvolver uma pesquisa cujo título é "Influência do ruído do motor de alta rotação na audição de dentistas".

O objetivo deste estudo é verificar se o ruído do equipamento de alta rotação estaria provocando alguma lesão auditiva nos dentistas e, para tanto, necessito de que o $\mathrm{Sr}$.(a) forneça informações a respeito de sua rotina de trabalho e de seus antecedentes de risco auditivos. As perguntas estão em anexo, devendo ocupá-lo por 40 minutos, tanto para completar as respostas como para fazer a avaliação clínica em que realizarei os seguintes procedimentos: todos deverão passar pelo Exame de Audiometria, que será precedido por avaliação otoscópica realizada por médico otorrinolaringologista, no intuito de detectar os pacientes que apresentem alterações em orelha externa e média e tratá-las antes de se fazer a audiometria. No caso em que se observar presença de rolha de cera no conduto auditivo externo, a mesma será retirada imediatamente e o exame realizado em seguida.

Para a audiometria será usado o audiômetro MA-41 da MAICO, devidamente calibrado, em cabina acústica. Será realizada a pesquisa do limiar tonal por via aérea nas freqüências de $250 \mathrm{~Hz}-500 \mathrm{~Hz}$ $1000 \mathrm{~Hz}-2000 \mathrm{~Hz}-3000 \mathrm{~Hz}-4000 \mathrm{~Hz}-6000 \mathrm{~Hz}-8000 \mathrm{~Hz}$; via óssea nas freqüências de $500 \mathrm{~Hz}-1000 \mathrm{~Hz}-$ $2000 \mathrm{~Hz}-3000 \mathrm{~Hz}-4000 \mathrm{~Hz}$; teste de discriminação auditiva e SRT em todos os exames.

Os dentistas deverão fazer repouso auditivo de 14 horas; desta forma, todos os exames serão marcados na parte da manhã, antes que os profissionais iniciem sua rotina de trabalho.

Sua participação nesta pesquisa é voluntária e constará de 13 perguntas que deverão ser respondidas sem minha interferência ou questionamento e da avaliação clínica, sem risco e/ou desconforto. Sua participação não trará qualquer benefício direto, mas proporcionará um melhor conhecimento a respeito dos riscos auditivos, que gerarão futuras orientações atualizadas nos programas de conservação auditiva e alertarão as indústrias que fabricam o motor de alta rotação sobre seus efeitos auditivos. Somente no final deste estudo poderemos concluir se haverá mesmo este benefício, de acordo com o que encontrarmos como resultado. Acreditamos não existir outra forma de se obter dados em relação ao procedimento em questão que possa ser mais vantajoso para ambas as partes.

Informo que o Sr.(a). tem a garantia de acesso, em qualquer etapa do estudo, a qualquer esclarecimento de eventuais dúvidas. Se tiver alguma consideração ou dúvida sobre a ética da pesquisa, entre em contato com o Comitê de Ética em Pesquisa (CEP) do Centro de Especialização em Fonoaudiologia Clínica (CEFAC), situado na Rua Cayowaá 664, CEP 05018-000, em São Paulo - SP., fone/fax: (11) 3675-1677, e-mail: cefac@cefac.br e comunique-se com o coordenador, Dr. Vicente José Assêncio Ferreira.

Também é garantida a liberdade de retirada do consentimento e de deixar de participar do estudo, sem qualquer prejuízo a qualquer momento. Garanto que as informações obtidas serão analisadas em conjunto com outros pacientes, não sendo divulgada a identificação de nenhum dos participantes. 0 Sr.(a) tem o direito de ser mantido atualizado sobre os resultados parciais da pesquisa e, caso seja solicitado, a todas as informações.

Não existirão despesas ou compensações pessoais para o participante em qualquer fase do estudo, incluindo exames e consultas. Também não há compensação financeira relacionada à sua participação. Se existir qualquer despesa adicional, ela será absorvida pelo orçamento da pesquisa.

Comprometo-me a utilizar os dados coletados somente para a pesquisa e os resultados serão veiculados através de artigos científicos em revistas especializadas e/ou em encontros científicos e congressos, sem nunca tornar possível sua identificação.

Anexo está o consentimento livre e esclarecido para ser assinado, caso não tenha ficado nenhuma dúvida. 


\section{TERMO DE CONSENTIMENTO LIVRE E ESCLARECIDO (TCLE)}

Acredito ter sido suficientemente informado a respeito das questões que li ou que foram lidas para mim, descrevendo o estudo "Influência do ruído na audição de dentistas que usam rotineiramente motor de alta rotação".

Discuti com a fonoaudióloga Milla Ferreira Couri Sternberg e/ou Ilma Alessandra L. Cabral Rodrigues sobre a minha decisão de participar desse estudo. Ficaram claros para mim quais são os propósitos do estudo, os procedimentos a serem realizados, seus desconfortos e riscos, as garantias de confidencialidade e de esclarecimentos permanentes.

Ficou claro também que a minha participação é isenta de despesas e que tenho garantia de acesso aos resultados e de esclarecer minhas dúvidas a qualquer tempo. Concordo voluntariamente em participar deste estudo e poderei retirar o meu consentimento a qualquer momento, antes ou durante o mesmo, sem penalidade ou prejuízo ou perda de qualquer benefício que eu possa ter adquirido.

Data

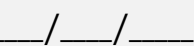

Assinatura do entrevistado

Nome:

Endereço:

RG:

Fone:

Data

Assinatura do pesquisador 


\section{ANEXO 2}

\section{CARTA-CONVITE}

Cara $\operatorname{Dr}(\mathrm{a})$

Nós, Milla F. Couri Sternberg e Ilma Alessandra L. C. Rodrigues, Fonoaudiólogas, viemos por meio desta convidá-lo a participar de uma pesquisa na área de Audiologia, cujo resultado será de grande valia para você, Cirurgião-Dentista, como para a Fonoaudiologia e, quem sabe, possamos também atingir empresas que fabricam os equipamentos odontológicos, aumentando a segurança dos profissionais.

0 projeto de pesquisa tem como título: "Influência do ruído do motor de alta rotação na audição de dentistas" e será apresentado como trabalho final do curso que fazemos de Especialização em Audiologia e Saúde do Trabalhador.

Como verificamos na literatura nacional e internacional, pode existir grande influência do ruído deste equipamento (motor de alta rotação) na audição dos profissionais expostos, considerando-se principalmente o número de horas de exposição ao ruído e a suscetibilidade individual. Vale a pena lembrar que a sintomatologia gerada pelo ruído excessivo pode causar, além da baixa de audição, outros sintomas desagradáveis como zumbido, fadiga, vertigens, enjôos entre outros.

A metodologia usada nesta pesquisa constará de um breve questionário, uma avaliação otológica e a realização do exame de Audiometria. Os resultados clínicos serão repassados no ato para o participante e o resultado final da pesquisa será repassado ao final da mesma.

Teremos como colaborador o Centro de Otorrinolaringologia, com apoio do Dr Róger Abdo Mendes na realização da avaliação otológica, que deverá anteceder ao exame de Audiometria com o objetivo de qualificar o mesmo.

Sua participação é o fator mais importante para que este projeto se torne realidade.

Agradecemos desde já sua colaboração.

\section{Milla Ferreira Couri Sternberg}

Fonoaudióloga

\section{Ilma Alessandra L. C. Rodrigues}

Fonoaudióloga 


\section{ANEXO 3}

\section{QUESTIONÁRIO OBJETIVO APLICADO AOS DENTISTAS}

Nome:

Idade:

Data:

HISTÓRIA PROFISSIONAL - RISCOS DE PAIR:

\section{1 - Há casos de surdez na família?}

$$
\text { ( ) NÃO ( ) SIM }
$$

2 - Há riscos auditivos fora do trabalho com a exposição excessiva a ruídos, como, por exemplo, walkman, armas de fogo, motor de moto, motor de avião ou outros?

$$
\text { ( ) NÃO ( ) SIM }
$$

\section{3- Faz uso de medicamentos por tempo prolongado?}
( ) NÃO
( ) SIM. Quais?

4- Já teve ou tem:
( ) Tuberculose
( ) Caxumba
( ) Diabetes
( ) Sarampo
( ) Meningite
( ) Sífilis
( ) Hipertensão

5- Na sua área de atuação você tem contato com o motor de alta rotação?

( ) NÃO (se escolheu esta alternativa, pule para o número 10)

( ) SIM

6- Há quantos anos está em contato com o motor de alta rotação?

( ) até 5 anos ( ) de 5 a 10 anos ( ) mais de 10 anos ( ) mais de 20 anos

7- Os procedimentos em que você usa o motor de alta rotação ocupam:
( ) até 10 horas por semana
( ) até 20 horas por semana
( ) até 30 horas por semana
( ) até 40 horas por semana

8- Quando está usando o motor de alta rotação, ele se encontra mais próximo de qual orelha?

( ) orelha direita ( ) orelha esquerda ( ) indiferente; ora de um lado, ora de outro 
9- A qual distância aproximadamente o motor de alta rotação fica da sua orelha?

( ) $20 \mathrm{~cm} \quad(\quad) 30 \mathrm{~cm} \quad$ ( ) mais de $30 \mathrm{~cm} \quad$ ( ) distâncias variadas

10- Acha que o ruído do motor de alta rotação pode prejudicar sua audição?

( ) NÃO ( ) SIM

11- Já fez exame de Audiometria?

( ) NÃO

( ) SIM. Por quê?

12- Tem queixa auditiva?

( ) NÃO

( ) SIM. Quais? ( ) perda auditiva ( ) dificuldade de comunicação

( ) intolerância a sons intensos ( ) zumbido

( ) outras

13 - Faz uso do EPI (equipamento de proteção individual) - protetores auditivos?

( ) NÃO

( ) SIM 


\section{Capítulo 3}

Fluxo de pacientes nas clínicas de atendimento odontológico após a centralização dos encaminhamentos pela Central de Recepção Triagem.

\section{Ana Caroline Santos Mariano}

Daniela Huller

Leomar Emanuel Almeida Mecca

Lauro Taques Neto

Flávia Gomes Matos

Fábio André dos Santos

Resumo: 0 presente trabalho tem como objetivo expor o fluxo de pacientes encaminhados entre as clínicas odontológicas após a implementação de uma central de encaminhamentos. Para a implementação dessa centralização, foram realizados treinamentos de alunos, professores e funcionários e foram distribuídas fichas impressas nas clínicas para que os dados dos pacientes fossem preenchidos e posteriormente cadastrados. Através do levantamento dos dados destas fichas, observou-se que a maior parte dos encaminhamentos foram direcionados às disciplinas de Dentística Clínica e Periodontia Clínica que constituem o tratamento inicial. Além da Clínica Integrada que realiza diferentes procedimentos sem a necessidade de muitos encaminhamentos. Em seguida a Reabilitação bucal II que ocorre, na maioria das vezes, após o tratamento em outras disciplinas. Também foi possível verificar que ainda ocorrem meios paralelos para encaminhamento de pacientes. Diante do exposto pode-se considerar que a centralização do sistema de encaminhamentos pelo setor de triagem foi positiva, pois a partir deste procedimento, apesar da fragmentação do processo de aprendizagem dos alunos, os pacientes podem receber um tratamento de forma integral, como o Sistema Único de Saúde preconiza.

Palavras-chave: Triagem odontológica. Clínicas odontológicas. Encaminhamento. 


\section{INTRODUÇÃO}

Nas clínicas escolas de instituições de ensino superior (IES), o processo de receptividade, cadastramento e encaminhamento dos pacientes preconizado pela entidade nem sempre é capaz de atender todas as necessidades da comunidade, alunos, professores e da própria instituição. Nesse sentido, um sistema de triagem eficiente permite que o paciente seja atendido integralmente, de forma a conciliar as necessidades acadêmicas para o aprendizado do aluno em seu respectivo nível do curso (GONÇALVEZ, VERDI, 2007), sob os cuidados de acolhimento, humanização e integralidade preconizados pelo Ministério da Saúde para atendimento no Sistema Único de Saúde (CYRINO et al, 2015).

Devido a fatores socioeconômicos, a demanda por atendimento odontológico em instituições públicas mostra-se superior ao suportado pelas disciplinas ofertadas na grade curricular dos cursos de graduação e pós-graduação (TRINDADE, ABRAMOWICZ, RAMOS, 1999). 0 mesmo acontece na Universidade Estadual de Ponta Grossa (UEPG) ao longo dos anos. Desta forma, é comum que pacientes não tenham suas necessidades tratadas de forma integral ou até mesmo não consigam este atendimento devido a imensas listas de espera (TRINDADE, ABRAMOWICZ, RAMOS, 1999) em que muitas vezes por esta delonga e falta de um sistema centralizado para cadastro e encaminhamentos o paciente acaba por extraviar-se.

A triagem é o primeiro atendimento recebido nos serviços de saúde, neste momento é classificado de acordo com sua necessidade e encaminhado para o tratamento adequado. 0 encaminhamento deste paciente para tratamento específico de acordo com o caso clínico auxilia na totalidade do atendimento. Porém, mesmo com a disponibilidade de Diretrizes Curriculares Nacionais comuns aos cursos de graduação em Odontologia preconizados pelo ministério de Educação, o funcionamento de uma clínicaescola é complexo pois engloba diferenças regionais e características estruturais de cada instituição, como o número de atendimentos realizados por período de tempo em cada clínica (TRONCON et al. 2016).

O modelo de escola-clínica aplicado deve aproximar o conhecimento básico da sua aplicação clínica (MEC, 2018), dessa forma, a divisão de disciplinas da grade curricular com suas respectivas aulas práticas permite a atuação fidedigna do aluno com o paciente, porém, leva por fragmentar o atendimento em diversos setores. Dessa forma, a sistematização de informações em saúde, como o cadastramento e obtenção/manutenção de prontuários eletrônicos de pacientes (PINTO, 2006), aprimora o atendimento odontológico, pois facilita o gerenciamento, precisão, controle de estatísticas, e agilidade no acesso e no movimento de informações, como perfis, diagnósticos e tratamentos de pacientes (MARTINS; LIMA, 2014; PINOCHET, 2011; SANTOS; CARVALHO, 2014).

Diante às premissas, algumas Universidades estão se adaptando às novas necessidades da sociedade com a implementação de sistemas mais tecnológicos de triagem, centralizando as atividades de acolhimento, cadastramento e encaminhamento de pacientes de acordo com suas necessidades por meio de prontuários eletrônicos (LEITE, et al. 2018). A execução dessa atividade por meio de softwares específicos como o software de gestão Dental Office ${ }^{\circledR}$ tem sido reportado por promover melhorias no sistema de triagem da Universidade Estadual de Ponta Grossa, centralizando o processo de cadastro e encaminhamento dos pacientes (Fig 1).

Anteriormente, os pacientes que procuravam a recepção do curso de odontologia da UEPG eram cadastrados em uma planilha no software Excel® para triagem e submetidos a uma imensa lista de espera. Diante da ineficiência deste sistema de encaminhamentos de pacientes triados os alunos procuravam pacientes por outros meios como redes sociais, entre conhecidos e professores além da livre-demanda, ocasionando a perda da integralidade no atendimento de pacientes já triados. Atualmente, com a implementação de um software especifico proveniente do projeto de extensão, os pacientes são previamente cadastrados no software odontológico Dental Office ${ }^{\circledR}$ (Fig 2), com a especialidade definida onde os alunos procuram por pacientes somente via recepção, a qual também os encaminham, dentro do mesmo sistema, para dar continuidade ao tratamento. 
Fig 1. Interface do software Dental Office ${ }^{\circledR}$ instalado nos smartphones demonstrando o acesso online de dados de anamnese, exame físico, laudos radiológicos e da pré-triagem. Observação: nome fictício utilizado. LODI: Liga

Odontológica de Diagnóstico por imagem da UEPG também integrada ao sistema online

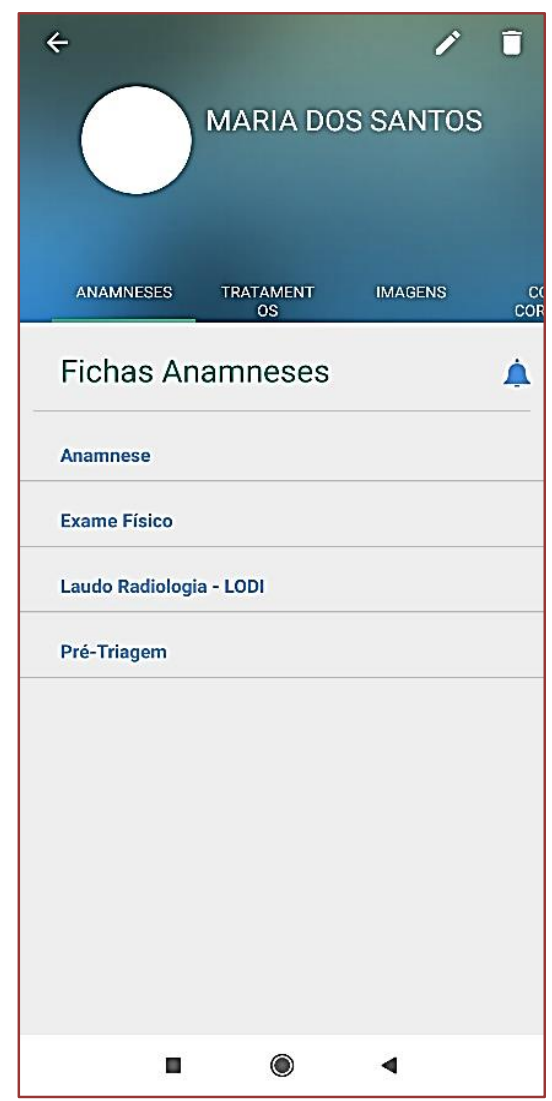

Fig 2. Representação do sistema de pré-triagem da UEPG via aplicativo instalado no smartphone.

\begin{tabular}{|c|c|}
\hline \multicolumn{2}{|c|}{$\leftarrow$ Pré-Triagem } \\
\hline \multicolumn{2}{|c|}{1 - Necessita de urgência no tratamento? } \\
\hline O sim & O Não \\
\hline \multicolumn{2}{|c|}{$\begin{array}{l}\text { 2- Possui alguma doença sistêmica ou } \\
\text { infecciosa? Se sim, qual(is)? }\end{array}$} \\
\hline O sim & O Não \\
\hline \multicolumn{2}{|c|}{ Resposta } \\
\hline \multicolumn{2}{|c|}{3 - Possui algum tipo de alergia? Se sim, qual(is)? } \\
\hline Osim & ○ Não \\
\hline \multicolumn{2}{|c|}{ Resposta } \\
\hline \multicolumn{2}{|c|}{4 - Toma algum medicamento? Se sim, qual(is)? } \\
\hline Sim & O Năo \\
\hline \multicolumn{2}{|c|}{ Resposta } \\
\hline \multicolumn{2}{|c|}{5 - Está em tratamento médico? Se sim, qual(is)? } \\
\hline Osim & ○ Não \\
\hline \multicolumn{2}{|c|}{ Resposta } \\
\hline \multicolumn{2}{|c|}{ EXAME FÍSICO } \\
\hline \multicolumn{2}{|c|}{6 - PSB I ( $\left.2^{\circ} \mathrm{SEM}\right)$} \\
\hline & () \\
\hline
\end{tabular}

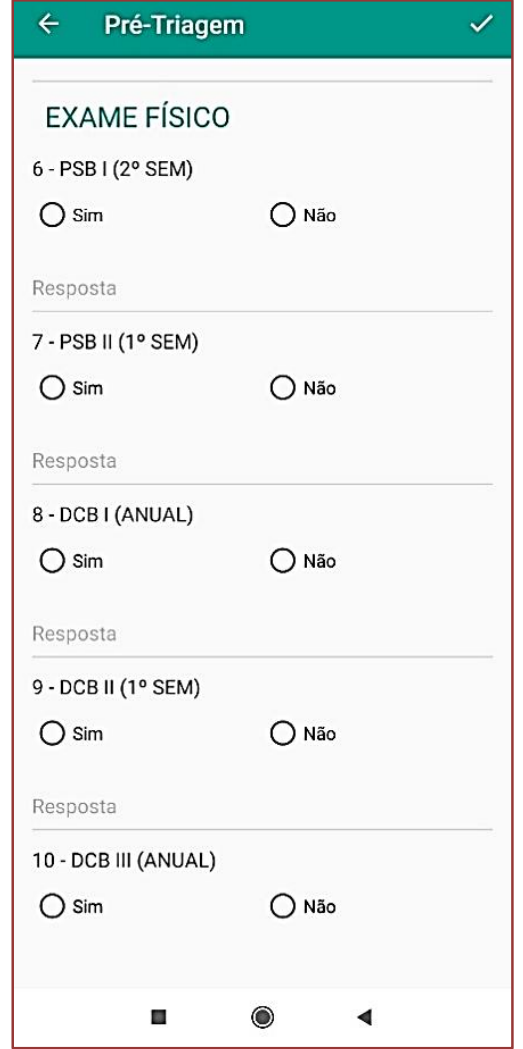


O software Dental Office ${ }^{\circledR}$, contém uma interface web para uso na recepção odontológica e um aplicativo para uso na clínica através de smartphones, mostrando ser uma ferramenta eficaz com interface autoexplicativa, permitindo acesso a qualquer hora e de qualquer lugar de maneira segura e fácil. Além disso, possibilita o aluno registrar fotos e outras informações detalhadas do paciente. Dessa forma, o uso de dispositivos como o software Dental Office ${ }^{\circledR}$ aparecem como uma possível alternativa moderna e eficiente aos sistemas de triagem, cadastramento e encaminhamento de pacientes em clínicas-escolas, onde há um demandante fluxo de pacientes em diversas especialidades odontológicas.

\section{OBJETIVO}

O presente projeto provém a partir do programa de "Estruturação do Setor de Triagem para as Clínicas Odontológicas da Universidade Estadual de Ponta Grossa" e possui como público alvo pacientes, alunos, funcionários e professores do Departamento de Odontologia da Universidade Estadual de Ponta Grossa. 0 programa tem suas atividades executadas por extensionistas, composto por alunos de iniciação científica, mestrandos e doutorandos. É realizada no Bloco M da UEPG e suas ações atingem principalmente o município de Ponta Grossa, Paraná.

Assim, este trabalho tem por objetivo principal expor o fluxo de encaminhamento de pacientes entre as clínicas odontológicas no ano de 2018 e primeiro semestre de 2019, após a centralização dos encaminhamentos pela central de Recepção e Triagem.

\section{METODOLOGIA}

O levantamento das informações sobre o fluxo de encaminhamento de pacientes entre as clínicas odontológicas foi realizado na UEPG nos períodos de Janeiro de 2018 a Julho de 2019 e os dados foram obtidos por meio de fichas de encaminhamento impressas provenientes das diferentes clínicas de atendimento odontológico. Inicialmente, realizou-se um treinamento com os alunos, professores e funcionários sobre como aconteceriam os encaminhamentos e a importância do preenchimento correto dos dados do paciente. As fichas com a relação de pacientes a serem encaminhados foram impressas e distribuídas em todas as clínicas, identificadas com o número da clínica correspondente e ficaram em um local de fácil acesso aos alunos. Elas foram preenchidas pelo aluno responsável pelo atendimento com: 1) Nome completo do paciente sem abreviações; 2) Telefone para contato; 3) Disciplina a ser encaminhado (especialidade mais urgente); 4) Nome do responsável pelo encaminhamento.

Inicialmente as fichas eram distribuídas e recolhidas pelos alunos extensionistas que desempenhavam sua função na recepção, e o cadastramento dos pacientes encaminhados era feito em uma planilha Excel ${ }^{\circledR}$ na disciplina correspondente à especialidade necessária. Após a implementação do software Dental Office ${ }^{\circledR}$ para o gerenciamento de pacientes, duas alunas extensionistas tiveram a função específica de fazer a distribuição e coleta das fichas de encaminhamento em todas as clínicas em que há circulação de pacientes. Antes de realizar o cadastro no sistema as alunas procuram por um cadastro prévio, se positivo ele é alterado para a especialidade indicada na ficha de encaminhamento e a "Situação atual" do paciente é colocada como "Triado- Em Espera", que significa que ele terá preferência em relação aos Não-Triados na ordem de atendimento. Caso não tenha cadastro, o paciente teve seu status classificado como "NãoTriado".

As fichas arquivadas foram inicialmente classificadas em 2018 e 2019, e os encaminhamentos foram contados de acordo com a disciplina de destino para a obtenção das disciplinas que possuem o maior fluxo de paciente através deste método de encaminhamento de pacientes.

\section{RESULTADOS E DISCUSSÃO}

A partir dos dados obtidos, foi possível conhecer o fluxo de pacientes encaminhados entre as clínicas de atendimento odontológico na UEPG. Ao todo, foram 487 encaminhamentos realizados entre 17 clínicas de atendimento odontológico nos níveis de graduação, especialização (Ortodontia) e extensão (Projeto Siso). As disciplinas, as atividades realizadas e a quantidade de encaminhamentos para cada disciplina estão descritas na Tabela 1. 
Tabela 1. As disciplinas, atividades realizadas e número de pacientes encaminhados.

\begin{tabular}{|c|c|c|c|}
\hline Disciplina & Atividade realizada & № de pacientes & Ano \\
\hline Dentística Clínica & Restaurações & $\begin{array}{l}77 \\
34 \\
\end{array}$ & $\begin{array}{l}2018 \\
2019\end{array}$ \\
\hline Periodontia Clínica & Tratamento periodontal não cirúrgico & $\begin{array}{l}66 \\
49 \\
\end{array}$ & $\begin{array}{l}2018 \\
2019\end{array}$ \\
\hline Endodontia Clínica & Tratamento endodôntico & $\begin{array}{c}22 \\
7\end{array}$ & $\begin{array}{l}2018 \\
2019\end{array}$ \\
\hline $\begin{array}{l}\text { Multidisciplinar em } \\
\text { Dentística e Periodontia }\end{array}$ & $\begin{array}{l}\text { Tratamento periodontal cirúrgico, } \\
\text { restaurações complexas }\end{array}$ & $\begin{array}{c}12 \\
7\end{array}$ & $\begin{array}{l}2018 \\
2019\end{array}$ \\
\hline $\begin{array}{l}\text { Práticas em Saúde Bucal II } \\
\text { (PSB II) }\end{array}$ & Prevenção de doenças bucais & $\begin{array}{l}3 \\
0\end{array}$ & $\begin{array}{l}2018 \\
2019\end{array}$ \\
\hline Reabilitação Bucal I & Prótese fixa unitária e prótese total & $\begin{array}{l}9 \\
2\end{array}$ & $\begin{array}{l}2018 \\
2019\end{array}$ \\
\hline Reabilitação Bucal II & Prótese parcial removível e prótese fixa & $\begin{array}{l}25 \\
28\end{array}$ & $\begin{array}{l}2018 \\
2019\end{array}$ \\
\hline $\begin{array}{l}\text { Multidisciplinar em } \\
\text { Endodontia e Prótese }\end{array}$ & $\begin{array}{l}\text { Prótese fixa, endodontia complexa e } \\
\text { retratamento endodôntico }\end{array}$ & $\begin{array}{l}6 \\
1 \\
\end{array}$ & $\begin{array}{l}2018 \\
2019\end{array}$ \\
\hline $\begin{array}{l}\text { Clínica de Disfunção } \\
\text { Temporomandibular } \\
\text { (DTM) }\end{array}$ & $\begin{array}{l}\text { Tratamento de disfunção } \\
\text { temporomandibular e dor orofacial }\end{array}$ & $\begin{array}{l}6 \\
8\end{array}$ & $\begin{array}{l}2018 \\
2019\end{array}$ \\
\hline $\begin{array}{l}\text { Diagnóstico e Cirurgia } \\
\text { Bucal II (DCB II) }\end{array}$ & Radiografias intrabucais & $\begin{array}{l}1 \\
0\end{array}$ & $\begin{array}{l}2018 \\
2019\end{array}$ \\
\hline $\begin{array}{l}\text { Diagnóstico e Cirurgia } \\
\text { Bucal IV (DCB IV) }\end{array}$ & Exodontias & $\begin{array}{c}17 \\
8\end{array}$ & $\begin{array}{l}2018 \\
2019\end{array}$ \\
\hline Estomatologia & Diagnóstico de lesões bucais e biopsias & $\begin{array}{l}7 \\
1\end{array}$ & $\begin{array}{l}2018 \\
2019\end{array}$ \\
\hline $\begin{array}{l}\text { Multidisciplinar em } \\
\text { Cirurgia e Estomatologia }\end{array}$ & $\begin{array}{l}\text { Exodontias complexas, } 3^{\circ} \text { molares } \\
\text { simples, biopsias. }\end{array}$ & $\begin{array}{c}11 \\
9\end{array}$ & $\begin{array}{l}2018 \\
2019 \\
\end{array}$ \\
\hline Clínica Integrada & Todos os procedimentos & $\begin{array}{c}37 \\
8\end{array}$ & $\begin{array}{l}2018 \\
2019\end{array}$ \\
\hline Clínica Integrada Infantil & Todos os procedimentos em crianças & $\begin{array}{l}8 \\
0\end{array}$ & $\begin{array}{l}2018 \\
2019 \\
\end{array}$ \\
\hline $\begin{array}{l}\text { Ortodontia } \\
\text { (especialização) }\end{array}$ & Ortodontia em adolescentes e adultos & $\begin{array}{l}1 \\
0\end{array}$ & $\begin{array}{l}2018 \\
2019\end{array}$ \\
\hline Projeto Siso & Exodontias de $3^{\circ}$ molares & $\begin{array}{c}13 \\
0\end{array}$ & $\begin{array}{l}2018 \\
2019\end{array}$ \\
\hline \multicolumn{2}{|c|}{ Total de encaminhamentos } & 487 & \\
\hline
\end{tabular}

Fonte: Autores

De acordo com o levantamento, as disciplinas que receberam maior número de pacientes foram: Dentística Clínica e Periodontia Clínica nas quais são realizados tratamentos restauradores de dentes acometidos por cáries, fraturas dentais, além de procedimentos estéticos e tratamentos básico da doença periodontal com raspagem e alisamento radicular. As doenças cárie e periodontal são consideradas as patologias mais comuns da cavidade bucal, sendo as maiores causadoras de perda dental (FRENCKEN, et al. 2017). Estudos epidemiológicos relatam que entre 1990 e 2010 a doença periodontal em sua forma grave já atingia $11 \%$ da população mundial sendo a sexta doença mais comum em todo o mundo (KASSEBAUM, et al. 2014). Embora com números crescentes de formação de profissionais na odontologia bem como da maior facilidade de acesso aos tratamentos e a informação (MARTIN et al. 2018), estudos recentes apontam que a prevalência de periodontite ainda é alta diferentemente da doença cárie em que se nota um decrescimento (FRENCKEN, et al. 2017). Além disso, doenças como a cárie tem sido reportada por estar intimamente ligada a fatores socioeconômicos atingindo principalmente grupos mais pobres e de fragilidade social (BOING, et al. 2014), grupos característicos na busca de tratamento em universidades e demais sistema públicos. Assim, é possível observar que a predominância dos encaminhamentos a essas disciplinas não é ao acaso, mas corroboram com a realidade epidemiológica.

Em seguida, observa-se um alto fluxo de pacientes para a clínica integrada. Nesta disciplina há o objetivo de integrar os conhecimentos de todas as áreas adquiridos ao decorrer da formação (REIS, et al. 2011). Deste modo, o aluno tem competência para avaliar toda a complexidade envolvida no caso clínico e 
realizar todos os procedimentos necessários ao paciente ao invés de fragmentá-lo em diversas disciplinas necessitando de vários encaminhamentos. Assim, apenas alunos de nível mais avançado no curso são responsáveis pela sua execução.

A Reabilitação Bucal II também se mostra importante para os encaminhamentos, uma vez que muitos pacientes, após os demais tratamentos, necessitam de próteses para a finalização do seu caso. Corresponde, portanto, à restituição da forma, estética e principalmente da função dentária e consequentemente da recuperação da qualidade do sistema estomatognático por meio de próteses totais e parciais, removíveis e fixas (BEZERRA, et al. 2011). Mesmo que o tratamento também seja realizado na Clínica Integrada observa-se que a demanda é alta e poucos pacientes são atendidos rapidamente devido a sequência de atendimento, a adequação para o aprendizado acadêmico além do próprio tempo exigido para a confecção do material protético. Projeções demonstram que até 2040 haverá uma queda de edêntulos na população brasileira entre 15-44 anos mas um aumento na população mais idosa (65-74 anos) (CARDOSO, et al. 2016), reflexos de um sistema de saúde bucal que ainda progride a passos lentos e que não teve alcance à totalidade da população.

As limitações nesse estudo envolvem o fato de que algumas disciplinas não obtiveram seus dados contabilizados no ano de 2019 pois sofreram mudanças em seus sistemas de encaminhamentos. Na PSB II e DCB II a maioria dos encaminhamentos ocorrem diretamente entre os alunos e conhecidos pois as necessidades nestas disciplinas são específicas para determinados casos. A Clínica Integrada Infantil, a Ortodontia e Projeto Siso (cirurgia bucal) agora possuem seus próprios sistemas de encaminhamento de pacientes, por este motivo os encaminhamentos para estas disciplinas não são contabilizados pela triagem. $\mathrm{O}$ baixo número de encaminhamento em certas disciplinas também se deve ao fato de que muitos alunos se dirigem diretamente à recepção para a atualização cadastral e encaminhamento de pacientes, tornando impossível a contabilização através das fichas.

\section{CONSIDERAÇõES FINAIS}

Diante dos resultados mostrados, pode-se considerar que a centralização do sistema de encaminhamentos pelo setor de triagem apresentou-se de maneira positiva, devido ao acesso dos alunos aos pacientes que necessitam da especialidade esperada e também pela facilidade de encaminhamento deste mesmo paciente para a continuidade do tratamento, o que garante a integralidade do atendimento. Ainda deve-se continuar com treinamentos de alunos, professores e funcionários afim de evitar meios paralelos de encaminhamento, incentivar a atualização cadastral frequente dos pacientes e o fornecimento de informações corretas nas fichas para evitar a perda do encaminhamento devido à falta de dados.

\section{AGRADECIMENTOS}

Gostaríamos de agradecer ao programa de extensão universitária da Universidade Estadual de Ponta Grossa pelo apoio e incentivo ao desenvolvimento de ações extensionistas e a empresa $R H$ Software por ceder a licença de uso do Software Dental Office ${ }^{\circledR}$ gratuitamente à instituição.

Agradecemos a discente Dominique Ellen Carneiro pela assistência durante o desenvolvimento do estudo.

Somos gratos também à Fundação Araucária por conceder subsídios para o andamento das ações desenvolvidas no projeto.

\section{REFERÊNCIAS}

[1] BEZERRA, F. et al. Avaliação do impacto do edentulismo total mandibular e da reabilitação fixa sobre implantes com carga imediata na qualidade de vida de pacientes idosos. Revista Dental Press de. Periodontia e Implantologia, v.5, n.3, p. 101-10, 2011.

[2] BOING, A. F. et al. Determinantes sociais da saúde e cárie dentária no Brasil: uma revisão sistemática da literatura entre 1999 e 2010. Revista Brasileira de Epidemiologia, v. 17, supl. 2, p. 102-115, 2014.

[3] CARDOSO, M. et al. Edentulism in Brazil: trends, projections and expectations until 2040. Ciência \& Saúde Coletiva, v. 21, n. 4, p. 1239-1246, 2016.

[4] CYRINO, E. G. et al. Há pesquisa sobre ensino na saúde no Brasil? ABCS Health Sciences, Santo André, v. 40, n. 3, p. 146-155, 2015. 
[5] FRENCKEN, J. E. et al. Global epidemiology of dental caries and severe periodontitis - a comprehensive review. Journal of Clinical Periodontology, v. 44, Suppl 18:S94-105, 2017.

[6] GONÇALVEZ, E. R.; VERDI, M. I. M. Os problemas éticos no atendimento a pacientes na clínica odontológica de ensino. Ciência \& Saúde Coletiva, v. 12, n. 3, p. 755- 764, 2007.

[7] KASSEBAUM, N. J. et al. Global burden of severe periodontitis in 1990-2010: a systematic review and metaregression. Journal of Dental Research, v.93, n.11, p. 1045-1053, 2014.

[8] LEITE, D. R.; SILVA, A.; SAMPAIO, G.; DA COSTA, L.; BONAN, P. R.; MÉLO, C. Prontuário Eletrônico de Estomatologia (PEEST): uma experiência de desenvolvimento e implantação no curso de Odontologia. Revista InterScientia, v. 6, n. 2, p. 112-123, 2018.

[9] MARTIN, A. S. S. et al. Distribuição dos cursos de odontologia e de cirurgiões-dentistas no Brasil: uma visão do mercado de trabalho. Revista da ABENO, 18, n. 1, 2018.

[10] MARTINS, C.; LIMA, S. M. Vantagens e desvantagens do prontuário eletrônico para instituição de saúde. Revista de Administração em Saúde, São Paulo, v. 16, n. 63, p.61-66, 2014.

[11] MORISHITA, A.; SILVA, E. A.; SOUZA, M. A. M. Concepção de triagem x demanda crescente do atendimento em unidades de urgência e emergência. Revista Ponto de Encontro, v. 1, n. 2, p. 196-209, 2009.

[12] PINTO, V. B. Prontuário eletrônico do paciente: documento técnico de informação e comunicação do domínio da saúde. Encontros Bibli: Revista Eletrônica de Biblioteconomia e Ciência da Informação, n. 21, p.34-48, 2006.

[13] REIS, S. C. G. B.; SANTOS, L. B.; LELES, C. R. Clínica Integrada de ensino odontológico: perfil dos usuários e necessidades odontológicas. Revista Odontológica do Brasil Central, 20, 2011.

[14] SANTOS, P. S.; CARVALHO, G. P. Prontuários eletrônicos em odontologia e obediência às normas do CFO. Revista Odontológica do Brasil Central, 23, 2014.

[15] TRINDADE, O. M.; ABRAMOWICZ, M.; RAMOS, D. L. P. Análise das rotinas adotadas nos serviços de triagem de instituições de ensino odontológico para atendimento e encaminhamento de pacientes: aspectos éticos. Revista de Pós-Graduação da Faculdade de Odontologia da USP, v. 6, p. 291-297, 1999.

[16] TRONCON, M. F. A. et al. Estruturação dos serviços de triagem e pronto-atendimento em uma clínica-escola de psicologia em fase de implantação. Adamantina: Faculdades Adamantinenses Integradas de Adamantina, 2006. 


\section{Capítulo 4}

Análise das necessidades de tratamento de pacientes cadastrados no Sistema Dental Office ${ }^{\circledR}$

\section{Marianne Grollmann}

Eduarda Cristina Santos

Laura Cristina Andrade Bubna

Dominique Ellen Carneiro

Lourdes Zeballos López

Fábio André dos Santos

Resumo: Pesquisas nacionais como o Brasil Sorridente tem como objetivo avaliar a saúde bucal da população e buscar maneiras para melhorar seus índices. Já o projeto de extensão "Estruturação do Setor de Triagem para as Clínicas Odontológicas da Universidade Estadual de Ponta Grossa" tem como um de seus objetivos melhorar o fluxo de pacientes para atendimento na clínica odontológica. Aqueles que necessitam de atendimento tem seu cadastro realizado na recepção de odontologia da Universidade, e em seguida, passam por uma triagem para serem direcionados ao seu tratamento. Para que o encaminhamento ocorra, é colocado no perfil do paciente a situação do atendimento, o tipo de tratamento necessário e observações sobre o paciente (exemplo: se usa algum medicamento ou tem alergias). Através desses dados é possível descobrir quais são os atendimentos mais realizados/necessitados, e assim, promover meios de informação sobre prevenção e como é realizado o tratamento. Através de uma análise de relatórios realizados por intermédio do banco de dados do sistema Dental Office ${ }^{\circledR}$, foi observado que a maior parte dos tratamentos que estão sendo requisitados pertencem a área de Periodontia. Mediante a esse resultado, é possível desenvolver medidas preventivas e informativas aos pacientes que estão em busca de atendimento odontológico.

Palavras-chave: Aplicativos odontológicos. Registros Odontológicos. Necessidade de Tratamentos. 


\section{INTRODUÇÃO}

O curso de Odontologia da Universidade Estadual de Ponta Grossa (UEPG) fornece atendimento gratuito para a comunidade nas áreas de dentística, periodontia, radiologia,cirurgia, endodontia, cobrando apenas a mão de obra do profissional técnico em prótese dentária durante a confecção de próteses totais, removíveis e fixas.

0 atendimento à população deve ser visto com totalidade e integralidade, desde a estrutura organizacional, administrativa, funcional dos serviços e da instituição, até o conhecimento da comunidade em que o paciente está inserido e suas necessidades sociais (ROSA, 2020). Apesar de ter afluência de pacientes um dos maiores problemas do atendimento era que o fluxo de pacientes se mostrava ineficiente, de tal forma que a reabilitação bucal completa estava sendo prejudicada. Muitos pacientes não finalizavam seus tratamentos, além de não serem encaminhados para o próximo procedimento. As causas podem ser diversas, como a perda do número para contato, inadequação do armazenamento de prontuários, não conseguir contato e o não encaminhamento entre as clínicas (JÚNIOR, 2016).

Para a resolução desse problema, em 2016 foi criado o projeto de Estruturação do Setor de Triagem para a Implementação de uma Porta de Entrada para os Pacientes. Para que os pacientes tenham acesso ao atendimento nos cursos de odontologia, é obrigatória a passagem pela triagem, que se concentra na busca de "casos clínicos" que possam se encaixar às necessidades técnicas de ensino.

Dessa forma a entrada do paciente era feita pelo sistema de Pré-Triagem, momento em que graduandos do curso e alunos da pós-graduação extensionistas realizavam a anamnese e o exame intra-oral inicial. A triagem é o primeiro contato entre os profissionais ou acadêmicos das clínicas-escola com o usuário e tem como finalidade a avaliação inicial, a seleção e o encaminhamento dos pacientes às unidades adequadas para sua assistência.

Em 2018, houve a implantação do sistema de prontuários eletrônicos por meio do software Dental Office ${ }^{\circledR}$. Com ele, é possível criar um perfil para cada paciente que será atendido pelo projeto, contendo dados como: nome completo, foto, observações, aluno/professor responsável, data/local de nascimento, estado civil, grupo, situação do tratamento, especialidade, indicação, números para contato, endereço e documentos (RG e CPF), além de um local para os dados dos responsáveis para menores de 18 anos. Depois do cadastro, o paciente será atendido pela Clínica de Pré-Triagem e serão adicionadas ao seu perfil as informações coletadas durante o exame, além das especialidades necessárias para o tratamento. As informações coletadas são armazenadas no banco de dados, e assim, os pacientes podem ser encaminhados para a especialidade necessária por meio de atualizações das listas dos pacientes triados como também do status de cada paciente. Durante um atendimento, o aluno responsável necessita de um smartphone com o aplicativo Dental Office ${ }^{\circledR}$ instalado e acesso à internet. Com isso, ele terá o perfil do paciente com todas as informações pessoais, clínicas e também de radiografias iniciais.

Nesse sentido, o presente estudo busca avaliar os problemas de saúde bucal mais frequentes dos pacientes que são atendidos na Universidade Estadual de Ponta Grossa, para aplicar futuramente os resultados obtidos em estratégias de prevenção e informação. Assim, a população terá conhecimento das doenças bucais mais comuns na região, de como preveni-las e quais são as opções de tratamento.

\section{OBJETIVOS}

O objetivo deste estudo foi avaliar o perfil e tratamentos de pacientes triados e cadastrados no sistema Dental Office ${ }^{\circledR}$ que são atendidos na Universidade Estadual de Ponta Grossa, juntamente com as informações fornecidas pelo Sistema Único de Saúde (SUS) e Instituto Brasileiro de Geografia e Estatística (IBGE).

\section{METODOLOGIA}

Este estudo foi do tipo observacional descritivo, e para a coleta dos dados foram acessados o sistema do banco de dados do Ministério de Saúde e do Instituto Brasileiro de Geografia e Estatística, além do sistema de prontuários eletrônicos da Universidade Estadual de Ponta Grossa no ano de 2020. Os dados coletados foram: índice CPOD (cariados, perdidos e obturados) para diferentes regiões do Brasil, população estimada para a cidade de Ponta Grossa, taxa de mortalidade, número de estabelecimentos de saúde para atendimento à população, áreas de atendimento odontológico e número de atendimentos realizados tanto pela prefeitura como pelas clínicas odontológicas da UEPG. 
A partir do banco de dados da UEPG verificou-se o número de pacientes em atendimento, aqueles que já foram atendidos, os que necessitavam de tratamento e aqueles que abandonaram o atendimento. Verificou-se também o tipo de tratamento mais realizado e otratamento mais requerido pelos pacientes. Para isso, usou-se a ferramenta para gerar relatórios que está disponível no sistema Dental Office ${ }^{\circledR}$, a qual permite filtrar os pacientes por estado do atendimento, grupo e especialidade que estão presentes nos perfis registrados.

\section{RESULTADOS E DISCUSSÃO}

O Brasil Sorridente conta com o índice CPOD que expressa a média de dentes cariados, perdidos e obturados em um grupo de indivíduos, (CYPRIANO; SOUSA; WADA, 2005). Existindo discrepâncias entre as regiões do país: $O$ Norte com um índice CPOD de 3,16 o Nordeste com 2,63 e o Centro-Oeste com 2,63 têm uma situação pior que as regiões Sudeste $(1,72)$ e Sul $(2,06)$. Os valores extremos (Norte e Sudeste) mostram uma diferença de cerca de $84 \%$, indicando que o ataque da doença cárie se combina com menor acesso aos serviços odontológicos na região.

Com cerca de 351 mil habitantes (IBGE, 2020), Ponta Grossa apresentou uma taxa de mortalidade infantil média de 12,66 para 1.000 nascidos vivos. Para o atendimento da população, existem cerca de 78 estabelecimentos de Saúde SUS, e além de ser fornecido o atendimento odontológico em Unidades Básicas de Saúde, existe o Centro de Especialidades Odontológicas (nível III). Nele, são realizados atendimentos nas áreas de: dentística, endodontia, periodontia, moldagem/manutenção de próteses, cirurgia bucal, atendimento a pessoa com deficiência e serviço laboratorial de prótese dentária total. De acordo com a Prefeitura, em 2018 o CEO realizou cerca de 5.263 atendimentos, porém não há informações sobre quais tipos de procedimentos foram realizados.

A respeito dos atendimentos na UEPG observou-se que há um total de 3.670 pacientescadastrados. Destes, 29 finalizaram seu tratamento, 51 não foi possível entrar em contato, 214 estão em tratamento, 218 abandonaram, 224 foram triados e encaminhados e 514 foram triados e estão em espera (Figura 1).

Figura 1: Histograma de frequência: Status de pacientes cadastrados no sistema de prontuários eletrônicos.

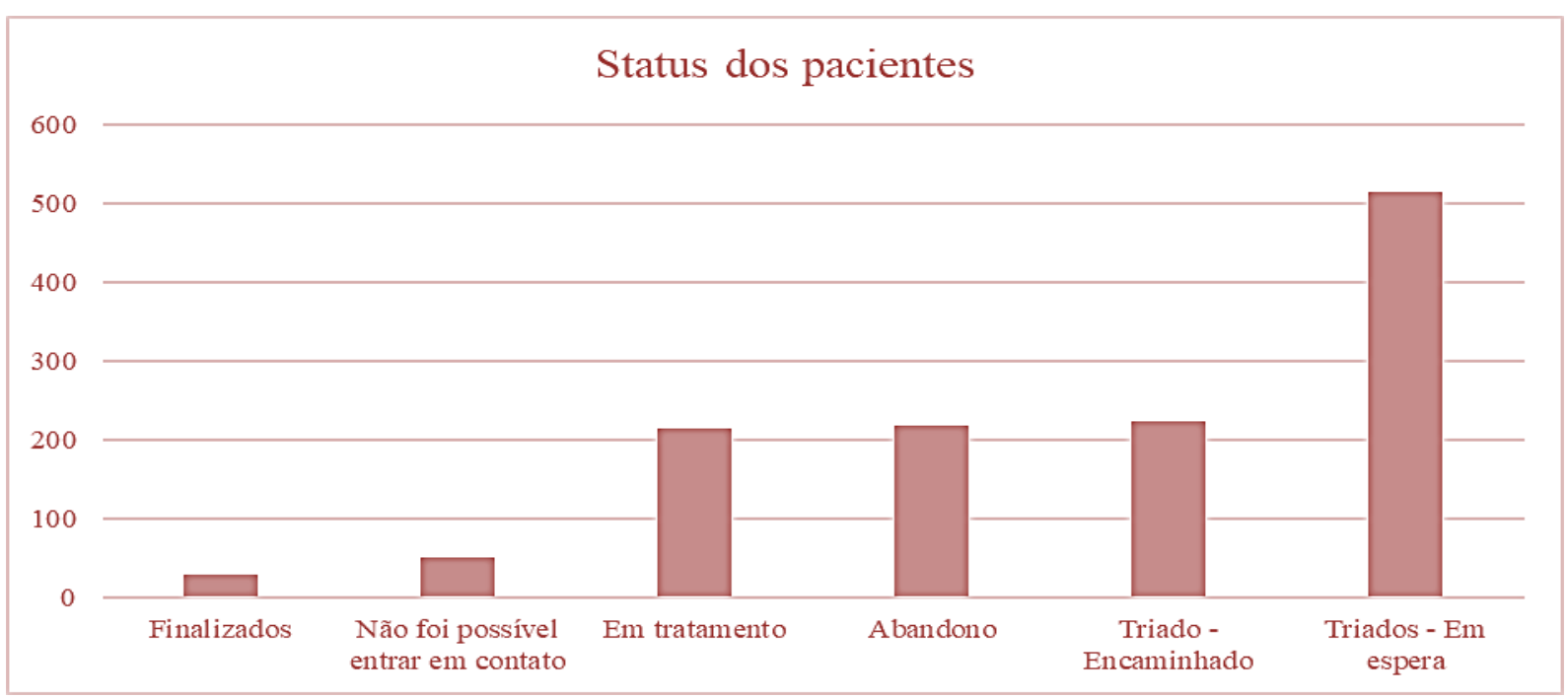

Fonte: Sistema de prontuários eletrônicos Software Dental Office ${ }^{\circledR}$. Universidade Estadual de Ponta Grossa. (UEPG)

Estes números mostram que há uma discrepância entre o total de pacientes que estão cadastrados no sistema e as demais categorias. Tal diferença pode ser o resultado da falta de atualização da situação dos pacientes (falha na comunicação entre os alunos e a recepção) ou baixo número de encaminhamentos de pacientes já triados (baixa frequência de alunos utilizando a recepção como um meio de encontrar pacientes). Desse modo, há um aumento na quantidade de pacientes em espera, o que pode acarretar em mais abandonos. 
Já em relação aos tipos de tratamento necessitados pelos pacientes triados e em espera, os maiores números foram das disciplinas de: Periodontia, Dentística e Reabilitação Bucal II. Já os encaminhamentos foram principalmente para: Periodontia clínica, Endodontia clínica e Clínica Integrada II (Tabela 1).

Caso estes pacientes buscassem atendimento pelo CEO III de Ponta Grossa (SUS), ainda teriam de aguardar o atendimento, pois existem listas de espera disponíveis no site da prefeitura. O Centro de Especialidades Odontológicas tipo III tem como demanda de produção mensal (considerada como boa): $\geq 190$ atendimentos de procedimentos básicos, $\geq 170$ procedimentos cirúrgicos, $\geq 150$ procedimentos periodontais e $\geq 95$ atendimentos endodônticos (RIOS, 2019). 0 acréscimo de todos os pacientes que estão cadastrados no sistema do Dental Office ${ }^{\circledR}$ elevaria o número de pessoas nas listas de espera, comprometendoa velocidade e o fluxo de atendimentos.

Tabela 1: Número de pacientes triados (\%) em espera e encaminhados para cada clínica odontológica.

\begin{tabular}{|c|c|c|}
\hline \multirow[b]{2}{*}{ Especialidades } & \multicolumn{2}{|c|}{ Status } \\
\hline & Triado - em espera (\%) & $\begin{array}{c}\text { Triado/encaminhado } \\
(\%)\end{array}$ \\
\hline Clínica de atenção básica & $0(0)$ & $1(0)$ \\
\hline Diagnóstico e cirurgia bucal I & $1(0)$ & $4(2)$ \\
\hline Diagnóstico e cirurgia bucal II & $1(0)$ & $0(0)$ \\
\hline Diagnóstico e cirurgia bucal III & $7(1)$ & $8(4)$ \\
\hline Diagnóstico e cirurgia bucal IV (cirurgia) & $13(2)$ & $18(9)$ \\
\hline Diagnóstico e cirurgia bucal IV (estomatologia) & $19(3)$ & $3(1)$ \\
\hline Práticas em saúde bucal I & $4(1)$ & $2(1)$ \\
\hline Práticas em saúde bucal II & $19(3)$ & $2(1)$ \\
\hline Endodontia clínica & $4(1)$ & $33(16)$ \\
\hline Dentistica clínica & $96(17)$ & $17(8)$ \\
\hline Periodontia clínica & $131(23)$ & $33(16)$ \\
\hline Periodontia optativa & $29(5)$ & $2(1)$ \\
\hline Clínica integrada I & $21(2)$ & $11(5)$ \\
\hline Clínica integrada II & $19(3)$ & $19(9)$ \\
\hline Clínica integrada III & $5(1)$ & $6(3)$ \\
\hline Reabilitação bucal I & $22(4)$ & $17(8)$ \\
\hline Reabilitação bucal II & $88(16)$ & $16(8)$ \\
\hline DTM & $22(4)$ & $1(0)$ \\
\hline Multidisciplinar de cirurgia e estomatologia & $7(1)$ & $7(3)$ \\
\hline Multidisciplinar de endodontia e prótese & $18(3)$ & $5(2)$ \\
\hline Multidisciplinar de Dentistica e periodontia & $37(7)$ & $2(1)$ \\
\hline Ortodontia & $2(0)$ & $3(1)$ \\
\hline Total & $565(100)$ & $210(100)$ \\
\hline
\end{tabular}

Fonte: Sistema de prontuários eletrônicos Software Dental Office ${ }^{\circledR}$. Universidade Estadual de Ponta Grossa(UEPG). 


\section{CONSIDERAÇÕES FINAIS}

Levando em conta os dados obtidos sobre os tipos de tratamento em pacientes já triados e encaminhados, é possível notar que grande parte necessita de tratamento periodontal, seguido de dentística e reabilitação bucal. Esse resultado pode sofrer alterações, pois há uma grande quantidade de pacientes que ainda não foram chamados para passar pela triagem ou que não atenderam à ligação. Mas usando as informações obtidas atualmente, pode-se criar um material educativo para o público com o objetivo de previnir e educar sobre tratamentos periodontais, restauradores e reabilitadores, contribuindo para o conhecimento e qualidade de vida.

\section{AGRADECIMENTOS}

Gostaríamos de agradecer ao programa de extensão universitária da Universidade Estadual de Ponta Grossa pelo apoio e incentivo ao desenvolvimento de ações extensionistas e a empresa $R H$ Software por ceder a licença de uso do Software Dental Office ${ }^{\circledR}$ gratuitamente à instituição.

Somos gratos também à Fundação Araucária por conceder subsídios para o andamento das ações desenvolvidas no projeto.

\section{REFERÊNCIAS}

[1] BRASIL. MINISTÉRIO DA SAÚDE; SECRETARIA DE ATENÇ̃̃o À SAÚDE; SECRETARIA DE VIGILÂNCIA EM SAÚDE. SB Brasil 2010: Pesquisa Nacional de SaúdeBucal: Resultados principais. Brasília: Ministério da Saúde; 2012.

[2] CYPRIANO, S.; SOUSA, M. L. R; WADA, R. S. - Avaliação de índices CPOD simplificados em levantamentos epidemiológicos de cárie dentária. Revista Saúde Pública, v. 39, n. 2, p. 285-92, 2005.

[3] JÚNIOR, H. M.; DIAS, V. O; SANTOS, M. L.; et al.- Dificuldades identificadas no atendimento odontológico após a triagem em uma universidade pública. Revista Intercâmbio. v. VII - 2016, p. 274.

[4] PONTA GROSSA. PREFEITURA MUNICIPAL: LISTAS DE ESPERA. Disponível em: <http://www.pontagrossa.pr.gov.br/fms/lista-de-espera> Acesso em: 1 jul. 2020.

[5] PONTA GROSSA. PREFEITURA MUNICIPAL- SAÚDE BUCAL: Odontologia municipal estabelece metas de trabalho para 2019. Disponível em: <http://pontagrossa.pr.gov.br/node/42149> Acesso em: 1 jul. 2020.

[6] PONTA GROSSA. IBGE; DIRETORIA DE PESQUISAS; COORDENAÇÃO DE POPULAÇ̃̃O E INDICADORES SOCIAIS. População estimada. Estimativas da população residente com data de referência 10 de julho de 2020. Disponível em: <https://cidades.ibge.gov.br/brasil/pr/ponta-grossa/panorama> Acesso em: 1 jul. 2020.

[7] RIOS, L. R. F. \& COLUSSI, C. F. Avaliação normativa dos Centros de Especialidades Odontológicas, Brasil, 2014. Saúde debate, Rio de Janeiro, v. 43, n. 120, p. 122-136, Mar.2019. Disponível em:

<https://www.scielo.br/scielo.php?pid=S010311042019000100122\&script=sci_arttext> Acesso em: 1 jul. 2020.

[8] ROSA, J. B.; BARKERT, K. A.; MENEGAZZO, G. R.; et al.- Análise dos encaminhamentos realizados pela triagem quanto ao acesso as clínicas do curso de Odontologia da Universidade Federal de Snta Maria. Revista da ABENO. v. 20, n.1, p. 91-101, 2020. 


\section{Capítulo 5}

Integração entre as escolas municipais de Ponta Grossa e o Banco de Dentes Humanos da Universidade Estadual de Ponta Grossa

\section{Thais Regina Kummer Ferraz. \\ Luiz Ricardo Marafigo Zander \\ Mariane Aparecida Sanson Wayar \\ Maria Eduarda Schimanski \\ Tamara Cristina Alves \\ Stella Kossatz}

Resumo: Os dentes humanos são considerados órgãos, e como tais, devem ser tratados, valorizados e dispor de origem conhecida. A utilização de dentes humanos é rotineira na formação profissional, tanto para fins didáticos como em pesquisas de relevância. Contudo, o seu uso deve respeitar princípios legais, éticos e sociais. O Banco de Dentes Humanos é a entidade que permite que os dentes sejam utilizados dentro de preceitos éticos e de biossegurança, coibindo o comércio ilegal do órgão dentário. Para seu funcionamento, eficácia e continuidade, esta entidade necessita de constantes doações de dentes que são recebidos, processados e armazenados adequadamente. Esse trabalho objetiva apresentar as iniciativas propostas, bem como os materiais produzidos pela atual equipe do Banco de Dentes Humanos da Universidade Estadual de Ponta Grossa e designados ao público infantil, visando aproximar à entidade da população pueril e estimular a participação ativa de discentes junto à entidade.

Palavras-Chave: Odontologia, Doações, Ética, Dente, Educação em saúde. 


\section{INTRODUÇÃO}

O dente é um órgão do corpo humano e, como tal, está submetido às disposições da Lei no 9.434/97, Lei de Transplantes no Brasil (BRASIL, 1997). A partir de seus preceitos, o uso de tecidos e órgãos humanos sem procedência passou por importantes reflexões éticas no que diz respeito ao comércio ilegal, armazenamento e biossegurança em seu manuseio que repercutiram diretamente no órgão dentário (KOSSATZ et al., 2020).

Os cursos de graduação e pós-graduação em Odontologia demandam da utilização de dentes humanos extraídos para pesquisas laboratoriais e treinamento pré-clínico, trazendo à luz a necessidade de uma entidade que administre as etapas envolvidas neste processo (IMPARATO, 2003). Nesse intento, os Bancos de Dentes Humanos (BDHs) vêm de anseio às necessidades expostas, pois são órgãos essenciais e obrigatórios nas Instituições de Ensino Superior (IES) que tenham curso de Odontologia presente, permitindo que acadêmicos, professores e pesquisadores possam executar suas atividades de forma ética e lícita (FREITAS et al., 2010; GOMES et al., 2013).

A Universidade Estadual de Ponta Grossa (UEPG) possui seu Banco de Dentes Humanos (BDH-UEPG) vinculado ao Departamento de Odontologia desde 2008, o qual tem como finalidade suprir as demandas acadêmicas de treinamento laboratorial pré-clínico, de ensino e pesquisa, documentando a procedência e destino de dentes humanos extraídos, garantindo os princípios éticos, de biossegurança e ciência aos alunos, pesquisadores e professores do curso de Odontologia. Atualmente, o BDH-UEPG apresenta uma equipe composta por uma servidora da instituição, quatro acadêmicos extensionistas e três professores do Departamento de Odontologia. Juntos eles organizam o trabalho e desenvolvem atividades de maneira remota para sensibilizar a comunidade sobre a importância do adequado destino dos dentes perdidos, não descartando-os junto aos resíduos domésticos (KOSSATZ et al., 2020).

Para pleno funcionamento de um BDH, a doação de elementos dentários, seja ele permanente ou decíduo ("dente de leite"), é a única possibilidade capaz de suprir a demanda crescente na utilização do órgão em treinamentos laboratoriais e pesquisas. Assim, aproximar o BDH da coletividade é fundamental para suprir o necessário ao perfeito funcionamento da entidade, possibilitando também o desenvolvimento de um trabalho de conscientização e informação acerca da importância da doação (IMPARATO, 1998).

0 público infantil escolar, além de potencial fonte de doação de elementos dentários oriundos das trocas ocorridas entre dentadura mista e permanente (esfoliação fisiológica), é muito receptivo, interessado e capaz de disseminar as informações recebidas para o seu núcleo familiar. Culturalmente, a fase de troca dentária, mais especificamente, a perda do dente decíduo, é rodeada de heranças culturais, como "jogar o dente no telhado", "jogar o dente para a fada" ou "trocar o dente por moedas", despontando a necessidade de especial atenção a esse público no que diz respeito à conscientização de que o dente é um órgão e como exemplo de outros, também pode ser doado (IMPARATO 1998).

Independente do estado e do tempo, o dente decíduo pode ser muito útil a um BDH e acredita-se que a doação não tira o encanto dessa fase, contribuindo para o desenvolvimento de crianças conscientes por este desígnio. Ademais, o contato no ambiente escolar contribui também para a difusão de bons hábitos de saúde entre alunos e professores (IMPARATO 1998).

Na UEPG, a procura por dentes decíduos para treinamento operatório em disciplinas e pesquisa tem aumentado. No entanto, a abordagem para doações resume-se aos pacientes atendidos nas clínicas odontológicas das disciplinas de Práticas de Saúde Bucal e Clínica Integrada Infantil, sendo pequeno o número de dentes decíduos na instituição. Sendo assim, expandir as ações do BDH-UEPG para essas populações oportuniza ultrapassar as fronteiras da universidade e aproximar o conhecimento da vivência popular.

O déficit nas doações pode ser justificado pela falta de informação sobre o correto destino desses elementos dentais, permeados na infância por fatores culturais arraigados. Nesse contexto, as atividades extensionistas visam expandir o conhecimento para o mundo concreto (AYRES, 2015) e levar informação voltada a melhoria da saúde bucal, bem como, abordar a temática da possibilidade e utilidade da doação desses dentes esfoliados pelo processo fisiológico, resultando em benefícios para os públicos envolvidos da universidade e comunidade (SANTOS; ROCHA; PASSAGLIO, 2016).

Assim, o objetivo deste manuscrito é apresentar as ações propostas e os materiais produzidos pela atual formação do BDH-UEPG, destinados ao público infantil com a finalidade de aproximá-los da entidade, além de estimular a participação ativa de discentes junto ao BDH-UEPG, possibilitando a estes o desenvolvimento de habilidades lúdicas e fortalecendo a divulgação da temática para as crianças da rede 
pública municipal de ensino, bem como com os pacientes pueris e responsáveis atendidos nas clínicas odontológicas da UEPG.

\section{METODOLOGIA}

O crescimento e desenvolvimento infantil são permeados de várias e constantes modificações estruturais, psicomotoras e emocionais. A troca dentária é um marco importante da vida das crianças e é permeada de simbolismos culturais. Contudo, o destino dentário é fator preocupante. As atividades propostas a serem desenvolvidas com este público buscam trabalhar o lúdico e sua simbologia (fada do dente, dente jogado no telhado, trocado por moedas e jogado no lixo) com o científico (descarte correto do lixo biológico e oportunidade da doação). 0 projeto realizado pelo BDH-UEPG propõe atividades lúdicas e educativas junto aos alunos $\left(1^{\circ}\right.$ ao $5^{\circ}$ ano) das escolas municipais da cidade de Ponta Grossa/PR, realizadas valendose de material de apoio produzido pela própria equipe do BDH-UEPG, objetivando conscientizar, divulgar e informar sobre o destino correto do lixo biológico.

As iniciativas que estão apresentadas no presente manuscrito foram desenvolvidas semanalmente, após leitura e discussão de literatura pertinente à temática. Destaca-se que, com a suspensão da maioria das atividades do curso de Odontologia da UEPG devido a situação de pandemia de COVID-19, segundo orientações da ANVISA, e com a troca de gestores municipais ocorrida após as eleições de novembro de 2020, os materiais e atividades feitos pela equipe do BDH-UEPG, foram desempenhados de maneira remota sob supervisão dos professores componentes da equipe.

Dentre as iniciativas propostas pela equipe do BDH-UEPG para fortalecer o vínculo escola-entidade, destaca-se a criação do Clube do doador. que conta com itens próprios, e a confecção de dois livros virtuais, todos construídos de acordo com a temática e personalizados de acordo com a faixa etária trabalhada. Os materiais foram desenvolvidos utilizando o aplicativo digital Canva - Design Gráfico para Todos.

Para a abordagem presencial nas escolas será programada junto aos diretores de cada local, previamente escolhido, tão breve seja possível e será personalizada de acordo com as faixas etárias de 7-9 anos e 10-11 anos. Durante as visitas, a orientação acerca das possíveis doações será realizada e a equipe responsável ficará disponível pelo esclarecimento de eventuais dúvidas e recebimento das doações ao BDH-UEPG. Com isso, estão programadas várias visitas até que todas as atividades e temáticas propostas possam ser contempladas.

\section{RESULTADOS}

As doações de dentes permanentes ao BDH-UEPG são muito superiores às de dentes decíduos. Neste âmbito, a divulgação junto à comunidade visa informar sobre a possibilidade de doação de elementos dentários e aproximar a entidade da população, aumentando a arrecadação de dentes decíduos esfoliados ou extraídos.

Durante o atual período de planejamento, foram projetadas atividades destinadas ao público do primeiro ao quinto ano do ensino fundamental, o qual é composto por crianças na faixa etária de 7 a 11 anos de idade. O Clube do doador foi estruturado como uma ideia de incentivo lúdico ao público infantil para doação no BDH-UEPG, estimulando o descarte correto e o desenvolvimento da empatia pela doação de órgãos.

Os pais/responsáveis exercem importante papel no processo de doação. Dessa forma, o comunicado e as orientações sobre a doação de dentes (Figura 1) serão enviadas a eles, solicitando sua participação nesse fundamental processo de conscientização. Havendo o interesse, o termo de doação para pais/responsáveis (Figura 2) também será disponibilizado e deverá ser devidamente preenchido, assinado pelos responsáveis e encaminhados junto ao dente doado ao BDH-UEPG. 
Figura 1 - Comunicado e orientações sobre a doação de dentes para os pais/responsáveis

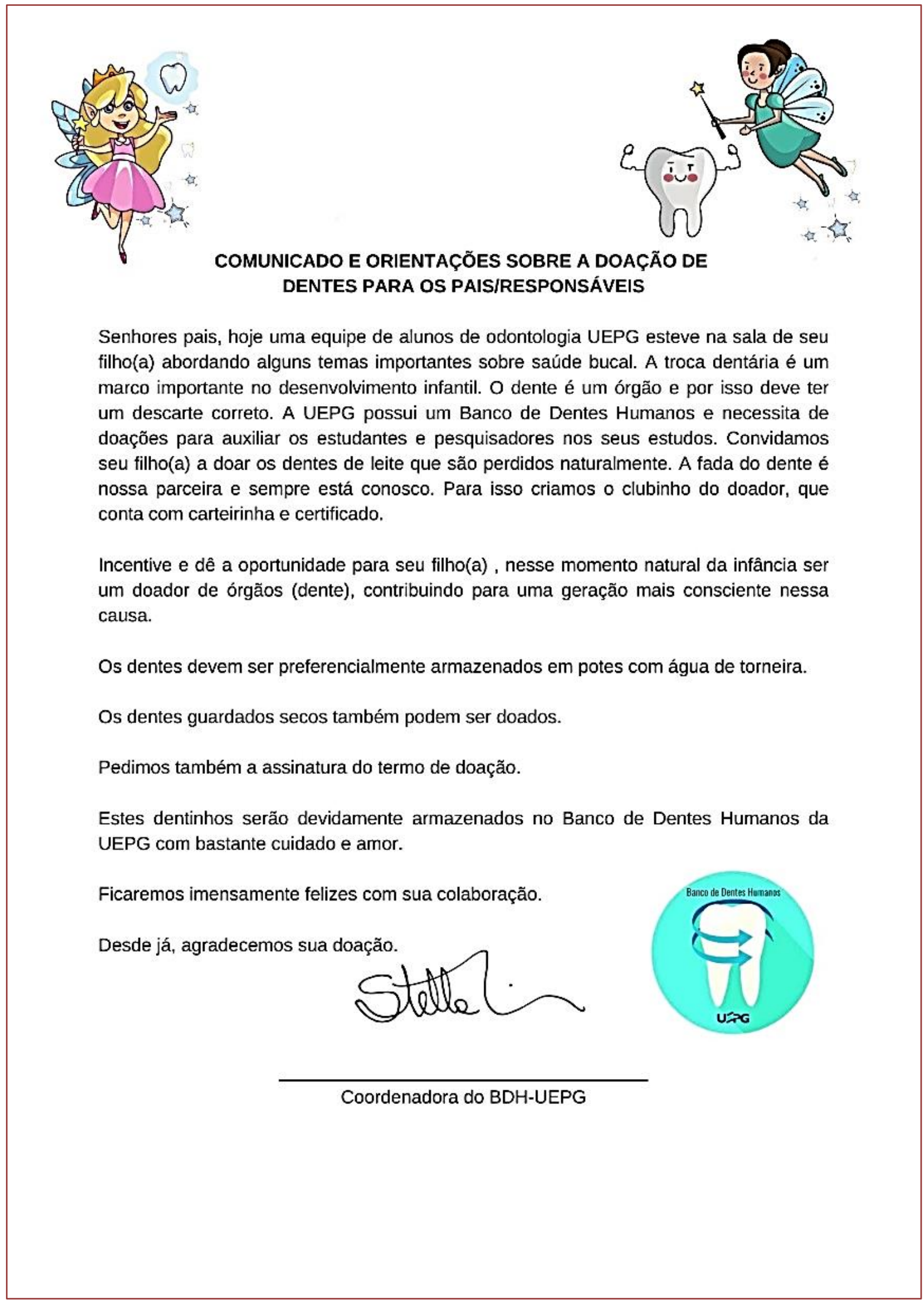


Figura 2 - Termo de doação para pais/responsáveis

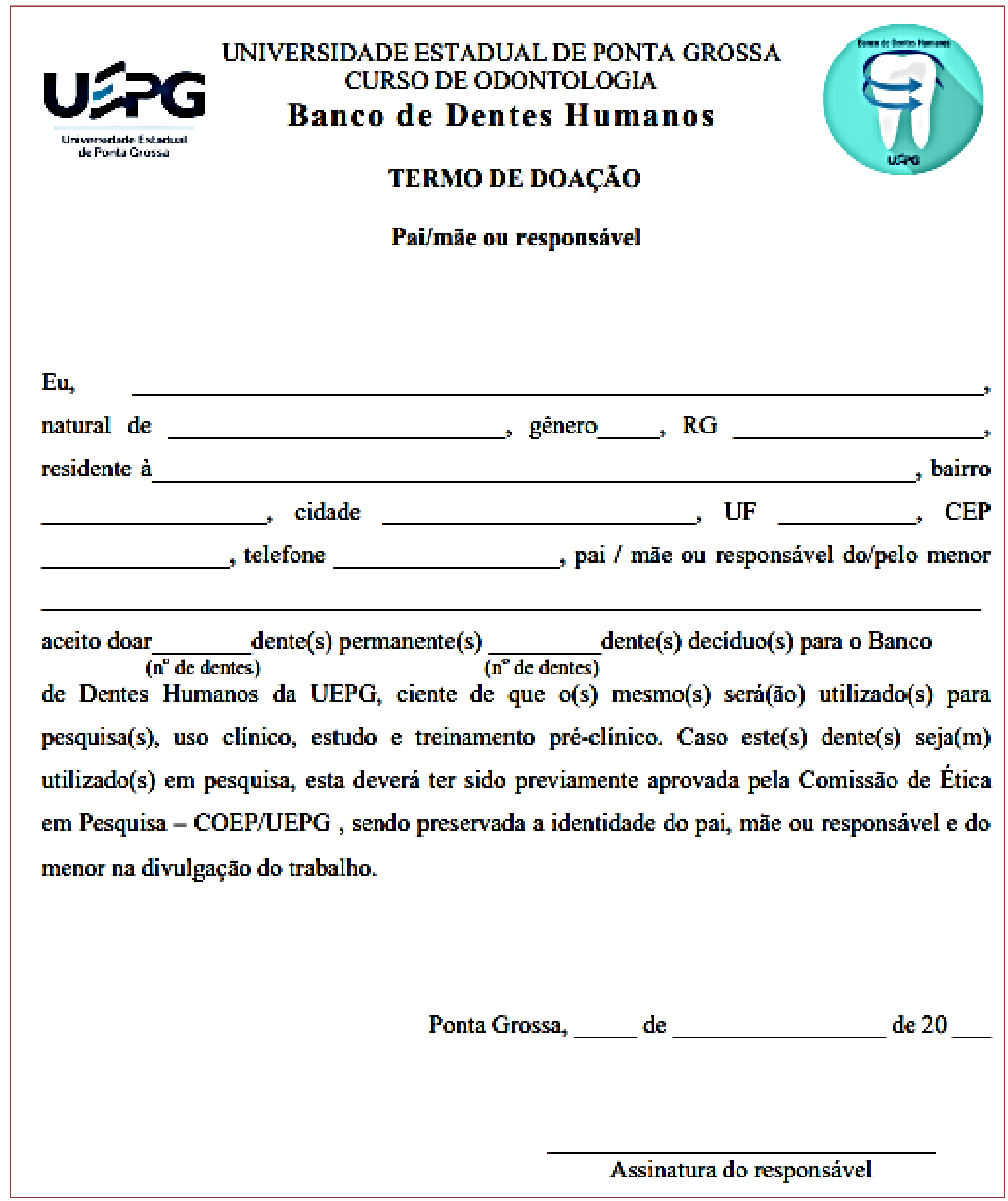

Fonte: os autores.

Como incentivo lúdico de participação do Clube do doador, foram confeccionadas carteirinhas de membro do Clubinho do Banco de Dentes na cor rosa (Figura 3) e azul (Figuras 4). A imagem da fada do dente utilizada nas carteirinhas remete a personagem mais vinculada nesse processo e faz esse elo do clube com o doador. Ela é a principal chave para comunicação com as crianças e através dos materiais propostos está fortemente vinculada ao BDH-UEPG. Cada doação dentária será estimulada pelo recebimento do certificado de doação de dentes do Clubinho do Banco de Dentes (Figura 5). 
Figura 3- Carteirinha do Clubinho do Banco de Dentes na cor rosa

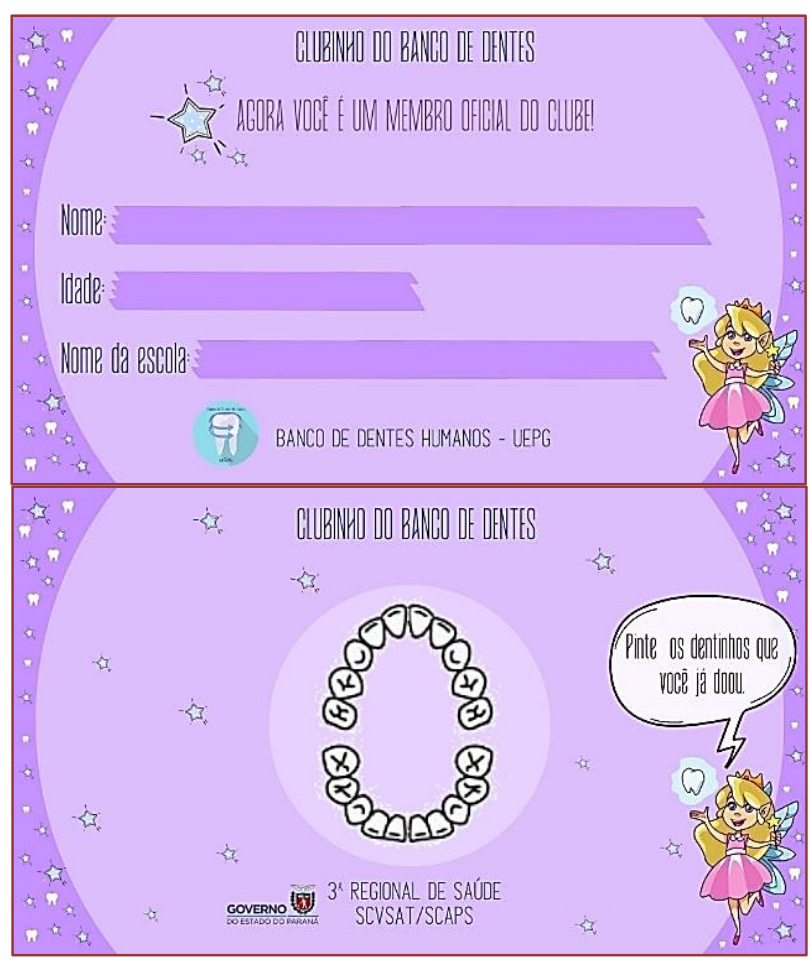

Fonte: os autores.

Figura 4 - Carteirinha do Clubinho do Banco de Dentes na cor azul

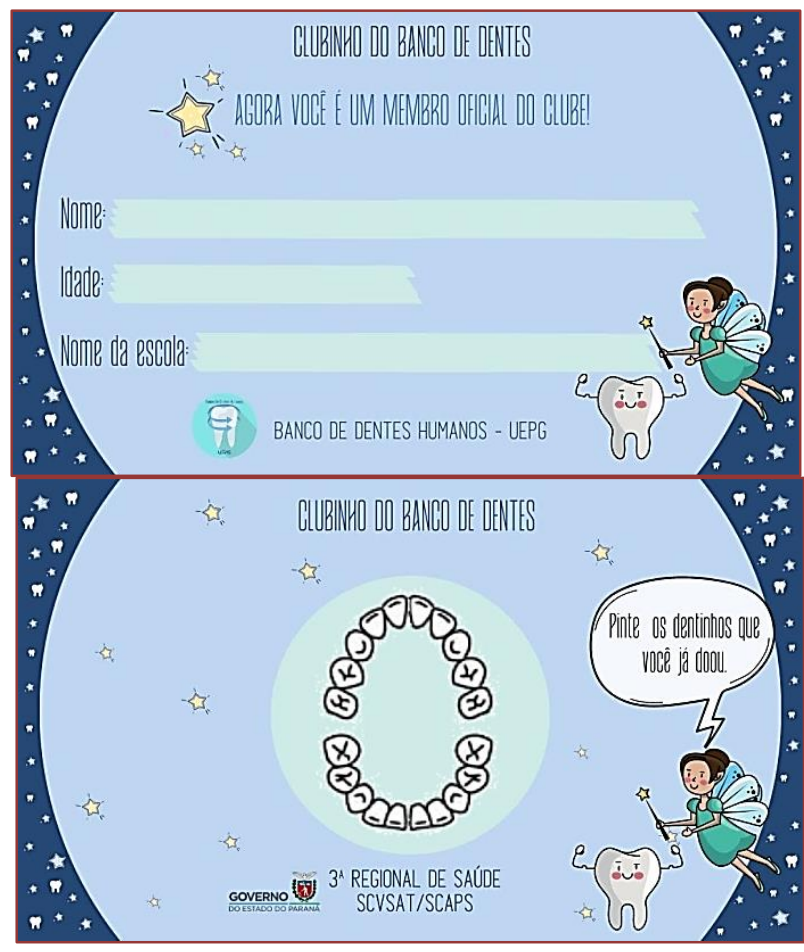


Figura 5 - Certificado de doação de dentes do Clubinho do Banco de Dentes

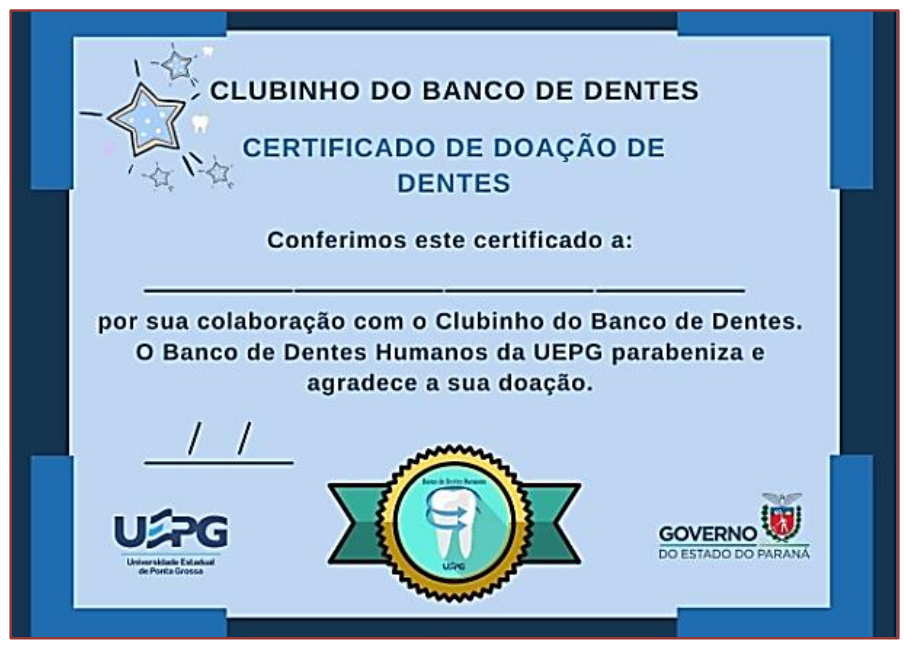

Fonte: os autores.

Uma história infantil de abordagem lúdica também foi criada, voltada às crianças de 7-9 anos e intitulada como "0 mundo secreto de Dentinholândia" (Figura 6). 0 objetivo desta história é abordar a temática da troca dentária e o destino dos dentes esfoliados naturalmente. A história permeia pelo mundo mágico das fadas e duendes, trazendo a missão nobre da Fada Alicia de conseguir proteger os dentes dos duendes. No enredo, ela faz contato com uma criança humana e sua família e encontram o BDH-UEPG como ajuda nas dificuldades apresentadas pela personagem principal. A história envolve o mundo mágico e humano, trazendo à tona a missão de que doações protegidas ao BDH-UEPG fortalecem a Fada dos Dentes na luta contra os duendes e os humanos na construção do espírito doador.

Figura 6 - Capa e Apresentação da história “O mundo secreto de Dentinholândia”

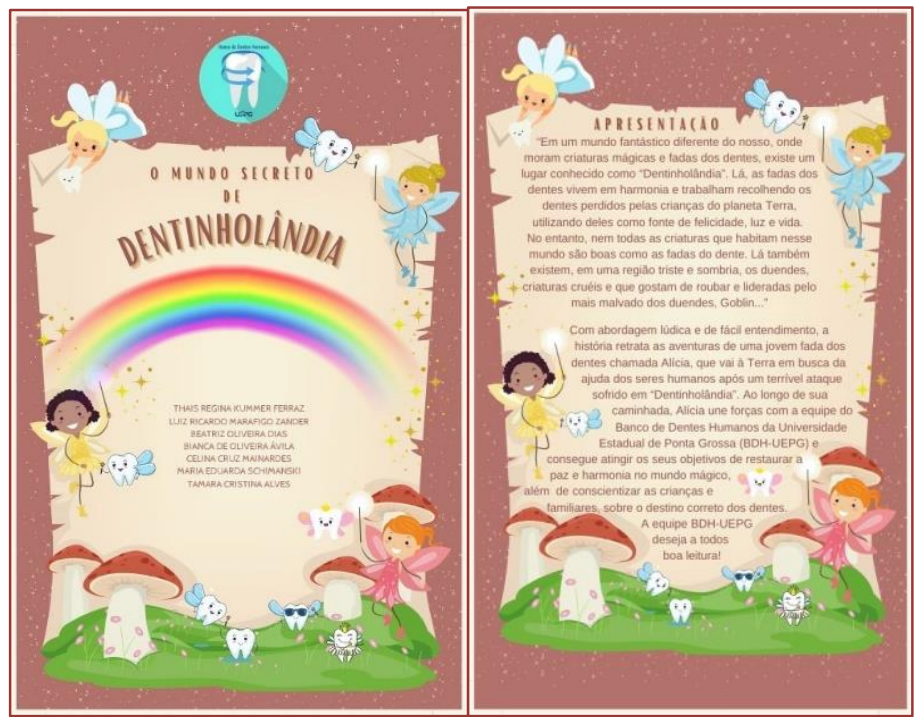

Fonte: os autores.

Destinados ao público infantil de 10-11 anos de idade, foi confeccionado o -book "O Grande Manual de Odontologia do Banco de Dentes Humanos da UEPG" (Figura 7), composto de palestras ilustradas e agrupadas que tratam sobre temas relacionados à saúde bucal. 0 material desenvolvido conta também 
com orientações sobre como proceder para doação dos dentes decíduos esfoliados ou dentes (decíduos e permanentes) que por algum motivo (ortodôntico, cárie) necessitaram ser extraídos. Os conteúdos presentes no $e$-book buscam promover o autocuidado em saúde e despertar nesse público os benefícios do descarte correto e da doação.

Figura 7 - Capa e Sumário do e-book “O Grande Manual de Odontologia do Banco de Dentes Humanos da UEPG"

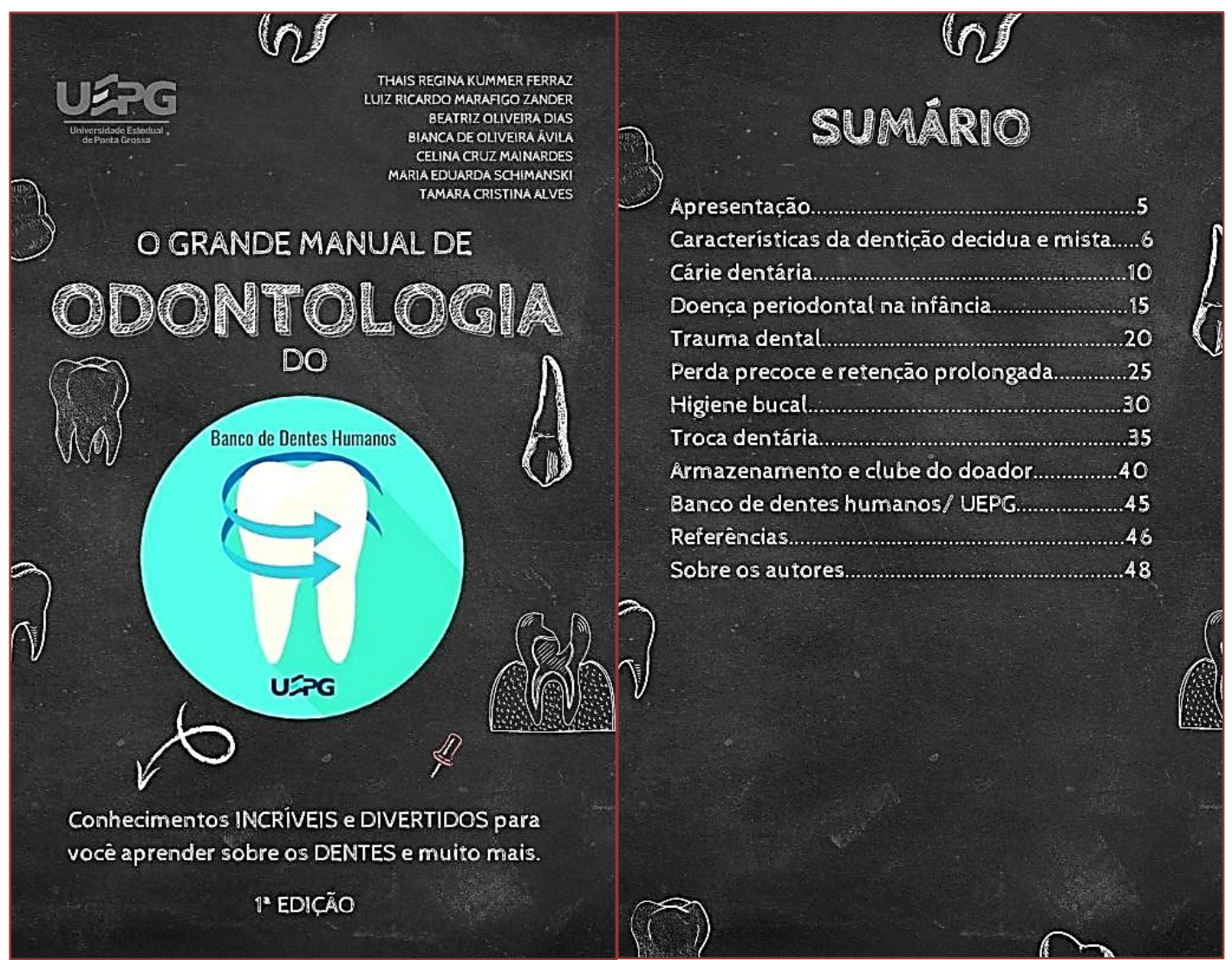

Fonte: os autores.

As atividades presenciais, propostas pelo BDH-UEPG, serão realizadas após o retorno pleno das atividades da UEPG, visto que estão suspensas as atividades acadêmicas e as aulas das Escolas Municipais devido à situação de pandemia de COVID-19. Prontamente que sejam retomadas as aulas na rede municipal de ensino, um planejamento de execução das atividades nas escolas será delineado, além do início da divulgação do trabalho a ser desenvolvido e do recebimento de doações. Espera-se que a equipe contemple uma escola a cada três meses.

\section{DISCUSSÃO}

As ações desenvolvidas pelo BDH-UEPG visam coibir a aquisição ilegal de dentes humanos pela comunidade discente e obter sua autossuficiência, disponibilizando exemplares suficientes aos alunos para as atividades laboratoriais e de pesquisa (KOSSATZ et al., 2020). O BDH-UEPG sempre se mostrou muito preocupado com os aspectos éticos e legais da aquisição de elementos dentários, bem como do preparo e manipulação adequada desses dentes seguindo as normas de biossegurança, a fim de evitar riscos com a infecção cruzada.

A doação de dentes decíduos nem sempre é uma tarefa fácil, visto que está permeada de elementos culturais arraigados. Além disso, estes dentes geralmente são extraídos em casa pelas próprias crianças ou pais/responsáveis e recebem o destino incorreto. Isso ocorre porque ainda hoje, as pessoas desconhecem 
sobre a devida importância dos dentes para o progresso da Odontologia no que diz respeito ao ensino e pesquisa.

A perda precoce dos dentes decíduos é uma realidade bem comum na população infantil, geralmente acometidos por lesões de cárie ou trauma. 0 fato de serem substituídos ao longo do desenvolvimento do corpo faz com que, muitas vezes, tenham seu cuidado negligenciado. Os dentes decíduos desempenham importantes funções biológicas e fisiológicas como: mantenedores de espaço, guia de erupção do dente permanente, mastigação, fonação, manutenção da dimensão vertical, além de possuir importância estética. A perda precoce deles leva a transtorno dessas funções e o desequilíbrio do sistema estomatognático. Nesse sentido, os dentes decíduos devem ser cuidados para que cumpram seu ciclo biológico na cavidade bucal e perdidos o mais fisiologicamente possível (SANTOS et al. 2013).

As crianças vivem em constante crescimento e desenvolvimento e passam por muitas as mudanças físicas, cognitivas e psicológicas. As atividades de educação em saúde bucal direcionadas a elas visam possibilitar acesso a informações importantes para a manutenção da saúde, motivação do autocuidado com instruções de higiene bucal, prevenindo a instalação de doenças bucais. Nesse âmbito, o desenvolvimento de atividades extensionistas impactam profundamente na dos atores envolvidos no processo: acadêmicos, docentes e comunidade; propiciando a troca de saberes, desenvolvimento do espírito crítico e construção de conhecimento. A melhoria da qualidade de vida dos indivíduos beneficiados também é bastante evidente (BENETTI; SOUSA; SOUZA, 2015).

As atividades criadas e planejadas para cada faixa etária levarão informações básicas e importantes sobre cuidados com a saúde bucal, além de auxiliar os acadêmicos e docentes no desenvolvimento do manejo e motivação com o público infantil. De mais a mais, a arrecadação de dentes doados visa colaborar para o fortalecimento do BDH-UEPG como entidade e sabe-se que ações de educação em saúde voltadas a esses objetivos se mostram bem-sucedidas (GUIRRA; QUEIROZ, 2020).

\section{CONCLUSÃO}

As ações educativas visam aproximar e informar o público infantil, professores, funcionários e núcleo familiar do papel do BDH-UEPG, incentivando a doação consciente dos elementos dentários esfoliados ou extraídos. As atividades propostas auxiliarão no aumento da captação de dentes decíduos pelo BDH-UEPG, permitirão a continuidade da entidade, suprindo a demanda para ensino e pesquisa, despertando a consciência sobre a doação de órgãos e contribuindo para a formação de bons profissionais promotores de saúde bucal e comprometidos com o desenvolvimento científico.

\section{REFERÊNCIAS}

[1] AYRES, J. R. Extensão universitária: aprender fazendo, fazer aprendendo. Revista de Medicina, São Paulo, v. 94, n. 2, p. 75-80, jun. 2015.

[2] BENETTI, P. C.; SOUSA, A. I.; SOUZA, M. H. N. Creditação da extensão universitária nos cursos de graduação: relato de experiência. Revista Brasileira de Extensão Universitária, v. 6, n. 1, p. 25-32, jun. 2015.

[3] BRASIL, Lei no 9.434 de 4 de fevereiro de 1997. Dispõe sobre a remoção de órgãos, tecidos e partes do corpo humano para fins de transplante e tratamento e dá outras providências. Diário Oficial da União, Brasília, 5 de fevereiro de 1997.

[4] FREITAS, A. B. D. A. et al. Uso de dentes extraídos nas pesquisas odontológicas publicadas em periódicos brasileiros de acesso online gratuito: um estudo sob o prisma da bioética. Arquivos em Odontologia,v. 46, n.3, jul./set., 2010.

[5] GOMES, G. M. et al. Utilização de dentes humanos: aspectos éticos e legais. RGO - Rev Gaúcha Odontol., Porto Alegre, v.61, suplemento 0, p. 477-483, jul./dez., 2013.

[6] GUIRRA, F. R.; QUEIROZ, L. S. V. Educação em saúde bucal e estímulo à doação de dentes decíduos para bancos de dentes em escolas e creches de Feira de Santana-BA: relato de experiência. Expressa Extensão.,v. 25, n. 3, p. 216-223, set-dez, 2020.

[7] PARATO, J. C. P. Banco de dentes humanos. Ed. FOUSP; 2003.

[8] IMPARATO, J. C. P. Organização e funcionalidade do banco de dentes humanos (ênfase para dentes decíduos) da Disciplina de Odontopediatria da Faculdade de Odontologia da Universidade de São Paulo. 133p. Tese (Doutorado em Odontopediatria) Faculdade de Odontologia, Universidade de São Paulo. São Paulo, 1998.

[9] KOSSATZ, S. et al. BANCO DE DENTES HUMANOS: UM RELATO DE EXPERIÊNCIA. BANCO DE DENTES 
HUMANOS: UM RELATO DE EXPERIÊNCIA, Problemas e oportunidades da saúde brasileira Editora Atena. p. 1-388416, 2020.

[10] SANTOS, A. G. C. et al. Perda precoce de molares decíduos em crianças atendidas na Faculdade de Odontologia da Universidade Federal da Bahia. Revista Odontologia Clínico-Científica, Recife, v. 12, n. 3, p.189-193, 2013.

[11] SANTOS, J. H. S; ROCHA, B. F.; PASSAGLIO, K. T. Extensão universitária e formação no ensino superior. Revista Brasileira de Extensão Universitária, v. 7, n. 1, p. 23-28, maio 2016. 


\section{Capítulo 6}

Prevalência de mucosite oral em pacientes portadores de câncer de cabeça e pescoço atendidos na Unidade de Alta Complexidade em Oncologia, Feira de Santana, Bahia

Vinicius Silva Bastos de Jesus

Ana Paula Eufrázio do Nascimento

Leonardo de Jesus Costa Santos

Márcio Campos Oliveira

Ágda Braga Teixeira

Resumo: Introdução: A mucosite oral é um dos efeitos colaterais agudos do tratamento oncológico realizado por meio da radioterapia de cabeça e pescoço e da quimioterapia que têm grande impacto no estilo de vida do paciente. Este estudo objetivou descrever a prevalência das lesões de mucosite oral em pacientes submetidos à radioterapia com câncer de cabeça e pescoço, atendidos na Unacon de Feira de Santana, Bahia, no ano de 2015, bem como caracterizar o perfil socioeconômico, hábitos de vida e história medical desses indivíduos. Materiais e métodos: Trata-se de um estudo transversal de caráter exploratório, realizado por meio da coleta de dados em prontuários médicos, de pacientes portadores de câncer de cabeça e pescoço, com idade igual ou superior a 18 anos, de ambos os sexos e que fizeram tratamento radioterápico no período de 2015. Resultados: Diagnosticou-se a mucosite oral em $61,7 \%$ dos pacientes, predominantemente de grau 2 (65,6\%), sendo que 40\% dos pacientes tiveram tumor primário em laringe e foram tratados com radioterapia concomitante à quimioterapia. Conclusão: A mucosite oral esteve presente em praticamente todos os pacientes com câncer de cabeça e pescoço do tipo CEC, em estágio IV, sendo a laringe o sítio mais acometido. Em sua maioria homens, pardos, entre 41 e 80 anos, naturais de Feira de Santana, com hábitos de etilismo e tabagismo, acolhidos pelo SUS, tratados com radioterapia.

Palavras-chave: Neoplasias de cabeça e pescoço; Radioterapia; Mucosite oral; Prevalência. 


\section{INTRODUÇÃO}

O câncer de cabeça e pescoço é o terceiro tipo de câncer em incidência, prevalência e mortalidade, não apenas no Brasil, mas também mundialmente, segundo o Instituto Nacional de Câncer (INCA) ${ }^{1}$. 0 termo "câncer de cabeça e pescoço" destina-se aos tumores originários do epitélio (grande maioria) e do mesênquima, desde a cavidade oral e nasal, faringe, até a laringe e o ouvido médio, como afirma Bigarani ${ }^{2}$, sendo responsável pela maior parte das neoplasias, em particular, do carcinoma escamocelular (doravante CEC).

O tratamento antineoplásico realizado por meio da radioterapia de cabeça e pescoço e da quimioterapia é responsável pela manifestação da mucosite oral, um dos principais efeitos colaterais agudos que têm grande impacto no estilo de vida do paciente, conforme Cruz et al.* e Almeida et al. ${ }^{3}$.

Essa inflamação é caracterizada pela ardência bucal, sendo os possíveis sintomas: dor, dificuldade para mastigar, deglutir, falar, nutrição deficiente e risco de infecções sistêmicas. Nesse sentido, além de interferir na função oral básica, ela pode predispor à infecção fúngica, viral e bacteriana, bem como provocar infecções oportunistas.

Martins et al. ${ }^{4}$ afirmam que a severidade e a duração da mucosite oral estão relacionadas ao nível de doença dental pré-existente ao esquema de tratamento, aos medicamentos utilizados e à ocorrência de infecções associadas, como no caso de pacientes portadores de herpes recorrente. Entretanto, Vieira et al. ${ }^{5}$ ressaltam que a mucosite oral é o efeito agudo de maior frequência e o maior fator dose-limitante para radioterapia na região de cabeça e pescoço.

Labbate et al.6, por sua vez, enfatizam que a associação de quimioterapia e radioterapia dá origem a um efeito sinérgico, potencializando a austeridade das alterações inflamatórias da mucosa oral. Para Cardoso et al. ${ }^{7}$, a odontologia possui papel fundamental nas diversas fases terapêuticas contra o câncer, atuando de forma eficaz na prevenção das sequelas que acontecem durante e após o tratamento radioterápico.

A radioterapia pode ser ministrada pela técnica bidimensional (2D) ou pela tridimensional (3D) e ainda pela técnica de modulação do feixe de radiação (IMRT). A técnica 2D só permite calcular a dose em cima de uma radiografia simples (bidimensional) da estrutura óssea, ou seja, impossibilita a modulação do feixe de radiação fazendo com que áreas ao redor do tumor sejam afetadas com a mesma intensidade que a região alvo. A técnica 3D é aplicada com o auxílio de uma máquina tomográfica que permite acesso a uma imagem tridimensional do alvo da terapia, possibilitando avaliar a radiação em áreas dentro e fora do tumor para saber se o tumor está sendo tratado adequadamente. Já o IMRT permite ir além da técnica conformacional (3D) e modular os feixes ao local da irradiação, reduzindo significativamente os feixes de radiação fora do tumor.

Marta et al. ${ }^{8}$ recomendam doses de 60 a 74 Gy para o tratamento do câncer de cabeça e pescoço. No entanto, as áreas em torno do tumor, como as glândulas salivares, geralmente suportam apenas 20 a 30 Gy.

Almeida et al. ${ }^{9}$ e Chiappelli10 ${ }^{10}$ relatam que o quadro da mucosite oral, dependendo da dosagem de radiação e da resposta individual do paciente, pode ser mais severo. Ao ser exposto, o tecido conjuntivo predispõe a colonização por fungos do tipo Candida albicans, que podem causar aumento significativo dos sintomas. Mediante essa situação, faz-se necessário um diagnóstico apropriado, além de uma intervenção antifúngica considerada.

A definição dos perfis dos pacientes da Unidade de Alta Complexidade em Oncologia (Unacon), de Feira de Santana, BA, pode contribuir para estabelecer grupos de risco e servir de base para ações de controle da doença, visto que, segundo Barasch et al.11, a mucosite oral tem relação tanto com as características do paciente como ao tipo de tratamento a que são submetidos.

Este trabalho tem como objetivo descrever a prevalência das lesões de mucosite oral em pacientes submetidos à radioterapia em câncer de cabeça e pescoço e à quimioterapia, atendidos na Unacon, Feira de Santana, BA, no ano de 2015, bem como caracterizar o perfil socioeconômico, hábitos de vida e história médica desses indivíduos.

\footnotetext{
*Cruz, Flávia Oliveira de Almeida Marques da. Manual de orientações para o paciente com câncer de cabeça e pescoço submetido à radioterapia: um estudo de validação. Brasília; 2015.
} 


\section{MATERIAIS E MÉTODOS}

Trata-se de um estudo transversal de caráter exploratório, realizado através da coleta em prontuários médicos. A pesquisa aconteceu na Unacon de Feira de Santana, BA. A população estudada se constituiu de todos os pacientes portadores de câncer de cabeça e pescoço, com idade igual ou superior a 18 anos, de ambos os sexos e que fizeram tratamento radioterápico isolado, adjuvante ou concomitante com a quimioterapia, conforme o registro médico no prontuário clínico, no período de 2015 . No entanto, foram excluídos do estudo os prontuários que não foram preenchidos corretamente e na íntegra.

A atividade foi realizada por dois pesquisadores. 0 instrumento de coleta dos dados consistiu de uma planilha, contemplando o levantamento de informações sociodemográficas, de hábitos de vida, clínicas e de história médica.

A planilha foi preenchida a partir das informações contidas nos prontuários referentes ao período de 2015. As primeiras variáveis trataram do perfil sociodemográfico dos indivíduos do estudo, tais como idade, sexo, ocupação, grau de escolaridade, renda, zona de procedência, naturalidade, raça/cor da pele e estado civil. As variáveis correspondentes aos hábitos de vida foram o consumo de álcool, tabaco e drogas. Ainda, no que diz respeito à condição de saúde sistêmica do paciente, também foram consultadas as informações acerca da presença ou não de doença sistêmica, se fez ou faz uso de medicamentos, informando o tipo de medicamento utilizado.

Por fim, em relação à mucosite oral, foi verificada nos prontuários clínicos a ausência (grau 0) ou presença nos pacientes em tratamento radioterápico de câncer de cabeça e pescoço, classificados segundo a Organização Mundial de Saúde (OMS): (grau 1, a mucosa encontra-se eritematosa e dolorida; o grau 2 é caracterizado por úlcera e o paciente alimenta-se normalmente; no grau 3, úlceras estão presentes e o paciente só consegue ingerir líquidos; e, no grau 4, o paciente não consegue se alimentar por via oral).

Nos pacientes com mucosite oral, a pesquisa levantou informações acerca do grau da lesão, segundo os critérios de classificação da OMS, tempo de aparecimento desde o início do tratamento oncológico, se houve agravamento da lesão e qual(is) o(s) procedimento(s) adotado(s) pela Unacon, a fim de controlar/evitá-la. 0 diagnóstico de mucosite oral colhido nos prontuários médicos é feito comumente por oncologistas clínicos e onco-radioterapeutas que utilizam os critérios estabelecidos pela OMS.

Esse projeto de pesquisa foi aprovado pelo Comitê de Ética em Pesquisa em Seres Humanos (CEP) da Universidade Estadual de Feira de Santana (UEFS), sob parecer de número 1.633 .784 atendendo ao disposto na Resolução 466/12 do Conselho Nacional de Saúde (CNS).

Os dados foram avaliados descritivamente por meio da apresentação das frequências absolutas e relativas, e apresentados em tabelas. 0 programa utilizado para a compilação dos dados foi o Statistical Package for Social Science - SPSS versão 17.020.

\section{RESULTADOS}

Dos 62 pacientes que tiveram sua história oncológica analisada e que realizaram tratamento radioterápico, seja de forma isolada, adjuvante ou concomitante a QT, diagnosticou-se a mucosite oral em $61,7 \%$ (37/60). Dos casos encontrados, 31,3\% (10/32) exibiu mucosite de grau 1; 65,6\% (21/32) de grau 2; e 3,1\% (1/32) de grau 3 (conforme é mostrado na Tabela 1); sendo que a 12 ${ }^{a}$ sessão da radioterapia foi a de surgimento mais comum dessa lesão.

Participaram da coleta 45 homens $(71,7 \%)$ e 17 mulheres $(28,3 \%)$, de cor da pele prevalentemente parda $(49,2 \%$ - 29/59), mais frequente entre 61 e 80 anos (44,3\% - 27/61), naturais de Feira de Santana $(26,8 \%$ - 15/56) e que habitam a zona urbana $(77,4 \%$ - 48/62). Os pacientes foram acolhidos pelo Sistema Único de Saúde (SUS) em sua maioria $(95,2 \%$ - 59/62). Quanto à profissão, eram predominantemente aposentados $(48,2 \%-27 / 56)$ ou lavradores, $(14,3 \%$ - 8/56). Não houve informações suficientes em prontuários para se determinar a prevalência de renda (Tabela 2). Em sua maioria eram pacientes etilistas (73\% - 43/59) e tabagistas (82,3\% - 50/60), com dados mostrados na Tabela 3.

Entre os tipos histológicos identificados, o CEC foi o mais frequente $(88,3 \%$ - 53/60). 0 estadio clínico de maior frequência foi o IV (57,5\% - 30/52); apresentaram-se também o estadio III (14/52 - 26,9\%), estadio I $(2 / 52-3,8 \%)$ e estadio II $(6 / 52-11,5 \%)$. Sobre a localização anatômica do tumor, os casos foram divididos em: laringe (24/60 - 40\%); faringe (19/60 - 31,7\%); glândulas salivares maiores (2/60 - 3,3\%); região cervical $(4 / 60-6,7 \%)$; cavidade nasal e seios paranasais $(2 / 60-3,3 \%)$. Em relação ao tipo de tratamento realizado, realizaram radioterapia de forma isolada (20/60 - 33,3\%); radioterapia 
concomitante (26/60 - 43,3\%); radioterapia pré-QT (1/60 - 1,7\%); radioterapia pós-QT (13/60 - 21,7\%). Entre os tratamentos nos quais foram realizadas etapas quimioterápicas, predominou, em frequência, a utilização do quimioterápico Cisplatina (CDDP) (26/38 - 68,4\%), em 3 ciclos (26/39 - 66,7\%), em intervalos de 21 dias $(17 / 39$ - 43,3\%). Houve suspensão do tratamento em $(10 / 60-16,7 \%)$. Os dados referentes às características clínicas são mostrados na Tabela 4.

Tabela 1 Número e percentual de indivíduos portadores de câncer de cabeça e pescoço atendidos na UNACOM, Feira de Santana, Bahia, 2015, segundo grau de mucosite (N=62)

\begin{tabular}{|c|c|c|}
\hline Grau de mucosite & \multicolumn{1}{c}{ N } & $\%$ \\
\hline 1 & 10 & 31,3 \\
\hline 2 & 21 & 65,6 \\
\hline 3 & 1 & 3,1 \\
\hline 4 & 0 & 0 \\
\hline Total & $\mathbf{3 2}$ & $\mathbf{1 0 0 \%}$ \\
\hline
\end{tabular}

Tabela 2 Características sociodemográficas, número e percentual de indivíduos portadores de câncer de cabeça e pescoço atendidos na UNACOM, Feira de Santana, Bahia, 2015 (N=62)

\begin{tabular}{|c|c|c|c|c|}
\hline \multirow{2}{*}{$\begin{array}{c}\text { Variáveis } \\
\text { Sexo }^{\text {a }}\end{array}$} & \multicolumn{2}{|c|}{ Todos os indivíduos } & \multicolumn{2}{|c|}{ Com mucosite } \\
\hline & $\mathrm{N}$ & $\%$ & $\mathrm{~N}$ & $\%$ \\
\hline Feminino & 17 & 28,3 & 12 & 32,7 \\
\hline Masculino & 43 & 71,7 & 25 & 67,6 \\
\hline Faixa etária b & $\mathrm{N}$ & $\%$ & $\mathrm{~N}$ & $\%$ \\
\hline De 0 a 40 anos & 5 & 8,5 & 4 & 11,2 \\
\hline 41-80 anos & 50 & 84,8 & 29 & 80,5 \\
\hline Acima de 81anos & 4 & 6,8 & 3 & 8,3 \\
\hline Cor da pele ${ }^{c}$ & $\mathrm{~N}$ & $\%$ & $\mathrm{~N}$ & $\%$ \\
\hline Parda & 29 & 49,2 & 19 & 51,4 \\
\hline Preta & 17 & 28,8 & 12 & 32,4 \\
\hline Branca & 13 & 22 & 6 & 16,2 \\
\hline Zona de procedência d & $\mathrm{N}$ & $\%$ & $\mathrm{~N}$ & $\%$ \\
\hline Urbana & 46 & 76,7 & 27 & 73,0 \\
\hline Rural & 14 & 23,3 & 10 & 27,0 \\
\hline Serviço de procedência e & $\mathrm{N}$ & $\%$ & $\mathrm{~N}$ & $\%$ \\
\hline Público & 58 & 96,7 & 35 & 94,6 \\
\hline Privado & 2 & 3,3 & 2 & 5,4 \\
\hline Variáveis & $\mathrm{N}$ & $\%$ & $\mathrm{~N}$ & $\%$ \\
\hline \multicolumn{5}{|l|}{ Estado civil $\mathrm{f}$} \\
\hline Solteiro & 23 & 38,3 & 15 & 40,5 \\
\hline Casado/amigado & 26 & 43,3 & 14 & 37,8 \\
\hline Viúvo & 9 & 15 & 6 & 16,2 \\
\hline Divorciado/Desquitado & 2 & 3,3 & 2 & 5,4 \\
\hline Escolaridade g & $\mathrm{N}$ & $\%$ & $\mathrm{~N}$ & $\%$ \\
\hline Não alfabetizado & 9 & 16,7 & 4 & 19,0 \\
\hline Alfabetizado & 45 & 83,3 & 17 & 81,0 \\
\hline Ocupação h & $\mathrm{N}$ & $\%$ & $\mathrm{~N}$ & $\%$ \\
\hline Aposentado & 25 & 46,4 & 10 & 51,8 \\
\hline Lavrador (a) & 8 & 14,8 & 7 & 21,9 \\
\hline Autônomo (a) & 5 & 9,3 & 4 & 12,5 \\
\hline Doméstica & 4 & 7,4 & 4 & 12,5 \\
\hline Motorista & 3 & 5,6 & 1 & 9,1 \\
\hline Outros & 9 & 15 & 6 & 18,7 \\
\hline
\end{tabular}

$\mathrm{a}=2$ casos perdidos; $\mathrm{b}=3$ casos perdidos; $\mathrm{c}=3$ casos perdidos; $\mathrm{d}=2$ casos perdidos; $\mathrm{e}=2$ casos perdidos; $\mathrm{f}=2$ casos perdidos; $\mathrm{g}=8$ casos perdidos; $\mathrm{h}=8$ casos perdidos. 
Tabela 3 Hábitos, número e percentual de indivíduos portadores de câncer de cabeça e pescoço atendidos na UNACOM, Feira de Santana, Bahia, $2015(\mathrm{~N}=62)$

\begin{tabular}{|c|c|c|c|c|}
\hline \multirow[t]{2}{*}{ Variáveis } & \multicolumn{2}{|c|}{ Todos os indivíduos } & \multicolumn{2}{|c|}{ Com mucosite } \\
\hline & $\mathrm{N}$ & $\%$ & $\mathrm{~N}$ & $\%$ \\
\hline \multicolumn{5}{|l|}{ Etilismo ${ }^{\mathrm{a}}$} \\
\hline Sim & 43 & 72,9 & 27 & 73 \\
\hline Não & 16 & 27,1 & 10 & 27 \\
\hline \multicolumn{5}{|l|}{ Tabagismo $\mathrm{b}$} \\
\hline Sim & 50 & 83,3 & 33 & 89,2 \\
\hline Não & 10 & 16,7 & 4 & 10,8 \\
\hline
\end{tabular}

$$
\mathrm{a}=3 \text { casos perdidos; } \mathrm{b}=2 \text { casos perdidos. }
$$

Tabela 4 Características clínicas, número e percentual de indivíduos portadores de câncer de cabeça e pescoço atendidos na UNACOM, Feira de Santana, Bahia, 2015 (N=62)

\begin{tabular}{|c|c|c|c|c|}
\hline \multirow{2}{*}{ Variáveis } & \multicolumn{2}{|c|}{ Todos os indivíduos } & \multicolumn{2}{|c|}{ Com mucosite } \\
\hline & $\mathrm{N}$ & $\%$ & $\mathrm{~N}$ & $\%$ \\
\hline Localizacão do tumora & & & & \\
\hline Laringe & 24 & 40 & 9 & 24,3 \\
\hline Cavidade oral & 9 & 15 & 7 & 18,9 \\
\hline $\begin{array}{l}\text { Faringe (orofaringe, nasofaringe, rinofaringe, } \\
\text { hipofaringe) }\end{array}$ & 19 & 31,7 & 17 & 47,5 \\
\hline Glândulas salivares maiores & 2 & 3,3 & 1 & 2,7 \\
\hline Região cervical & 4 & 6,7 & 3 & 8,1 \\
\hline Cav. Nasal e seios paranasais & 2 & 3,3 & 0 & 0 \\
\hline Estádio Clínico ${ }^{\mathrm{b}}$ & $\mathrm{N}$ & $\%$ & $\mathrm{~N}$ & $\%$ \\
\hline Estádio I & 6 & 11,5 & 2 & 6,3 \\
\hline Estádio II & 2 & 3,8 & 1 & 3,1 \\
\hline Estádio III & 14 & 29,6 & 9 & 28,1 \\
\hline Estádio IV & 30 & 57,7 & 20 & 62,5 \\
\hline Tipo de tratamento ${ }^{c}$ & $\mathrm{~N}$ & $\%$ & $\mathrm{~N}$ & $\%$ \\
\hline Radioterapia & 20 & 33,3 & 8 & 21,6 \\
\hline Radioterapia concomitante à quimioterapia & 26 & 43,3 & 20 & 54,1 \\
\hline Radioterapia Pós QT & 13 & 21,7 & 8 & 21,6 \\
\hline Radioterapia Pré QT & 1 & 1,7 & 1 & 2,7 \\
\hline Realização de cirurgia $^{d}$ & $\mathrm{~N}$ & $\%$ & $\mathrm{~N}$ & $\%$ \\
\hline Sim & 17 & 28,3 & 11 & 29,7 \\
\hline Não & 43 & 71,7 & 26 & 70,3 \\
\hline Intervalo de ciclos e & $\mathrm{N}$ & $\%$ & $\mathrm{~N}$ & $\%$ \\
\hline 7 dias & 9 & 23,1 & 6 & 21,4 \\
\hline 15 dias & 1 & 2,6 & 1 & 3,6 \\
\hline 21 dias & 17 & 43,6 & 14 & 50 \\
\hline 30 dias & 12 & 30,8 & 7 & 30,8 \\
\hline Quimioterápicos ${ }^{\mathrm{f}}$ & $\mathrm{N}$ & $\%$ & $\mathrm{~N}$ & $\%$ \\
\hline Cisplatina (CDDP) & 26 & 68,4 & 21 & 77,8 \\
\hline Outros & 12 & 31,5 & 6 & 22,2 \\
\hline Técnica Radioterápica g & $\mathrm{N}$ & $\%$ & $\mathrm{~N}$ & $\%$ \\
\hline $2 \mathrm{D}$ & 57 & 95 & 34 & 91,9 \\
\hline $3 \mathrm{D}$ & 3 & 5 & 3 & 8,1 \\
\hline Total De Frações De RT h & $\mathrm{N}$ & $\%$ & $\mathrm{~N}$ & $\%$ \\
\hline 20 a 30 & 6 & 10 & 4 & 10,8 \\
\hline 31 a 35 & 51 & 85,1 & 31 & 83,7 \\
\hline 36 a 39 & 3 & 5 & 3 & 8,1 \\
\hline Dose Total De RT ${ }^{\mathrm{i}}$ & $\mathrm{N}$ & $\%$ & $\mathrm{~N}$ & $\%$ \\
\hline 36 a 49 & 4 & 6,7 & 4 & 6,7 \\
\hline 50 a 69 & 15 & 24,9 & 15 & 24,9 \\
\hline 70 a 76 & 41 & 68,4 & 41 & 68,4 \\
\hline
\end{tabular}

$\mathrm{a}=2$ casos perdidos; $\mathrm{b}=10$ casos perdidos; $\mathrm{c}=2$ casos perdidos; $\mathrm{d}=2$ casos perdidos; $\mathrm{e}=23$ casos perdidos; $\mathrm{f}=24$ casos perdidos; $\mathrm{g}=2$ casos perdidos; $\mathrm{h}=2$ casos perdidos; $\mathrm{i}=2$ casos perdidos. 


\section{DISCUSSÃO}

0 estudo apresentado mostra uma maior frequência de pessoas do sexo masculino acometidas pela doença câncer de cabeça e pescoço, com cerca de 40 a 80 anos de idade, que apresentavam condições orais precárias, sem tratamento prévio para radioterapia. Apresentando similaridade com dados dos estudos de Rocha et al. ${ }^{12}$ e Ciesielski et al. ${ }^{13}$. A sugestão sobre a semelhança desses dados, nesse sentido, pode estar associada à maior prevalência de hábitos tabagistas e etilistas entre esse grupo, em relação a toda a amostra da pesquisa.

No entanto, o presente estudo apresentou uma maioria de pacientes da raça parda, dessemelhante ao estudo de Stockwell et al. ${ }^{14}$, que aponta grande parcela de denominados brancos. Pode-se explicar esta relação pela diferença étnica entre populações pertencentes a regiões diferentes no mundo. Existem também questões ideológicas e de afirmação étnico-culturais e miscigenação, que alteram um possível reconhecimento do indivíduo como pardo, branco ou negro.

O estudo de caráter exploratório não consegue definir com precisão os fatores de risco ao surgimento do CEC relacionados a cada ocupação. Mas pode-se identificar uma frequência das profissões listadas nos resultados. 0 fato da alta incidência se dá entre aqueles com profissão de lavrador, nesta população de estudo, pode estar relacionado à exposição solar proveniente do próprio trabalho, e à maior dificuldade de acesso à informação e a assistência médica, predominante na zona rural em relação à zona urbana.

Este estudo apresenta concordância com as informações evidenciadas por Casati 15 , cujos estadiamentos em que se apresentaram os tumores em maior frequência foram os estádios III e IV, que podem refletir uma demora no diagnóstico e início do tratamento. 0 tipo histológico de câncer predominante nos casos estudados foram os de CEC. Sobre isso, o trabalho descritivo e comparativo de Daher et al. ${ }^{16}$ ressaltam que este é o tipo mais comum de câncer da região de cabeça e pescoço, ao analisar dados de pacientes no período de 1999 a 2003, no Hospital Dr. Hélio Angotti, na cidade de Uberaba, no Estado de Minas Gerais.

A maior incidência desse tipo de câncer tem sido relacionada às questões habituais verificadas, como o tabagismo, o alcoolismo, as profissões mais expostas aos raios solares, como lavradores e a idade mais avançada, visto que são hábitos que representam ações contínuas e cumulativas, danificando as estruturas das células epiteliais e/ou mucosas.

As características histopatológicas das lesões dos pacientes avaliados sugerem maior ocorrência de mucosite oral em portadores do CEC, situação atribuída ao fato do mesmo ser mais frequente que os demais tipos, acometendo, portanto, o maior número de pacientes. Quanto à localização do tumor, o presente estudo constatou que portadores de neoplasias na orofaringe possuem o maior índice de desenvolvimento de mucosite oral, corroborando com a literatura consultada, em que evidenciou a probabilidade de a orofaringe ser a região mais afetada por essa afecção, em relação aos outros sítios examinados, conforme Santos et al.* .

Toledo e colaboradores ${ }^{17}$ atribuem à explicação de a região faríngea ser a mais afetada seria devido à dificuldade de controle da microbiota e a outros efeitos colaterais como, por exemplo, a xerostomia. Esta contribui para a proliferação de microorganismos desencadeadores de processo inflamatório mais intenso nessas áreas, já que sua limpeza é dificultada pela falta de um fluxo salivar adequado. Também se destaca a agressividade dos tratamentos quimioterápicos e radioterápicos, que desequilibram o processo de renovação celular, diminuindo-o e, consequentemente, danificando o DNA das células, levando-as à morte.

A técnica radioterápica mais usada nos pacientes atendidos na UNACON foi a terapia 2D e em mais da metade dos casos observou-se algum grau de mucosite. Em contrapartida, entre os pacientes que receberam a técnica 3D de tratamento, todos apresentaram mucosite. Porém, a observância destes dados não parece relevante quanto às diferenças de toxicidade das referidas modalidades de tratamento, já que este modelo de estudo não designa essa relação como causa e efeito e possui pequena amostra da técnica 3D.

Sobre o assunto, Deng et al. ${ }^{18}$ relatam que a técnica bidimensional atinge uma região em torno do tumor com a mesma intensidade e profundidade, o que causa um maior dano a regiões sadias. Porém, a técnica tridimensional, segundo Matsuzaki et al. ${ }^{19}$, é uma tecnologia recente que mostra o tumor e os tecidos adjacentes à região tumoral e permite com a técnica de IRMT direcionar e modular os raios para que doses

\footnotetext{
*Santos, Renata Cristina Schmidt. Mucosite oral em pacientes portadores de câncer de cabeça e pescoço submetidos à radioterapia e quimioterapia concomitantes. São Paulo; 2009.
} 
menores e com menor profundidade atinjam as regiões adjacentes, permitindo a recuperação dos tecidos e minimizando os efeitos colaterais, fato que é corroborado através do trabalho de Nutting et al. ${ }^{20}$

Os autores supracitados ainda permite inferir que o acesso ao tratamento 3D continua limitado, por apresentar custos mais elevados, culminando na maioria dos casos serem tratados pelo método 2D. Sendo assim, não é possível, no presente estudo, devido à baixa quantidade de sujeitos expostos ao tratamento 3D, avaliar a relevância do tipo de tratamento com a presença de algum grau de mucosite. Contudo, podese considerar que a técnica 3D, por ser menos agressiva a regiões saudáveis, seja a técnica preferível para evitar ou controlar o avanço da mucosite oral.

De acordo com Vissink et al. ${ }^{21}$; Neville et al. * e Rolim et al. ${ }^{22}$, o tratamento radioterápico ainda é dividido em frações ou doses para reduzir a toxicidade em tecidos sadios e permitir sua renovação celular, aumentando a eficácia do tratamento. Todavia, pacientes com carcinomas de cabeça e pescoço recebem entre 50 e 70 Gy de dose para eliminar o tumor. Nesse caso, a presença de efeitos colaterais como a mucosite oral já se manifesta em doses entre 10 a 30 Gy.

A fração das doses de radioterapia, no presente estudo, demonstra que a maior parte dos pacientes acometida pela mucosite oral foi submetida entre 20 a 35 frações. Outro fator é a dose de radiação, em que se observou maior acometimento da afecção em pacientes que receberam doses entre 50 e 76 Grays (Gy).

A maioria dos pacientes avaliados nesta pesquisa, apresentava, em sua predominância, mucosite oral de graus 1 e 2, sendo o grau moderado (2) o mais predominante. Em conformidade com este trabalho, Santos et al. ${ }^{21}$ também observaram o predomínio de mucosite graus 1 e 2, sendo a orofaringe o sítio mais afetado. Entretanto, Ciesielski et al. ${ }^{14}$ encontraram, em seu estudo, maior prevalência dos graus 3 e 4 , com predomínio do grau 3. Eles afirmam que a maioria dos pacientes afetados por essa reação inflamatória tinha condições precárias de higiene bucal e não recebiam quaisquer assistências odontológicas preventivas. Os mesmos pacientes acometidos pelos graus 3 e 4 representaram o maior índice de abandono do tratamento.

Ao analisar os estudos citados na discussão deste trabalho, é possível sugerir que o acesso à tratamentos preventivos odontológicos pode alterar significativamente a prevalência do grau de mucosite oral dos pacientes, bem como auxiliar na diminuição da interrupção do tratamento oncológico. Porém, este cuidado, que visa à prevenção, geralmente é raro, e ainda carece de protocolo e maior organização por quem presta o serviço.

\section{CONCLUSÃO}

A mucosite oral foi encontrada na maior parte dos pacientes acometidos por câncer de cabeça e pescoço tratados com radioterapia isolada, concomitante ou adjuvante a quimioterapia e cirurgia, em sua maioria no grau 2. Os pacientes acometidos foram, majoritariamente, homens, pardos, da faixa etária de 61 a 80 anos, naturais de Feira de Santana, habitantes da zona urbana, aposentados, com hábitos de etilismo e tabagismo e acolhidos pelo SUS. A afecção se manifestou, predominantemente, em portadores de câncer do tipo carcinoma escamocelular, em estádio clínico IV, localizada na laringe e tratada com radioterapia.

\section{REFERÊNCIAS}

[1] Brasil Ministério da Saúde. Instituto Nacional de Câncer. Coordenação de Prevenção e Vigilância do Câncer. Estimativa 2012: Incidência de câncer no Brasil. Rio de Janeiro: Inca, 2011.

[2] BIGARANI, Lisiane Artico. Consequências bucais da radioterapia em pacientes com câncer de cabeça e pescoço. 2014. 58 fls. Trabalho de Conclusão de Curso (Graduação em Odontologia) - Universidade Estadual de Londrina, Londrina, 2014.

[3] Silva, DP da et al. Radioterapia em cabeça e pescoço: efeitos colaterais agudos e crônicos bucais. R. Bras. Patol. Oral, Natal, v.3, n.2, p.62-69, abr./jun. 2004.

[4] Martins, Adriane de Castro Martinez; Caçador, Neli Pialarissi; Gaeti, Walderez Penteado. Complicações bucais da quimioterapia antineoplásica. Acta Scientiarum, Maringá, v.24, n.3, p.663-670, 2002.

[5] Vieira ACF et al. Mucosite oral: efeito adverso da terapia antineoplásica. R. Ci. méd. biol., Salvador, v. 5, n. 3, p. 268-274, set./dez. 2006.

[6] Labbate, Rogério; Lehn, Carlos Neutzling; Denardin, Odilon Victor Porto. Efeito da clorexidina na mucosite

\footnotetext{
*Neville, B.W et al. Patologia Oral e Maxilofacial. 2. Ed. Rio de Janeiro: Guanabara Koogan; 2004.
} 
induzida por radioterapia em câncer de cabeça e pescoço. Rev Bras Otorrinolaringol. V.69, n.3, p. 349-54, mai./jun. 2003.

[7] Cardoso M de FA et al. Prevenção e controle das sequelas bucais em pacientes irradiados por tumores de cabeça e pescoço. Radiol.Bras., v.38, n.2, p.107-115, mar./abr. 2005.

[8] Gustavo Nader Marta, Samir Abdallah Hanna, Marcus Castilho, Michael J Chen, Robson Ferrigno. Diretrizes para tratamento de tumores da cabeça e pescoço com radioterapia de intensidade modulada. Sociedade Brasileira de Radioterapia;[Internet]. [acesso em 17 ser 2018]; Disponível em: www.sbradioterapia.com.br.

[9] Almeida PNM et al. Avaliação epidemiológico-clínica da mucosite oral radioinduzida em pacientes com neoplasias malignas na região de cabeça e pescoço. Rev Odontol UNESP, Araraquara, v. 38, n. 4, p. 211-16, jul./ago. 2009.

[10] Barasch, Andrei; Peterson, Douglas E. Risk factors for ulcerative oral mucositis in Cancer patients: unanswered questions. Rev Oral Oncol, V. 39, n. 2, p. 91-100. February. 2003.

[11] Rocha BQC et al. Características epidemiológicas de pacientes portadores de neoplasias de cabeça e pescoço submetidos à radioterapia em Juiz de Fora; MG. HU Revista, Juiz de Fora, v. 43, n. 1, p. 71-75, jan./jun. 2017.

[12] Ciesielski FI N et al. Severidade Da Mucosite Bucal Em Pacientes Com Câncer De Cabeça E Pescoço Submetidos À Radioterapia Centro De Ensino Superior Dos Campos Gerais - Cescage www.cescage.edu.br/publicacoes/journalofhealth 6 a Edição. ISSN 2178 - 3594. Jul-Dez, 2011.

[13] Stockwell, HG; Lyman, GH. Impact of smoking and smokeless tobacco on the risk of câncer of the head and neck. Head Neck. v. 9, n. 2, p. 104-10, Nov-Dec. 1996.

[14] Casati, MFM et al. Epidemiologia do câncer de cabeça e pescoço no Brasil: estudo transversal de base populacional. Rev. bras. cir. cabeça pescoço. v. 41, n. 4, out.-dez. 2012.

[15] Daher, Graziela Cassimiro de Araújo; Pereira, Gilberto de Araújo; Oliveira, Ana Carolina D’Arelli oliveira. Características epidemiológicas de casos de câncer de boca registrados em hospital de Uberaba no período 1999 2003: um alerta para a necessidade de diagnóstico precoce. Rev. bras. epidemiol.; São Paulo, v. 11, n. 4, p. 584-596, Dec. 2008.

[16] Toledo HV, Ferragut MA, Almeida DB. - Basics of Radiobiology: What Does a Neurosurgeon Needs to Know?, J Bras Neurocirurg. v. 25, n. 3, p.193-199, 2014.

[17] Deng JY, et al. Reduced toxity with - 58 - three-dimensional conformal radiotherapy or intensity modulated radiotherapy compared with conventional two-dimensional radiotherapy for esophageal squamous cell carcinoma: a secondary analysis of data from four prospective clinical trials. Diseases of the Esophagus. V. 30, n. 7, P. 1-7, July 2017.

[18] Matsuzaki $\mathrm{H}$, et al. The role of dentistry other than oral care in patients undergoing radiotherapy fo head and neck cancer. Japanese Dental Science Review. v. 53, n. 2, p. 46-52, 2017.

[19] Nutting CM et al. JP Morden, Harrington KJ, et al. Modulação da intensidade de parótida versus radioterapia convencional em câncer de cabeça e pescoço (PARSPORT): um estudo randomizado controlado multicêntrico de fase 3. Lancet Oncol . 2011; 12 (2): 127-36.

[20] Vissink A, et al. Oral sequelae of head and neck radiotherapy. Crit Rev Oral Biol Med. v. 14, n. 3, p.199-212. 2003.

[21] Santos, RCS et al. Mucositis en pacientes portadores de cáncer de cabeza y cuello sometidos a radioquimioterapia, Rev Esc Enferm USP. v. 45, n. 6, p.1338-44, 2011.

[22] Rolim, Ana Emília Holanda; Costa, Lino João da; Ramalho, Luciana Maria Pedreira. Repercussões da radioterapia na região orofacial e seu tratamento. Radiol Bras, São Paulo. v. 44, n. 6, p. 388-395, Dec. 2011. 


\title{
Capítulo 7
}

\section{Atenção à saúde da mulher na prevenção do câncer cervicouterino: Possibilidades e desafios}

\author{
Ana Flávia de Lima Rocha Cruz \\ Alexandre Bezerra Silva \\ Brenda Helen Freire Barbosa \\ José Deusvando Freire Campos \\ Josivan Felix da Silva
}

Resumo: Analisou-se a atuação do enfermeiro na prevenção do câncer cervicouterino no contexto da Atenção Primária à Saúde. Foi realizado um estudo do tipo revisão integrativa onde as buscas dos artigos foram realizadas entre os meses de abril a maio de 2018, tendo como fonte de dados artigos científicos publicados na Biblioteca Virtual de Saúde. A busca foi realizada nas bases de dados Literatura Latino-Americana e do Caribe em Ciências da Saúde, Scientific Eletronic Library Online, Base de Dados de Enfermagem. Para seleção dos artigos que compõem a amostra, foram utilizados os seguintes critérios de inclusão: artigos completos, disponível em português, publicados nos últimos 8 anos (2010 a 2018), e considerando ligação com a temática. E quanto aos critérios de exclusão destacam-se: artigos que oferecem apenas resumo e carta ao leitor, com período de publicação inferior ao estabelecido e títulos que não condizem com a temática. Observa-se que a maioria dos artigos tratam como principais medidas preventivas as ações educativas como forma de orientar as mulheres na realização do exame citopatológico. Os achados apontam a necessidade de criação de vínculo e acolhimento com as mulheres adscrita no âmbito da Atenção Primária à Saúde, explorando a confiança delas no sentido de refletirem sobre a importância da realização do exame citopatológico e levando em consideração o período de realização do exame, com as especificidades de cada mulher.

Palavras-chave: Saúde da mulher, Enfermagem, Câncer cervicouterino, Prevenção Primária. 


\section{INTRODUÇÃO}

O câncer cervicouterino (CCU) é identificado pelo crescimento desordenado das células do epitélio de revestimento do órgão, podendo prejudicar tecidos e estruturas que estão próximas ou distantes, sendo o vírus Papilomavírus Humano (HPV) responsável pela infecção que causa esta neoplasia (BRASIL, 2013; ZARDO et al., 2014; MOREIRA et al.,2017).

Existem elementos que contribuem para a progressão deste tipo de câncer como o tabagismo, uso de anticoncepcionais, parceiros sexuais múltiplos, imunossupressores e relações sexuais precoces. Deste modo, é possível perceber que, trata-se de um vírus que não atinge apenas mulheres, mas também homens, podendo ser assintomáticos ou não (ZARDO et al., 2014; MOREIRA et al., 2017).

O HPV é transmitido pelo contato íntimo e tem uma variedade de mais de 100 tipos. Dentre estes, os tipos HPV16 e HPV18 são os que possuem grande potencial oncogênico, com um percentual de 70\% dos casos de neoplasias de colo do útero. Assim, com objetivo de diminuir a transmissão deste vírus foi desenvolvida uma vacina que combate os dois tipos oncogênicos, para meninas e meninos na faixa etária entre 9 a 15 anos (ZARDO et al., 2014; MOREIRA et al.,2017).

De acordo com Instituto Nacional de Câncer Jose Alencar Gomes da Silva (2017), em 2018 estima-se que surgirão, no Brasil, em torno de 16.370 casos novos de mulheres acometidas pelo CCU, sendo esta doença responsável por cerca de 265 mil óbitos por ano e o quarto tumor mais recorrente entre as mulheres.

Apesar de sua grande incidência, esse câncer tem possibilidade de prevenção por meio de exame clínico e prevenção de fatores de risco. Porém, este, ainda não consegue diminuir a morbimortalidade de mulheres durante sua fase reprodutiva (CAMPOS; CASTRO; CAVALIERI, 2016; BRASIL, 2017).

Devido à alta taxa de mortalidade de pessoas do sexo feminino com CCU, houve um reconhecimento por parte das autoridades brasileiras, de maneira que, políticas públicas na Atenção Primárias à Saúde (APS) vêm sendo implantadas no intuito de haver uma redução dessas taxas. São políticas de ações de promoção a saúde, prevenção e deteç̧ão precoce da doença, tratamento e cuidados paliativos - quando estes se fizerem indispensáveis na rede da APS (BRASIL, 2013).

Em 1997, o Ministério da Saúde (MS) implementou o Programa Nacional de Combate ao Câncer do Colo Uterino (PNCC) apontando o exame citopatológico como um método de rastreamento para deteção de anormalidade e tratamento de lesões indicadoras de neoplasia de colo.

Nessa direção, após 60 anos de idade, as mulheres que tiveram acesso regular à rotina dos exames preventivos, com resultados normais, apresentam risco diminuído para o desenvolvimento do câncer cervical, devido a sua lenta evolução. A continuidade do rastreamento após os 60 anos deve ser individualizada e, após os 65 anos, a recomendação é de suspender o rastreamento caso os últimos exames tenham apresentado resultados normais (BRASIL, 2010).

Para as mulheres com mais de 65 anos de idade e que nunca realizaram o exame citopatológico, deve-se realizar dois exames com intervalo de um a três anos. Se ambos os exames forem negativos, estas mulheres podem ser dispensadas de exames adicionais (BRASIL, 2011).

Na realização do exame citopatológico, é necessário que o enfermeiro, realize uma coleta de qualidade com esfregaço suficiente para a análise oncótica, bem como o acondicionamento e o transporte adequados dessas amostras para que se tenha um resultado fidedigno (BRASIL, 2013).

Além desses cuidados, o enfermeiro deve ter o compromisso de realizar ações que motivem o público feminino a refletir sobre ameaças de enfermidades, bem como sobre o valor do autocuidado e prevenções de patologias. Com isso, a comunicação deve ser uma ferramenta importante na atuação preventiva deste profissional, de forma a possibilitar novos conhecimentos às mulheres da área de abrangência da APS (PEUKER et al., 2017).

Dessa forma, este estudo tem como questionamento de pesquisa: como ocorre a atuação do enfermeiro na prevenção do CCU na APS? Assim, o objetivo da investigação é analisar a atuação do enfermeiro na prevenção do CCU no contexto da APS.

\section{METODOLOGIA}

Trata-se de uma revisão integrativa, a qual tem por objetivo reunir resultados de estudos já existentes sobre um ponto de interesse, objetivando contextualizar o problema da pesquisa, permitindo que se alcance conclusões gerais através da comparação de dados resumidos (CROSSETTI, 2012). 
As buscas dos artigos foram realizadas entre os meses de abril a maio de 2018, tendo como fonte de dados artigos científicos publicados na Biblioteca Virtual em Saúde (BVS). A busca ocorreu nas bases de dados Literatura Latino-Americana e do Caribe em Ciências da Saúde (LILACS), Scientific Eletronic Library Online (SciELO) e na Base de Dados de Enfermagem (BDENF).

A seleção dos artigos se deu por meio dos Descritores em Ciência da Saúde (DeCS): Enfermagem, Câncer cervicouterino, Prevenção e Acolhimento. Com relação ao refinamento para selecionar os artigos usou-se o operador booleano $A N D$, da seguinte forma: "Enfermagem $A N D$ Câncer cervicouterino (794 artigos); "Enfermagem $A N D$ Prevenção" (2.671 artigos); "Prevenção AND Câncer cervicouterino (3.740 artigos); Acolhimento $A N D$ Câncer cervicouterino (150 artigos). Ao final, foram utilizados 11 artigos.

Para seleção dos artigos que compõem a amostra, foram utilizados os seguintes critérios de inclusão: artigos completos, disponíveis em português, publicados nos últimos 8 anos (2010 a 2018), e considerando ligação com a temática. E quanto aos critérios de exclusão destacam-se: artigos que oferecem apenas resumo e carta ao leitor, com período de publicação inferior ao estabelecido e títulos que não condizem com a temática.

Para análise e interpretação dos artigos que compõem esta amostra, foi realizada a leitura exaustiva dos mesmos, sendo as informações adequadamente referenciadas, atribuindo a identificação dos autores a fim de conservar o rigor ético da propriedade intelectual dos artigos científicos utilizados de forma a evitar possíveis vieses.

\section{ANÁLISE E DISCUSSÃO DOS RESULTADOS}

Após leitura dos artigos na integra, foi elaborado o quadro abaixo, com informações quanto ao título do artigo, ano de publicação, objetivo e principais resultados.

Quadro 1. Síntese das principais informações dos artigos, quanto ao título do artigo, ano de publicação, objetivo e resultados. Natal-RN, 2018.

\begin{tabular}{|c|c|c|c|c|}
\hline Título & Autores & $\begin{array}{c}\text { Ano de } \\
\text { Publicação }\end{array}$ & Objetivo & Resultados \\
\hline $\begin{array}{l}\text { Acolhimento no } \\
\text { processo de trabalho } \\
\text { da enfermagem: } \\
\text { estratégia para } \\
\text { adesão ao controle do } \\
\text { câncer do colo } \\
\text { uterino. }\end{array}$ & $\begin{array}{l}\text { COSTA, C.O.; } \\
\text { COSTA, C.F.S; } \\
\text { VA, AGHETTI, } \\
\text { H.H. }\end{array}$ & 2010 & $\begin{array}{l}\text { Comparar o número de } \\
\text { mulheres atendidas em } \\
\text { consultas de } \\
\text { enfermagem com a } \\
\text { realização de exame } \\
\text { citopatológico de colo } \\
\text { uterino, entre os anos de } \\
2002 \text { e } 2007 .\end{array}$ & $\begin{array}{l}\text { Como resultado, identificou-se a } \\
\text { ocorrência, entre } 2005 \text { e } 2006 \text {, de uma } \\
\text { elevação no quantitativo de consultas, } \\
\text { passando de } 240 \\
\text { para } 373(64,3 \%) .\end{array}$ \\
\hline $\begin{array}{l}\text { Formação do } \\
\text { enfermeiro para a } \\
\text { prevenção do câncer } \\
\text { de colo uterino. }\end{array}$ & $\begin{array}{l}\text { VIANA, M.R. } \\
\text { et al. }\end{array}$ & 2013 & $\begin{array}{l}\text { Analisar a formação do } \\
\text { enfermeiro para a } \\
\text { prevenção do câncer de } \\
\text { colo uterino no contexto } \\
\text { da Estratégia de Saúde } \\
\text { da Família. }\end{array}$ & $\begin{array}{l}\text { Os enfermeiros possuem formação para a } \\
\text { prevenção do câncer de colo uterino na } \\
\text { ESF, em nível de graduação, } \\
\text { especialização e educação permanente, } \\
\text { no entanto, essa formação deve basear-se } \\
\text { numa aprendizagem significativa e na } \\
\text { possibilidade de transformar as práticas } \\
\text { profissionais com vista às mudanças de } \\
\text { toda a organização dos serviços de saúde. }\end{array}$ \\
\hline $\begin{array}{l}\text { Percepção das } \\
\text { mulheres sobre } \\
\text { promoção da saúde } \\
\text { durante a consulta de } \\
\text { enfermagem. }\end{array}$ & $\begin{array}{l}\text { MICHELIN, } \\
\text { S.R. et al. }\end{array}$ & 2015 & $\begin{array}{l}\text { Identificar a percepção } \\
\text { das mulheres a respeito } \\
\text { das atividades de } \\
\text { Promoção da Saúde nas } \\
\text { ações de prevenção do } \\
\text { câncer ginecológico no } \\
\text { Centro de Saúde de } \\
\text { Florianópolis. }\end{array}$ & $\begin{array}{l}\text { A análise dos temas investigados foi } \\
\text { realizada à luz do referencial teórico da } \\
\text { Promoção da Saúde. Faz-se necessário } \\
\text { entender a importância do diálogo no } \\
\text { momento de interação entre o } \\
\text { profissional enfermeiro e a mulher, } \\
\text { levando em consideração suas dimensões } \\
\text { biológicas, ambientais, sociais, } \\
\text { emocionais e espirituais. }\end{array}$ \\
\hline
\end{tabular}


Quadro 1. Síntese das principais informações dos artigos, quanto ao título do artigo, ano de publicação, objetivo e resultados. Natal-RN, 2018. (continuação)

\begin{tabular}{|c|c|c|c|c|}
\hline Título & Autores & $\begin{array}{c}\text { Ano de } \\
\text { Publicação }\end{array}$ & Objetivo & Resultados \\
\hline $\begin{array}{l}\text { Educação popular } \\
\text { como instrumento } \\
\text { Participativo para a } \\
\text { Prevenção do câncer } \\
\text { ginecológico: } \\
\text { percepção de } \\
\text { mulheres }\end{array}$ & $\begin{array}{l}\text { SOUZA, K. R. } \\
\text { et al. }\end{array}$ & 2015 & $\begin{array}{l}\text { Objetivou-se neste } \\
\text { estudo avaliar a } \\
\text { percepção de mulheres } \\
\text { sobre o câncer do colo } \\
\text { do útero, através da } \\
\text { prática de educação } \\
\text { popular como } \\
\text { instrumento } \\
\text { participativo }\end{array}$ & $\begin{array}{l}\text { Foi possível perceber que as participantes } \\
\text { têm conhecimento da realização do } \\
\text { preventivo, reconhecendo a importância } \\
\text { deste para detecção precoce do câncer } \\
\text { ginecológico, afirmando haver pouca } \\
\text { difusão, correlacionando com } \\
\text { ausência/pouca educação popular realizada } \\
\text { pelos profissionais de saúde. }\end{array}$ \\
\hline $\begin{array}{l}\text { Adesão as mulheres } \\
\text { ao exame citológico } \\
\text { do colo uterino na } \\
\text { atenção básica. }\end{array}$ & $\begin{array}{l}\text { OLIVEIRA, A. } \\
\text { E. C. et al. }\end{array}$ & 2016 & $\begin{array}{l}\text { Avaliar o perfil sócio } \\
\text { demográfico e a adesão } \\
\text { das mulheres ao exame } \\
\text { citológico do colo } \\
\text { uterino na Atenção } \\
\text { Básica }\end{array}$ & $\begin{array}{l}96,4 \% \text { das entrevistadas referiram ter } \\
\text { realizado o exame citológico ao menos uma } \\
\text { vez e possuía periodicidade anual. } \\
\text { Vergonha, ansiedade, prazo para } \\
\text { recebimento do resultado do exame, foram } \\
\text { os principais fatores que dificultam a adesão } \\
\text { do citológico. }\end{array}$ \\
\hline $\begin{array}{l}\text { Atividades educativas } \\
\text { estimulando o } \\
\text { autocuidado e } \\
\text { prevenção do câncer } \\
\text { feminino. }\end{array}$ & $\begin{array}{l}\text { MENDES, L.C. } \\
\text { et al. }\end{array}$ & 2017 & $\begin{array}{l}\text { Descrever as práticas } \\
\text { educativas, realizadas } \\
\text { com estudantes do } \\
\text { ensino médio noturno } \\
\text { de escolas estaduais do } \\
\text { município de } \\
\text { Uberaba/MG, a respeito } \\
\text { da prevenção do câncer } \\
\text { de mama e do colo do } \\
\text { útero. }\end{array}$ & $\begin{array}{l}\text { As mulheres eram carentes de informações } \\
\text { relacionadas à temática e possuíam um } \\
\text { déficit de conhecimento maior referente à } \\
\text { auto palpação das mamas e em relação ao } \\
\text { exame Papanicolau, sendo as mesmas } \\
\text { orientadas através de práticas educativas } \\
\text { realizadas por meio de estratégias como o } \\
\text { "breast awareness" que significa estar alerta } \\
\text { para a saúde das mamas. }\end{array}$ \\
\hline $\begin{array}{l}\text { Conhecimento de } \\
\text { Mulheres a respeito } \\
\text { do Exame } \\
\text { Papanicolau. }\end{array}$ & $\begin{array}{l}\text { VASCONCEL } \\
\text { OS, L.C. et al. }\end{array}$ & 2017 & $\begin{array}{l}\text { Descrever o } \\
\text { conhecimento de } \\
\text { mulheres pertencentes a } \\
\text { um município do } \\
\text { interior de Minas Gerais } \\
\text { a respeito da prevenção } \\
\text { CCU, por meio do exame } \\
\text { Papanicolau. }\end{array}$ & $\begin{array}{l}\text { Quanto ao conhecimento sobre o exame, } 78 \\
(83,8 \%) \text { afirmaram ter conhecido através de } \\
\text { profissionais de saúde. No que diz respeito } \\
\text { ao conhecimento dos fatores de risco para o } \\
\text { câncer de colo uterino, } 43(46,2 \%) \text { tinham } \\
\text { conhecimento correto sobre o tema. }\end{array}$ \\
\hline $\begin{array}{l}\text { Papanicolau: } \\
\text { refletindo sobre o } \\
\text { cuidado de } \\
\text { enfermagem na } \\
\text { Atenção } \\
\text { Básica. }\end{array}$ & $\begin{array}{l}\text { MOURA, J. } \\
\text { B.L.C; SILVA, } \\
\text { G.S.V. }\end{array}$ & 2017 & $\begin{array}{l}\text { Identificar as estratégias } \\
\text { que estão sendo } \\
\text { utilizadas pelos } \\
\text { enfermeiros das } \\
\text { Estratégias de Saúde da } \\
\text { Família para conseguir a } \\
\text { adesão das mulheres ao } \\
\text { exame Papanicolau. }\end{array}$ & $\begin{array}{l}\text { As estratégias identificadas foram a } \\
\text { "prontidão para cuidar", esta, é uma } \\
\text { ferramenta para acolher a pessoa e se } \\
\text { disponibilizar para cuidar do indivíduo, } \\
\text { independentemente, da hora e local que ele } \\
\text { esteja. Além disso, a educação em saúde } \\
\text { pode ser realizada na sala de espera e rodas } \\
\text { de conversa. }\end{array}$ \\
\hline $\begin{array}{l}\text { Acolhimento na } \\
\text { consulta ginecológica } \\
\text { de enfermagem: } \\
\text { percepções de } \\
\text { mulheres da } \\
\text { Estratégia Saúde da } \\
\text { Família. }\end{array}$ & $\begin{array}{l}\text { ROCHA, M. G. } \\
\text { L. et al. }\end{array}$ & 2018 & $\begin{array}{l}\text { Descrever as percepções } \\
\text { de mulheres atendidas } \\
\text { na Estratégia Saúde da } \\
\text { Família (ESF) acerca do } \\
\text { acolhimento nas } \\
\text { consultas ginecológicas } \\
\text { de enfermagem. }\end{array}$ & $\begin{array}{l}\text { As mulheres expuseram o acolhimento de } \\
\text { forma positiva na promoção da saúde e } \\
\text { prevenção do câncer de cervicouterino. }\end{array}$ \\
\hline
\end{tabular}


Quadro 1. Síntese das principais informações dos artigos, quanto ao título do artigo, ano de publicação, objetivo e resultados. Natal-RN, 2018. (continuação)

\begin{tabular}{|c|c|c|c|c|}
\hline Título & Autores & $\begin{array}{c}\text { Ano de } \\
\text { Publicação }\end{array}$ & Objetivo & Resultados \\
\hline $\begin{array}{l}\text { Câncer do colo } \\
\text { do útero: papel } \\
\text { do enfermeiro } \\
\text { na estratégia e } \\
\text { saúde da família. }\end{array}$ & $\begin{array}{l}\text { SILVEIRA, } \\
\text { M.B.O.; MAIA, } \\
\text { R.C.B.; } \\
\text { CARVALHO, } \\
\text { M.F.A. }\end{array}$ & 2018 & $\begin{array}{l}\text { Descrever por meio de } \\
\text { uma revisão de } \\
\text { literatura, o valor do } \\
\text { exame Papanicolau na } \\
\text { prevenção do câncer do } \\
\text { colo do útero, com foco } \\
\text { na atuação da equipe de } \\
\text { enfermagem na ESF. }\end{array}$ & $\begin{array}{l}\text { Percebeu-se que é de suma } \\
\text { importância o exame Papanicolau } \\
\text { para o diagnóstico precoce da doença } \\
\text { e, concomitante, a redução de danos à } \\
\text { saúde da mulher, bem como, a efetiva } \\
\text { atuação do enfermeiro dentro da ESF, } \\
\text { uma vez que este possui formação } \\
\text { mais generalista, com focos em } \\
\text { humanização e educação em saúde, o } \\
\text { que pode contribuir de maneira } \\
\text { significativa para o enfrentamento do } \\
\text { câncer de colo uterino. }\end{array}$ \\
\hline $\begin{array}{l}\text { Caracterização } \\
\text { dos resultados } \\
\text { de exames } \\
\text { citopatológicos } \\
\text { do colo do útero } \\
\text { entre } \\
2014 \text { e } 2016\end{array}$ & $\begin{array}{l}\text { MATOS, } \\
\text { G.H.P. et al. }\end{array}$ & 2018 & $\begin{array}{l}\text { Analisar resultados dos } \\
\text { exames citopatológicos } \\
\text { de colo do útero } \\
\text { alterados de mulheres } \\
\text { submetidas à } \\
\text { colposcopia. }\end{array}$ & $\begin{array}{l}\text { Foram analisados } 218 \text { registros, } \\
\text { prevalecendo entre as mulheres } \\
\text { abaixo de } 25 \text { anos e entre } 25 \text { a } 35 \\
\text { anos lesão de baixo grau, } 65,85 \% \text {, e } \\
38,46 \% \text { respectivamente; } 36 \text { a } 45 \\
\text { anos, } 35,71 \% \text { lesão de alto grau; } 46 \text { a } \\
55 \text { anos, } 39,39 \% \text { células escamosas } \\
\text { atípicas de significado } \\
\text { indeterminado; entre } 56 \text { a } 64 \text { anos, } \\
27,77 \% \text { células escamosas atípicas de } \\
\text { significado indeterminado; } 27,77 \% \\
\text { lesão de alto grau e entre } 65 \text { anos ou } \\
\text { mais, } 31 \% \text { células escamosas atípicas } \\
\text { de significado indeterminado. }\end{array}$ \\
\hline
\end{tabular}

Fonte: Os autores.

De acordo com a análise do quadro acima, foi possível identificar que em relação ao ano de publicação dos artigos que fazem parte desta amostra, 3 (37,7\%) foram publicados em 2017 e 03 (37,7\%) publicados no ano de 2018. Com isto percebe-se que, a maioria dos artigos pesquisados apresentam-se atualizados no que diz respeito a seus conteúdos.

Além disso, no que se refere ao título e objetivos dos artigos pesquisados, percebe-se que grande parte trata as medidas preventivas utilizando-se das ações educativas como forma de orientar as mulheres na realização do exame contra o CCU.

Assim, ficou evidente que, muito é discutido sobre a atuação do enfermeiro na prevenção do CCU na APS. Diante destas reflexões e, no que concerne à população das mulheres mais vulneráveis ao CCU, é necessário que se conheça o perfil sanitário e socioeconômico das mesmas para que as medidas preventivas sejam traçadas de acordo com as especificidades desta clientela.

Com isso, sabe-se que no âmbito da equipe de enfermagem, a consulta de enfermagem deve ser realizada na assistência à saúde, seja ela pública ou privada. É por esse meio que se realiza o acolhimento, anamnese e o exame físico. Nesta consulta, o profissional deve ter o conhecimento das vidas dessas mulheres, suas rotinas, sentimentos, seus parceiros e sobre seu conhecimento acerca da detecção precoce do câncer de colo de útero (COSTA; COSTA; VAAGHETTI, 2010).

No estudo de Rocha et al (2019), é necessário conhecer sobre a vida destas mulheres, pois é de suma importância a realização do acolhimento baseado no diálogo, tornando mais fácil o processo de humanização. Este diálogo deve favorecer a troca de saberes e práticas sobre o exame citopatológico para que possíveis dúvidas sejam minimizadas, de forma a incentivar as mulheres para a realização deste (ROCHA et al., 2018).

Nessa perspectiva, percebe-se que é importante salientar que o enfermeiro na APS deve realizar ações que estimulem a mulher a participar do seu autocuidado, de forma a proporcionar o autoconhecimento, a confiança e o respeito. Assim, muitos sentimentos apresentados pelas mulheres e que dificultam na 
realização do exame preventivo, como a vergonha e o medo, podem ser superados com a aquisição do autoconhecimento (OLIVEIRA et al., 2016).

Nesse contexto, pode-se inferir que os enfermeiros passam a ser um canal de contato direto com as mulheres, tanto para a prevenção de doenças quanto para o apoio psicológico. No que diz respeito à prevenção, os enfermeiros atuam numa camada mais direta com a paciente, neste sentido, tão importante quanto orientar em relação ao tratamento, é orientar quanto a realização, conforme a necessidade de se realizar o exame citopatológico, levando em consideração as queixas, medos e anseios da mulher (MOURA, SILVA, 2017).

O exame contra o CCU tem o propósito de identificar lesões existentes no colo do útero e possibilitar o diagnóstico inicial da patologia e, assim, elevar a taxa de cura. Contudo, o enfermeiro deve orientar essas mulheres sobre o preparo para a realização do exame preventivo. Dentre estas orientações, destaca-se o ato de evitar relações sexuais, bem como não utilizar medicações vaginais e duchas na vulva num intervalo de 48 horas antes do exame. Além disso, é essencial que elas não estejam menstruadas (SILVEIRA, MAIA, CARVALHO, 2018).

Segundo Vasconcelos et al (2017), após o acolhimento e durante a consulta de enfermagem, é realizado o preenchimento do formulário de requisição de exame onde se deve ter o cuidado de responder as perguntas corretamente. Logo após essa etapa, o enfermeiro começa a realizar o exame clínico da mulher através do preventivo, o qual é feito através da inspeção da região genital e do esfregaço da ectocérvice e endocérvice substâncias contidas no colo uterino - que serão submetidas a análise laboratorial.

Dessa maneira, o enfermeiro deve atentar para a qualidade desta coleta pois para que se tenha um diagnóstico fidedigno, é preciso que a amostra seja eficiente. Para tanto, é necessário que a ectocérvice e endocérvice coletadas sejam bem-dispostas em uma lâmina, cuidando para não sobrepor as amostras e, assim, não comprometer a visualização das células. Após a coleta, o enfermeiro tem o papel de identificar essas amostras e, então, enviá-las à análise (SILVEIRA; MAIA; CARVALHO, 2018).

Além disto, o exame citopatológico tem a capacidade de detectar outras infecções do trato vaginal da mulher, dentre elas temos as vaginoses bacterianas, sendo as mais frequentes a Gardnerella vaginalis, a tricomoníase (Trichomonas vaginalis) - esta é uma Infecção Sexualmente Transmissível (IST) não viral. Outra infecção bastante recorrente é a candidíase vulvovaginal, a qual causa grande incômodo nas mulheres devido a sua elevada incidência de episódios repetitivos (BATISTA et. al., 2015).

Após o resultado do exame, é fundamental que essas mulheres retornem à unidade para que se tenha novamente um diálogo com o enfermeiro. No caso de alteração no exame, as lesões devem ser classificadas como baixo e alto grau, assim, deve-se encaminhar a mulher, imediatamente, para a realização de uma colposcopia - através de um especialista - para que se tenha uma confirmação do diagnóstico e escolha do tratamento. Nos casos de infecção tanto por bactérias e fungos devem ser adotadas rotinas de medicamentos para tratamento (MATOS, et al. 2018).

Contudo, é de extrema importância que os enfermeiros da APS promovam rodas de conversa, banners informativos, programas focados para a educação e orientação sobre a prevenção do CCU. Neste sentido, poderá, também, promover ações de educação em saúde sobre as IST's, orientando quanto ao seu modo de transmissão, tratamentos e, principalmente, as melhores formas de prevenção (MENDES, et al. 2017).

Além das ações que devem ser realizadas pelo enfermeiro, é importante que este profissional leve em consideração o contexto socioeconômico da mulher, para que o mesmo possa basear as condutas de enfermagem de acordo com a realidade em que ela se encontra. Durante a consulta para a realização do exame preventivo, é preciso observar a presença de maus hábitos, a saúde mental e física, os fatores genéticos, bem como a sua cultura, para que se possa conduzir, da melhor forma possível, a promoção à saúde desta mulher (MICHELIN, et al. 2015).

Nessa direção, o enfermeiro deve adotar o pensamento crítico reflexivo para que se tenha o mecanismo de poder se posicionar frente aos problemas de saúde da população nesta condição, tendo o potencial de desenvolver ações a partir das dificuldades que aparecerem. Dessa forma, na prevenção do CCU, o profissional embasado num processo frequente de reflexão, é apto a desempenhar uma assistência adequada, holística, de acordo com a necessidade de cada mulher nas áreas adscritas (VIANA, et al. 2013). 


\section{CONSIDERAÇÕES FINAIS}

Os achados apontam a possibilidade da importância do diálogo, da ação e reflexão frente as ações da prevenção do CCU no contexto da APS, uma vez que essas atitudes podem possibilitar um melhor vínculo e uma boa relação do enfermeiro com o paciente explorando, assim, a confiança das mulheres em seguir corretamente todos os passos a serem percorridos na prevenção contra o câncer cervicouterino.

Portanto, é perceptível que a saúde da mulher na APS tem avançado bastante em relação à prevenção do CCU. Neste avanço, é possível ver o empenho, principalmente, dos enfermeiros em levar a informações necessárias à população-alvo desta doença. Entretanto, apesar do empenho, se faz necessário a articulação dos outros níveis de atenção à saúde com a APS, no sentido de estarem diminuindo a morbimortalidade destas mulheres acometidas pelo CCU.

Assim, este estudo deixa como sugestão para melhoria da atuação do enfermeiro na prevenção do CCU na APS, um acompanhamento das usuárias pelas redes sociais, formando grupos administrados pelo enfermeiro a fim de diminuir as distâncias entre o paciente e as equipes de saúde.

\section{REFERÊNCIAS}

[1] BATISTA, K.R. et al. Educação popular como instrumento participativo para a prevenção do câncer ginecológico: percepção de mulheres. Rev. Cuidarte. v. 6, n. 1, 2015). Disponível em: < https://revistacuidarte.udes.edu.co/index.php/cuidarte/article/view/129> Acesso em : 28 abr. 2018.

[2] BRASIL. Ministério da Saúde. Instituto Nacional do câncer Câncer Jose Alencar Gomes da Silva (INCA). Colo de útero. 2017. Disponível em:

<http://www2.inca.gov.br/wps/wcm/connect/tiposdecancer/site/home/colo_utero/definicao> Acesso em: 27 abr. 2018.

[3] __. Ministério da Saúde. Controle dos cânceres do colo do útero e da mama. (Cadernos de Atenção Básica, n. 13). In: Departamento de Atenção Básica, editor. Brasília: Editora do Ministério da Saúde; 2013. p. P.13, 42, 128. Disponível em: <http://189.28.128.100/dab/docs/portaldab/publicacoes/cab13.pdf> Acesso em: 28 abr. 2018.

[4] __ _ Instituto Nacional de Câncer. Sistema de informação do controle do câncer de mama (SISMAMA) e do câncer do colo do útero (SISCOLO). Rio de Janeiro: INCA, 2011.

[5] __. Secretaria de Atenção à saúde. Departamento de Atenção Básica. Rastreamento. Brasília: MS, 2010.

[6] CAMPOS; E. A., CASTRO; L. M., CAVALIERI; F. E.S.Uma doença da mulher: experiência e significado do câncer cervical para mulheres que realizaram o Papanicolau. Interface (botucatu), v.21, n.61, p.385-396, 2017. Disponível em: <http://www.scielo.br/scielo.php?pid=S141432832016005020105\&script=sci_abstract> Acesso em: 27 abr. 2018.

[7] COSTA, C.O; COSTA, C.F.S; VAAGHETTI, H.H. Acolhimento no processo de trabalho da enfermagem: estratégia para adesão ao controle do câncer do colo uterino. Rev Baiana Saude Publica Miolo, v.34, n.3, p. 706-717, jul./set, 2010. Disponível em:http://repositorio.furg.br/handle/1/1529> Acesso em: 25 jul. 2018.

[8] CROSSETTI, M. G. O. Revisão integrativa de pesquisa na enfermagem o rigor cientifico que lhe é exigido. Revista gaúcha de enfermagem. Porto Alegre. v. 33, n. 2, p. 8-13, (jun. 2012). Disponível em: $<$ https://lume.ufrgs.br/handle/10183/94920> Acesso em: 28 abr.2018.

[9] MATOS, G. H. P. et al. Caracterização dos resultados de exames citopatológicos do colo do útero entre 2014 e 2016. Journal Health NPEPS. v.3, n.1, p. 153-165, 2018.Disponivel em:https://periodicos.unemat.br/index.php/jhnpeps/article/view/2726 Acesso em: 25 jul. 2018

[10] MENDES; L. C. et al. Atividades educativas estimulando o autocuidado e prevenção do câncer feminino. Revista de Enfermagem a Atenção Saúde, v.6, n.1, p.140-147, Jan/Jun 2017. Disponível em: <http://seer.uftm.edu.br/revistaeletronica/index.php/enfer/article/view/1792>Acesso em: 25 jul. 2018.

[11] MICHELIN, S. R. et. al. Percepção das mulheres sobre promoção da saúde durante a consulta de enfermagem. Revista Ciência, Cuido e Saúde. v.14, n.1, p. 901-909, Jan/Mar 2015. Disponível em: <http://www.periodicos.uem.br/ojs/index.php/CiencCuidSaude/article/view/20300> Acesso em: 25 jul. 2018.

[12] MOREIRA, T. R.; LIMA, A. C. S. de; SANTOS, M. A. dos; TURKIEWICZ, M.; CHAVES, M. A. F.; PLEWKA, J. Perfil das mulheres usuárias do sus com lesões intraepiteliais em um município do oeste do Paraná. Arq. Cienc. Saúde UNIPAR, Umuarama, v. 21, n. 3, p, 181-186, set./dez. 2017.

[13] MOURA, J. B. L. C.; SILVA, G. S. V. Papanicolau: refletindo sobre o cuidado de enfermagem na atenção básica. Revista pró-universus. v.8, n.1, p.12-16, 2017. Disponível em: <file:///C:/Users/JRMC/Downloads/697-2604-3PB\%20(1).pdf> Acesso em: 28 jul. 2018.

[14] OLIVEIRA, A. E. C. et al. Adesão as mulheres ao exame citológico do colo uterino na atenção básica. Rev 
enferm UFPE on line., Recife, v.10(11) p. 4003-14, nov., 2016. Disponível em: <https://periodicos.ufpe.br/revistas/revistaenfermagem/article/download/11483/13336> Acesso em: 28 abr. 2018.

[15] PEUKER, A. C. et al. Construção de um material educativo para a prevenção do câncer de colo do útero. Estudos Interdisciplinares em Psicologia, Londrina, v. 8, n. 2, p. 146-160, dez. 2017. Disponível em: http://www.uel.br/revistas/uel/index.php/eip/article/view/25114/23148> Acesso em: 28 abr. 2018.

[16] ROCHA, M. G. L. et al. Acolhimento na consulta ginecológica de enfermagem: percepções de mulheres da Estratégia Saúde da Família. Revista da Rede de Enfermagem do Nordeste. v.19, 2018. Disponível em: <http://periodicos.ufc.br/rene/article/view/33382> Acesso em: 25 jul. 2018.

[17] SILVEIRA, B. L.; MAIA, R. C. B.; CARVALHO, M. F. A. câncer do colo do útero: papel do enfermeiro na estratégia e saúde da família. Revista Científica da Faculdade de Educação e Meio Ambiente (FAEMA), v. 9, n. 1, jan./jun., 2018. Disponível em: <file:///C:/Users/JRMC/Downloads/517-Texto\%20do\%20artigo-1932-3-10-20180412.pdf> Acesso em: 25 jul. 2018

[18] SOARES; M. B. O.; SILVA; S.R. Analise de um programa municipal de prevenção do câncer cérvicouterino. Revista Brasileira de Enfermagem, Brasília, v.63, n.2, março/abril. 2010. Disponível em:< http://www.scielo.br/scielo.php?script=sci_arttext\&pid=S0034-71672010000200002> Acesso em: 28 abr. 2018.

[19] UCHIMURA; N.S. et al. Qualidade e desempenho das colpocitologias na prevenção de câncer de colo uterino. Rev. Assoc. Med. Bras. São Paulo, v. 55, n.5, 2009. Disponível em: <http://www.scielo.br/scielo.php?pid=S0104$42302009000500021 \&$ script=sci_abstract\&tlng=pt.> Acesso em: 28 abr. 2018.

[20] ASCONCELOS, L. C. et al. Conhecimento de Mulheres a Respeito do Exame Papanicolau. Uniciências. v.21, n.2, p. 105-109, 2017.Disponível em:<http://www.pgsskroton.com.br/seer/index.php/uniciencias/article/view/5195> Acesso em: 28 abr. 2018.

[21] VIANA, M. R. P. et al. Formação do enfermeiro para a prevenção do câncer de colo uterino. Revista de enfermagem do UERJ, Rio de Janeiro, v.21, n.1, p. 624 -630, dez. 2013. Disponível em:<http://www.facenf.uerj.br/v21nesp1/v21e1a11.pdf> Acesso em: 28 abr. 2018.

[22] ZARDO; G.P. et al.Vacina como agente de imunização contra HPV. Revista Ciência Saúde Coletiva, Rio de janeiro, v.19, n.9, set. 2014. Disponível em: <http://www.scielo.br/pdf/csc/v19n9/1413-8123-csc-19-09-3799.pdf> Acesso em: 28 abr. 2018. 


\section{Capítulo 8}

\section{O uso de óleo essencial de lavanda pela fisioterapia no tratamento de mulheres no climatério}

\section{Ruth Barin}

Jeronimo Costa Branco

Sheila Spohr Nedel

Larissa Santos Nunes

Quelen Carpes Grützmacher

Resumo: Dos diversos óleos essenciais usados na aromaterapia, destaca-se o óleo essencial de lavanda (OEL), por suas propriedades antibactericidas, antifúngicas, ansiolíticas, antidepressivas, analgésicas, relaxante muscular além de apresentar efeitos imunomoduladores. $\mathrm{Na}$ fase do climatério, as alterações hormonais acarretam em mudanças do estado tanto físico como emocional das mulheres, sendo os principais sintomas apresentados ansiedade, depressão, vasomotores (por exemplo, ondas de calor e suores noturnos) e distúrbios do sono. 0 presente artigo possui intenção de apresentar o tratamento dos sintomas de mulheres climatéricas com o uso das Práticas Integrativas e Complementares (PICs) através da aromaterapia de óleo essencial de lavanda (OEL), da espécie Lavandula angustifolia.

Palavras-chave: Aromaterapia; Mulheres climatéricas; Práticas integrativas e complementares. 


\section{INTRODUÇÃO}

O climatério, segundo a Organização Mundial da Saúde (OMS), é definido como uma fase biológica da vida e não como um processo patológico. Inclui a transição entre os períodos reprodutivo e não reprodutivo da mulher, ou seja, é determinada pela queda na produção dos hormônios estrogênio e progesterona pelos ovários (BRASIL, 2008). Acredita-se que, das várias fases da vida, o climatério é o que causa maior impacto na saúde da mulher (DUARTE; TRIGO; PAIM DE OLIVEIRA, 2016).

Os sintomas mais prevalentes nessa fase do climatério são alterações de humor, apetite, além das ondas de calor, suores noturnos, e rubor (SOUZA GUERRA et al., 2019), além disso relatos de ansiedade e depressão demonstram alterações na atividade de neurotransmissão como possíveis reflexos da diminuição dos níveis hormonais (MAHESHWARI et al., 2015).

A terapia hormonal é o principal tratamento para os sintomas do climatério, porém na última década, o uso da aromaterapia com o óleo essencial de Lavandula angustifolia vem aumentando significativa para redução dos sintomas do climatério e os efeitos colaterais da reposição hormonal (KAZEMZADEH et al., 2016), pois acredita-se que o óleo essencial de L. angustifolia pode ser benéfico para aliviar os sintomas estressantes do climatério (LIU; CHIEN; CHENG, 2012).

No estudo de Kazemzadeh et al. (2016) em um ensaio clínico duplo-cego cruzado com 100 mulheres no climatério com idade entre 45 a 55 anos que sofriam de rubor, onde foram divididas em dois grupos, grupo lavanda $(n=50)$ que inalou o óleo essencial de Lavanda angustifolia duas vezes na semana por 20 minutos durante o período de 12 semanas, já o grupo placebo $(n=50)$ inalou leite diluído duas vezes na semana por 20 minutos durante o período de 12 semanas. Os resultados encontrados nesse estudo indicam que as mulheres que inalaram o óleo essencial de L. angustifolia teve uma redução significativamente no rubor $(\mathrm{p}<0,001)$, assim concluindo que o uso do óleo essencial de L. angustifolia pode auxiliar na diminuição dos sintomas do climatério.

Partindo do que preceitua a literatura sobre o óleo essencial de L. angustifolia, em face dos benefícios supramencionados que abrangem diversas áreas da saúde, 0 presente artigo possui intenção de apresentar o tratamento dos sintomas de mulheres climatéricas com o uso das Práticas Integrativas e Complementares (PICS) através da aromaterapia de óleo essencial de lavanda (OEL), da espécie Lavandula angustifolia.

\section{METODOLOGIA}

Este estudo caracteriza-se como uma Revisão de Literatura. A busca dos estudos ocorreu no mês de março de 2021, nas bases de dados eletrônicas Pubmed (National Library of Medicine), Scielo (Scientific Electronic Library Online). Os descritores em ciências da saúde e operadores boleanos utilizados foram: Aromatherapy AND Lavandula angustifolia AND Climacteric, Lavandula angustifolia AND Climacteric AND Complementary Therapies, Physical Therapy AND Oils, Volatile AND Lavandula angustifolia. Os critérios de inclusão utilizados para selecionar os artigos foram: artigos completos e disponíveis online na íntegra, publicados nos idiomas português e inglês que abordassem a relação entre o uso do óleo essencial de Lavanda angustifolia pela fisioterapia no tratamento de mulheres no período do climatério. Estudos que não estavam descritos a concentração e espécie da lavanda utilizada no estudo bem como artigos em duplicata foram excluídos da amostra.

Após a busca nas bases de dados, foi realizada a avaliação dos títulos e dos resumos (abstracts) e os estudos que contemplaram os critérios de inclusão foram selecionados para leitura na íntegra.

\section{RESULTADOS E DISCUSSÕES}

No que tange a fisioterapia, desde sua origem, tem caráter essencialmente curativo e reabilitador em decorrência das grandes guerras e dos altos índices de acidente de trabalho oriundos da revolução industrial. Sendo assim, sua atuação restringia a restauração, desenvolvimento e conservação da capacidade física (NASCIMENTO et al., 2006).

Atualmente é um curso de graduação reconhecido pelo Conselho Federal de Fisioterapia e Terapia Ocupacional [COFFITO, conselho criado em 1975, com o objetivo de normalizar e exercer o controle ético, científico e social da profissão] (NAVES; BRICK, 2011). Curso, com 53 anos, que proporcionou o reconhecimento profissional à fisioterapia no Brasil. Perante suas diretrizes, inclui a atuação nos três 
níveis de atenção: primário (promoção de saúde), secundário (diagnóstico precoce), terciário (reabilitação) (NEVES; ACIOLE, 2011).

Diante desta realidade cabe ao fisioterapeuta uma releitura de seus fundamento e análise da sua prática profissional e contribuir para a mudança sanitária, social e funcional do país, em consonância dos princípios do Sistema Único de Saúde (SUS). Dentro desta perspectiva o fisioterapeuta pode aturar com a aromaterapia com o intuito de proporcionar melhorar físicas e emocionais para mulheres no climatério.

O climatério é a fase da vida da mulher onde ocorre a transição entre o período reprodutivo e não reprodutivo, devido a diminuição dos hormônios sexuais produzidos pelos ovários (KINGSBERG; LARKIN; LIU, 2020). Essa diminuição tende a implicar em alterações cerebrais, cutâneas, cardiovasculares, geniturinárias, vasomotoras e ósseas, além de mudanças no humor e no apetite (LIMA et al., 2019).

Com a queda dos níveis de estrogênio, ocorrem modificações do estado emocional, visto que o hipoestrogenismo interfere na produção de neurotransmissores que modulam o comportamento e provocam alterações psíquicas, como mudanças comportamentais, emocionais e dificuldade com a memória, além da baixa dos níveis séricos de melatonina (de forma mais gradual devido também à idade), prejudicando a qualidade de sono e de vida de mulheres no climatério (CONTE; FRANZ; IDALÊNCIO, 2014; JEHAN et al., 2017). Além das questões biológicas, as transições econômicas, epidemiológicas, demográficas e comportamentais que ocorrem ao longo da vida, resultam em impacto negativo para a saúde das mulheres (KINGSBERG; LARKIN; LIU, 2020). Em relação aos fatores psicológicos destaca-se a depressão e a ansiedade, os quais vêm aumentando na população em geral, sendo mais prevalente no sexo feminino (MOLINA, 2012).

Conforme a OMS, o climatério não é um processo patológico, e sim uma fase biológica da vida. A menopausa acontece geralmente em torno dos 48-50 anos de idade, depois de passado 12 meses da ocorrência do último ciclo menstrual (BRASIL, 2008). Os sintomas de ansiedade, depressão, vasomotores (por exemplo, ondas de calor e suores noturnos) e distúrbios do sono, pioram na menopausa, e tem seu início na perimenopausa, período que antecede a menopausa e dura geralmente entre 4 e 10 anos, quando começa a transição do caráter reprodutivo ao não reprodutivo da mulher (GREENDALE; KARLAMANGLA; MAKI, 2020). Segundo consta no Manual de Atenção à Mulher no Climatério/Menopausa (BRASIL, 2008), do Ministério da Saúde, o tratamento a ser utilizado durante o climatério pode ser hormonal ou o não hormonal. Neste último, encontra-se a Política Nacional de Práticas Integrativas e Complementares no SUS (PNPIC), aprovada pelo Conselho Nacional de Saúde, em 15 de dezembro de 2005.

As Práticas Integrativas e Complementares, por privilegiarem a atividade terapêutica e se basearem em teorias voltadas para os aspectos ambientais e comportamentais do processo saúde-doença, caracterizamse como estratégias potencialmente interessantes para o enfrentamento dos novos desafios na atenção à saúde (HABIMORAD et al., 2020).

Por essa razão, o Ministério da Saúde aprovou a Política Nacional de Práticas Integrativas e Complementares (PNPIC) no Sistema Único de Saúde (SUS) no ano de 2006 através da Portaria no. 971, de 03 de maio de 2006, onde estabeleceu um crescimento do uso dessas práticas terapêuticas como da Medicina Tradicional Chinesa - Acupuntura, Homeopatia, Fitoterapia, bem como da Medicina Antroposófica e do Termalismo (Crenoterapia). Ela contribui para a validação científica com o pensamento emergente da abordagem integral do indivíduo segundo sua natureza biopsicossocial e reconhece os saberes tradicionais, valorizando mecanismos naturais de manutenção e recuperação da saúde (BRASIL, 2006; FEITOSA et al., 2016).

Portanto no de 2017, o Ministério da Saúde através da portaria no. 849, de 23 de março de 2017 atualizou a Política Nacional de Práticas Integrativas e Complementares (PNPIC) incluindo novas práticas terapêuticas como a arteterapia, ayurveda, biodança, dança circular, meditação, musicoterapia, naturopatia, osteopatia, quiropraxia, reflexoterapia, reiki, shantala, terapia comunitária integrativa e yoga (BRASIL, 2017), posteriormente, a PNPIC foi mais uma vez atualizada a partir da publicação de nova portaria sob o ํㅡ. 702, de 21 de março de 2018, que ampliou a oferta de novas práticas terapêuticas com a apiterapia, aromaterapia, bioenergética, constelação familiar, cromoterapia, geoterapia, hipnoterapia, imposição de mãos, ozonioterapia e terapia de florais (BRASIL, 2018). Dessa forma, o SUS autoriza, atualmente, 29 práticas integrativas e complementares, intensificando o desafio da capacitação, implantação e oferta destas na saúde pública do País (DACAL; SILVA, 2018).

Em vista disso Domingos e Braga (2015) em meio as várias opções de Práticas Integrativas e Complementares (PICS), evidencia a utilização da fitoterapia que abrange a aromaterapia, a qual faz a utilização dos óleos essenciais que promovem o bem-estar e auxiliam no tratamento de doenças, dessa 
forma a aromaterapia é uma prática natural, não invasiva que atua no equilíbrio natural do organismo como um todo, essa terapia entende que dentro de uma estratégia de tratamento há que se levar em consideração que cada pessoa possui uma necessidade única, tendo uma visão ampla e não fragmentada, incluindo a parte física e mental do indivíduo (AHMAD et al., 2019).

Dessa maneira as PICS podem ser utilizadas por diferentes tipos de populações, idade e gênero, para tratar diversas comorbidades em qualquer fase da vida humana, sendo uma o período do climatério, ajudando a promover uma nova cultura de cuidado, bem como fortalecer o vínculo terapeuta-paciente, o empoderamento do indivíduo e o seu protagonismo no processo de cura, possuindo assim um grande potencial desmedicalizador, porém não concorrem com os tratamentos convencionais, apenas complementam e possibilitam um olhar integrativo na saúde (COFFITO, 2020). A Fisioterapia tem poder de ação e conhecimento para atender a população feminina tanto no caráter clínico, quanto ao não clínico, fazendo uso das PICS principalmente da aromaterapia.

A aromaterapia é definida como uma terapia que utiliza óleos essenciais aromáticos, extraídos de diversas partes das plantas, e que podem ser absorvidos pelo por via oral, tópica ou inalado (BABAKHANIAN et al., 2018). Portanto a utilização dos óleos essenciais vem sendo difundido cada vez mais com o passar do tempo pois são misturas naturais complexas de compostos voláteis considerados como agentes multifuncionais (CAPUTO et al., 2018).

Sobretudo estudos referem que a utilização óleo essencial de Lavanda angustifolia associado a aromaterapia auxilia na redução de dor (JARUZEL et al., 2019), ansiedade/depressão (XIONG et al., 2018), problemas com sono (NASIRI; MAHMODI, 2018), atividades antimicrobiana, antisséptica, antifúngica (CHRYSARGYRIS; PANAYIOTOU; TZORTZAKIS, 2016), bem como efeitos imunomoduladores (MALCOLM; TALLIAN, 2017).

Além disso o óleo essencial de Lavandula angustifolia (L. angustifólia) apresenta diversos componentes, sendo que dois deles são considerados principais, o linalol e o acetato de linalila (SADANI; SHAKERI, 2016). Tais componentes são responsáveis pelas atividades antidepressivas, sedativas e antioxidantes proporcionadas pelo óleo de lavanda (ROOZBEH et al., 2019).

As principais vias de administração do óleo essencial de lavanda (OEL) são a via inalatória, por meio de difusor eletrônico, bolas de algodão embebidas em óleo e inalador nasal, a via tópica, ao exemplo das massagens, e a via oral, na forma de comprimido ou chás (GREENBERG; SLYER, 2018; MALCOLM; TALLIAN, 2017; LÓPEZ et al., 2017; KIM, 2016). Todas as vias direcionam o estímulo para o sistema nervoso central, chegando até o sistema límbico, responsável pelo controle da memória, emoção, impulsos e reações instintivas (FRANCO, 2016). Os óleos essenciais utilizados por via inalatória, apresentam efeitos psicológicos, devido ao fato da amígdala e hipocampo terem ação sobre a memória e a emoção, podendo elas serem acessadas pelas entradas límbicas do bulbo olfativo (MALCOLM; TALLIAN, 2017). O OEL é absorvido minutos após sua inalação, atingindo um nível plasmático máximo em 60 a 90 minutos (SAYED et al., 2020).

Foi demonstrado através da meta-análise de Salehi-Pourmehr et al. (2020) que a aromaterapia usando OEL (L. angustifolia Mill ou L. intermedia Loisel) se mostra eficaz para a melhora de sintomas da menopausa em mulheres entre 45-65 anos, pois os autores do estudo, acreditam que o linalol, um de seus componentes, parece inibir a ligação do glutamato, podendo torná-la atuante como sedativo e ansiolítico. No estudo de revisão sistemática de Roozbeh et al. (2019), a lavanda (Lavandula angustifolia) em forma de cápsula (500mg) ou aromaterapia (inalação por meio de difusor, travesseiro ou algodão embebido em óleo) se mostrou eficaz em mulheres na menopausa para a melhora de sintomas como a qualidade do sono e ansiedade.

\section{CONCLUSÃO}

De forma fácil e saudável, a efetividade do uso de OEL traz diversos benefícios para a população de mulheres climatéricas, tem melhor ação principalmente para a redução de ansiedade, estresse e depressão. 


\section{REFERÊNCIAS}

[1] BABAKHANIAN, M., et al. Effect of Aromatherapy on the Treatment of Psychological Symptoms in Postmenopausal and Elderly Women: a systematic review and meta-analysis. Journal Of Menopausal Medicine. v. 24, n. 2, p. 127, 2018. http://dx.doi.org/10.6118/jmm.2018.24.2.127.

[2] Brasil - Ministério da Saúde: Manual de Atenção à Mulher no Climatério / Menopausa. Ministério da Saúde. Brasília - DF, 2008. Disponível em:

<https://bvsms.saude.gov.br/bvs/publicacoes/manual_atencao_mulher_climaterio.pdf>. Acesso em: 13/05/2020.

[3] Brasil, Ministério da Saúde. Portaria no 971 de 03 de maio de 2006, aprova a Política Nacional de Práticas Integrativas e Complementares (PNPIC) no Sistema Único De Saúde. Ministério da Saúde; 2006 Disponível em: http://bvsms.saude.gov.br/bvs/saudelegis/gm/2006/prt0971_03_05_2006.html

[4] Brasil. Ministério da Saúde. Portaria no 849, de 27 de março de 2017. Inclui a Arteterapia, Ayurveda, Biodança, Dança Circular, Meditação, Musicoterapia, Naturopatia, Osteopatia, Quiropraxia, Reflexoterapia, Reiki, Shantala, Terapia Comunitária Integrativa e Yoga à Política Nacional de Práticas Integrativas e Complementares. Diário Oficial da União. 28 Mar 2017. Ministério da Saúde; 2017. Disponível em: https://bvsms.saude.gov.br/bvs/saudelegis/gm/2017/prt0849_28_03_2017.html

[5] Brasil. Ministério da Saúde. Portaria $\mathrm{n}^{\circ}$ 702, de 21 de março de 2018. Altera a Portaria de Consolidação n⿳o 2/GM/MS, de 28 de setembro de 2017, para incluir novas práticas na Política Nacional de Práticas Integrativas e Complementares - PNPIC. Diário Oficial da União. 22 Mar 2018. Ministério da Saúde; 2018. Disponível em: http://bvsms.saude.gov.br/bvs/saudelegis/gm/2018/prt0702_22_03_2018.html

[6] CAPUTO, Lucia et al. Lavandula angustifolia essential oil and linalool counteract social aversion induced by social defeat. Molecules, v. 23, n. 10, 2018.

[7] CHRYSARGYRIS, Antonios; PANAYIOTOU, Christakis; TZORTZAKIS, Nikos. Nitrogen and phosphorus levels affected plant growth, essential oil composition and antioxidant status of lavender plant (Lavandula angustifolia Mill.). Industrial Crops \& Products, v. 83, p. 577-586, 2016

[8] COFFITO - Práticas Integrativas e Complementares em Saúde - PICS. Brasil, 2020. Disponível em: <https://coffito.gov.br/campanha/pics/index.php?nome=principal>. Acesso em: 08/05/2020.

[9] CONTE, F.A.; FRANZ, L.B.B.; IDALÊNCIO, V.H. Compulsão alimentar e obesidade no climatério: uma revisão de literatura. ABCS Health Sciences. v. 39, n. 3, p. 199-203, 2014. https://doi.org/10.7322/abcshs.v39i3.656.

[10] DACAL, Maria del Pilar Ogando; SILVA, Irani Santos. Impactos das práticas integrativas e complementares na saúde de pacientes crônicos. Saúde em Debate, v. 42, n. 118, p. 724-735, 2018.

[11] DOMINGOS, T.S.; BRAGA, E.M. Massage with aromatherapy: effectiveness on anxiety of users with personality disorders in psychiatric hospitalization. Revista da Escola de Enfermagem da Usp. v. 49, n. 3, p. 450-456, 2015. http://dx.doi.org/10.1590/S0080-623420150000300013.

[12] DUARTE, Gleison V.; TRIGO, Ana Claúdia Moura; PAIM DE OLIVEIRA, Mária De Fátima. Skin disorders during menopause. Cutis, v. 97, n. 2, p. E16-E23, 2016.

[13] FEITOSA, Maria Helena Alves et al. Inserção do Conteúdo Fitoterapia em Cursos da Área de Saúde. Revista Brasileira de Educação Médica, v. 40, n. 2, p. 197-203, 2016.

[14] FRANCO, L., et al. Both lavender fleur oil and unscented oil aromatherapy reduce preoperative anxiety in breast surgery patients: A randomized trial. Journal of Clinical Anesthesia. v. 33, p. 243-249, 2016. http://dx.doi.org/10.1016/j.jclinane.2016.02.032.

[15] GREENBERG, M.J.; SLYER, J.T. Effectiveness of Silexan oral lavender essential oil compared to inhaled lavender essential oil aromatherapy for sleep in adults. Jbi Database Of Systematic Reviews And Implementation Reports. v. 16, n. 11, p. 2109-2117, 2018. https://doi.org/10.11124/jbisrir-2017-003823.

[16] GREENDALE, G.A.; KARLAMANGLA, A. S.; MAKI, P. M. The Menopause Transition and Cognition. JAMA. v. 323, n. 15, p. 1495-1496, 2020. https://doi.org/10.1001/jama.2020.1757.

[17] HABIMORAD, Pedro Henrique Leonetti et al. Implementation of brazil's national policy on complementary and integrative practices: Strengths and weaknesses. Ciencia e Saude Coletiva, v. 25, n. 2, p. 395-405, 2020.

[18] JARUZEL, Candace B. et al. Aromatherapy for Preoperative Anxiety: A Pilot Study. Journal of Perianesthesia Nursing. v. 34, n. 2, p. 259-264, 2019.

[19] JEHAN, S., et al. Sono, melatonina e a transição da menopausa: quais são os links? Sleep Science. v. 10, n. 1, p. 11-18, 2017. https://doi.org/10.1590/S0101-60832006000200010.

[20] KAZEMZADEH, Rafat et al. Effect of lavender aromatherapy on menopause hot flushing: A crossover randomized clinical trial. Journal of the Chinese Medical Association, v. 79, n. 9, p. 489-492, 2016. 
[21] KIM, D.W., et al. Integrative Evaluation of Automated Massage Combined with Thermotherapy: physical, physiological, and psychological viewpoints. Biomed Research International. v. 2016, p. 1-8, 2016. http://dx.doi.org/10.1155/2016/2826905.

[22] KINGSBERG, S.A.; LARKIN, L.C.; LIU, J.H. Clinical Effects of Early or Surgical Menopause. Obstetrics \& Gynecology. v. 135, n. 4, p. 853-868, 2020. http://dx.doi.org/10.1097/aog.0000000000003729.

[23] LIMA, A.M., et al. Perda de qualidade do sono e fatores associados em mulheres climatéricas. Ciência \& Saúde Coletiva. v. 24, n. 7, p. 2667-2678, 2019. https://doi.org/10.1590/1413-81232018247.19522017.

[24] LÓPEZ, V., et al. Exploring Pharmacological Mechanisms of Lavender (Lavandula angustifolia) Essential Oil on Central Nervous System Targets. Frontiers in Pharmacology. v. 8, n. 280, p. 1-8, 2017. https://doi.org/10.3389/fphar.2017.00280

[25] LIU, Chi Feng; CHIEN, Li Wei; CHENG, Su Li. The effect of lavender aromatherapy on autonomic nervous system in midlife women with insomnia. Evidence-based Complementary and Alternative Medicine, v. 2012, p. 01-08, 2012.

[26] MAHESHWARI, PK et al. Understanding Climacteric Depression and Depression in Other Phases of a Women's Life. The Journal of South Asian Federation of Menopause Societies, v. 3, n. 1, p. 20-23, 2015.

[27] MALCOLM, B.J.; TALLIAN, K. Essential oil of lavender in anxiety disorders: Ready for prime time? Mental Health Clinician. v. 7, n. 4, p. 147-155, 2017. http://dx.doi.org/10.9740/mhc.2017.07.147.

[28] MOLINA, M.R.A.L., et al . Prevalência de depressão em usuários de unidades de atenção primária. Revista de Psiquiatria Clínica. v. 39, n. 6, p. 194-197, 2012. http://dx.doi.org/10.1590/S0101-60832012000600003.

[29] NASCIMENTO, Maria do Carmo et al. A profissionalização da fisioterapia em Minas Gerais. Brazilian Journal of Physical Therapy, v. 10, n. 2, p. 241-247, 2006. https://doi.org/10.1590/S1413-35552006000200016.

[30] NASIRI, A.; MAHMODI, M. A. Aromatherapy massage with lavender essential oil and the prevention of disability in ADL in patients with osteoarthritis of the knee: A randomized controlled clinical trial. Complementary Therapies in Clinical Practice, v. 30, p. 116-121, 2018.

[31] NAVES, Cristiane Roberta; BRICK, Vanessa de Souza. Análise quantitativa e qualitativa do nível de conhecimento dos alunos do curso de fisioterapia sobre a atuação do fisioterapeuta em saúde pública. Ciência \& Saúde Coletiva, v. 16, p. 1525-1534, 2011. https://doi.org/10.1590/S1413-81232011000700088.

[32] NEVES, Laura Maria Tomazi; ACIOLE, Giovanni Gurgel. Desafios da integralidade: revisitando as concepções sobre o papel do fisioterapeuta na equipe de Saúde da Família. Interface-Comunicação, Saúde, Educação, v. 15, p. 551$564,2011$.

[33] ROOZBEH, N., et al. Effect of Lavender on Sleep, Sexual Desire, Vasomotor, Psychological and Physical Symptom among Menopausal and Elderly Women: a systematic review. Journal of Menopausal Medicine. v. 25, n. 2, p. 88, 2019. http://dx.doi.org/10.6118/jmm.18158.

[34] SADANI, S; SHAKERI, A. Antimicrobial activity of the essential oils of Lavandula stoechas flowers extracted by microwave. Journal of Medicinal Plants Studies. v. 4, n. 3, p. 224-228, 2016.

[35] SALEHI-POURMEHR, H., et al. Does aromatherapy with lavender affect physical and psychological symptoms of menopausal women? A systematic review and meta-analysis. Complementary Therapies in Clinical Practice. v. 39, p. 101150, 2020. http://dx.doi.org/10.1016/j.ctcp.2020.101150.

[36] SAYED, A.M., et al. The best route of administration of lavender for anxiety: a systematic review and network meta-analysis. General Hospital Psychiatry. v. 64, p. 33-40, 2020. https://doi.org/10.1016/j.genhosppsych.2020.02.001.

[37] SOUZA GUERRA, Geraldo Edson et al. Quality of life in climacteric women assisted by primary health care. PLoS ONE, v. 14, n. 2, p. 1-13, 2019.

[38] XIONG, Mei et al. Effectiveness of aromatherapy massage and inhalation on symptoms of depression in Chinese community-dwelling older adults. Journal of Alternative and Complementary Medicine, v. 24, n. 7, p. 717-724, 2018. 


\section{Capítulo 9}

Violência por parceiro íntimo em mulheres atendidas em uma maternidade de referência: Prevalência, repercussões na saúde e acompanhamento pré-natal

\section{Luciana Maia Santos}

\section{Benvinda Matias Dantas Neta}

Iandra Sara dos Santos Ferreira

Ana Karoline Brito dos Santos

Luzimara Gomes Melo

Rosely Cabral de Carvalho

Resumo: Objetivo: Analisar a prevalência, a presença de problemas de saúde referidos e associados à violência por parceiro íntimo na gestação e acompanhamento pré-natal em mulheres em uma maternidade de referência, em Feira de Santana, Bahia. Método: estudo transversal, com dados primários socioeconômicos, demográficos, gineco-obstétricos das mulheres e itens do Abuse Assessment Screening (AAS), com 324 puérperas atendidas em uma maternidade de referência. Resultados: A prevalência de violência por parceiro íntimo na gestação foi de 21,0\%. A maioria das puérperas tinha idade superior a 19 anos, eram casadas ou tinham união estável, totalmente dependência financeira dos seus parceiros, com renda inferior a um salário mínimo, tiveram dois a três companheiros. Em relação aos problemas de saúde e achados gineco-obstétricos referidos foram cefaleias constantes, falta de apetite, problemas gástricos, depressão, hipertensão arterial sistêmica, diabetes mellitus, infecção do trato urinário, hemorragia vaginal e rotura prematura de membranas ovulares, dentre outros, $75,1 \%$ das mulheres do estudo iniciaram o prénatal no primeiro trimestre, os dados de acompanhamento do pré-natal das mulheres em situação de VPI $70,8 \%$ iniciaram o pré-natal no primeiro trimestre. Em se tratando da rede de serviços $77 \%$ das mulheres não procuraram nenhum serviço de saúde, no entanto a rede de apoio familiar obteve destaque com suporte para essas mulheres. 0 estudo não mostrou nenhuma associação significativa da violência com o acompanhamento pré-natal. Considerações finais: A violência por parceiro íntimo durante a gestação traz implicações importantes na saúde das gestantes e crianças, o que reforça a necessidade de sensibilizar profissionais que trabalham em diferentes contextos de saúde, para notificação dos casos e que possam planejar medidas de prevenção.

Palavras-Chave: Violência por parceiro íntimo. Gestação e pré-natal. Problemas de saúde. Antecedentes gineco-obstétricos. 


\section{INTRODUÇÃO}

A violência por parceiro íntimo (VPI) é definida como qualquer comportamento que cause mal físico, psicológico ou sexual, como atos de agressão física, abuso psicológico, comportamentos controladores, relações sexuais forçadas ou outras formas de coerção sexual (OMS, 2002).

No Brasil, apesar da atuação dos movimentos feministas e de mulheres no enfrentamento das violências e de todos os avanços legais e institucionais nas últimas décadas, este fenômeno ainda atinge milhares de mulheres no país, com altos níveis de ocorrência na maioria dos estados brasileiros (ANDRADE; ALMEIDA, 2017).

A violência contra a mulher deve ser entendida a partir da estrutura patriarcal construída historicamente na sociedade, que legitima a prática desta violência e torna essa violação de direito humano invisível na sociedade. Devido ao caráter cíclico da violência, além da grave morbidade para a mulher, a violência se torna potencialmente letal na evolução deste ciclo (ÁVILA, 2017).

A VPI na gestação tem sido considerada importante questão de saúde, pois seus agravos incluem diversas repercussões na saúde e qualidade de vida da mãe e bebê, tais como: trabalho de parto prematuro, hemorragias, baixo peso ao nascer, abortamento, ruptura prematura de membranas, morte materna, transtornos mentais (MARQUES et al., 2017). Dessa forma a violência é reconhecida como problema global de saúde pública, desde o 49oAssembleia Mundial da Saúde em 1996 e empreendidos esforços para compreensão dos fatores associados a essa violência.

Os programas atuais de prevenção se concentram em um único nível dos três níveis possíveis de ação. Esses níveis englobam estratégias primárias, secundárias e terciárias. A primeira estratégia visa prevenir a VPI antes que ela ocorra, a segunda direcionada a resposta imediata a VPI depois de ocorreu, enquanto a terceira concentra as ações em cuidados após a VPI. Nas últimas décadas, a maioria dos financiamentos e recursos foram direcionados para esforços terciários (WHO, 2010).

A VPI está presente em todos os períodos da vida das mulheres, incluindo a gravidez e pós-parto, e pode ocasionar consequências para a saúde das mães e das pessoas que delas dependem, implicando em várias consequências para saúde materna e neonatal.

A assistência pré-natal deve propor avaliação dinâmica das situações de riscos clínicos e sociais voltados a gestação e puerpério com suas ações e atividades direcionadas à identificação de problemas e atuação frente a estes, e dependendo do problema encontrado, impedir um resultado desfavorável tanto à mulher como seu filho. A presença mais frequente da gestante nos serviços de saúde pode gerar um vínculo maior com a equipe e favorecer a identificação dos casos de violência. Porém, a maior parte dos casos não é registrada, o que garante a invisibilidade da situação e maior risco para a mulher e o bebê (MARQUES et al., 2017).

Para Borsoi, Brandão e Cavalcanti (2009) os serviços de saúde, por estarem no cotidiano das mulheres devem ser um local de acolhimento e apoio ao invés de se tornarem um obstáculo na vida das mesmas, em especial as que estão em situação de opressão. Deve-se ainda considerar a atenção primária como um local privilegiado para realização de ações de prevenção, acompanhamento e orientação sobre o tema violência, tendo em vista o aumento dessa cobertura nos serviços de saúde, em ações voltadas ao pré-natal, assistência ao parto e puerpério, o que permite maior disseminação de ações de enfrentamento e apoio emocional às mulheres em situação de violência por parceiros íntimos e suas famílias.

Este artigo tem como objetivo analisar a prevalência da violência entre parceiros íntimos, a presença de problemas de saúde referidos e associados à violência por parceiro íntimo na gestação e o acompanhamento de mulheres nos serviços pré-natal em uma maternidade de referência em Feira de Santana, Bahia.

\section{MÉTODO}

Estudo de corte transversal, realizado no Hospital da Mulher, referência em urgências e emergências obstétricas, em Feira de Santana, Bahia.

Participaram do estudo puérperas com 24 horas de pós-parto, atendidas na referida Instituição, tendo como critérios de exclusão mulheres no pós-parto imediato, óbitos fetais e as que tinham problemas psiquiátricos. Trabalhou-se com uma amostra de 324 mulheres calculada a partir do total de 5.888 partos, 
no ano de 2015, com frequência esperada de 24,3\% da violência doméstica na gestação. Erro amostral de $5 \%$ e intervalo de confiança de $95 \%$.

Os dados foram coletados entre os meses de maio a julho de 2016, por meio de um questionário adaptado, aplicado em sala reservada, contendo variáveis socioeconômicas e demográficas (faixa etária da mulher e companheiro, escolaridade, estado civil, trabalho fora de casa, ocupação da mulher e companheiro, dependência financeira da mulher, renda familiar), variáveis gineco-obstétricas (início da vida sexual, presença de aborto, número de gestações e partos, consultas pré-natal, intercorrências obstétricas). A variável dependente foi a presença de violência doméstica ou não. As questões relacionadas à violência doméstica foram formuladas, utilizando-se como referência o questionário padronizado e validado no Brasil Abuse Assessment Screening (AAS) e adaptado e revalidado para a população em estudo, em maternidade de referência na cidade de Salvador, Bahia (REICHENHEIM; MORAES; HASSELMANN, 2000; SENA, 2014).

Os dados foram digitados duplamente com realização de validação no Epidata, armazenados, utilizando-se o pacote estatístico IBM SPSS, versão 20. Foi realizada uma análise descritiva, com distribuição das frequências para variáveis qualitativas, cálculo de média, mediana e desvio padrão para variáveis quantitativas. Na análise bivariada, foi aplicado teste Qui quadrado de Pearson, para identificar associações estatísticas entre as variáveis de estudo com um nível de significância de 5\% e IC 95\%.

A análise multivariada foi realizada no programa estatístico STATA, versão 10.0, através do modelo de regressão logística e com ajuste de variáveis que obtiveram o valor de $p<0,05$, tendo como medida de efeito razão de chances (OR), com IC 95\% e logo após, realizado testes para diagnóstico do modelo de regressão logística com resultados satisfatórios.

Esta pesquisa é resultado de uma dissertação de mestrado do Programa de Pós-Graduação em Saúde Coletiva da Universidade Estadual de Feira de Santana (UEFS), que recebeu aprovação do Comitê de Ética em Pesquisa da UEFS, com CAAE 51273915.0.0000.0053 e n. de protocolo 1.524.705.

\section{RESULTADOS E DISCUSSÃO}

As características socioeconômicas e demográficas de mulheres atendidas em uma maternidade de referência apresentadas tratam-se de um estudo com 324 puérperas na sua maioria com idade superior a 19 anos $(82,1 \%)$. Nos dados da Tabela 1 verifica-se que a maioria se autodeclarou negra (92\%), e casada ou tinha união estável $(78,7 \%)$.

Ainda na Tabela 1 em relação a escolaridade a maioria relatou ensino médio completo (59\%), não exerciam trabalho remunerado (62,3\%), totalmente dependente (54,3\%), renda inferior a 1 salário mínimo (50,6\%). Em relação a idade do companheiro há um predomínio da idade inferior a 29 anos $(55,3 \%)$, em relação a ocupação do companheiro a maioria exercia atividade remunerada informal $(47,1 \%)$.

Os dados da Tabela 1 se aproximam dos resultados de estudos realizados por Marcacine et al. (2018) onde a maioria das puérperas tinham idade superior a 29 anos, ensino médio $(67,1 \%)$, a maioria não exercia atividade remunerada $(54,6 \%)$ e os companheiros eram os principais profissionais da família $(50,2 \%)$. Entretanto, em relação a esse estudo diverge quando comparado a renda mensal entre um a três salários mínimos (56,5\%), na idade companheiros onde a maioria tinha 31 anos e referente ao trabalho formal $(61,8 \%)$.

Nesse estudo a prevalência de VPI na gestação foi de 21\%. Resultado que se assemelha ao realizado por Telles et al. (2016) no Japão (20,7\%). Obtendo um valor superior aos estudos realizado por Oliveira et al. (2015) que evidenciou uma prevalência de 17,6\%, e inferior ao realizado por Ludermir et al. (2010), que evidenciou 30,7\% e Marcacine et al. (2018) com prevalência de 36,7\%. 
Tabela 1 Características socioeconômicas e demográficas de mulheres atendidas em uma maternidade de referência, em Feira de Santana, Bahia, 2016.

\begin{tabular}{|c|c|c|}
\hline \multicolumn{3}{|l|}{ Variáveis } \\
\hline Idade da mulher em anos $(n=324)$ & $\mathrm{N}$ & $\%$ \\
\hline$\leq 19$ & 58 & 17,9 \\
\hline$>19$ & 266 & 82,1 \\
\hline Raça/cor (n=323) & $\mathrm{N}$ & $\%$ \\
\hline Negra (preto + parda) & 297 & 92,0 \\
\hline Outras (branca + amarela) & 26 & 8,0 \\
\hline \multicolumn{3}{|l|}{ Estado Civil $(\mathrm{n}=324)$} \\
\hline Casada + União estável & 255 & 78,7 \\
\hline Solteira & 67 & 20,7 \\
\hline Outros & 02 & 0,6 \\
\hline Escolaridade $(n=324)$ & $\mathrm{N}$ & $\%$ \\
\hline Ensino fundamental & 112 & 34,6 \\
\hline Ensino Médio & 191 & 59,0 \\
\hline Ensino Superior & 21 & 6,4 \\
\hline Trabalho fora de casa $(n=324)$ & $\mathrm{N}$ & $\%$ \\
\hline Sim & 122 & 37,7 \\
\hline Não & 202 & 62,3 \\
\hline Ocupação da mulher (n=324) & $\mathrm{N}$ & $\%$ \\
\hline Desempregada & 30 & 9,2 \\
\hline Trabalho informal & 63 & 19,4 \\
\hline Trabalho formal & 65 & 20,1 \\
\hline Outros & 166 & 51,3 \\
\hline Dependência financeira da mulher $(n=324)$ & $\mathrm{N}$ & $\%$ \\
\hline Independente & 70 & 21,6 \\
\hline Parcialmente dependente & 78 & 24,1 \\
\hline Totalmente dependente & 176 & 54,3 \\
\hline Renda familiar (salários mínimos) (n=281) & $\mathrm{N}$ & $\%$ \\
\hline$\leq 1$ & 164 & 50,6 \\
\hline $1-2$ & 105 & 32,4 \\
\hline$>2$ & 55 & 17,0 \\
\hline Idade do companheiro $(n=309)$ & $\mathrm{N}$ & $\%$ \\
\hline$\leq 29$ & 171 & 55,3 \\
\hline$>29$ & 138 & 44,7 \\
\hline Ocupação do companheiro(n=312) & $\mathrm{N}$ & $\%$ \\
\hline Desempregado & 25 & 8,0 \\
\hline Trabalho informal & 147 & 47,1 \\
\hline Trabalho formal & 130 & 41,7 \\
\hline Outros & 10 & 3,2 \\
\hline
\end{tabular}

Fonte: Banco de dados da pesquisa original.

Na Tabela 2 os resultados apresentados sobre as informações dos companheiros, demonstram que a maioria das mulheres com VPI na gestação tiveram dois a três companheiros $(95,6 \%)$, tendo estes a idade entre vinte a vinte nove anos (38\%) e exerciam atividade remunerada com emprego fixo (41,2\%). Referente ao número de filhos com o companheiro atual relataram que tiveram um filho (70,6\%).

Os resultados desse estudo referente a idade do companheiro se assemelham ao estudo realizado por Audi et al. (2008) sendo a maioria maior que 19 anos (91,5\%).

No Gráfico 1 foram apresentados os problemas de saúde referidos em decorrência a VPI na gestação, identificou que a maior parte relatou cefaleias constantes $(20,5 \%)$ e falta de apetite $(20,5 \%)$. Em menor proporção diminuição da libido $(16,9 \%)$, depressão $(12,1 \%)$, contrações na barriga $(7,2 \%)$, HAS $(6 \%)$, problemas gástricos $(4,8 \%)$ e hemorragia $(4,8 \%)$. 
Tabela 2 Características de VPI e informações do companheiro de mulheres atendidas em uma maternidade de referência, em Feira de Santana, Bahia, 2016.

\begin{tabular}{|c|c|c|c|c|}
\hline \multirow{3}{*}{ Variáveis } & \multicolumn{4}{|c|}{ Presença de violência } \\
\hline & \multirow{2}{*}{$\begin{array}{c}\text { Sim } \\
\mathrm{N}\end{array}$} & \multicolumn{3}{|c|}{ Não } \\
\hline & & $\%$ & $\mathrm{~N}$ & $\%$ \\
\hline \multicolumn{5}{|c|}{ Número de companheiros } \\
\hline $2-3$ & 65 & 95,6 & 253 & 98,8 \\
\hline Mais de 4 & 3 & 4,4 & 3 & 1,2 \\
\hline \multicolumn{5}{|c|}{ Idade do companheiro atual } \\
\hline 16 a 19 & 4 & 5,9 & 14 & 5,5 \\
\hline 20 a 29 & 26 & 38,2 & 127 & 49,6 \\
\hline $30-39$ & 20 & 29,4 & 75 & 29,3 \\
\hline $40-49$ & 8 & 11,8 & 30 & 11,7 \\
\hline 50 ou mais & 2 & 2,95 & 3 & 1,2 \\
\hline Não se aplica & 6 & 8,8 & 5 & 1,9 \\
\hline Ignorado & 2 & 2,95 & 2 & 0,8 \\
\hline \multicolumn{5}{|c|}{ Ocupação do companheiro } \\
\hline Desempregado & 5 & 7,4 & 20 & 7,8 \\
\hline Autonômo & 26 & 38,2 & 121 & 47,3 \\
\hline Emprego Fixo & 28 & 41,2 & 102 & 39,8 \\
\hline Outro & 2 & 2,9 & 8 & 3,1 \\
\hline Nao Se Aplica & 6 & 8,8 & 5 & 2 \\
\hline Ignorado & 1 & 1,5 & 0 & 0 \\
\hline \multicolumn{5}{|c|}{$\mathrm{N}^{\circ}$ filho companheiro atual } \\
\hline 1 & 48 & 70,6 & 158 & 61,7 \\
\hline $2-3$ & 15 & 22,1 & 85 & 33,2 \\
\hline $4 \mathrm{OU}+$ & 2 & 2,9 & 8 & 3,1 \\
\hline NÃO SE APLICA & 3 & 4,4 & 5 & 2 \\
\hline
\end{tabular}

Fonte: Banco de dados da pesquisa original.

Gráfico 1 Problemas de saúde decorrentes a VPI na gestação em uma maternidade de referência, em Feira de Santana, Bahia, 2016.

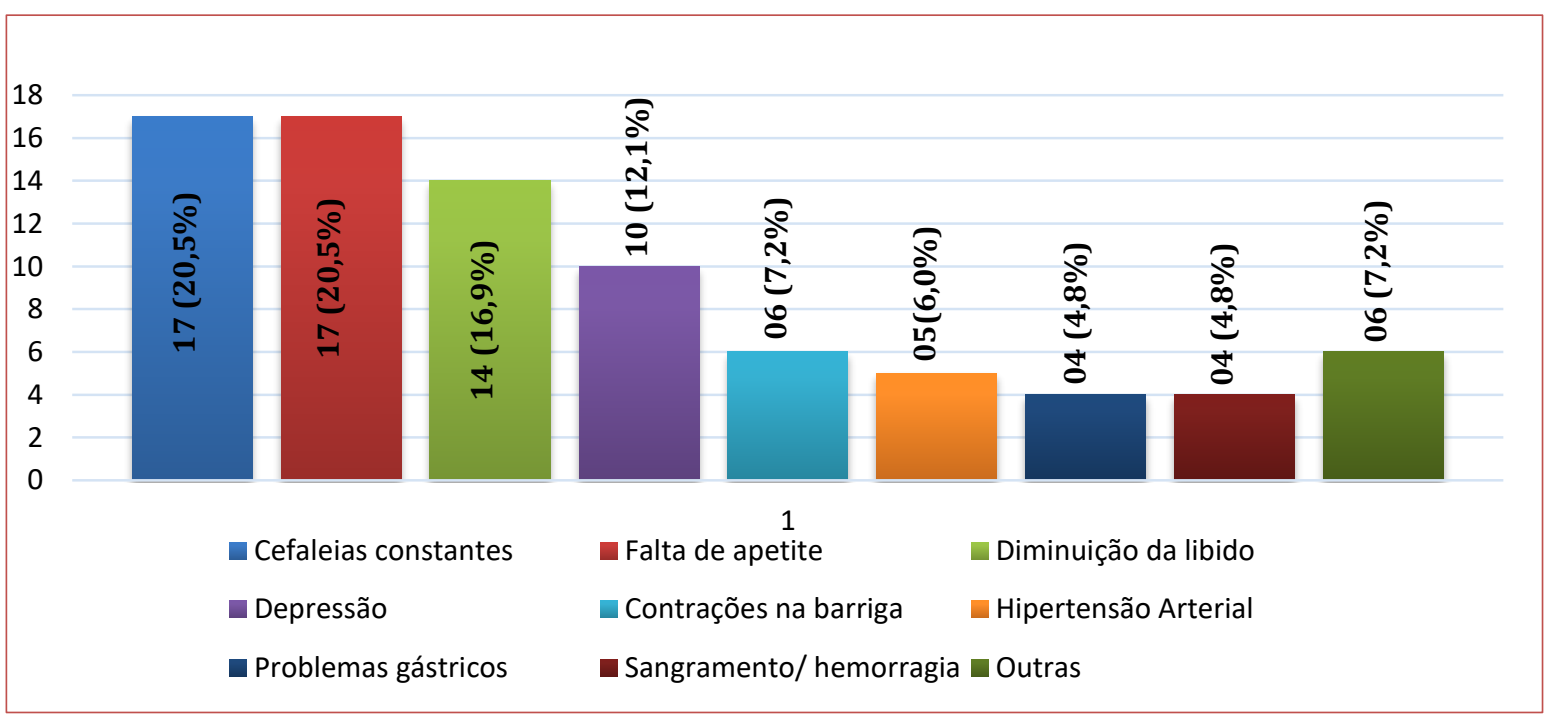

Fonte: Banco de dados da pesquisa original. 
Lamus (2019) em seu estudo identificou proporções diferentes nos achados desse estudo referentes as condições clínicas onde cerca de um terço das mulheres $(30,2 \%)$ relataram ter algum problema de saúde, e principalmente no que tange a depressão $(36,9 \%)$.

Na Tabela 3 registram os antecedentes gineco-obstétricos pregressos, tendo a maioria menarca entre onze e treze anos $(57,4 \%)$, coitarca entre 14 e 16 anos (39,7\%), maior ou igual a duas gestações $(72,1 \%$,) e um e dois filhos vivo $(67,6 \%)$. Há um predomínio das que tiveram um a dois partos $(66,2 \%)$ e minoria relatou aborto (27,9\%). A uma prevalência das que realizaram acompanhamento pré-natal (95,6\%), iniciando o acompanhamento no primeiro trimestre $(67,7 \%)$ e a realização de quatro a seis consultas pré-natais $(47,1 \%)$.

Tabela 3 Perfil de VPI e achados gineco-obstétricos pregressos em mulheres atendidas em uma maternidade de referência, em Feira de Santana, Bahia, 2016.

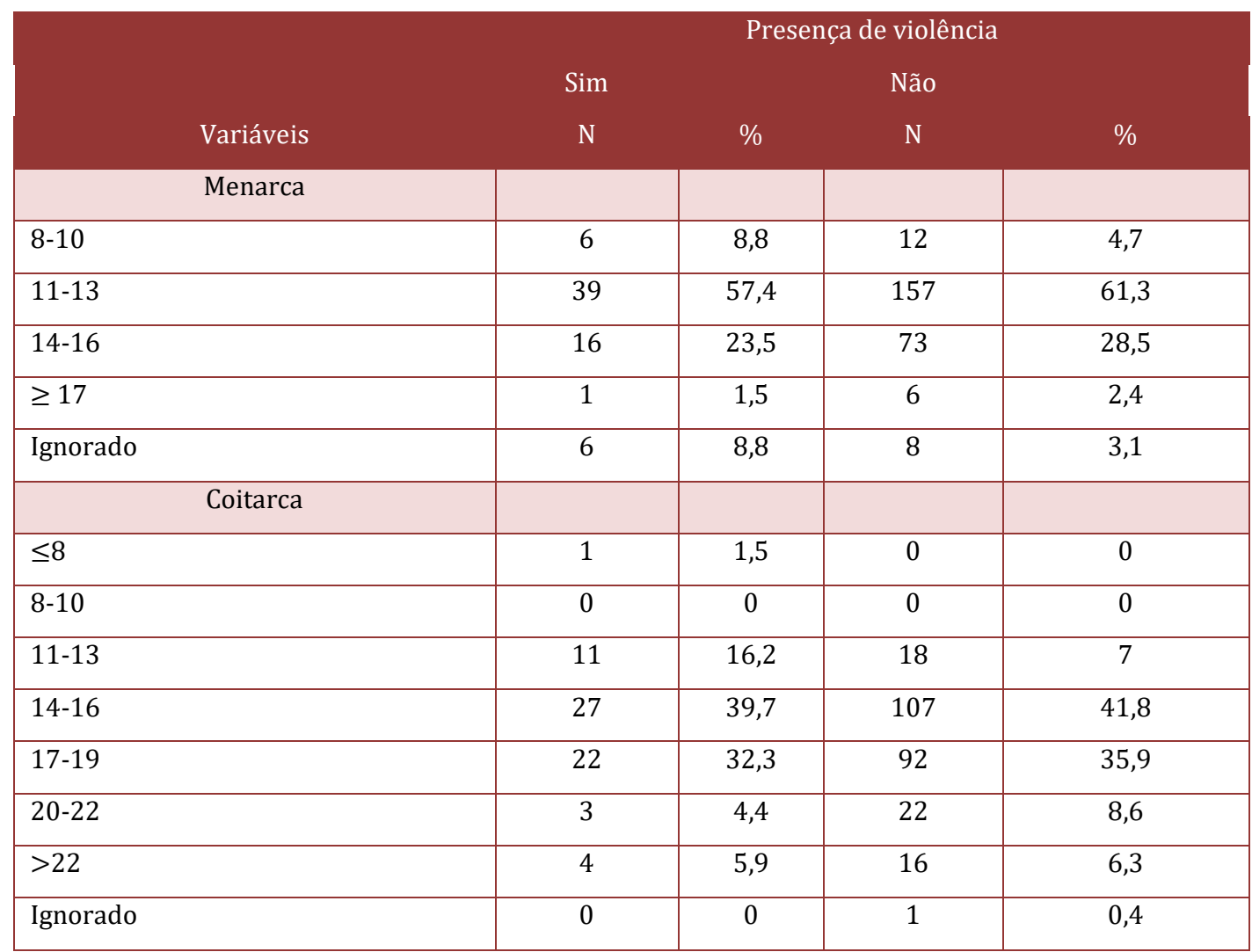


Tabela 3 Perfil de VPI e achados gineco-obstétricos pregressos em mulheres atendidas em uma maternidade de referência, em Feira de Santana, Bahia, 2016.

\begin{tabular}{|c|c|c|c|c|}
\hline & \multicolumn{4}{|c|}{ Presença de violência } \\
\hline \multirow[b]{2}{*}{ Variáveis } & \multicolumn{2}{|l|}{ Sim } & \multicolumn{2}{|l|}{ Não } \\
\hline & $\mathrm{N}$ & $\%$ & $\mathrm{~N}$ & $\%$ \\
\hline \multicolumn{5}{|c|}{ Número de gestações } \\
\hline$\leq 1$ & 19 & 27,9 & 116 & 45,3 \\
\hline$\geq 2$ & 49 & 72,1 & 140 & 54,7 \\
\hline \multicolumn{5}{|l|}{ Aborto } \\
\hline Sim & 19 & 27,9 & 41 & 16 \\
\hline Não & 49 & 72,1 & 215 & 84 \\
\hline \multicolumn{5}{|c|}{ Abortos espontâneos } \\
\hline 1 & 10 & 14,7 & 32 & 12,5 \\
\hline 2 & 2 & 2,9 & 4 & 1,6 \\
\hline 3 & 0 & 0 & 1 & 0,4 \\
\hline Não se aplica & 56 & 82,4 & 219 & 85,5 \\
\hline \multicolumn{5}{|c|}{ Abortos provocados } \\
\hline 1 & 6 & 8,8 & 1 & 0,4 \\
\hline 2 & 1 & 1,5 & 0 & 0 \\
\hline 3 & 61 & 89,7 & 255 & 99,6 \\
\hline \multicolumn{5}{|l|}{ Partos } \\
\hline $1-2$ & 45 & 66,2 & 207 & 80,9 \\
\hline $3-4$ & 19 & 27,9 & 40 & 15,6 \\
\hline$\geq 5$ & 4 & 5,9 & 9 & 3,5 \\
\hline \multicolumn{5}{|c|}{ Filhos vivos } \\
\hline $1-2$ & 46 & 67,6 & 208 & 81,3 \\
\hline $3-4$ & 18 & 26,5 & 41 & 16 \\
\hline$\geq 5$ & 4 & 5,9 & 7 & 2,7 \\
\hline \multicolumn{5}{|l|}{ Pré-natal } \\
\hline Sim & 65 & 95,6 & 252 & 98,4 \\
\hline Não & 3 & 4,4 & 4 & 1,6 \\
\hline \multicolumn{5}{|c|}{ Trimestre de pré-natal } \\
\hline 1ㅇ Trimestre & 46 & 67,7 & 192 & 75 \\
\hline 2o Trimestre & 16 & 23,5 & 53 & 20,7 \\
\hline 3o Trimestre & 3 & 4,4 & 7 & 2,7 \\
\hline Não se aplica & 3 & 4,4 & 4 & 1,6 \\
\hline \multicolumn{5}{|c|}{$\mathrm{N}^{\circ}$ de pré-natal } \\
\hline$>4$ consultas & 10 & 14,7 & 35 & 13,7 \\
\hline $4-6$ & 32 & 47,1 & 93 & 36,3 \\
\hline$\geq 7$ & 23 & 33,8 & 124 & 48,4 \\
\hline Não se aplica & 3 & 4,4 & 4 & 1,6 \\
\hline
\end{tabular}

Fonte: Banco de dados da pesquisa original.

Os resultados encontrados em nossa pesquisa possuem valores divergentes quando comparados aos estudos de Audi et al. (2008) em relação ao início da vida sexual antes dos 16 anos (59,4\%) e acompanhamento pré-natal no primeiro trimestre (79,2\%). Vale destacar que Rodrigues et al. (2014) encontrou valores inferiores na prevalência do de um a dois partos $(17,2 \%)$. Os dados encontrados nesse estudo possuem valores semelhantes a pesquisa de Marcacine et al. (2018) em relação ao número de 
consultas pré-natais inferiores a 6 consultas $(55,6 \%)$ e valores inferiores em relação a multíparas (59,9\%). Esses estudos em seus resultados apontaram que a VPI durante a gestação não interferiu no acompanhamento do pré-natal.

Dados presentes na tabela 4, sobre o perfil da VPI na gestação e achados gineco-obstétricos atuais, relataram intercorrências obstétricas $(70,6 \%)$, tendo relatado ITU $(45,6 \%)$, vulvaginites $(5,9 \%)$, amniorexe prematura (5,9\%), parto prematuro (16,2\%), IST (8,8\%) e DM (1,5\%).

Tabela 4. Perfil da VPI na gestação e achados gineco-obstétricos atuais em mulheres atendidas em uma maternidade de referência, em Feira de Santana, Bahia, 2016.

\begin{tabular}{|c|c|c|c|c|}
\hline & & Pres & ência & \\
\hline Variáveis & & & & \\
\hline & $\mathrm{N}$ & $\%$ & $\mathrm{~N}$ & $\%$ \\
\hline Intercorrências ob & & & & \\
\hline Sim & 48 & 70,6 & 183 & 71,5 \\
\hline Não & 20 & 29,4 & 73 & 28,5 \\
\hline ITU & & & & \\
\hline Sim & 31 & 45,6 & 95 & 37,1 \\
\hline Não & 37 & 54,4 & 161 & 62,9 \\
\hline Vulvovaginit & & & & \\
\hline Sim & 4 & 5,9 & 29 & 11,3 \\
\hline Não & 64 & 94,1 & 227 & 88,7 \\
\hline Anemia crôn & & & & \\
\hline Sim & 19 & 27,9 & 62 & 24,2 \\
\hline Não & 49 & 72,1 & 194 & 75,8 \\
\hline Amniorexe prem & & & & \\
\hline Sim & 5 & 5,9 & 28 & 10,9 \\
\hline Não & 64 & 94,1 & 228 & 89,1 \\
\hline Ameaça de $a b$ & & & & \\
\hline Sim & 5 & 7,4 & 21 & 8,2 \\
\hline Não & 63 & 92,6 & 235 & 91,8 \\
\hline Parto premat & & & & \\
\hline Sim & 11 & 16,2 & 37 & 14,4 \\
\hline Não & 57 & 83,8 & 219 & 85,5 \\
\hline IST's & & & & \\
\hline Sim & 6 & 8,8 & 12 & 4,7 \\
\hline Não & 62 & 91,2 & 244 & 95,3 \\
\hline DMG & & & & \\
\hline Sim & 1 & 1,5 & 2 & 0,8 \\
\hline Não & 67 & 98,5 & 254 & 99,2 \\
\hline
\end{tabular}

Fonte: Banco de dados da pesquisa original.

No gráfico 2 os dados sobre a procura da rede de serviços de atenção à saúde, pode-se observar que 77\% das mulheres em situação de violência não procuraram esses serviços, no entanto $20 \%$ procuraram os serviços de emergência e a atenção primária. Esses dados chamam atenção pelo fato da mulher ser acompanhada nos serviços de saúde como observado nas frequências (tabela 3) e não fazerem o uso devido da atenção do pré-natal para expor aos profissionais sobre as situações de violência vivenciadas na gestação.

A procura pela rede de serviços por $20 \%$ das mulheres pode também sinalizar para situações em que existiu agravamento do caso, justificando o percentual das mulheres que procuraram os serviços de atendimento de urgência (13\%). Esse achado, corrobora com o estudo de Netto et al. (2017) das 20 mulheres entrevistadas, somente sete procuraram por instituições de saúde diante das consequências da violência, os serviços que predominaram no atendimento foram as Unidades Básicas de Saúde, Clínicas da Família e Unidades de Pronto Atendimento como elementos de atuação das redes sociais de apoio.

Um fator que negligência a violência por parte dos serviços de saúde é a falta de percepção da violência nas relações íntimas como um problema de saúde, que possibilita a um processo de (re) vitimizar essas mulheres, e consequentemente um modo de adoecimento pelas vivências de situações desrespeitosas e desumanas. Dessa forma, não se sentindo acolhidas pelos profissionais de saúde e decididas a não realizar a denúncia, elas permanecem no silêncio (NETTO et al., 2017). 
Em vistas a essa não procura, a literatura traz que muitas vezes, as mulheres em situação de violência se inibem e não procuram os serviços de saúde, por temerem o risco de serem expostas a seus conflitos mais íntimos e muitas vezes a presença do agressor no próprio domicílio (ANDRADE et al., 2016).

Segundo Santi, Nakamo e Lettiere (2010) o uso dos serviços se processa através da consciência e gravidade em situação, ou seja: "procuram primeiramente compreender intrinsecamente a violência; depois procuram profissionais, tanto da justiça quanto da saúde; e, também, buscam respaldo na família e/ou amigos de modo a se cuidarem e serem cuidadas, o que lhes parece de maior importância no alívio da dor".

Marques et al. (2017) trazem que a violência continua sendo um tabu para as mulheres e muitas vezes para os prestadores de serviços de saúde, por ser um caso íntimo e doloroso que deve ser resolvido na esfera doméstica. E essa postura indica que os serviços estão se afastando da responsabilidade de enfrentar a problemática e as mulheres gestantes se apresentam ainda mais vulneráveis diante da fragilidade demonstrada por esses serviços na detecção e enfrentamento dos casos.

A VPI enquanto problema de saúde pública não tem reduzido e, apesar de estar presente cotidianamente na rotina dos serviços de saúde, o desconhecimento dos profissionais do setor sobre o problema e seu enfrentamento contribui significativamente para a subnotificação. É possível que as ações de prevenção e cuidado careçam de maior integração dos setores envolvidos, entendendo-se que a prática de medidas precisa ser inclusiva e ampla (BARROS et al., 2016).

Gráfico 2 - Rede de serviços procuradas por mulheres em situação de violência atendidas no Hospital da Mulher, em Feira de Santana, Bahia.

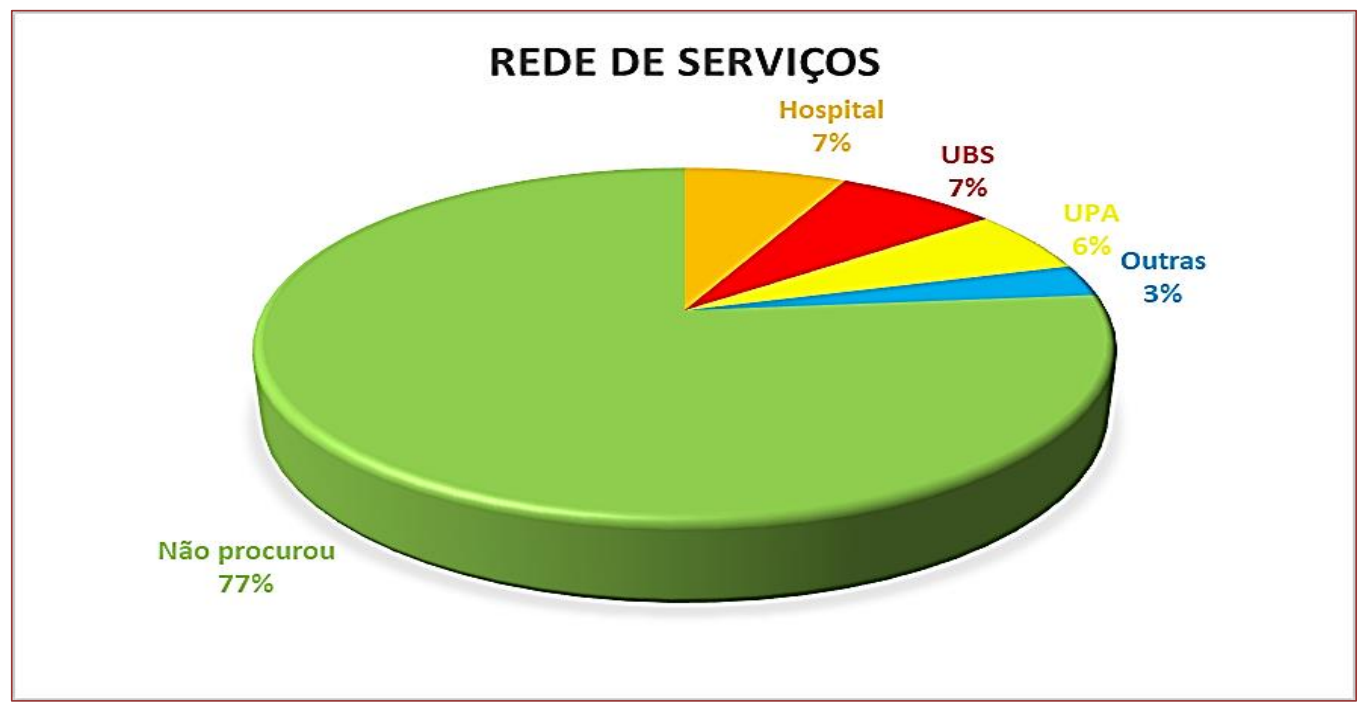

Fonte: Banco de dados da pesquisa original.

Na tabela 5 os dados de perfil da rede de apoio a mulheres em situação de violência, destaca-se o suporte e a presença de outras mulheres nesse acompanhamento como 27 mães (27,8\%) e 21 amigas (o)s (20,4\%), o que totaliza (48,2\%). Verificou-se também outros percentuais menores de relações parentais consanguínea constituindo a rede de apoio como, irmão (a)s 17 (16,5\%) e pai $11(10,8 \%)$.

Corroborando com esses achados, Rocha, Galeli e Antoni (2019) em seu estudo sobre a rede de apoio social e afetiva de mulheres que vivenciaram violência verificaram que a maioria das mulheres refere a presença de familiares e amigos como a rede mais importante e decisiva para interrupção do ciclo de violência e para o término da relação abusiva por meio da oferta de possibilidades de ação e do suprimento de ajuda, sendo os principais provedores de apoio, onde são essas as pessoas que estão mais envolvidas com elas durante a situação de violência.

Esses resultados apontam para a presença de mulheres e familiares como rede de apoio, reforçando outros estudos, onde o apoio da família se torna necessário frente ao acolhimento à vítima, bem como ao suporte no momento de desamparo (ACOSTA et al., 2015). 
Netto et al. (2017) em sua pesquisa com 20 mulheres vítimas de violência por parceiro íntimo atendidas no Centro Especializado de Atendimento do Rio de Janeiro trazem que a naturalização da violência pelos parentes e amigos tende a culpabilizar a mulher pelos atos de violência de seus parceiros, desta forma, essa mulher que não tem o apoio na rede primária vai buscar as instituições da rede secundária como as delegacias, os postos de saúde, hospitais e centros de atendimento especializados.

Os autores denominam rede de apoio como uma teia de relacionamentos interpessoais que atua com promotora de adaptação das pessoas ao prover apoio social, emocional e informativo. Em se tratando de violência, a ajuda/apoio para as mulheres vítimas desse agravo é encontrado na rede primária. (NETTO et al., 2017)

Para Santi, Nakamo e Lettiere (2010) em seu estudo com 57 mulheres vítimas de violência doméstica do tipo lesão corporal dolorosa, que foi desenvolvido no Instituto Médico Legal de Ribeirão Preto trazem que, buscar ajuda na família demonstra que os papéis de gênero tradicionais têm grande influência na percepção e reação em situações de violência. Dessa forma, a busca pelo apoio das famílias, antes mesmo da instituição, é trazida como estratégia de autoproteção, a fim de evitar outra vitimização, uma vez que os membros da família cuidam uns dos outros.

Ainda no que compete ao cuidado familiar as autoras mostram no estudo que para a mulher procurar os serviços de saúde ou a justiça, significa rompimento de sua parte com a reciprocidade da família (SANTI; NAKAMO; LETTIERE, 2010).

Tabela 5 - Rede de apoio às mulheres que sofreram violência na gestação atendidas no Hospital da mulher em Feira de Santana, Bahia, 2016.

\begin{tabular}{|l|c|c|}
\hline \multicolumn{2}{|c|}{ Variável } & $\%$ \\
\hline Em situação de violência com quem conversou & 11 & 10,8 \\
\hline Mãe & 27 & 26,2 \\
\hline Irmão (a) & 17 & 16,5 \\
\hline Companheiro & 2 & 1,9 \\
\hline Amiga (o) & 21 & 20,4 \\
\hline Não conversou & 12 & 11,6 \\
\hline Outros & 13 & 12,6 \\
\hline Total & 103 & 100 \\
\hline
\end{tabular}

Fonte: Banco de dados da pesquisa original.

Na tabela 6 os resultados de análise bivariada, das variáveis de estudo de entre presença de violência a frequência das consultas pré-natais, nenhuma das variáveis de interesse apresentaram significância estatística como acompanhamento pré-natal $(\mathrm{p}=0,1)$ e trimestre que iniciou o pré-natal e consultas realizadas $(\mathrm{p}=0,3)$.

Semelhante a esse achado, o estudo de Carneiro et al. (2016) sobre violência física por parceiro íntimo (VFPI) não mostrou associação estatisticamente significante com a não realização do pré-natal. No entanto, as mulheres vítimas de VFPI iniciaram o PN mais tardiamente, fizeram menos de seis consultas e tiveram maior chance de realizar o PN inadequado.

Os resultados do estudo de Moraes, Arana e Reichenheim (2010) com 528 puérperas realizado em três maternidades públicas do município do Rio de Janeiro, RJ, revelam que mulheres que sofreram VPI antes ou depois da gestação iniciarão o pré-natal tardiamente, não realizaram o número de consultas como preconizado pelo Ministério da saúde.

Os resultados encontrados apontam para os limites desse estudo e estão relacionados ao delineamento transversal e o momento que essas mulheres foram entrevistadas após 24 horas pós-parto, apesar de toda cautela na calibração da coleta de dados e da utilização de instrumento validado e adaptado para população de estudo, a violência entre parceiros íntimos destaca como um tema complexo e de difícil abordagem. Desse modo, pode ter ocorrido omissão nas informações das mulheres entrevistadas pela exposição ao tema. 
Tabela 6 - Associação e características sobre o perfil de acompanhamento de pré-natal mulheres segundo a presença ou não de situação de violência atendidas no Hospital da mulher em Feira de Santana, Bahia, 2016.

\begin{tabular}{|c|c|c|c|c|c|}
\hline \multirow{3}{*}{ Variáveis } & \multicolumn{4}{|c|}{ Presença de violência } & \multirow{3}{*}{ Valor de p } \\
\hline & \multicolumn{2}{|c|}{ Sim } & \multicolumn{2}{|c|}{ Não } & \\
\hline & $\mathrm{n}$ & $\%$ & $\mathrm{n}$ & $\%$ & \\
\hline \multicolumn{6}{|c|}{ Acompanhamento pré natal } \\
\hline Sim & 65 & 95,6 & 252 & 98,4 & \multirow{2}{*}{0,1} \\
\hline Não & 3 & 4,4 & 4 & 1,6 & \\
\hline \multicolumn{6}{|c|}{ Trimestre que iniciou o pré natal } \\
\hline Primeiro & 46 & 67,7 & 192 & 75,0 & \multirow{4}{*}{0,3} \\
\hline Segundo & 16 & 23,5 & 53 & 20,7 & \\
\hline Terceiro & 3 & 4,4 & 7 & 2,7 & \\
\hline Não realizou & 3 & 4,4 & 4 & 1,6 & \\
\hline \multicolumn{6}{|c|}{ Consultas realizadas } \\
\hline Até 4 consultas & 10 & 14,7 & 35 & 13,7 & \multirow{4}{*}{0,1} \\
\hline De 4-6 consultas & 32 & 47,1 & 93 & 36,3 & \\
\hline+ de 7 consultas & 23 & 33,8 & 124 & 48,4 & \\
\hline Não realizou & 3 & 4,4 & 4 & 1,6 & \\
\hline
\end{tabular}

Fonte: Banco de dados da pesquisa original.

\section{CONSIDERAÇÕES FINAIS}

A violência por parceiro íntimo durante a gestação traz implicações importantes na saúde das gestantes e crianças, o que reforça a necessidade de sensibilizar profissionais que trabalham em diferentes contextos de saúde, para que possam planejar medidas de prevenção primária, secundária e terciária. Deve ser compreendida e investigada nos serviços de pré-natal situações suspeitas ou relatos de violência atentando não apenas nas repercussões clinicas prejudiciais à saúde materna, mas seus componentes psicossociais, culturais e econômicos.

Recomenda-se ainda a necessidade de um acompanhamento pré-natal a VPI psicológica, muitas vezes não expressada, visto que essa violência em nossos resultados está correlacionada aos problemas de saúde referidos mais frequentes durante o período gestacional. Os profissionais de saúde devem visar uma abordagem mais abrangente e cuidados de suporte a essas mulheres e suas famílias.

Vale destacar, a relevância e a contribuição dessa pesquisa para a percepção e a visibilidade da violência por parceiros íntimos por meio da formação continuada de agentes públicos e comunitários e redirecionamento de políticas públicas que visem prevenção, proteção das mulheres e filhos e famílias em situação de violência.

A importância do trabalho se faz presente em diversos setores sociais e órgãos federais para a construção de um compromisso de respeito e igualdade nas relações de gênero, tendo em vista, uma maior percepção das rotas críticas percorridas pelas mulheres em situação de violência e o fortalecimento das Redes de Atendimento, enfrentamento e prevenção da violência contra mulheres no município de Feira de Santana.

\section{REFERÊNCIAS}

[1] ACOSTA, Daniele Ferreira et al. Violência contra a mulher por parceiro íntimo: (in)visibilidade do problema. Texto Contexto Enferm., Florianópolis, v. 24, n. 1, p. 121-127, jan./mar. 2015. Disponível em: <https://www.scielo.br/pdf/tce/v24n1/pt_0104-0707-tce-24-01-00121.pdf>. Acesso em: 25 fev. 2020.

[2] ANDRADE, Júlia de Oliveira et al. Indicadores da violência contra a mulher provenientes das notificações dos serviços de saúde de Minas Gerais-Brasil. Texto Contexto Enferm., Florianópolis, v. 25, n. 3, 2016. Disponível em: <https://www.scielo.br/pdf/tce/v25n3/pt_0104-0707-tce-25-03-2880015.pdf>. Acesso em: 25 fev. 2020.

[3] ANDRADE, Luciana Vieira Rubim; ALMEIDA, Marlise Miriam de Matos. A criminalização da violência contra as mulheres no Brasil: de "legítima defesa da honra" à violação dos direitos humanos. Revista Socais e Humanas CCSH/UFSM, Santa Maria, v. 30, n. 2, 2017. Disponível em: <https://periodicos.ufsm.br/sociaisehumanas/article/view/27565/pdf>. Acesso em: 3 abr. 2021.

[4] AUDI, Celene Aparecida Ferrari et al. Violência doméstica na gravidez: prevalência e fatores associados. Rev. Saúde Públ., São Paulo, v. 42, n. 5, p. 877-885, out 2008. Disponível em:

<http://www.scielo.br/pdf/rsp/v42n5/6642.pdf>. Acesso em: 17 out. 2018. 
[5] ÁVILA, Thiago André Pierobom de. Violência contra a mulher: consequências da perspectiva de gênero para as políticas de segurança pública. Revista da Faculdade de Direito UFPR, Curitiba, v. 62, n. 3, p. 103-132, set. /dez. 2017. Disponível em: <http://revistas.ufpr.br/direito/article/view/51841>. Acesso em: 3 abr. 2021.

[6] BARROS, Érika Neves de et al. Prevalência e fatores associados à violência por parceiro íntimo em mulheres de uma comunidade em Recife/Pernambuco, Brasil. Ciênc. Saúde Colet., Rio de Janeiro, v. 21, n. 2, p. 591-598, 2016. Disponível em: <https://www.scielo.br/pdf/csc/v21n2/1413-8123-csc-21-02-0591.pdf>. Acesso em: 23 fev. 2020.

[7] BORSOI, Tatiana dos Santos; BRANDÃo, Elaine Reis; CAVALCANTI, Maria de Lourdes Tavares. Ações para o enfrentamento da violência contra a mulher em duas unidades de atenção primária à saúde no município do Rio de Janeiro. Interface - Comunic., Saúde, Educ., Botucatu, v. 13, n. 28, p. 165-174, mar. 2009. Disponível em: <https://www.scielo.br/pdf/icse/v13n28/v13n28a14.pdf >. Acesso em: 2 dez. 2018.

[8] CARNEIRO, Jackelyne Faierstein et al. Violência física pelo parceiro íntimo e uso inadequado do pré-natal entre mulheres do Nordeste do Brasil. Rev. Bras. Epidemiol., São Paulo, v. 19, n. 2, p. 243-255, abr./jun. 2016. Disponível em: <https://www.scielo.br/pdf/rbepid/v19n2/1980-5497-rbepid-19-02-00243.pdf >. Acesso em: 27 jun. 2019.

[9] LAMUS, Martha Beatriz Narvaez. Prevalência e repercussões da morbidade materna no pós-parto utilizando o instrumento WOICE - Organização Mundial de Saúde. 2019. 107f. Dissertação (Mestrado em Ciências da Saúde) Programa de Pós-Graduação em Tocoginecologia, Faculdade de Ciências Médicas, Universidade Estadual de Campinas, Campinas, 2019. Disponível em:

<http://repositorio.unicamp.br/bitstream/REPOSIP/335717/1/NarvaezLamus_MarthaBeatriz_M.pdf>. Acesso em: 3 abr. 2021.

[10] LUDERMIR, Ana Bernarda et al. Violence against women by their intimate partner during pregnancy and postnatal depression: a prospective cohort study. The Lancet, v. 376, n. 9744, p. 903-910, sep. 2010. Disponível em: <https://www.thelancet.com/journals/lancet/article/PIIS0140-6736(10)60887-2/fulltext>. Acesso em: 1 abr. 2021.

[11] MARCACINE, Karla Oliveira et al. Prevalência de violência por parceiro íntimo relatada por puérperas. Acta Paul Enferm., São Paulo, v. 26, n. 4, p. 395-400, 2013. Disponível em: <https://www.scielo.br/pdf/ape/v26n4/v26n4a15.pdf>. Acesso em: 1 abr. 2021.

[12] MARQUES, Samara Silva et al. Estratégias para identificação e enfrentamento de situação de violência por parceiro íntimo em mulheres gestantes. Rev. Gaúcha Enferm., Porto Alegre, v. 38, n. 3, abr. 2017. Disponível em: <https://www.scielo.br/pdf/rgenf/v38n3/0102-6933-rgenf-38-3-e67593.pdf>. Acesso em: 3 abr. 2021.

[13] MORAES, Claudia Leite; ARANA, Flávia Dias Nogueira; REICHENHEIM, Michael Eduardo. Violência física entre parceiros íntimos na gestação como fator de risco para a má qualidade do pré-natal. Rev. Saúde Públ., São Paulo, v. 44, n. 4, p. 667-676, ago. 2010. Disponível em: <https://www.scielo.br/pdf/rsp/v44n4/10.pdf>. Acesso em: 17 nov. 2018.

[14] NETTO, Leônidas de Albuquerque et al. As redes sociais de apoio às mulheres em situação de violência pelo parceiro íntimo. Texto Contexto Enferm., Florianópolis, v. 26, n. 2, p. 1-11, 2017. Disponível em: <https://www.scielo.br/pdf/tce/v26n2/0104-0707-tce-26-02-e07120015.pdf>. Acesso em: 25 fev. 2020.

[15] OLIVEIRA, Lisiane Camargo Quialheiro de et al. Violência por parceiro íntimo na gestação: identificação de mulheres vítimas de seus parceiros. Rev. Gaúcha Enferm., Porto Alegre, v. 36, n. esp., p. 233-238, 2015. Disponível em: <www.scielo.br/pdf/rgenf/v36nspe/0102-6933-rgenf-36-spe-0233.pdf>. Acesso em: 17 out. 2018.

[16] OMS, Organização Mundial da Saúde. Relatório mundial sobre violência e saúde. Genebra: Organização Mundial da Saúde, 2002. Disponível em: <https://www.cevs.rs.gov.br/upload/arquivos/201706/14142032-relatoriomundial-sobre-violencia-e-saude.pdf>. Acesso em: 1 abr. 2021.

[17] REICHENHEIM, Michael E.; MORAES, Claudia Leite; HASSELMANN, Maria Helena. Equivalência semântica da versão em português do instrumento Abuse Assessment Screen para rastrear a violência contra a mulher grávida. Rev. Saúde Públ., São Paulo, v. 34, n. 6, p. 610-616, dez. 2000. Disponível em: <https://www.scielo.br/pdf/rsp/v34n6/3575.pdf>. Acesso em: 17 out. 2018.

[18] ROCHA, Roberta Zanini da; GALELI, Paola Rodegheri; ANTONI, Clarissa de. Rede de apoio social e afetiva de mulheres que vivenciaram violência conjugal. Contextos Clínicos, São Leopoldo, v. 12, n. 1, jan. /abr. 2019. Disponível em: <http://pepsic.bvsalud.org/pdf/cclin/v12n1/v12n1a07.pdf>. Acesso em: 03 abr. 2021.

[19] RODRIGUES, Driéli Pacheco et al. Violência do parceiro íntimo contra a gestante: estudo sobre as repercussões nos resultados obstétricos e neonatais. Rev Esc Enferm USP, São Paulo, v. 48, n. 2, p. 206-212, abr. 2014. Disponível em: <https://www.scielo.br/pdf/reeusp/v48n2/pt_0080-6234-reeusp-48-02-206.pdf>. Acesso em: 1 abr. 2021.

[20] SANTI, Liliane Nascimento de; NAKANO, Ana Márcia Spanó; LETTIERE, Angelina. Percepção de mulheres em situação de violência sobre o suporte e apoio recebido em seu contexto social. Texto Contexto Enferm., Florianópolis, v. 19, n. 3, p. 417-424, jul./set. 2010. Disponível em: <https://www.scielo.br/pdf/tce/v19n3/a02v19n3.pdf >. Acesso em: 25 fev. 2020. 
[21] SENA, Chalana Duarte de. Fatores associados à violência doméstica em gestantes atendidas em uma maternidade pública. 2014. 111f. Dissertação (Mestrado em Enfermagem) - Escola de Enfermagem, Universidade Federal da Bahia, Salvador, 2014. Disponível em:

<https://repositorio.ufba.br/ri/bitstream/ri/17103/1/Disserta\%c3\%a7\%c3\%a3o_Chalana_Duarte_Sena_Enfermage m.pdf>. Acesso em: 17 out. 2018.

[22] TELLES, Lisieux E. de B. et al. Intimate partner violence during pregnancy: case report of a forensic psychiatric evaluation. Brazilian Journal of Psychiatry, São Paulo, v. 38, n. 1, p. 87-88, jan./mar. 2016. Disponível em: <https://www.scielo.br/pdf/rbp/v38n1/1516-4446-rbp-38-01-00087.pdf>. Acesso em: 1 abr. 2021.

[23] WHO, World Health Organization. World health statistics 2010. World Health Organization, 2010. Disponível em: <https://www.who.int/whosis/whostat/EN_WHS10_Full.pdf?ua=1>. Acesso em: 1 abr. 2021. 


\section{Capítulo 10}

Sepse: Desafios e perspectivas para o enfrentamento no contexto hospitalar

\section{Alisson Junior dos Santos}

Resumo: 0 objetivo do presente artigo é realizar um levantamento bibliográfico com análise reflexiva acerca da atualização dos principais aspectos da sepse, complicação infecciosa extremamente importante do ponto de vista da clínica e da saúde pública. A sepse provoca anualmente milhões de mortes em todo o mundo. É sabido que a detecção precoce se mostra fundamental para o tratamento adequado e também maiores chances de cura. Neste cenário, a capacitação da equipe multiprofissional e o reconhecimento precoce do para a identificação de sinais e sintomas é primordial. Diante do contexto hospitalar, é prioritário que os profissionais de saúde tenham pleno conhecimento de todo o processo de identificação, cuidados e tratamento no atendimento ao paciente séptico. Isso permite que o paciente seja atendido de maneira coordenada e rápida em todas as instâncias de atendimento.

Palavras-chave: Sepse; Hospitais; Infecção Hospitalar. 


\section{INTRODUÇÃO}

Numa perspectiva histórica, a palavra sepse deriva do grego septikós. Atribuída por Hipócrates (460-377 a.C.), significa apodrecer, que causa putrefação. Sepse é definida como a ruptura do tecido, a qual resulta em uma desordem orgânica capaz de originar ou manter essa desordem ou doença (CARRARA; STRABELLI; UIP, 2017).

No século XIX, os trabalhos de Semmelweis, Pasteur e Lister definiram que o processo de infecção era causado por microrganismos vivos, dessa maneira a palavra sepse relaciona-se a uma infecção invasiva séria e devastadora (SINGER et al., 2016).

A sepse é considerada uma das doenças fatais mais comumente encontradas em todo o mundo. Trata-se de uma das poucas moléstias democráticas, já que atinge tanto pessoas em localidades com poucos recursos, como as residentes em áreas mais desenvolvidas. Aproximadamente, 20 a 30 milhões de pessoas são atingidas pela doença, anualmente, com elevado número de mortes. Apesar disso, é uma enfermidade pouco conhecida pelos profissionais de saúde e leigos (SANTOS et al., 2019).

Por este motivo, torna-se relevante que a equipe interdisciplinar em saúde tenha conhecimento dos sinais e sintomas característicos da sepse, já que a mesma vem adquirindo crescente importância devido ao aumento de sua incidência, seja pela melhoria no atendimento de emergência, para que mais pacientes graves sobrevivam ao insulto inicial; seja pelo aumento da população idosa e do número de pacientes imunossuprimidos e com doenças crônicas, consideradas populações suscetíveis ao desenvolvimento de infecções graves. Além disso, o aumento da resistência bacteriana tem impacto direto no crescimento da sepse (LOBO et al., 2019).

Estudo recente mostrou aumento significativo do número de casos graves de sepse, reportados nos Estados Unidos, de 415 mil, em 2003, para mais de 700 mil casos, em 2007. Os custos associados também subiram, significativamente, de 15,4 bilhões de dólares para 24,3 bilhões, em 2007. A despeito disso, sua gravidade tem sido negligenciada. Parte desse crescimento pode ser decorrente do aumento de notificações, decorrente da melhor percepção do problema, por parte dos profissionais de saúde (SANTOS et al., 2015).

Sepse é a principal causa de morte em unidades de terapia intensiva (UTIs) não cardiológicas, com elevadas taxas de letalidade. Essas taxas variam, essencialmente, de acordo com as características socioeconômicas do país. Não se deve esquecer que estes dados podem estar subestimados, pois, muitas vezes, a causa da morte é atribuída à patologia de base e não propriamente à sepse (BARRETO et al., 2016).

Os dados nacionais disponíveis apontam para uma elevada letalidade, principalmente em hospitais públicos vinculados ao Sistema Único de Saúde (SUS). Infelizmente, o número de casos de sepse no Brasil não é conhecido. Estudo de prevalência, de um só dia, em cerca de 230 UTIs brasileiras, selecionadas aleatoriamente de forma a representar o conjunto de UTIs do País, aponta que $30 \%$ dos leitos estão ocupados por pacientes com sepse ou choque séptico. Esse estudo, conduzido pelo Instituto Latino Americano para Estudos da SEPSE (ILAS), mostram que seus resultados iniciais são alarmantes, com letalidade próxima dos $50 \%$. Esses dois achados nos fazem perceber o custo elevado da sepse em nosso país, tanto do ponto de vidas perdidas como do ponto de vista econômico (MOURA et al., 2017).

Apesar da importância do conhecimento sobre a sepse e da demanda de recursos, seu diagnóstico, muitas vezes, ainda não ocorre em tempo hábil, deixando margem para a ocorrência de disfunção de múltiplos órgãos e sistemas (MACHADO et al., 2018).

Isso, por si só, justifica o planejamento de ações voltadas à redução dessa mortalidade. Estudos prévios em outros países e no Brasil mostram que a efetiva implementação de protocolos assistenciais gerenciados é capaz de melhorar a evolução desses pacientes (PETTERLE et al., 2016).

Trata-se de levantamento bibliográfico reflexivo acerca dos desafios e perspectivas para o enfrentamento da sepse dentro do ambiente hospitalar. 


\section{REFERENCIAL TEÓRICO}

\subsection{CONCEITOS E DEFINIÇÕES}

Diversas definições foram propostas, ao longo dos anos, a fim de melhor caracterizar o paciente com infecção grave. Isso constituiu uma importante limitação para o seu melhor conhecimento. As nomenclaturas anteriormente utilizadas, como septicemia, síndrome séptica ou infecção generalizada, causavam inconvenientes, tanto do ponto de vista assistencial como do ponto de vista de pesquisa.

Em 1991, as primeiras definições para a sepse foram estabelecidas, cuja consideração dessa condição foi dada como uma síndrome da resposta inflamatória sistêmica (SIRS) associada a uma infecção. Em 2001, houve novas definições, porém, sem modificar efetivamente o conhecimento e a conceituação da sepse, mantendo-se assim os critérios da SIRS. Todavia, em 2016, houve uma mudança significativa nas definições de sepse, estabelecida pelas sociedades americanas e européias de medicina intensiva, através de uma extensa revisão, a incorporação de novos conceitos, tais como a exclusão da classificação sepse grave, a não dependência da presença de SIRS para o diagnóstico da sepse e uma nova definição para choque séptico. O ILAS aceitou parcialmente as novas definições, que devem ser conhecidas pelos profissionais da saúde (ILAS, 2017).

A diferenciação entre SIRS e sepse, por vezes, é difícil porque nem sempre é clara a presença de foco infeccioso. Esse diagnóstico diferencial torna-se um desafio, por exemplo, em pacientes com SIRS secundária a politrauma ou cirurgia de grande porte. Caso esses pacientes passem a ter um foco infeccioso, seu diagnóstico correto é dificultado pela presença dos sinais de resposta inflamatória em resposta à agressão anterior. Por outro lado, pacientes imunossuprimidos ou com idade avançada podem manifestar disfunção orgânica e mesmo choque séptico, sem a presença dos sinais clássicos de SIRS (ZONTA et al., 2018).

Numa tentativa de deixar mais claras essas definições, a Society Critical Care Medicine (SCCM) e o American College of Chest Physicians (ACCP) reuniram-se novamente, em 2001, para a segunda conferência de consenso. Elas procuraram aumentar a especificidade destas definições acrescendo sinais e sintomas comumente encontrados em pacientes sépticos. Essa nova classificação em muito colaborou para o entendimento de diversos outros aspectos ligados às manifestações da resposta inflamatória, como a presença de balanço hídrico positivo por edema intersticial em decorrência do aumento da permeabilidade capilar, hiperglicemia ou alterações laboratoriais, como o aumento da proteína C reativa ou procalcitonina (ILAS, 2015).

Em 2016, a Society of Critical Care Medicine (SCCM) e a European Society of Intensive Care Medicine (ESICM) publicaram novas definições baseadas em uma análise bastante robusta de grandes bancos de dados, basicamente americanos, na qual houve uma mudança conceitual. Sepse passa a ser definida pela presença de disfunção orgânica ameaçadora a vida secundária a resposta desregulada do hospedeiro a uma infecção. Como pontos positivos das novas definições, os critérios de SIRS passam a não ser mais requeridos para o diagnóstico de sepse. A expressão "sepse grave" foi extinta, simplificando a nomenclatura, sendo que o uso da palavra sepse passa a ser restrito aos pacientes já com disfunção orgânica. Entretanto, houve modificação do critério sugerido para definir a presença de disfunção orgânica. Anteriormente, a presença de apenas uma disfunção orgânica definia a presença de sepse grave. Pelos novos critérios, definiu-se como disfunção orgânica o aumento em 2 pontos no escore Sequential Organ Failure Assessment (SOFA) basal, em consequência da infecção. Esse novo critério baseou-se na identificação de uma curva receiver operator characteristic (ROC) mais acurada para essa variação de SOFA do que a da presença de SIRS. Também houve modificação da definição de choque séptico, agora conceituado como presença de hipotensão com necessidade de vasopressores para manter pressão arterial média $\geq 65 \mathrm{mmHg}$ associada a lactato $\geq 2 \mathrm{mmol} / \mathrm{L}$, após adequada ressuscitação volêmica (MOURA et al., 2017).

Foi também sugerido um novo escore, denominado quick SOFA (qSOFA). A presença de duas das três variáveis que compõe esse escore, a saber, rebaixamento de nível de consciência, frequência respiratória (FR) acima de $22 \mathrm{ipm}$ e pressão artéria sistólica (PAS) menor que $100 \mathrm{mmHg}$, seria preditiva de maior mortalidade. Embora tenha sido sugerida a utilização desse escore no processo de triagem de pacientes com infecção, o mesmo não foi validado para esse fim. A avaliação se baseou apenas na área sob a curva ROC (AUC) sem levar em conta qual o componente preponderante a gerar essa área, se sensibilidade ou especificidade. Provavelmente, a AUC do qSOFA observada pelos autores é determinada muito mais pela especificidade do que pela sensibilidade - o que confere a capacidade de predizer óbito. Se essa hipótese é verdadeira, a sensibilidade pode ser baixa, o que desqualifica o qSOFA como instrumento de triagem (MACHADO et al., 2018). 
Neste sentido, portanto, houve uma modificação na forma escolhida para definir sepse. Basear a definição de uma doença em predição de mortalidade pode fazer com que casos mais graves sejam selecionados, o que não é de interesse de instituições que ainda procuram aumentar sua sensibilidade. Diversas críticas foram publicadas, baseadas no risco desses critérios de disfunção selecionarem uma população muito grave, reduzirem a sensibilidade e aumentarem a especificidade para o diagnóstico de sepse, o que vai de encontro aos interesses das instituições que pretendem aumentar a percepção da equipe de saúde para com os pacientes sépticos (MEDEIROS; VALENÇA; ANJOS, 2016).

Para fins práticos, o entendimento do ILAS, assim como o da Surviving Sepsis Campaign, é de que os processos de melhoria de qualidade não devem alterar suas definições de disfunção orgânica, pelo risco de desvalorização dos critérios de SIRS como parte da estratégia de triagem para suspeição precoce da presença de infecção. Uma parte do esforço atual no combate a síndrome baseia-se no diagnóstico precoce e no aumento da percepção dos profissionais de saúde. Idealmente, esses pacientes devem ser reconhecidos em fase precoce, não somente quando a disfunção já estiver instalada. Desse modo, o ILAS julga válida a nova definição "lato senso", ou seja, disfunção orgânica ameaçadora a vida secundária a resposta desregulada do hospedeiro a uma infecção, mas sem a necessidade de se calcular o escore SOFA (LOBO et al.,2019).

\subsection{ASPECTOS EPIDEMIOLÓGICOS}

A despeito de a sepse poder estar relacionada a qualquer foco infeccioso, as infecções mais comumente associadas à sua ocorrência são a pneumonia, a infecção intra-abdominal e a infecção urinária. Pneumonia, na maior parte dos levantamentos epidemiológicos, é o foco responsável pela metade dos casos. São, ainda, focos frequentes: a infecção relacionada a cateteres, abscessos de partes moles, meningites, endocardites, entre outros (MACHADO; CAVALCANTI; BOZZA, 2017).

Tanto infecções de origem comunitária como aquelas associadas à assistência à saúde podem evoluir para sepse ou choque. Mesmo germes amplamente sensíveis advindos da comunidade podem levar a quadros graves. Nem sempre é possível identificar o agente. As hemoculturas são positivas em cerca de $30 \%$ dos casos e em outros 30\% a choque. Mesmo germes amplamente sensíveis advindos da comunidade podem levar a quadros graves. Nem sempre é possível identificar o agente. As hemoculturas são positivas em cerca de $30 \%$ dos casos e em outros $30 \%$ a identificação é possível por meio de culturas de outros sítios. 0 perfil de resistência do agente etiológico parece ser um fator relevante para determinar a má evolução (BARROS; MAIA; MONTEIRO, 2016). A multirresistência bacteriana, amplamente presente nas instituições, é uma das principais causas de aumento da incidência, embora sua relação direta com maior letalidade não esteja clara. Pacientes com germes multirresistentes muitas vezes trazem consigo outros determinantes de mau prognóstico (BROOKS et al., 2017).

Os custos diretos relacionados ao tratamento do paciente séptico e àqueles indiretos secundários ao capital humano são elevados. Existem vários estudos abordando custo em diferentes países. A estimativa de custo de um caso de sepse nos Estados Unidos da América é cerca de US\$ 38 mil e na Europa varia entre US\$ 26 mil e US\$ 32 mil. A projeção destes números sugere que entre $20 \%$ e $40 \%$ do custo total das UTIs resulta de cuidados a pacientes com sepse (ROTHMAN et al., 2017). Esses gastos têm íntima relação com gravidade e tempo de internação. No Brasil, o estudo COSTS mostrou dados semelhantes. 0 gasto hospitalar com cuidados aos pacientes com sepse grave ou choque séptico foi de US\$10.595, com um gasto diário médio de US\$1.028. De forma interessante, o custo diário de pacientes não sobreviventes foi persistentemente mais elevado, corroborando a ideia da associação entre gravidade e custos (ZONTA et al., 2018).

Os fatores determinantes de má evolução e óbito não são totalmente compreendidos. Sabe-se que, além do perfil do agente agressor, características ligadas ao hospedeiro são importantes. A presença de imunossupressão decorrente de neoplasias, infecção pelo vírus da imunodeficiência adquirida ou uso de imunossupressores são fatores clássicos. Além disso, características genéticas estão claramente associadas com a modulação da resposta inflamatória e anti-inflamatórias. Notoriamente, a precocidade e adequação do tratamento estão relacionadas à evolução (ROTHMAN et al., 2017).

Os dados brasileiros já publicados sobre letalidade por sepse são um pouco antigos. Dentre eles, temos três estudos multicêntricos. 0 primeiro, denominado BASES, foi conduzido em cinco unidades de terapia intensiva, de maio de 2001 a janeiro de 2002. Ele mostrou que a letalidade por sepse grave e choque séptico foi de 47,3\% e 52,2\%, respectivamente. 0 estudo Sepse Brasil, de 2003, abrangendo 75 UTIs de 17 estados brasileiros, mostrou que $17 \%$ dos leitos de terapia intensiva são ocupados por esses pacientes. A 
taxa de letalidade para sepse grave e choque séptico foi de 34,4\% e 65,3\%, respectivamente. O COSTS, com dados colhidos entre 2003 e 2004, em 21 UTIs brasileiras, mostrou um dado de alta relevância: uma letalidade maior em hospitais ligados ao SUS - 49,1\% - em relação àqueles do Sistema de Saúde Suplementar (36,7\%). Posteriormente, uma análise mais detalhada desses pacientes apontou algumas diferenças importantes entre a rede privada e a pública, sugerindo que o atraso no diagnóstico e a baixa aderência aos indicadores de tratamento são mais frequentes no sistema público, o que explica, pelo menos parcialmente, a maior mortalidade (SANTOS et al., 2019).

Essa letalidade elevada no Brasil fica ainda mais clara quando se verifica os dados do estudo PROGRESS, que apontou importante diferença de letalidade entre outros países do mundo e o Brasil. Nessa casuística global de 12.570 pacientes, a letalidade hospitalar foi de 49,6\%. No Brasil, a letalidade foi de 67,4\%, comparável apenas com a da Malásia (66,1\%) e bem distante da letalidade de outros países (Alemanha 43,4\%; Argentina - 56,6\%; Canadá - 50,4\%; Índia - 39,0\%; Estados Unidos - 42,9\% e Austrália 32,6\%) (ZONTA et al., 2018).

Há várias possíveis razões para essa mortalidade elevada no Brasil e, particularmente, na rede pública. Não se pode afastar a possibilidade de que pelo menos parte dessa mortalidade seja decorrente de um viés de seleção. Os estudos epidemiológicos brasileiros são centrados nos pacientes que foram efetivamente admitidos em UTIs. Dada à carência de leitos de terapia intensiva, são admitidos nessas unidades os pacientes mais graves (CAMARGO et al., 2014).

Outras potenciais razões são o desconhecimento entre os profissionais de saúde, principalmente médicos e enfermeiros, sobre os sinais de alerta de gravidade associados a quadros infecciosos fazendo com que esses pacientes sejam reconhecidos tardiamente. Além disso, a despeito da existência de diretrizes claras de tratamento, parte dos profissionais de saúde desconhece as medidas iniciais de tratamento, o que retarda sua aplicação. A dificuldade em transpor diretrizes para cuidados efetivos beira leito é bastante conhecida (MOURA et al., 2017).

Parte dessa limitação também se deve à falta de infraestrutura e número inadequado de profissionais para atendimento. Isso é provavelmente mais significativo nos atendimentos ligados ao SUS. No Brasil, o sistema privado de saúde é geralmente considerado de melhor nível, principalmente no que tange a infraestrutura e qualidade de gestão. 0 sistema público apresenta déficits importantes em todos os níveis. Não estão bem definidas as razões pelas quais os pacientes em sepse têm letalidade maior nessa última categoria de hospital. Faltam dados recentes no tocante às diferenças no perfil demográfico e de gravidade dos pacientes admitidos nesses hospitais, bem como no tratamento recebido por esses pacientes. Esse melhor entendimento pode embasar ações de saúde voltadas para combate a essa doença, responsável por número significativo de óbitos no nosso país (CUNHA; TEIXEIRA; FRANÇA, 2017).

As complicações podem ocasionar ainda danos irreversíveis ao indivíduo acometido, uma vez que a possibilidade de novas infecções nessas pessoas é de três a cinco vezes maior que em indivíduos que nunca tiveram sepse (ZHOU et al., 2014).

Infelizmente, o ônus da sepse não se restringe ao período de internação hospitalar. Sabe-se que os pacientes, quando sobreviventes da sepse, desenvolvem complicações decorrentes do próprio processo de saúde-doença, das medidas terapêuticas necessárias ao tratamento da afecção, bem como do prolongado período de internação. Além disso, a mortalidade pós-alta desses pacientes é elevada, não sendo facilmente explicada por eventuais doenças de base presentes antes do evento séptico.

\subsection{A IMPORTÂNCIA DO MANEJO E IDENTIFICAÇÃO PRECOCE DA SEPSE}

A sepse é diagnosticada, frequentemente, de forma tardia, já que os sinais e sintomas atualmente utilizados para o diagnóstico, como alterações na contagem de leucócitos, febre, taquicardia e taquipnéia não são específicos da sepse. Concomitantemente, falta adequado conhecimento a seu respeito entre profissionais da saúde. Esse desconhecimento tem inúmeras causas, entre elas, o déficit na formação e a falta de definições precisas e processos adequados para ajudar na identificação e tornar o planejamento de cuidados mais rápido e efetivo (MACHADO; CAVALCANTI; BOZZA, 2017).

Devido à alta morbimortalidade da sepse, é imprescindível sua rápida identificação. Porém, esta é uma tarefa complicada, pois suas manifestações podem ser confundidas com as de outros processos não infecciosos ou podem, em muitos casos, passar despercebidas. Além disso, exames laboratoriais, como hemograma, dosagem de creatinina ou ionograma possuem baixa sensibilidade e especificidade. Por sua 
vez, as culturas solicitadas na suspeita de sepse não têm resultados prontamente disponíveis, o que poderia postergar o início do tratamento específico dirigido ao agente etiológico (QUINTEN et al., 2017).

A maioria dos estudos mostra que a rápida identificação da sepse, associada à terapêutica adequada e agressiva, pode trazer resultados favoráveis para o paciente. Para a identificação da sepse, deve-se levar em conta um fator de extrema importância: o tempo. 0 menor tempo para reconhecimento está associado a uma melhor evolução do quadro e um prognóstico mais favorável. A recomendação é instituir a terapêutica para o paciente séptico no primeiro atendimento, antes mesmo de sua internação na UTI. 0 uso de antimicrobianos específicos na primeira hora, logo após o diagnóstico, contribui para a sobrevivência do paciente (SANTOS et al., 2019).

Porém, para que a identificação seja precoce e o tratamento adequado é fundamental a aplicação efetiva dos protocolos de sepse e o treinamento dos profissionais de saúde, para que estes sejam capazes de identificar os sinais da sepse, reconhecendo as principais manifestações clínicas.

A formação interdisciplinar para o diagnóstico e manejo precoce da sepse objetiva integrar conhecimentos, habilidades e atitudes necessários ao processo de desenvolvimento profissional e humano (PARULLA et al., 2016).

Face ao problema representado pela elevada incidência, altos custos e mortalidade, o principal desafio das instituições hospitalares é implementar, de forma institucionalmente gerenciada, programas que levem à beira do leito as melhores evidências científicas disponíveis, visando garantir a melhor prática assistencial. Na sepse, as diretrizes para tratamento são bem estabelecidas, o que teoricamente dá sustentação à implementação de processos adequados de assistência (PERNER et al., 2018).

A precocidade na identificação e no diagnóstico da disfunção orgânica e, consequentemente, seu tratamento estão diretamente relacionados com o prognóstico do paciente. Uma vez diagnosticada a sepse ou o choque séptico, condutas que visam à estabilização do paciente são prioritárias e devem ser tomadas imediatamente, dentro das primeiras horas. Uma vez que inúmeros motivos podem atrasar sua adoção na prática clínica, a Campanha de Sobrevivência à Sepse (Surviving Sepsis Campaign) recorreu ao Institute for Healthcare Improvement (IHI) para elaborar um programa educacional no sentido de acelerar esse processo (DEWITTE et al., 2017)

Foram então criados os pacotes (bundles) da sepse. Conceitualmente, pacote se refere a um conjunto de intervenções baseadas em evidências científicas sólidas oriundas de estudos publicados na literatura que, quando praticadas em conjunto, apresentam maior eficácia do que quando aplicadas individualmente. Inicialmente foram criados os pacotes de seis e 24 horas. Os pacotes atuais, de três e seis horas, contêm sete intervenções diagnósticas e terapêuticas selecionadas entre as diretrizes, criando assim prioridades no tratamento inicial da doença (GIACOMINI et al., 2015).

Dentro do programa educacional é possível mensurar a aderência a esses pacotes, gerando indicadores de qualidade reprodutíveis e confiáveis. Por meio da auditoria de dados de aderência a cada intervenção individual e a aderência ao pacote como um todo, além das taxas de letalidade, é possível medir o progresso de implantação e direcionar as políticas institucionais de melhoria assistencial.

\subsection{ELABORAÇÃO E IMPLEMENTAÇÃO DO PROTOCOLO INSTITUCIONAL DE SEPSE}

As novas diretrizes da Campanha de Sobrevivência à Sepse recomendam fortemente que todas as instituições tenham estratégias para a deteç̧ão de pacientes com sepse e tentem instituir programas de melhoria da qualidade de atendimento baseados em indicadores bem definidos.

No Brasil, a casuística de uma grande rede privada nacional, em parceria com o ILAS e utilizando a estratégia de implementação do Instituto, obtiveram redução importante da letalidade ao longo dos trimestres do processo, de $55 \%$ para $26 \%$. Além disso, uma cuidadosa análise de fármacoeconomia mostrou que o processo, além de efetivo, economizava custos em termos de anos de vida salva com qualidade. Em termos absolutos, os custos de internação de um paciente caíram de US\$ 29,3 mil para US\$17,5 mil, no último trimestre avaliado (LOBO et al., 2019).

As dificuldades do processo de implementação do protocolo de sepse visando melhoria de qualidade assistencial são muitas. Um dos principais entraves ao processo é o diagnóstico tardio desses pacientes, com consequente atraso na intervenção e aumento de mortalidade, como já foi claramente demonstrado em hospitais públicos brasileiros. A falta de estrutura dos hospitais, a limitação de profissionais 
qualificados, o desconhecimento das diretrizes de tratamento também são causas potenciais (MARTINS et al., 2014).

Os atuais dados nacionais e a existência clara de diretrizes bem estabelecidas para o tratamento dão sustentação ao planejamento de ações visando à detecção precoce da sepse e seu tratamento adequado nas instituições hospitalares.

A educação em saúde possibilita a transformação das práticas profissionais e da própria organização do trabalho, capacitando os profissionais de saúde com base na problematização do seu processo laboral. Contribui para efetua relações integradas entre ensino, serviços e atenção à saúde, possibilitando a agregação entre aprendizado, reflexão crítica sobre o trabalho e resolutividade da clínica e da promoção da saúde (SINGER et al., 2016).

\section{CONSIDERAÇÕES FINAIS}

Evidenciando a necessidade de pôr em prática estratégias com o objetivo de reverter este cenário, é de extrema importância que sejam realizados novos estudos na busca por informações e dados que possam contribuir de forma significativa para a implantação de intervenções terapêuticas efetivas relacionadas à sepse.

Embora as progressivas quedas das taxas de mortalidade sejam animadoras, as diferenças entre hospitais são preocupantes e devem direcionar esforços das políticas de saúde pública para melhorias de gestão. Estimular melhor organização, particularmente nas instituições públicas de um sistema de saúde que sofre com falta de recursos e má distribuição de vagas, deve fazer parte das políticas de saúde pública.

Neste sentido, os profissionais de saúde assumem uma importante função com relação ao fortalecimento para o diagnóstico e manejo da sepse dentro ambiente hospitalar, contribuindo para a melhoria assistencial e segurança ao paciente.

Espera-se que a análise reflexiva proposta sobre a sepse no contexto hospitalar possa direcionar para que os planos de gestão hospitalar incluam estratégias com enfoque para a promoção da saúde, com ênfase para o reconhecimento de práticas imprescindíveis para o cuidado seguro e efetivo junto aos pacientes assistidos.

\section{REFERÊNCIAS}

[1] ANSELMO JÚNIOR, E. Incidência de sepse nosocomial em adultos de uma Unidade de Terapia Intensiva, Tubarão (SC), em 2013. Arq. Catarin Med., v. 46, n.4, p. 17-26, 2017.

[2] BARRETO, M.F.C.; et al. Sepse em um hospital universitário: estudo prospectivo para análise de custo da hospitalização de pacientes. Rev Esc Enferm USP, v. 50, n.2, p. 302-08, 2016.

[3] BARROS, L.L.S.; MAIA, C.S.F.; MONTEIRO, M.C. Fatores de risco associados ao agravamento de sepse em pacientes em Unidade de Terapia Intensiva. Cad Saúde Colet, v. 24, n.4, p. 388-96, 2016.

[4] BROOKS, D.; et al. Sepsis caused by bloodstream infection in patients in the intensive care unit: the impact of inactive empiric antimicrobial therapy on out come. J Hosp Infect, v.98, n.4, p.369-74, 2017.

[5] CAMARGO, C.C.; et al. Prevalência de Infecções Nosocomiais em Unidades de Terapia Intensiva: Revisão Sistemática. Rev Pan Inf, v.16, n.3, p.180-86, 2014.

[6] CARRARA, D.; STRABELLI, T.M.V.; UIP, D.E. Controle de Infecção: a prática no terceiro milênio, 1.ed., Rio de Janeiro: Guanabara Koogan, 2017.

[7] CUNHA, C.C.; TEIXEIRA, R.; FRANÇA, E. Avaliação da investigação de óbitos por causas mal definidas no Brasil em 2010. Epidemiol. Serv. Saúde, v. 26, n.1, p. 19-30, 2017.

[8] DEWITTE, A.; et al. Blood platelets and sepsis pathophysiology: A new therapeutic prospect in critical ill patients?. An Intensive Care, v.7, n.1, p.115, 2017.

[9] GIACOMINI, M.G.; et al. Choque séptico: importante causa de morte hospitalar após alta da unidade de terapia intensiva. Rev. bras. ter. intensiva, São Paulo, v. 27, n.1, p.51-56, 2015.

[10] INSTITUTO LATINO AMERICANO PARA ESTUDOS DA SEPSE (ILAS). Sepse: um problema de saúde pública. Brasília: CFM, 2015.

[11] INSTITUTO LATINO AMERICANO PARA ESTUDOS DA SEPSE (ILAS). Relatório ILAS, 2017.Disponível em: <http://ilas.org.br/assets/arquivos/upload/declaracao\%20sepse\%203.0\%20ILAS.pdf.>. Acesso em: 13 jan. 2020. 
[12] LOBO, S.M. et al.; Mortalidade por sepse no Brasil em um cenário real: projeto UTIs Brasileiras. Rev. bras. ter. intensiva, São Paulo, v.31, n.1, 2019. Disponível em: < http://www.scielo.br/scielo.php?script=sci_arttext\&pid=S0103507X2019000100001>. Acesso em: 12 jan. 2020.

[13] MACHADO, F.R.; et al. The epidemiology of sepsis in Brazilian intensive care units (the Sepsis prevalence Assessment Database, SPREAD): an observational study. Lancet Infect Dis, v.17, n.10, p.124-45, 2017.

[14] MARTINS, F.P.; et al. Avaliação da adesão ao protocolo de septicemia em um hospital de médio porte em Minas Gerais. Rev Per, v.11, n.1, p. 207-23, 2014.

[15] MOURA, J.M.; et al. Diagnóstico de sepse em pacientes após internação em unidade de terapia intensiva. Arq. Ciênc. Saúde, v. 24, n.3, p. 55-60, 2017.

[16] PARULLA, C.D.; et al. Sepse: desenvolvimento e avaliação de um curso em EAD para formação interdisciplinar. R Epidemiol Control Infec, Santa Cruz do Sul, v.6, n.1, p. 06-11, 2016.

[17] PERNER, A.; et al. Common Sense Approach to Managing Sepsis. Crit Care Clin, v. 34, n.1, p.127-38, 2018.

[18] PETTERLE, R.R.; et al. Associação da taxa de mortalidade e disfunção de órgãos na sepse grave. Rev Bras Biom., v.34, n.4, p. 455-67, 2016.

[19] QUINTEN, V.M.; et al. Protocol of the sepsivit study: a prospective observational study to determine whether continuous heart rate variability measurement during the first 48 hours of hospitalisation provides an early warning for deterioration in patients presenting with infection or sepsis to the emergency department of a Dutch academic teaching hospital. BMJ Open, v.7, n.11, 2017.

[20] ROTHMAN, M.; et al. Sepsis as 2 problems: Identifying sepsis at admission and predicting onset in the hospital using an electronic medical record-based acuity score. J Crit Care, v.38, p.237-44, 2017.

[21] SANTOS, A.M.; SOUZA, G.R.B.; OLIVEIRA, A.M.L. Sepse em adultos na unidade de terapia intensiva: características clínicas. Arq Med Hosp Fac Cienc Med Santa Casa São Paulo, v.61, p.3-7, 2016.

[22] SANTOS, A.V.; et al. Perfil epidemiológico da sepse em um hospital de urgência. Rev Prevenção Infecção Saúde, v.1, n.1, p. 19-30, 2015.

[23] SANTOS, M.R.; et al. Mortes por sepse: causas básicas do óbito após investigação em 60 municípios do Brasil em 2017. Rev Bras Epidemiol, v.22, p. 01-14, 2019.

[24] SINGER, M.; et al. The third international consensus definitions for sepsis shock (sepsis-3). JAMA, v. 315, n.8, p. 801-10, 2016.

[25] MEDEIROS, L.M.; VALENÇA, A.M.G.; ANJOS, U.U. Modelo preditivo para diagnostico da sepse em unidades de terapia intensiva. Tempus Actas Saúde Coletiva, v. 10, n.2, p.143-65, 2016.

[26] ZHOU, J.; et al. Epidemiology and outcome of severe sepsis and septic shock in intensive care units in mainland China. PLoS One, v.16, n.9, p.177-81, 2014.

[27] ZONTA, F.N.S.; et al. Características epidemiológicas e clínicas da sepse em um hospital público do Paraná. R Epidemiol Control Infec, Santa Cruz do Sul, v.8, n.3, p. 224-31, 2018. Cunha CC, Teixeira R, França E. Avaliação da 


\section{Capítulo 11}

\section{Saúde mental das enfermeiras: Diferenciais de gênero e saúde}

\section{Iracema Lua}

Paloma de Sousa Pinho

Tânia Maria de Araújo

Resumo: As discussões apresentadas neste ensaio repousam na apreensão de que a saúde é resultante de relações sociais, de classe e de sexo, construídas históricoculturalmente, em que o trabalho desempenha papel crucial. A proposta é refletir sobre a temática gênero, trabalho e saúde com ênfase nas repercussões dos diferenciais de gênero na concepção do trabalho em saúde, bem como, na estruturação do trabalho feminino na saúde mental das enfermeiras, tanto no âmbito profissional quanto doméstico. Nesse sentido, pretende-se contribuir para as discussões no campo da Saúde Mental e do Trabalho, apresentando os aspectos econômicos e ambientais como fatores determinantes da saúde dando visibilidade ao conflito existente em equilibrar as demandas familiares, as cobranças pessoais e do trabalho que recaem, principalmente, entre as mulheres e podem ser fatores condicionantes para o desenvolvimento de transtornos mentais comuns.

Palavras chave: Gênero; Divisão sexual do trabalho profissional e doméstico; Enfermagem; Estresse Ocupaconal 


\section{CONSIDERAÇÕES INICIAIS}

A partir da década de 70, observa-se crescente introdução dos estudos referentes ao gênero, o qual se constitui como elemento das relações sociais, baseadas principalmente nas relações de poder. As reivindicações feministas foram as precursoras da introdução desta categoria analítica nos estudos nas diferentes áreas de conhecimento, incluindo os estudos epidemiológicos, o que permite a incorporação de aspectos relacionados ao gênero nas teorias explicativas das persistentes desigualdades sociais entre os homens e as mulheres (SCOTT, 1990).

A saúde das populações é identificada como expressão de condições sociais, culturais e históricas das coletividades, evidenciando-se o papel fundamental do trabalho neste processo. A reestruturação produtiva modificou os processo e relações de trabalho e, em consequência, modificou também a realidade dos (as) trabalhadores (as), agregando novos elementos e diversos enfoques que colaboram para a produção de novas desigualdades e heterogeneidades, enquanto mantêm e, muitas, aprofundam as antigas e permanentes distinções laborais entre homens e mulheres (BRITO, 2000). Os estudos referentes à divisão sexual do trabalho e às relações de gênero são relevantes exatamente por dar visibilidade a essas desigualdades.

Lévi-Strauss (1981) defende que é, sobretudo, essa divisão do trabalho entre os sexos que tornou o casamento indispensável, numa concepção de que a divisão do trabalho institui um estado de dependência recíproca entre os sexos. Brito (1999) corrobora com esta concepção de que as tarefas são determinadas/destinadas segundo o sexo, ao entender que as relações de gênero, bem como a divisão sexual do trabalho, têm caráter normativo/prescritivo, que se apresenta, de forma naturalizada. Em outras palavras, os autores identificam que as atividades de um sexo são interditas ao outro e os distintos mundos do trabalho são imposição do meio, ficando o homem com o espaço público, produtivo e com reconhecimento social e a mulher com o espaço privado, reprodutivo, sem visibilidade e/ou prestígio (SOUZA; GUEDES, 2016).

A abordagem de gênero pode ser articulada às análises com foco na atividade do trabalho, na medida em que esta comporta reconhecimento das normatizações e das tentativas de subvertê-las. Além disso, poderá dar visibilidade e contribuir na compreensão do trabalho concreto das mulheres.

Esse ensaio tem a finalidade de refletir sobre a temática gênero, trabalho e saúde, pautado no conceito ampliado de trabalho - que abrange o trabalho doméstico - e suas interações com a reprodução social e os modos de vida. As discussões repousam na compreensão de que a saúde e o trabalho são resultantes das relações sociais, de classe e de sexo.

Dessa forma, objetiva-se realizar uma revisão teórica sobre as influências das relações de gênero na saúde mental das enfermeiras, com foco na divisão do trabalho profissional e doméstico. No que tange ao trabalho profissional, será feita uma revisão da construção histórico-social da feminilização e subordinação da profissão de enfermagem, bem como análise crítica da sobrecarga de trabalho das mulheres que têm demandas profissionais e familiares, buscando identificar as possíveis repercussões nas condições de saúde dessa população, com ênfase na saúde mental. Para isso, utilizaram-se artigos que abordam a temática de interesse, com destaque para Scott (1990), Steagall-Gomes e Mendes (1995), Aquino e Menezes (1998), Thompson (2000), Bourdieu (2002), Barbosa e Soler (2003), Araújo e colaboradores (2003; 2005), Elias e Navarro (2006), Hirata e Kergoat (2007), Araujo e Rotenberg (2011), Bilac (2014) e Sousa e Guedes (2016).

\section{GÊNERO E TRABALHO}

A divisão sexual do trabalho é decorrente das relações sociais e culturais. Mais do que isso, é fator prioritário para a permanência de tipos específicos de relações sociais entre os sexos, sendo também modulada histórica e socialmente. Origina-se na designação, construída culturalmente, dos homens à esfera produtiva e das mulheres à reprodutiva (SOUZA; GUEDES, 2016) e, simultaneamente, a apropriação pelos homens do poder e das funções com maior valor social, político e econômico (HIRATA; KERGOAT, 2007).

Pesquisas históricas demonstraram que as mulheres sempre trabalharam, e este trabalho sempre repercutiu na sua saúde, ainda que a invisibilidade do trabalho realizado por esse grupo tenha dificultado a identificação das repercussões desse trabalho na vida e na saúde dessas mulheres. Uma explicação para sua permanência na penumbra é que em muitos casos o trabalho profissional das mulheres guarda proximidade com o trabalho doméstico. Outra explicação relaciona-se à concepção de que as competências 
requeridas nessas atividades são qualidades naturais, mantendo-as imperceptíveis e submetendo-as a permanente desvalorização. As duas perspectivas apresentadas são importantes para o desvelamento das relações de poder e subordinação que sustentam a divisão sexual do trabalho.

0 trabalho profissional, estudado e analisado aqui por meio das configurações existentes na estruturação do trabalho em saúde, em especial dentro dos hospitais, organiza-se em práticas diferenciadas de tratamento e de cuidado, as quais orientam e são orientadas pela divisão sexual e social do trabalho e a definição de papéis, através das funções e dos espaços diferenciados entre homens e mulheres. Desse modo, este espaço é um campo fértil para o estudo e análise das relações/questões de gênero quanto à conformação da divisão sexual do trabalho.

0 trabalho em saúde, analisado sob a ótica da enfermagem, carrega características perpetuadas na profissão e se configura como uma atividade essencialmente feminina, com práticas focadas no cuidado ao doente como uma extensão do domínio privado. Esta feminilização da enfermagem tem sua origem atribuída aos "sistemas de diferenças" que determinam as construções das distinções sociais com base nas diferenças anatômicas, a partir das importantes representações do órgão sexual (BOURDIEU, 2002, p. 10).

As desigualdades de gênero são sustentadas pela ideia de que a mulher é qualificada para as atividades domiciliares e para o cuidado dos mais fragilizados, como crianças, idosos e enfermos. Nessa perspectiva, as escolhas profissionais das mulheres seguem o padrão determinado pela construção social simbólica, ou seja, na área da saúde, a "aptidão" feminina volta-se para as práticas do cuidado. Os dados provenientes do estado de São Paulo, apresentados no estudo de Bilac (2014), sinalizam que, entre os grandes grupos ocupacionais, as mulheres predominam amplamente entre aquelas funções ligadas ao cuidar, mas um cuidar agora exercido fora de casa, sendo elas a maioria entre as professoras, assistentes sociais e enfermeiras.

É perceptível, dessa forma, a existência, no campo da enfermagem, de uma construção até mesmo de profissão com base em 'qualidades' e não em 'qualificações', produzindo desta forma, a desvalorização do trabalho feminino, e consequentemente a subordinação das mulheres aos "qualificados" homens da medicina, o que muito bem abordam Araújo e Rotenberg (2011) em seu trabalho:

"A compreensão dos processos de qualificação feminina e masculina importante sustentáculo das relações de poder segundo o gênero - é central para dar visibilidade aos processos de dominação e subordinação da enfermagem, no interior dos hospitais, na medida em que constrói e perpetua o envolver da valorização/desvalorização profissional" (p. 135-36).

Percebe-se, nesta configuração, que o trabalho no setor saúde é tendenciosamente diferenciado para homens e mulheres, sendo consequências das diferenças sociais conservadas entre os sexos. Esta divisão sexual do trabalho em saúde produz o conceito do senso comum de que a enfermagem é uma profissão que deve ser exercida pelas mulheres e que o masculino é representado pela medicina.

Alguns autores citam a recente existência de uma "transição de gênero", referindo-se à inserção de mulheres na ocupação médica e de homens na enfermagem. Entretanto, pode-se observar, na prática e em estudos realizados neste sentido, que esses dois processos se dão de formas opostas. Em estudo realizado por Martins (2008), sobre a inversão dos papéis no mercado de trabalho, observou-se que no caso da medicina, há a inserção feminina, entretanto, a hierarquia do sexo masculino não deixa de prevalecer, permanecendo numa mesma profissão o reconhecimento e os papéis diferenciados entre homens e mulheres, estando as mulheres em condições inferiores. Esta hierarquia masculina também é percebida na profissão de enfermagem, quando há a inserção dos mesmos nessa atividade.

Araújo e Rotenberg (2011) corroboram com a constatação da concretização da hierarquia masculina e demonstram que mesmo quando os homens são inseridos em uma profissão considerada como feminina, estes se encontram em cargos/funções de maior prestígio e poder.

É nesse sentido que Thompson (2000) aponta para a existência de uma relação de dominação sustentáculo das relações de poder. Para o mesmo "as formas simbólicas estão inseridas em contextos sociais estruturados que envolvem relações de poder, formas de conflito e desigualdades em termos de distribuição de recursos" (p.54). Dessa forma, identifica-se que a divisão dos espaços e atividades laborais, bem como as diferentes formas de reconhecimento e remuneração profissional e atribuição de poder, se dão segundo características simbólicas sexuais e, mesmo que venham ocorrendo inserções do sexo oposto 
nos mundos femininos ou masculinos, essa divisão ainda persiste, e a dominação simbólica (dominação masculina) está corporificada, fazendo vítimas tanto entre as mulheres quanto entre os homens (BOURDIEU, 2002).

Neste sentido corpo é visto como o nosso capital cultural, onde ocorrem as disputas pelo poder. É através dele que os sujeitos são identificados ao nascer - como homens ou mulheres. Por conseguinte, a depender das formas de educação, os sujeitos se posicionarão como dominantes ou dominados. Assim:

“a simples observação dos órgãos externos 'diagnostica' uma condição que deve valer para toda a vida. Passamos a ser homens ou mulheres e as construções culturais provenientes dessa diferença evidenciam inúmeras desigualdades e hierarquias que se desenvolveram e vêm se acirrando ao longo da história humana, produzindo significados e testemunhando práticas de diferentes matizes" (SAYÃO, 2003, p. 122).

A consequência de tais representações sociais engendradas pelo capital simbólico é o quase consenso de que a mulher é o ser menos capaz, o sexo frágil, que precisa a todo tempo de um protetor; além disso, ainda hoje relegada a seu papel de reprodutora, enquanto a virilidade e os atributos considerados masculinos como forte e protetor são preferidos em detrimento daqueles concebidos como "femininos". Essa concepção se estende para as atividades laborais, onde as mulheres são destacadas como profissionais menos capazes e que possuem atividades técnicas e sociais específicas para sua condição feminina, configurando assim a divisão sexual do trabalho. Adicionalmente as mulheres ainda precisam conviver com a distinção na valorização do trabalho, com menor reconhecimento e diferenças na remuneração e nos privilégios.

Conforme descrito anteriormente, os papéis sociais atribuídos aos gêneros estabelecem formas diferenciadas de organizar as atividades laborais. Essa desigualdade de atribuições e espaços também se estende para a vida fora do trabalho - continuam no interior das famílias. Estudos revelam o caráter essencial das complexas relações entre as esferas domésticas e profissional, apontando para as possíveis repercussões na saúde das mulheres. Essa é uma das questões que impulsionam esse ensaio.

0 conceito de trabalho defendido pela sociologia de cunho feminista questiona a limitação apenas ao trabalho remunerado, propondo uma definição que aborde todas as formas laborais, incluindo assim o trabalho doméstico (KERGOAT, 1989). Neste sentido, não se pode discutir divisão sexual do trabalho, trabalhos femininos ou questões de gênero, sem levar em consideração as conformações do trabalho doméstico e os papéis socialmente atribuídos a homens e mulheres, na medida em que eles envolvem diferentes fatores de exposição, e são concretamente formas de trabalho.

Apesar da peculiaridade do trabalho profissional das mulheres, limitado ou acrescido por responsabilidades domiciliares, aspectos relacionados ao trabalho doméstico ainda permanecem pouco estudados. Essa invisibilidade decorre da percepção desta atividade como não-trabalho, uma vez que não possui remuneração, não produz valor (ARAUJO et al., 2005). Na concepção capitalista, o principal definidor das atividades é o lucro produzido - a mais valia (MARX, 2014). Em função disso, as atividades não remuneradas não são reconhecidas cultural, social e economicamente.

As demandas do âmbito doméstico se configuram como uma atividade organizativa, complexa e desgastante, principalmente pela falta de uma rede de apoio minimamente articulada ou oferecida pelo Estado (escolas em tempo integral, creches ou transportes públicos de qualidade). Disto decorre uma sobrecarga laboral sobre as mulheres, a obrigando a construir estratégias de conciliação entre o trabalho e a família, isto é, entre o trabalho remunerado e não remunerado (HIRATA; KEGOART, 2007; BILAC, 2014; SOUSA; GUEDES, 2016) e então tem-se o cansaço e o desgaste (STEAGALL-GOMES; MENDES, 1995). Alguns estudos que abordam o trabalho doméstico sinalizam possíveis consequências dessa sobrecarga, como o isolamento, a falta de estímulos, as relações de poder, a dependência e o sofrimento psíquico (BORDERÍAS; CARRASCO, 1994; ARAÚJO et al., 2005).

A atribuição feminina, dada como natural para o trabalho doméstico, é consequência dos "sistemas de diferenças" (conforme conceito de Bourdieu) e das "relações de poder" (na acepção de Thompson), já mencionadas. Outrossim, esta atividade é vista socialmente como condicional à natureza anatômica feminina. Portanto, o trabalho doméstico constitui, assim, um campo de trabalho merecedor de análises embasadas nas questões referentes ao gênero e a saúde do trabalhador e da trabalhadora, conformadas também pelas divisões sexuais e sociais do trabalho. 
Em estudo de Araújo e colaboradores (2005), com 2055 mulheres, observou-se a conformação feminina ao trabalho doméstico, ao identificar que 13,7\% das mulheres entrevistadas eram chefes de família; 83,8\% realizavam as tarefas domésticas todos os dias da semana e 25,4\% das mulheres não recebiam qualquer tipo de ajuda nesta atividade, e quando havia o apoio, em 51,8\% dos casos, esse era disponibilizado por outras mulheres ou por empregada (12,2\%). Essas características do trabalho doméstico são corroboradas por Hirata e Kergoat (2007) quando tratam dos modelos tradicional (mulheres reprodutoras e cuidadoras e homens provedores) e de delegação (mulheres delegam a outras mulheres as atividades domésticas e familiares).

Ou seja, a realização do trabalho doméstico compete aos membros femininos, observando-se proporção elevada de mulheres que executam tarefas domésticas e a falta de apoio na realização das mesmas, principalmente disponibilizado pelo sexo masculino. Corroborando, portanto, diferenciação de reponsabilidades/espaços para homens e mulheres também nas atividades realizadas fora do mercado de trabalho.

Aquino e Menezes (1998), ao abordarem essa divisão sexual no ambiente doméstico, destacam ainda que o apoio masculino às atividades domésticas se limita as atividades de "circulação pública", ou aos pequenos consertos domésticos, e evidenciam as distinções de atribuições laborais também no interior da família. Em outras palavras, as atividades domésticas realizadas pelos homens possuem caráter mais flexível, no qual as atividades podem ter seus horários adaptados aos turnos de realização do trabalho profissional, enquanto que para as mulheres o trabalho doméstico sofre restrição do tempo, porque são tarefas tempo-dependentes como preparo da alimentação e cuidado de crianças e idosos.

As atividades domésticas são caracterizadas como monótonas, repetitivas, desvalorizadas, com interrupções constantes, ou seja, tão logo se finaliza uma tarefa já se inicia um novo ciclo de atividades, dando a sensação de um trabalho que não acaba. Essa sensação pode produzir sofrimento psíquico, depressão, ansiedade ou doenças psicossomáticas. Essa especificidade de adoecimento proveniente das atividades doméstica é elevada quando associada ao desgaste no trabalho profissional (ARAUJO et al, 2005). Por sua vez, verifica-se que os aspectos referentes ao trabalho doméstico que causam efeitos negativos à saúde são vivenciados frequentemente pelas mulheres.

\section{ADOECIMENTO MENTAL DAS ENFERMEIRAS}

As especificidades do ciclo vital das mulheres juntamente com os papeis atribuídos a elas socialmente, em especial pelas definições de gênero e da dominação masculina, determinam formas diferenciadas de adoecer e morrer desta população. Estas formam são determinadas pelo contexto no qual as populações estão inseridas, sendo, assim, socialmente produzidas. Portanto, as desigualdades de gênero, que trazem desvantagens às mulheres, têm repercussões sobra a sua saúde.

0 trabalho profissional responde por importantes exposições que colocam em risco a saúde das pessoas, sendo uma importante dimensão da vida a ser considerada nos processos saúde-doença. Como já mencionado, a divisão sexual do trabalho estabelece espaços ocupacionais distintos, configurando, por sua vez exposições diferenciadas para homens e mulheres. Na situação atual, caracterizada pela precarização do trabalho, a insegurança gerada pelo medo do desemprego, segundo Elias e Navarro (2006), faz com que os/as trabalhadores/as se submetam à regimes e contratos de trabalho precários, baixos salários e arriscam a vida em ambientes insalubres, de alto risco, reforçando os danos à saúde. Essas configurações são confirmadas por diversos estudos (ARAÚJO et al, 2003; BARBOSA; SOLER, 2003; REIS et al, 2003; COELHO, 2005; FARIAS, BARBOZA, DOMINGOS, 2005; ELIAS, NAVARRO, 2006) no campo da enfermagem, que sinalizam a submissão das mulheres à condições de trabalho precárias com consequente desvalorização enquanto profissionais.

As profissionais de enfermagem (enfermeiras e técnicas de enfermagem) são consideradas um grupo ocupacional que se destaca por suas características relacionadas ao gênero, hierarquia e sobrecarga, tanto física quanto emocional (REIS et al., 2003). Tais condições favorecem a ocorrência de problemas de saúde, frequentemente relacionados à situação e setor de trabalho, provocando prejuízos pessoais, sociais e econômicos, desvalorização das práticas de cuidado, subordinação e constantes conflitos entre categorias (BARBOZA; SOLER, 2003).

Essas profissionais são comumente expostas à ambientes de trabalhos insalubres, cujas condições de trabalho precárias associadas à baixa qualidade de vida conduzem para situações que dificultam a manutenção e garantia da própria saúde (ELIAS; NAVARRO, 2006). 
Araújo e colaboradores (2005) em seu estudo aponta uma preocupação crescente com o diagnóstico e a avaliação da saúde mental das populações, dentre os efeitos avaliados, destacam-se os transtornos mentais comuns (TMC), que designam situações de sofrimento mental e serão tomados aqui como desfecho de análise.

Estudos revelam a existência de distinções sociais/sexuais na ocorrência dos transtornos mentais em todas as sociedades, e apontam fatores que podem colocar as mulheres em situação de vulnerabilidade, tais como: baixa escolaridade, violência intradomiciliar, oportunidades de emprego e sobrecarga doméstica (SANTOS et al., 2010). Pinho e Araújo (2012), em sua investigação, corroboram com esse achado ao identificar elevada prevalência de TMC entre as mulheres (39,4\%), principalmente quando comparada à estimativa da Organização Mundial de Saúde, que refere uma prevalência média de 24\% na população geral.

Em outro estudo de Araújo e colaboradores (2003), incluindo 502 trabalhadoras de enfermagem de um hospital público de Salvador, Bahia, a prevalência de TMC encontrada foi de 33,3\%, reforçando a hipótese de que a enfermagem é uma profissão com registro elevado de adoecimento mental. Os TMC também foram mais prevalentes entre as mulheres no estudo de Araujo e colaboradores (2005), que também observou sua associação com a falta de apoio no trabalho doméstico e a inexistência de atividades de lazer.

0 restrito tempo para cuidar de si e ausência de lazer foram identificados por Araújo e colaboradores (2003), como consequência de sobrecarga de atividades e a busca das mulheres em atender todas as demandas, colocando o cuidado do outro sempre em primeiro plano.

Elias e Navarro (2006) revelarem que o devotamento e abnegação das mulheres as levam a uma negação da dor, à uma banalização de sua própria saúde. Nesse aspecto, foi identificado por esses autores que, apesar das várias queixas referenciadas pelas enfermeiras, nenhuma delas se identificava com problemas de saúde. Isto foi atribuído à existência de um mecanismo de defesa das mulheres, já que a doença é identificada pelo capitalismo como empecilho à produção e deve ser ocultado. 0 disfarçar de emoções produz sofrimento e pode se constituir em porta de entrada para problemas psicológicos.

Ao adoecimento é acrescida a falta de oportunidade de tratamento e, sobretudo, a falta de tempo já que as mulheres utilizam suas horas de folga, na maioria das vezes, para responder às suas demandas familiares. Para muitas profissionais de enfermagem, os dias de labor dificilmente se encerram após a jornada do trabalho profissional, pois muitas convivem com a dupla ou tripla jornada de trabalho (seja iniciando uma nova jornada em outro vínculo de trabalho, seja continuando seus afazeres domésticos e/ou exigências da família) (ELIAS e NAVARRO, 2006).

Barboza e Soler (2003) acrescenta ainda, que as mulheres possuem alterações fisio-morfológicas que não são consideradas no planejamento de seu trabalho, somados aos aspectos sociais supracitados. Esses determinantes podem repercutir no adoecimento desta população e consequentemente aumentar o absenteísmo. Além disso, os problemas relacionados a sua condição feminina invadem, mais uma vez, o ambiente de trabalho na medida em que as intercorrências relacionada aos filho e à família interrompe, geralmente o trabalho das mulheres (STEAGALL-GOMES e MENDES, 1995).

As cargas de trabalho são sentidas primeiro e mais fortemente pelas mulheres, do que pelos homens, uma vez que elas já chegam no trabalho cansadas pela fadiga residual e pelo que já fizeram antes de sair de casa, acarretando cansaço muscular multiplicado, o qual se soma ao cansaço mental atribuído ao conflito em tentar conciliar as demandas familiares com as demandas e exigências do trabalho.

\section{CONSIDERAÇÕES FINAIS}

Esse ensaio pretendeu contribuir para as discussões no campo da saúde, trabalho e as relações de gênero, apresentando os aspectos conceituais e fatores estruturais do processo de trabalho da enfermagem e possíveis determinantes da saúde.

Levando em conta a interface direta das questões de saúde mental do/a trabalhador/a, propõe-se que essas duas áreas realizem outros trabalhos conjunto para dar conta das necessidades complexas que ocorrem no mundo real e que garantam uma qualidade social de vida das trabalhadoras da saúde, a fim de melhorar a saúde mental.

Em suma, pode-se afirmar que as conformações dos espaços profissionais e das demandas familiares expõem as mulheres a diversas e elevadas cargas de trabalho que são acrescidas pela abnegação e negação de seus problemas de saúde. Então se supõem com essa revisão teórica que as distinções de gênero devem 
ser consideradas em muitos aspectos como determinante de saúde para as mulheres, em especial para as enfermeiras, que se encontram desvalorizadas, sem reconhecimento e, sobretudo, expostas as características estressantes inerentes a essa profissão.

O panorama apresentado reforça a necessidade de valorização da mulher no mercado de trabalho e a necessidade da divisão e aceitação do trabalho doméstico como algo presente e desgastante. Nesse âmbito, a sobrecarga de afazeres e as cobranças pessoais e do mercado de trabalho são fatores condicionantes para o adoecimento mental, sendo identificado em especial o desenvolvimento de transtornos mentais comuns.

Por fim, deve-se ter consciência de que a eliminação ou redução da exposição às condições de risco e a melhoria dos ambientes de trabalho para promoção e proteção da saúde das trabalhadoras constituem um desafio que ultrapassa o âmbito de atuação dos serviços de saúde.

\section{REFERÊNCIAS}

[1] AQUINO, E.M.L.; MENEZES, G.M.S. Para pensar o exercício da paternidade: contribuições a partir de um estudo sobre trabalho e saúde das mulheres. In: SILVEIRA, P. Exercício da Paternidade. Porto Alegre: Artes Médicas, 1998. p: 131-31.

[2] ARAUJO, T.M. et al. Aspectos psicossociais do trabalho e distúrbios psíquicos entre trabalhadoras de enfermagem. Rev. Saúde Pública [online], vol.37, n.4, pp. 424-433. 2003.

[3] ARAUJO, T.M. et al. Prevalência de transtornos mentais comuns em mulheres e sua relação com as características sociodemográficas e o trabalho doméstico. Rev. Bras. Saúde Matern. Infant., vol. 5, n. 3, pp. 337-348. Recife, jul. / set., 2005.

[4] ARAUJO, TM; ROTENBERG, L. Relações de Gênero no Trabalho em Saúde: a divisão sexual do trabalho e a saúde dos trabalhadores. In: ASSUNÇÃO. AA; BRITO, J. (org.). Trabalhar na saúde: experiências cotidianas e desafios para a gestão do trabalho e do emprego. Rio de Janeiro: Editora Fiocruz, 2011. Cap.6, p. 131-150.

[5] BARBOZA, D. B.; SOLER, Z. A. S. G. Afastamentos do trabalho na enfermagem: ocorrências com trabalhadores de um hospital de ensino. Rev. Latino-am Enfermagem; vol. 11, n.2, pp.177-83. Março-abril, 2003.

[6] BILAC, E.D. Trabalho e família: articulações possíveis. Tempo Social, revista de sociologia da USP, v. 26, n. 1, p. 129-45. 2014.

[7] BORDERIAS, C.; CARRASCO, C. Las mujeres y el trabajo: Aproximaciones históricas, sociológicas y económicas. In: BORDERÍAS, C.; CARRASCO, C.; ALEMANY, C. Las Mujeres y el Trabajo: Rupturas Conceptuales. pp. 15-109, Barcelona: Icaria - Suhem. 1994.

[8] BOURDIEU, Pierre. A dominação Masculina. Tradução Maria Helena Kuhner - 2ª ed.- Rio de Janeiro: Bertrand Brasil, 2002.160p.

[9] BRITO J. Saúde, trabalho e modos sexuados de viver. Fiocruz, Rio de Janeiro, 1999.

[10] BRITO, Jussara Cruz de. Enfoque de gênero e relação saúde/trabalho no contexto de reestruturação produtiva e precarização do trabalho. Cad. Saúde Pública, vol.16, no.1,p.195-204. Jan, 2000.

[11] COELHO, Edméia de Almeida Cardoso. Gênero, saúde e enfermagem. Rev. bras. enferm. [online]. vol.58, n.3, pp. 345-348. Brasília, 2005.

[12] ELIAS, Marisa Aparecida Elias; NAVARRO, Vera Lúcia. A relação entre o trabalho, a saúde e as condições de vida: negatividade e positividade no trabalho das profissionais de enfermagem de um hospital escola. Rev Latino-am Enfermagem.; vol. 14, n. 4, pp. 517-25. Julho-agosto, 2006.

[13] FABBRO, Márcia Regina C.; HELOANI, José Roberto M. Mulher, maternidade e trabalho acadêmico. Invest. educ. enferm [online], vol.28, n.2, pp. 176-186. 2010.

[14] FARIA, A. C.; BARBOZA, D. B.; DOMINGOS, N. A. M. Absenteísmo por transtornos mentais na enfermagem no período de 1995 a 2004. Arq Ciênc Saúde, vol. 12, n. 1, pp. 14-20. Jan-mar, 2005.

[15] HIRATA, H.; KERGOAT, D. Novas Configurações da Divisão Sexual do Trabalho. In: Cadernos de Pesquisa, V. 37, n. 132, p. 595-609, Set/Dez, 2007. 
[16] KERGOAT, D. Da divisão do trabalho entre os sexos. Tempo Social. Revista de sociologia da USP, vol. 1, n. 2, pp. 73-103, 1989.

[17] LÉVI-STRAUSS, Claude. Les strutures elementaires de lá parente. Paris, Mouton, 1981.

[18] MARTINS, MR. A inversão de papéis no mercado de trabalho. Ogerente.com [internet]. São Paulo: Ogerente.com; 19/Ago/2008.

[19] MARX, K. O Capital: crítica da economia política: Livro I; Tradução de Reginaldo Sant'Anna. - 33ª ed. - Rio de Janeiro: Civilização Brasileira, 2014.

[20] PINHO, P. S.; ARAUJO, T. M. Associação entre sobrecarga doméstica e transtornos mentais comuns em mulheres. Rev Bras Epidemiol; vol. 15, n. 3, pp. 560-72. 2012.

[21] REIS, R.J. et al. Fatores relacionados ao absenteísmo por doença em profissionais de enfermagem. Rev Saúde Pública, v. 37, n. 5, p. 616-23. 2003.

[22] SANTOS, K.O.B. et al. Avaliação de um Instrumento de Mensuração de Morbidade Psíquica: Estudo de Validação do Self-Reporting Questionnaire (SRQ-20). Rev Baiana Saúde Publica, v.34, n.3, p.544-560. jul./set. 2010.

[23] SAYÃO, Débora Thomé. Corpo, poder e dominação: um diálogo com Michelle Perrot e Pierre Bourdieu. Revista Perspectiva, v.21 n.01, jan/jun 2003. Editora da UFSC: NUP/CED. Florianópolis.

[24] SCOTT, J. Gênero: uma categoria útil de análise histórica. Educação e Realidade, vol. 16, n. 2, pp. 522, 1990.

[25] SOUSA, L.P.; GUEDES, D.R. A desigual divisão sexual do trabalho: um olhar sobre a última década. Estudos Avançados, vol. 30, n. 87, p 123-39. 2016.

[26] STEAGALL-GOMES, D.L.; MENDES, I.J.M. A Força de Trabalho da Mulher. Acta Paul Enf., v. 8, n.1, p. 61-74. São Paulo, 1995.

[27] THOMPSON, J. B. Ideologia e Cultura Moderna. 5a.ed., Petrópolis: Editora Vozes, 2000 


\section{Capítulo 12}

Prevalência de distúrbios psíquicos menores em fisioterapeutas intensivistas de uma grande cidade do estado da Bahia

\section{Cleide Lucilla Carneiro Santos}

Núbia Samara Caribé de Aragão

Lorena Pacheco Cordeiro Lisboa

Eder Pereira Rodrigues

Gabriella Bené Barbosa

Davi Félix Martins Júnior

Mônica de Andrade Nascimento

Carlito Lopes Nascimento Sobrinho

Resumo: INTRODUÇÃO: Os estudos sobre Distúrbios Psíquicos Menores (DPM) em fisioterapeutas intensivistas são raros e muitos desses profissionais ainda desconhecem a relação entre o trabalho e saúde mental. OBJETIVO: Estimar a prevalência de Distúrbios Psíquicos Menores (DPM) em Fisioterapeutas intensivistas de uma grande cidade do Estado da Bahia. MÉTODOS: Estudo epidemiológico descritivo, populacional, abrangendo 60 fisioterapeutas intensivistas que atuavam na cidade em 2016. Um questionário autoaplicável avaliou dados sociodemográficos, características do trabalho e DPM por meio do Self Report Questionnaire (SRQ-20). RESULTADOS: Dos trabalhadores estudados 51,7\% trabalhavam em UTI adulto, 20,0\% em UTI pediátrica e $28,3 \%$ em UTI neonatal, $38,4 \%$ dos profissionais estudados trabalhavam em duas ou mais unidades. 0 sexo feminino predominou com $80,0 \%$ dos trabalhadores estudados, a média de idade foi de $32,2 \pm 4,9,45,0 \%$ tinham companheiro, 58,3\% não tinham filhos. A prevalência de DPM foi de 41,7\%. CONCLUSÃO: Observou-se elevada prevalência de DPM entre os fisioterapeutas intensivistas estudados. Os resultados apontam à necessidade de novos estudos que investiguem a relação entre trabalho e saúde mental em fisioterapeutas intensivistas.

Palavras-Chave: Sofrimento Mental. Prevalência. Fisioterapeutas. Unidade de Terapia Intensiva. 


\section{INTRODUÇÃO}

O interesse por questões relacionadas aos vínculos entre trabalho e saúde/ doença mental, vem ganhando visibilidade na literatura acadêmica e tem fortalecido a investigação da relação trabalho e saúde entre os profissionais de saúde. Estudos indicam o aumento na frequência de doenças, de estresse ocupacional e de sofrimento mental entre esses trabalhadores, especificamente entre os fisioterapeutas intensivistas ${ }^{1,2}$. Diversas pesquisas apontam uma contribuição importante das características do ambiente de trabalho, das condições gerais da oferta e gestão do trabalho nos serviços de saúde com o sofrimento psíquico dos trabalhadores que atuam nesses serviços ${ }^{3,4,5,6,7,8}$.

As atividades dos fisioterapeutas intensivistas são fortemente tensionadas por longas jornadas de trabalho e pelo desgaste psicoemocional nas tarefas realizadas no ambiente da Unidade de Terapia Intensiva (UTI) ${ }^{1,2}$. No Brasil, pesquisadores têm realizado estudos epidemiológicos com trabalhadores da área de saúde observando a associação entre as condições e características do trabalho em saúde e os Distúrbios Psíquicos Menores (DPM) 3,4,6,7,8,9,10,11.

Os Distúrbios Psíquicos Menores são condições clínicas caracterizadas por alterações nos pensamentos e nas emoções ou por comportamentos relacionados à angústia pessoal e/ou à deterioração do funcionamento psíquico, tendo efeitos deletérios, atingindo não somente o indivíduo, mas a família e a comunidade $^{5}$. Os sintomas de DPM incluem esquecimento, dificuldade na concentração e tomada de decisões, insônia, irritabilidade e fadiga, assim como queixas somáticas (cefaleia, falta de apetite, tremores, má digestão, entre outros), o que pode comprometer o desempenho nas atividades laborais ${ }^{12}$.

As Unidades de Terapia Intensiva são historicamente consideradas como importante causa de estresse para os pacientes e seus familiares. Porém, atualmente tem se destacado que esse ambiente também é estressante para a equipe profissional. Este estresse pelo trabalho em UTI ocorre principalmente por se tratar de um ambiente fechado, com condições e ritmos de trabalho extenuantes, rotinas exigentes, questões éticas que cabem decisões frequentes e difíceis, convívio com sofrimento e morte, imprevisibilidade e carga horária de trabalho excessiva $2,7,13,14,15$.

0 profissional fisioterapeuta passou a ser membro integrante da equipe multidisciplinar nas UTIs, por meio da Portaria 3432/98 do Ministério da Saúde que também definiu a proporção de leitos por profissional, que não deve ultrapassar a de 01 (um) fisioterapeuta para cada 10 (dez) leitos, compondo a equipe básica de saúde junto com médicos e enfermeiros ${ }^{16}$.

A literatura registra que DPM constituem um importante fator de adoecimento entre os trabalhadores de saúde $3,4,5,6,7,8,10,11$, porém existe poucos estudos abordando fisioterapeutas intensivistas e muitos profissionais desconhecem esse distúrbio como fator de adoecimento no trabalho.

Diante do exposto, esse estudo tem como objetivo estimar a prevalência de Distúrbios Psíquicos Menores em Fisioterapeutas intensivistas de uma grande cidade do Estado da Bahia.

\section{METODOLOGIA}

Trata-se de um estudo epidemiológico descritivo, populacional, abrangendo todos os fisioterapeutas intensivistas que atuavam na cidade no ano de 2016. Este estudo representa um recorte do projeto "Saúde Mental de Trabalhadores Intensivistas de uma Grande Cidade da Bahia", elaborado e executado por pesquisadores da Sala de Situação e Análise Epidemiológica e Estatística (SSAEE). 0 estudo foi aprovado pelo Comitê de Ética em Pesquisa da Universidade Estadual de Feira de Santana (CEP/UEFS), Parecer no 1.355.188, CAAE 49119315.4.0000.0053, cumprindo dessa forma, as determinações da Resolução $466 / 201212$.

Foi estudada a população de fisioterapeutas intensivistas, que no ano da realização do estudo totalizavam 60 trabalhadores. Esses fisioterapeutas trabalhavam em sete (07) dos oito (08) hospitais, que tinham Unidade de Terapia Intensiva e foram incluídos no estudo após a autorização da participação dos mesmos pela direção dos hospitais. Ressalta-se que a direção de um 01 hospital não autorizou a pesquisa, porém, os fisioterapeutas intensivistas que trabalhavam nessa unidade foram pesquisados, pois, também trabalhavam em outros hospitais da cidade. Dentre as unidades incluídas no estudo: um (01) hospital geral de referência em urgência e emergência da macrorregião Centro-leste da Bahia, um (01) hospital estadual de referência em atendimento pediátrico, um (01) hospital municipal e quatro (04) hospitais da rede privada, sendo uma (01) maternidade, um (01) de referência em cardiologia, e dois (02) de urgência/emergência (adulto/pediátrico). 
Foram considerados elegíveis, todos os fisioterapeutas $(n=60)$ que atuavam em terapia intensiva, cadastrados no setor de Recursos Humanos dos sete hospitais investigados. 0 critério de inclusão foi trabalhar em UTI há pelo menos seis meses, para evitar o viés de trabalhador saudável. Os critérios de exclusão foram: atuar em atividade administrativa, estar em gozo de férias, em licença médica ou licença maternidade.

A coleta de dados foi realizada entre julho a setembro de 2016, por meio da distribuição do questionário autoaplicável, acompanhado do Termo de Consentimento Livre e Esclarecido (TCLE). Os questionários foram acompanhados de carta de apresentação e justificativa do trabalho e encaminhados aos trabalhadores de UTI, chegando-se os profissionais que devolviam os questionários pelos respectivos números de identificação (cada número de questionário correspondia a um profissional pesquisado).

Foi utilizado um questionário autoaplicável, anônimo, composto por nove blocos de questões: identificação geral; informações gerais sobre o trabalho; características psicossociais do trabalho; síndrome de estafa profissional; qualidade de vida; capacidade para o trabalho; aspectos relacionados à saúde (SRQ 20)5; hábitos de vida e padrão de sono e fatores de estresse na UTI.

0 questionário e o TCLE foram entregues a cada trabalhador nas unidades pelos pesquisadores, marcando-se o local e a hora da devolução. Os pesquisadores esclareceram sobre os objetivos do estudo e as instruções gerais sobre o preenchimento. Os profissionais que não devolviam o questionário na data agendada eram contatados por telefone, buscando-se minimizar perdas e/ou recusas. Os questionários foram devolvidos em envelopes lacrados para garantir o sigilo e a confidencialidade.

O SRQ foi desenvolvido por Harding et al. (1980) ${ }^{17}$ sob a coordenação da Organização Mundial de Saúde (OMS) e validado para utilização no Brasil por Mari e Willians (1986), com a finalidade de suspeitar morbidade psiquiátrica em instituições primárias de saúde (não hospitalares). A versão brasileira do SRQ possui 20 questões, 04 sobre sintomas físicos e 16 sobre sintomas psicoemocionais, que apresentam respostas dicotômicas. "sim" ou "não", atribuindo-se respectivamente os valores "1" e "0" às respostas. A validação do SRQ 20 adotou o escore de 07 ou mais respostas positivas ( $\geq 7$ ) para a suspeição de morbidade psiquiártrica (DPM), obtendo-se sensibilidade de 83\% e especificidade 80\% ${ }^{17,18}$.

O grau de suspeição para distúrbios psíquicos foi avaliado com base no escore alcançado por cada fisioterapeuta no SRQ-20. Adotou-se o ponto de corte igual ou maior que sete respostas positivas, adotado em outras pesquisas na área de saúde do trabalhador $3,4,9$.

Foi realizada dupla digitação dos dados coletados no programa EpiData versão 3.1, para minimizar possíveis erros. Utilizou-se o software Statistical Package for Social Science (SPSS®) para a análise estatística. A análise descritiva dos dados foi realizada com o cálculo das frequências absolutas e relativas das variáveis qualitativas e da média e do desvio padrão das variáveis quantitativas. Os resultados foram apresentados por meio de tabelas.

\section{RESULTADOS}

Este estudo teve a participação de 60 fisioterapeutas, sendo $80 \%$ (48) do sexo feminino. A média observada para a faixa etária foi de $32,2 \pm 4,9$. Quanto a cor da pele, 53,3\% (32) se consideram pardos, 30,0\% (18) brancos, 8,3\% (05) pretos, 6,7\% (04) amarelos e 1,7\% (01) não responderam. Em relação a situação conjugal 55\% (33) eram solteiros, 36,7\% (22) eram casados, 5,0\% (03) tinham união estável e 3,3\% (02) eram divorciados. Em relação a ter filhos, 58,3\%. Dentre os profissionais estudados 76,7 \% (46) têm o título de especialistas, 15,0\% (09) não tinham especialização, 6,7\% (04) têm mestrado e 1,7\% (01) tem residência. Em relação a renda 63,3\% (38) informaram renda mensal entre $\mathrm{R} \$ 3.001,00-6.000,00$, $18,3 \%$ (11) renda mensal menor que $R \$ 3.000,00,11,7 \%$ (7) entre $6.001-10.000,00$ e $6,7 \%(4)$ entre 10.001- 20.000,00. Entre os trabalhadores estudados 51,7\% (31) trabalhavam em UTI adulto, 20,0\% (12) em UTI pediátrica e 28,3\% (17) em UTI neonatal. (Tabela 1). 
Tabela 1 - Características sociodemográficas da população de fisioterapeutas intensivistas, Feira de Santana, Bahia, 2016.

\begin{tabular}{|c|c|c|}
\hline $\begin{array}{c}\text { Características sociodemográficas dos fisioterapeutas } \\
\text { intensivistas }\end{array}$ & $\mathbf{N}^{*}$ & $\%$ \\
\hline \multicolumn{3}{|l|}{ Sexo $(N=60)$} \\
\hline Feminino & 48 & 80,0 \\
\hline Masculino & 12 & 20,0 \\
\hline \multicolumn{3}{|l|}{ Faixa Etária $(\mathrm{N}=60)$} \\
\hline $\begin{array}{l}\leq 33 \text { anos } \\
34 \text { anos ou mais }\end{array}$ & $\begin{array}{l}36 \\
24\end{array}$ & $\begin{array}{l}60,0 \\
40,0\end{array}$ \\
\hline \multicolumn{3}{|l|}{ Cor da Pele $(\mathrm{N}=60)$} \\
\hline Branca & 18 & 30,0 \\
\hline Amarela & 4 & 6,7 \\
\hline Parda & 32 & 53,3 \\
\hline Preta & 5 & 8,3 \\
\hline Não sabe & 1 & 1,7 \\
\hline \multicolumn{3}{|l|}{ Situação Conjugal $(\mathrm{N}=60)$} \\
\hline Solteiro & 33 & 55,0 \\
\hline Casado & 22 & 36,7 \\
\hline União estável & 3 & 5,0 \\
\hline Divorciado (a) & 2 & 3,3 \\
\hline \multicolumn{3}{|l|}{ Filhos $(\mathrm{N}=60)$} \\
\hline Não & 35 & 58,3 \\
\hline Sim & 25 & 41,7 \\
\hline \multicolumn{3}{|l|}{ Formação Acadêmica $(\mathrm{N}=60)$} \\
\hline Especialista & 46 & 76,7 \\
\hline Sem especialização & 9 & 15,0 \\
\hline Mestrado & 4 & 6,7 \\
\hline Residência & 1 & 1,7 \\
\hline \multicolumn{3}{|l|}{ Tipo de UTI $(\mathrm{N}=60)$} \\
\hline Adulto & 31 & 51,7 \\
\hline Neonatal & 17 & 28,3 \\
\hline Pediátrica & 12 & 20,0 \\
\hline \multicolumn{3}{|l|}{ Renda Mensal $(\mathrm{N}=60)$} \\
\hline$\leq 3.000,00$ & 11 & 18,3 \\
\hline $3.000,00-6.000,00$ & 38 & 63,3 \\
\hline $6.000,00-10.000,00$ & 7 & 11,7 \\
\hline $10.000,00-20.000,00$ & 4 & 6,7 \\
\hline $\begin{array}{c}\text { Características sociodemográficas dos fisioterapeutas } \\
\text { intensivistas }\end{array}$ & $\mathbf{N}^{*}$ & $\%$ \\
\hline \multicolumn{3}{|l|}{ Sexo $(\mathrm{N}=60)$} \\
\hline $\begin{array}{l}\text { Feminino } \\
\text { Masculino }\end{array}$ & 48 & 80,0 \\
\hline \multicolumn{3}{|l|}{ Faixa Etária $(\mathrm{N}=60)$} \\
\hline $\begin{array}{l}\leq 33 \text { anos } \\
34 \text { anos ou mais }\end{array}$ & $\begin{array}{l}36 \\
24\end{array}$ & 60,0 \\
\hline \multicolumn{3}{|l|}{ Cor da Pele $(\mathrm{N}=60)$} \\
\hline Branca & 18 & 30,0 \\
\hline Amarela & 4 & 6,7 \\
\hline Parda & 32 & 53,3 \\
\hline Preta & 5 & 8,3 \\
\hline Não sabe & 1 & 1,7 \\
\hline \multicolumn{3}{|l|}{ Situação Conjugal $(\mathrm{N}=60)$} \\
\hline Solteiro & 33 & 55,0 \\
\hline Casado & 22 & 36,7 \\
\hline União estável & 3 & 5,0 \\
\hline Divorciado (a) & 2 & 3,3 \\
\hline \multicolumn{3}{|l|}{ Filhos $(\mathrm{N}=60)$} \\
\hline Não & 35 & 58,3 \\
\hline Sim & 25 & 41,7 \\
\hline
\end{tabular}

* Respostas válidas excluídas as ignoradas. 
Tabela 2 - Características do trabalho da população de fisioterapeutas intensivistas, Feira de Santana, Bahia, 2016.

\begin{tabular}{|c|c|c|}
\hline $\begin{array}{l}\text { Características do trabalho dos fisioterapeutas } \\
\text { intensivistas }\end{array}$ & $\mathbf{N}^{*}$ & $\%$ \\
\hline \multicolumn{3}{|l|}{ Tempo/Trabalho na UTI (anos) $(\mathrm{N}=60)$} \\
\hline $\begin{array}{l}\leq 5 \text { anos } \\
\geq 6 \text { anos }\end{array}$ & $\begin{array}{l}38 \\
22\end{array}$ & $\begin{array}{l}63,3 \\
36,7\end{array}$ \\
\hline \multicolumn{3}{|l|}{$\mathrm{CH}^{* *}$ de Trabalho em UTI $(\mathrm{N}=60)$} \\
\hline $\begin{array}{l}24 \text { horas } \\
12 \text { horas } \\
\text { Outros }\end{array}$ & $\begin{array}{c}34 \\
24 \\
2\end{array}$ & $\begin{array}{c}56,7 \\
40,0 \\
3,3\end{array}$ \\
\hline \multicolumn{3}{|l|}{$\mathrm{CH}^{* *}$ Semanal de plantão em UTI $(\mathrm{N}=60)$} \\
\hline $\begin{array}{l}12 \text { horas } \\
24-30 \text { Horas } \\
36-78 \text { Horas }\end{array}$ & $\begin{array}{c}3 \\
39 \\
18\end{array}$ & $\begin{array}{c}5,0 \\
65,0 \\
30,0\end{array}$ \\
\hline \multicolumn{3}{|l|}{$\mathrm{CH}^{* *}$ de plantão noturno em UTI $(\mathrm{N}=60)$} \\
\hline $\begin{array}{l}12-24 \text { Horas } \\
36-96 \text { Horas }\end{array}$ & $\begin{array}{c}54 \\
6\end{array}$ & $\begin{array}{l}90,0 \\
10,0\end{array}$ \\
\hline \multicolumn{3}{|l|}{$\mathrm{CH}^{* *}$ total semanal $(\mathrm{n}=57)^{*}$} \\
\hline $\begin{array}{l}\leq 56 \text { horas } \\
\text { Maior que } 56 \text { horas }\end{array}$ & $\begin{array}{l}30 \\
27\end{array}$ & $\begin{array}{l}50,8 \\
45,8\end{array}$ \\
\hline \multicolumn{3}{|l|}{ Vínculo Institucional $(\mathrm{N}=60)$} \\
\hline $\begin{array}{l}\text { Assalariado privado } \\
\text { Assalariado público } \\
\text { Cooperativado } \\
\text { Prestador de serviço } \\
\text { Contrato temporário } \\
\text { Pessoa Jurídica } \\
\text { Sócio }\end{array}$ & $\begin{array}{c}16 \\
14 \\
13 \\
8 \\
5 \\
2 \\
2\end{array}$ & $\begin{array}{c}26,7 \\
23,3 \\
21,7 \\
13,3 \\
8,3 \\
3,3 \\
3,3\end{array}$ \\
\hline \multicolumn{3}{|l|}{ Atividade laboral fora da UTI $(\mathrm{N}=60)$} \\
\hline $\begin{array}{l}\text { Fisioterapia em outra especialidade } \\
\text { Não tem } \\
\text { Docência } \\
\text { Fora da área da saúde }\end{array}$ & $\begin{array}{c}38 \\
11 \\
8 \\
3\end{array}$ & $\begin{array}{c}63,3 \\
18,3 \\
13,3 \\
5,0\end{array}$ \\
\hline \multicolumn{3}{|l|}{ Trabalho em UTI $(\mathrm{N}=60)$} \\
\hline $\begin{array}{l}1 \text { hospital } \\
2 \text { hospitais } \\
3 \text { hospitais } \\
4 \text { hospitais }\end{array}$ & $\begin{array}{c}37 \\
18 \\
4 \\
1\end{array}$ & $\begin{array}{c}61,7 \\
30,0 \\
6,7 \\
1,7\end{array}$ \\
\hline \multicolumn{3}{|l|}{ Pacientes por plantão $(\mathrm{N}=60)$} \\
\hline $\begin{array}{l}05 \text { pacientes } \\
08 \text { pacientes } \\
10 \text { pacientes } \\
14 \text { pacientes } \\
15 \text { pacientes }\end{array}$ & $\begin{array}{c}2 \\
10 \\
45 \\
2 \\
1\end{array}$ & $\begin{array}{c}3,3 \\
16,7 \\
75,0 \\
3,3 \\
1,7\end{array}$ \\
\hline \multicolumn{3}{|l|}{ Vem de outro trabalho $(n=60)$} \\
\hline $\begin{array}{l}\text { Sim } \\
\text { Não }\end{array}$ & $\begin{array}{l}22 \\
38\end{array}$ & $\begin{array}{l}36,7 \\
63,3\end{array}$ \\
\hline
\end{tabular}

* Respostas válidas excluídas as ignoradas;

${ }^{* *} \mathrm{CH}=$ Carga horária. 
Tabela 3 - Hábitos de vida da população de fisioterapeutas intensivistas, Feira de Santana, Bahia, 2016

\begin{tabular}{|c|c|c|}
\hline Hábitos de vida dos fisioterapeutas intensivistas & $\mathrm{N}^{*}$ & $\%$ \\
\hline \multicolumn{3}{|l|}{ Bebida alcoólica $(\mathrm{N}=60)$} \\
\hline Bebe & 25 & 41,7 \\
\hline Não bebe & 35 & 58,3 \\
\hline \multicolumn{3}{|l|}{ Hábito de fumar $(\mathrm{N}=60)$} \\
\hline Nunca Fumou & 53 & 88,3 \\
\hline Ex-fumante & 4 & 6,7 \\
\hline Fuma até 4 cigarros $p /$ dia & 1 & 1,7 \\
\hline Outros & 2 & 3,3 \\
\hline \multicolumn{3}{|l|}{ Pratica alguma atividade física(N=60) } \\
\hline Pratica & 34 & 56,7 \\
\hline Não pratica & 26 & 43,3 \\
\hline \multicolumn{3}{|l|}{ Frequência semana $(\mathrm{N}=34)$} \\
\hline 1x na semana & 2 & 5,9 \\
\hline 2x na semana & 25 & 73,5 \\
\hline $3 x$ na semana & 7 & 20,6 \\
\hline \multicolumn{3}{|l|}{ Peso Corporal $(\mathrm{N}=60)$} \\
\hline Peso ideal & 21 & 35,0 \\
\hline Abaixo do ideal & 5 & 8,3 \\
\hline Pouco acima do ideal & 27 & 45,0 \\
\hline Muito acima do ideal & 7 & 11,7 \\
\hline
\end{tabular}

* Respostas válidas excluídas as ignoradas.

Tabela 4 - Prevalência de Distúrbio Psíquico Menor (DPM) medido pelo SRQ-20 na população de fisioterapeutas intensivistas, Feira de Santana, Bahia, 2016

\begin{tabular}{|l|c|c|}
\hline \multicolumn{1}{|c|}{ Sofrimento Mental (identificado pelo SRQ 20) } & N & $\%$ \\
\hline Positivo & 25 & 41,7 \\
\hline Negativo & 35 & 58,3 \\
\hline Total & 60 & 100,0 \\
\hline
\end{tabular}

Entre os aspectos relacionados ao trabalho, a maioria dos fisioterapeutas, 63,3 \% (38) apresentavam menos de 5 anos e 36,7\% (22) mais que 6 anos de trabalho em UTI. Trabalhavam em plantão de 24 horas $56,7 \%$ (22) e 40\% (24) em plantões de 12 horas em UTI. Em relação à carga horária semanal de plantão 65\% (39) trabalhavam de 24 a 30 horas, 30\% (18) trabalhavam de 36 a 78 horas e 5\% (3) trabalhavam 12 horas semanais. A carga horária total de trabalho semanal informada, incluindo, além dos plantões, outras atividades laborais que geram renda, 50,8\% (30) dos profissionais trabalhavam menos que 56 horas e 45,8\% (27) mais que 56 horas, uma média de 57,26 de carga horária total de trabalho semanal e mediana de 55 horas.

Dentre essas atividades além da UTI, a maioria 63,3\% (38) dos fisioterapeutas trabalhavam em outra especialidade, $13,3 \%$ (8) eram docentes, 18,3\% (11) não apresentavam outra atividade e 5\% (3) informaram trabalhar em outro tipo de atividade, diferente da área de saúde. Com relação ao trabalho noturno em UTI, 90\% (54) dos profissionais trabalhavam entre 12 a 24 horas e 10\% (6) trabalhavam entre 36 a 96 horas, com uma média 19,3 horas e mediana de $12 \mathrm{~h}$ de trabalho noturno. Em relação à quantidade de hospitais que esses trabalhadores atuavam, verificou-se que a maioria $61,7 \%(37)$ trabalhavam em 1 hospital, 30\% (18) trabalhavam em 2 hospitais, 6,7\% (4) trabalham em 3 hospitais e $1,7 \%$ (1) em até 4 hospitais.

Pôde-se verificar uma diferença quanto ao número de pacientes atendidos por plantão, a maioria dos profissionais 75\% (45) atendiam 10 pacientes, 16,7\% (10) atendiam 08 pacientes, 3,3\% (2) 14 pacientes, 3,3\% (2) 5 pacientes e 1,7\% (1) atendiam até 15 pacientes por plantão. 0 vínculo Institucional mais comum entre os fisioterapeutas foi assalariado no setor privado, representado por $26,7 \%(16), 23,3 \%(14)$ eram assalariados no setor público 23,3\% (14), 21,7\% (13) eram cooperativados, 13,3\% (8) informaram ser prestador de serviço, 8,3\% (5) apresentavam contrato temporário e 3,3\% (2) atuavam como pessoa jurídica, 36,7\% vem de outro trabalho antes do plantão na UTI. (Tabela 2).

Em relação aos hábitos de vida dos trabalhadores estudados, 58,3\% (35) não bebiam e 41,7\% (25) faziam uso de bebida alcoólica. Quanto ao hábito de fumar, 88,3\% (53) nunca fumaram, 6,7\% (4) eram exfumantes, 1,7\% (1) fumava até 4 cigarros por dia. A prática de atividade física estava presente nos hábitos 
de vida de 56,7\% (34) dos fisioterapeutas estudados e 43,3\% (26) não realizavam nenhuma atividade física. No entanto, entre os que praticam atividade física, 73,5\% (25) apresentavam frequência de duas vezes por semana, $20,6 \%$ (7) três vezes por semana e 5,9\% (2) uma vez por semana. Desses trabalhadores, $45 \%$ (27) se considerava um pouco acima do peso ideal, $35 \%$ (21) concordam que estão com peso ideal, $11,7 \%$ (7) acham que estão muito acima do peso e 8,3\% (5) abaixo do peso ideal. (Tabela 3). A prevalência de Distúrbio Psíquico Menor medida pelo SRQ-20, em fisioterapeutas intensivistas foi de $41,7 \%$ (25) dos trabalhadores estudados. (Tabela 4).

\section{DISCUSSÃO}

Os fisioterapeutas intensivistas estudados são em sua maioria do sexo feminino, adultos jovens (idade < 34 anos), solteiros, sem filhos, com tempo de até 6 anos de trabalho em UTI, renda mensal entre $\mathrm{R} \$ 3.001,00$ a $6.000,00$, carga horária de trabalho semanal de 24 a 30 horas, carga horária habitual de plantão de até 24 horas, carga horária de plantões noturnos de 12 a 24 horas. A maioria trabal hava em apenas um hospital, atendia pelo menos 10 pacientes por plantão, apresentava vínculo de trabalho assalariado (privado/público), não fazia uso de bebida alcoólica e não fumava, realizava atividade física com uma frequência de duas vezes por semana.

0 perfil dos fisioterapeutas observado foi semelhante ao encontrado em outros trabalhos consultados que estudaram fisioterapeutas atuantes em UTI, predomínio do sexo feminino, solteiros ${ }^{1,2}$ e também, com o de outras categorias profissionais, idade média menor que 40 anos $4,7,8,11,19$, e tempo de trabalho em UTI menor que 5 anos $^{1,7}$.

A prevalência de DPM encontrado neste estudo foi de 41,7\%, resultado semelhante com o estudo de Pinhatti et al., (2018) que apresentou uma prevalência global de DPM entre trabalhadores de enfermagem de 32,6\%, com o de Marcelino Filho e Araújo (2015) que estudou profissionais de saúde de um Centro de Assistência especializada em Aracaju que estimou uma prevalência nos fisioterapeutas de 57,1\% e o de Carvalho et al., (2013) 20 que obteve uma prevalência de 51,1\% em residentes da cidade de Recife.

Observou-se também, uma prevalência maior do que a encontrada no estudo de Nascimento et al., (2019) de $24,6 \%$, em enfermeiras intensivistas de Feira de Santana, Bahia, com a de Rodrigues et al., (2014) que estimou uma prevalência de 35,0\% em enfermeiros de um hospital geral, em Feira de Santana, Bahia, de Alves et al., (2015) que obteve 27,9\% de positividade para DPM em profissionais de saúde do Hospital de Clínicas da Universidade Federal do Triângulo Mineiro, de Nascimento Sobrinho et al., (2006) de 26,0\% em uma amostra aleatória de médicos, em Salvador, Bahia, com a de Araújo et al., (2003) de 33,3\% em profissionais de enfermagem de um hospital público, em Salvador, Bahia, e com o de Carvalho, Araújo e Bernardes (2016) que encontrou uma prevalência de 22,9\% em trabalhadores da Atenção Básica.

Em relação à predominância do sexo feminino, sabe-se há muitas décadas que o trabalho em saúde se apresenta historicamente feminino, fato que pode estar relacionado a essência das profissões de saúde, o ato de cuidar, visto como uma ação de dedicação e múltiplas funções, atribuída historicamente ao sexo feminino ${ }^{21,22,23}$.

Os resultados apresentados apontam que os Distúrbios Psíquicos Menores podem estar relacionados ao trabalho e assim, podem ser considerados um problema de saúde pública em função de sua alta prevalência em trabalhadores de saúde e de suas consequências, como o absenteísmo, incapacidade para o trabalho e aposentadoria precoce.

0 trabalho em sistema de plantão noturno foi citado no estudo de Monteiro (2013) ${ }^{24}$ como causa de estresse e de complicações à saúde, uma vez que o desequilíbrio do ritmo biológico pode gerar dificuldade na quantidade e na qualidade do sono, confirmando os achados com o estudo de Nascimento et al., (2019), que foi verificada maior prevalência de DPM entre enfermeiros intensivistas que trabalhavam à noite.

Esses distúrbios ainda não são reconhecidos com frequência nos atendimentos clínicos e setores em que as demandas psicossociais são elevadas como as UTIs, devido às características estressantes do tipo de trabalho realizado, o que torna esses trabalhadores mais vulneráveis ao sofrimento e ao adoecimento mental ${ }^{5}$.

Em relação ao consumo de bebida alcoólica, observou-se que 41,7\% dos fisioterapeutas intensivistas estudados consumiam bebida alcoólica. Em um estudo realizado com trabalhadores de enfermagem de um Hospital Geral da Bahia que utilizou o teste CAGE, instrumento de triagem, para detecção de abuso no consumo de bebidas alcoólicas, dos que informaram o uso de bebida alcoólica, 27,7\% destes foram considerados bebedores-problema ${ }^{4}$ e no estudo de Nascimento et al (2019) com enfermeiras 
intensivistas, foi encontrada associação positiva entre o consumo de bebida alcoólica e DPM, o que pode comprometer a saúde e o desempenho profissional, colocando em risco a segurança do paciente.

Com relação aos hábitos de vida, a maior parte dos fisioterapeutas 56,7\% relatou praticar atividade física e dos que praticavam 73,5\% informaram uma frequência de duas vezes por semana. A literatura aponta inúmeros benefícios relacionados com a prática da atividade física nos hábitos cotidianos e profissionais, tais como: melhora cognitiva, combate ao estresse, ansiedade, depressão, melhora das relações interpessoais e melhor desempenho nas atividades laborais ${ }^{25}$.

Importante tecer algumas considerações metodológicas desse estudo: os estudos descritivos não permitem estabelecer nexo causal, apenas descrevem a magnitude de um determinado problema de saúde, nesse caso, a prevalência de Distúrbios Psíquicos Menores e a frequência e ocorrência de certas características como sexo, idade, características do trabalho, hábitos de vida.

Por se tratar de um estudo populacional, os resultados observados dizem respeito tão somente aos fisioterapeutas intensivistas de Feira de Santana, não sendo adequado, a extrapolação dos resultados obtidos para outras realidades; a utilização do questionário autoaplicável, pela característica subjetiva do respondente, pode influenciar os resultados a depender do grau de compreensão, bem como, permite a devolução de questionários com respostas incompletas. Por fim, observou-se uma escassez na literatura de estudos que abordem os DPM em fisioterapeutas que atuam em terapia intensiva, assim, prejudicando a comparação e a discussão dos resultados observados.

\section{CONCLUSÃO}

Os resultados apontaram elevada prevalência de DPM entre os fisioterapeutas estudados, o que sinaliza para a reflexão sobre a adoção de medidas que possam prevenir e/ou modificar os resultados encontrados. Por fim, os resultados apontam para a necessidade de novos estudos que investiguem a relação entre trabalho e saúde mental de fisioterapeutas intensivistas.

\section{REFERÊNCIAS}

[1] Silva G de JP da, Ferreira PAM, Costa RP, Jesus SFC de, Gondim LAR, Ferreira PR. Danos à saúde relacionados ao trabalho de fisioterapeutas que atuam em terapia intensiva. Vol. 7, Ago. 2016. DOI: 10.47066/2177-9333/ac.25328. < file://C:/Users/User/Downloads/25328-122578-1-PB\%20(1).pdf>.

[2] Santos CLC, Barbosa GB, Nascimento DSS, Martins Júnior DF, Nascimento Sobrinho CL. Prevalência de Síndrome da Estafa Profissional e fatores associados em fisioterapeutas intensivistas. Rev Pesqui em Fisioter. 2018 Sep 17;8(3):336-44. DOI: 10.17267/2238-2704rpf.v8i3.2032.< file://C:/Users/User/Downloads/2032-11529-1PB.pdf>.

[3] Nascimento Sobrinho CL, Carvalho FM, Bonfim TAS, Cirino CAS, Ferreira IS. Condições de trabalho e saúde dos médicos em Salvador, Brasil. Cad. Saúde Pública vol.22 no.1 Rio de Janeiro. 2006. DOI: 10.1590/S0102311X2006000100014. < https://www.scielo.br/scielo.php?script=sci_arttext\&pid=S0102-311X2006000100014>.

[4] Rodrigues EP, Rodrigues US, Oliveira L de MM, Laudano RCS, Nascimento Sobrinho CL. Prevalência de transtornos mentais comuns em trabalhadores de enfermagem em um hospital da Bahia. Rev Bras Enferm. 2014 Mar 1;67(2):296-301. DOI: 10.5935/0034-7167.20140040.< https://www.scielo.br/pdf/reben/v67n2/0034-7167reben-67-02-0296.pdf>.

[5] Carvalho DB de, Araújo TM de, Bernardes KO. Transtornos mentais comuns em trabalhadores da Atenção Básica à Saúde. Rev Bras Saúde Ocup. 2016;41(0). DOI: 10.1590/2317-6369000115915. < https://www.scielo.br/scielo.php?pid=S0303-76572016000100210\&script=sci_abstract\&tlng=pt >.

[6] Pinhatti EDG, Ribeiro RP, Soares MH, Martins JT, Lacerda MR. Distúrbios psíquicos menores na enfermagem: prevalência e fatores associados. Rev Bras Enferm. 2018;71:2176-83. DOI: 10.1590/0034-7167-2018-0028. <https://www.scielo.br/scielo.php?pid=S0034-71672018001102176\&script=sci_abstract\&tlng=pt>.

[7] Nascimento DDSS, Barbosa GB, Santos CLC, Martins Júnior DF, Sobrinho CLN. Prevalência de Distúrbio Psíquico Menor e fatores associados em enfermeiros intensivistas. Rev Baiana Enfermagem. 2019 Jun 21;33:280-91. DOI: 10.18471/rbe.v33.28091. < http://www.revenf.bvs.br/pdf/rbaen/v33/1984-0446-rbaen-33-e28091.pdf>.

[8] Pascoal KPMF, Santos ACB da C, Silva JASS da, Fernandes VM de S, Sousa MN de. Avaliação da qualidade de vida, estresse e saúde mental dos profissionais de saúde das Unidade de Terapia Intensiva. Rev Interdiscip em saúde. 2019 Nov 25;6(5):19-30. DOI: 10.35621/23587490.v6.n5.p19-30. < https://www.interdisciplinaremsaude.com.br/Volume_27/Trabalho_02.pdf>. 
[9] Araújo TM, Aquino E, Menezes G, Santos CO, Aguiar L. Aspectos psicossociais do trabalho e distúrbios psíquicos entre trabalhadoras de enfermagem. Rev Saude Publica. 2003;37(4):424-33. DOI: 10.1590/S003489102003000400006. < https://www.scielo.br/scielo.php?script=sci_arttext\&pid=S0034-89102003000400006>.

[10] Alves AP, Pedrosa LAK, Coimbra MAR, Miranzi MAS, Hass VJ. Prevalência de transtornos mentais comuns entre profissionais de saúde. Rev Enferm. 2015 Jan 1;23(1):64-9. DOI: 10.12957/reuerj.2015.8150. < https://pesquisa.bvsalud.org/portal/resource/pt/lil-762098>.

[11] Marcelino Filho A, Araújo TM de. Estresse ocupacional e saúde mental dos profissionais de Centro de Especialidades Médicas de Aracaju. Trab Educ e Saúde. 2015;13(suppl 1):177-99. DOI: 10.1590/1981-7746-sip00016. <https://www.scielo.br/scielo.php?script=sci_arttext\&pid=S1981-77462015000400177\&lng=pt\&tlng=pt>.

[12] Fiorotti KP, Rossoni RR, Borges LH, Miranda AE. Transtornos mentais comuns entre os estudantes do curso de medicina: prevalência e fatores associados Common mental disorders in medical students: prevalence and associated factors. J Bras Psiquiatr. 2010;59(1):17-23. DOI: 10.1590/S0047-20852010000100003. <https://www.scielo.br/pdf/jbpsiq/v59n1/v59n1a03.pdf>.

[13] Barros DDS, Tironi MOS, Nascimento Sobrinho CL, Neves FS, Bitencourt AGV, Almeida ADM, et al. Médicos plantonistas de unidade de terapia intensiva: perfil sócio-demográfico, condições de trabalho e fatores associados à síndrome de burnout. Rev Bras Ter Intensiva. 2008;20(3):235-40. DOI: 10.1590/S0103-507X2008000300005. < https://www.scielo.br/pdf/rbti/v20n3/v20n3a05.pdf>.

[14] Tironi MOS, Nascimento Sobrinho CL, Barros DDS, Reis EJFB, Marques Filho ES, Almeida A, et al. Trabalho e síndrome da estafa profissional (Síndrome de Burnout) em médicos intensivistas de Salvador. Rev Assoc Med Bras. 2009;55(6):656-62. DOI: 10.1590/S0104-42302009000600009. < https://www.scielo.br/pdf/ramb/v55n6/09.pdf>.

[15] Tironi MOS, Teles JMM, Barros D de S, Vieira DFVB, Silva Filho CM, Martins DF, et al. Prevalência de síndrome de burnout em médicos intensivistas de cinco capitais brasileiras. Rev Bras Ter Intensiva. 2016;28(3):270-7. DOI: 10.5935/0103-507X.20160053. < https://www.scielo.br/pdf/rbti/v28n3/0103-507X-rbti-28-03-0270.pdf>.

[16] Portaria GM/MS no 3432 de 12 de agosto de 1998. - DOU No 154 Estabelece critérios de classificação para as Unidades de Tratamento Intensivo - UTI. Ministério da Saúde. 1998;(D):1-5. < http://bvsms.saude.gov.br/bvs/saudelegis/gm/1998/prt3432_12_08_1998.html>.

[17] Harding, TW et al. Mental disorders in primary health care: a study of their frequency and diagnosis in four developing countries. Psychological Medicine, v. 10, n. 2, p. 231-241,1980.

[18] Mari JJ; Willians P. A validity study of a psychiatric screening questionnaire (SRQ-20) in primary care in the city of São Paulo. The British Journal of Psychiatry, v. 148, n. 1, p. 23-26, 1986.

[19] Koch MO, França DA, Nascimento FC do, Segura D de CA. Estresse físico e mental em fisioterapeutas e equipe de enfermagem em unidade de terapia intensiva. Rev Interdiscip. 2019;12(1):23-31. < file://C:/Users/User/Downloads/1390-3840-1-PB\%20(1).pdf>.

[20] Carvalho CN, Melo-filho DA De, Alberto J, Carvalho G De, Carla A, Amorim G De. Prevalência e fatores associados aos transtornos mentais comuns em residentes médicos e da área multiprofissional. J Bras Psiquiatr. 2013;62(1):38-45. DOI: 10.1590/S0047-20852013000100006.

<https://www.scielo.br/scielo.php?script=sci_arttext\&pid=S0047-20852013000100006>.

[21] Guerrer FJL, Bianchi ERF. Caracterização do estresse nos enfermeiros de unidades de terapia intensiva. Rev da Esc Enferm. 2008;42(2):355-62. DOI: 10.1590/S0080-62342008000200020.< http://www.scielo.br/scielo.php?script=sci_arttext\&pid=S0080-62342008000200020>.

[22] Borges T; Bianchin MA. Qualidade de vida dos profissionais de enfermagem de um hospital universitário do interior de São Paulo. Arq Ciênc Saúde. 2015;22:53-8. < file://C:/Users/Cleide/Downloads/29-1-105-1-1020150331\%20(2).pdf>.

[23] Machado MH, Aguiar Filho W, Lacerda WF de, Oliveira E, Lemos W, Wermelinger M, et al. Características gerais da enfermagem: o perfil sócio demográfico. Vol. 6. 2015. < http://biblioteca.cofen.gov.br/wpcontent/uploads/2016/07/Caracter\%C3\%ADsticas-gerais-da-enfermagem-o-perfil-s\%C3\%B3ciodemogr\%C3\%A1fico.pdf>.

[24] Monteiro JK, Oliveira ALL de, Ribeiro CS, Grisa GH, Agostini N de. Adoecimento Psíquico de Trabalhadores de Unidades de Terapia Intensiva. Psicol Ciência e Profissão. 2013;33(2):366-79. DOI: 10.1590/S141498932013000200009. < https://www.scielo.br/pdf/pcp/v33n2/v33n2a09.pdf>.

[25] Freire CB, Dias RF, Schwingel PA, de França EET, de Andrade FMD, Costa EC, et al. Qualidade de vida e atividade física em profissionais de terapia intensiva do sub médio São Francisco. Rev Bras Enferm. 2015;1;68(1):2631. DOI: 10.1590/0034-7167.2015680104p < https://www.scielo.br/pdf/reben/v68n1/0034-7167-reben-68-010026.pdf>. 


\section{Capítulo 13}

Distúrbios psíquicos menores e qualidade de vida de enfermeiros intensivistas em uma grande cidade do interior da Bahia

Núbia Samara Caribé de Aragão

Cleide Lucilla Carneiro Santos

Deise dos Santos Silva Nascimento

Eder Pereira Rodrigues

Gabriella Bené Barbosa

Davi Félix Martins Júnior

Mônica de Andrade Nascimento

Carlito Lopes Nascimento Sobrinho

Resumo: Introdução: as condições de trabalho configuram-se como um dos fatores determinantes da situação de saúde dos trabalhadores. 0 ambiente de trabalho no decorrer do tempo passou por diversas transformações que muitas vezes interferiram diretamente na saúde do trabalhador. No setor saúde, observa-se transformações constantes e progressivas, com relação as Unidades de Terapia Intensiva (UTI) são apontadas como um dos ambientes mais exaustivos e tensos do hospital. Caracteriza-se pela exposição ao desgaste físico e emocional, decorrente da convivência diária com a angústia e o sofrimento dos pacientes e familiares. Os enfermeiros são os profissionais responsáveis pela coordenação da equipe de enfermagem, organização, gerenciamento, bem como, a prestação de assistência direta aos pacientes que demandam cuidados intensivos. São trabalhadores intensamente expostas a riscos de origem biológica, química, física, ergonômica, além dos riscos psicossociais, que podem comprometer a saúde mental desses trabalhadores. Objetivo: estimar a prevalência e os fatores associados aos Distúrbios Psíquicos Menores em enfermeiros intensivistas. Método: estudo de corte transversal, censitário, exploratório, realizado em nove Unidades de Terapia Intensiva de sete hospitais de uma grande cidade do interior da Bahia, Brasil, no período de julho a novembro de 2016. Utilizou-se um questionário validado, autoaplicável e não identificado. Resultados: observou-se associação com as variáveis: idade, carga horária total de trabalho; carga horária de trabalho, plantão noturno, duplo vínculo e tipo de Unidade de Terapia Intensiva; e consumo de álcool. Discussão: a prevalência de DPM foi de $24,6 \%$, corroborando com o resultado do estudo sobre a sintomatologia de Transtorno Mental Comum (TMC) em enfermeiros de UTI, que encontrou uma prevalência de $27,7 \%$. Conclusão: a prevalência estimada foi de $24,6 \%$ com elevada prevalência de Distúrbios Psíquicos Menores na população estudada.

Palavras-chave: Sofrimento Mental. Enfermeiros. Unidades de Terapia Intensiva. 


\section{INTRODUÇ̃̃OO}

As condições de trabalho configuram-se como um dos fatores determinantes da situação de saúde dos trabalhadores, podendo contribuir para o seu fortalecimento ou a sua deterioração. Com o aumento da competitividade no mundo contemporâneo, o ambiente de trabalho passou a ser identificado como um local de muitas exigências laborais e desencadeador de intenso desgaste físico e mental dos trabalhadores (1). O trabalho em saúde, considerado parte do setor de serviços, é uma atividade da esfera da produção não material, que se completa no ato da sua realização. É organizado com base em uma crescente divisão técnica e hierárquica, que implica na fragmentação do processo de trabalho ${ }^{(2)}$. Por isso, o serviço de enfermagem desempenha papel fundamental nas unidades de saúde.

0 ambiente de trabalho no decorrer do tempo passou por diversas transformações que muitas vezes interferiram diretamente na saúde do trabalhador (2). No setor saúde, observou-se transformações constantes e progressivas, especialmente nas últimas décadas do século XX e nas duas primeiras décadas do século XXI. Na atualidade os trabalhadores são submetidos a regimes de intensos de trabalho e tiveram perdas significativas em seus diretos e na sua remuneração. Além da intensa jornada de trabalho, cobranças, precarização, somadas aos fatores específicos da área da saúde, tais como, o envolvimento com a dor e sofrimento do outro $(3,4)$.

As Unidades de Terapia Intensiva (UTI) podem ser apontadas como um dos ambientes mais exaustivos e tensos do hospital. Caracteriza-se pela exposição ao desgaste físico e emocional, decorrente da convivência diária com a angústia e o sofrimento dos pacientes e familiares (4).

Os enfermeiros são os profissionais responsáveis pela coordenação da equipe de enfermagem, organizando e gerenciando os cuidados prestados aos pacientes. Além dessas funções, é também responsabilidade dos enfermeiros a prestação de assistência direta aos pacientes que demandam cuidados intensivos ${ }^{(3-4)}$. Nesse contexto, os enfermeiros vivenciam o desafio de implementar uma prática de trabalho de natureza gerencial e assistencial.

Distúrbio Psíquico Menor (DPM) é uma expressão criada por Goldberg \& Huxley (1993) (5) para designar sintomas tais como insônia, fadiga, irritabilidade, dificuldade de concentração e de memorização, além de queixas somáticas, que sinalizam ruptura do funcionamento normal do indivíduo, porém, não configuram categoria nosológica da $10^{a}$ Classificação Internacional de Doenças (CID-10), bem como, dos Manuais de Diagnóstico e Estatístico (DSM) da Associação Psiquiátrica Americana (6).

Assim, os distúrbios psíquicos menores se constituem em um importante problema de saúde pública e apresentam impactos econômicos relevantes em função das demandas geradas aos serviços de saúde e do absenteísmo no trabalho ${ }^{(7)}$. Nos últimos anos tem-se observado que a saúde mental dos trabalhadores tem ganhado visibilidade, assim, estudos epidemiológicos são importantes para evidenciar a prevalência de Distúrbios Psíquicos Menores em determinadas populações.

Com relação aos profissionais de enfermagem, são trabalhadores intensamente expostas a riscos de origem biológica, química, física, ergonômica, além dos riscos psicossociais, que podem comprometer a saúde mental desses trabalhadores (7). Nesse sentido, pesquisas tem demonstrado que profissionais que trabalham em contato direto com pessoas representam o grupo mais exposto, como é o caso dos enfermeiros. 0 objetivo deste estudo foi estimar a prevalência e os possíveis fatores associados aos Distúrbios Psíquicos Menores em enfermeiros intensivistas.

\section{MÉTODO}

Foi realizado um estudo epidemiológico populacional, exploratório, de corte transversal, realizado com enfermeiros intensivistas de nove UTIs de hospitais públicos e privados de uma grande cidade do interior da Bahia, Brasil. Do total de hospitais da cidade, dois estavam com a UTI desativada no período da coleta de dados e, por isso, não participaram da pesquisa. Dos sete hospitais incluídos no estudo, alguns tinham mais de uma UTI.

Foram considerados elegíveis, todos os enfermeiros $(n=85)$ que atuavam em terapia intensiva, cadastrados no setor de Recursos Humanos dos sete hospitais investigados. 0 critério de inclusão foi trabalhar em UTI há pelo menos seis meses, para evitar o viés de trabalhador saudável. Os critérios de exclusão foram: atuar em atividade administrativa, estar em gozo de férias, em licença médica ou licença maternidade. 
A coleta de dados foi realizada no período de julho a novembro de 2016, por meio da distribuição de questionário validado, autoaplicável, não identificado, acompanhado do TCLE. O questionário foi composto por blocos buscando conhecer: o perfil sociodemográfico dos entrevistados; as informações gerais sobre o trabalho em UTI; o ambiente de trabalho; as atividades domésticas e os hábitos de vida, questões para detectar o abuso no consumo de bebidas alcoólicas, utilizando o Teste CAGE e a realização de atividades de lazer. A saúde mental dos trabalhadores foi avaliada mediante a utilização do Self-Report Questionnaire (SRQ-20), para detecção de DPM.

0 teste CAGE é um questionário padronizado, composto de 04 perguntas. Sua denominação é derivada das iniciais das palavras chaves de cada pergunta do original em inglês: 1) Alguma vez sentiu que deveria diminuir ou parar de beber? (Cut down?); 2) As pessoas o aborrecem porque criticam o seu modo de beber? (Annoying by criticism?); 3) Sente-se culpado pela maneira que costuma beber? (Guiltier about drinking?); 4) Costuma beber pela manhã para diminuir o nervosismo e a ressaca? (Eye-opener drink?). 0 CAGE é utilizado como teste de triagem para deteç̧ão de abuso no consumo de bebidas alcoólicas, adotando-se o ponto de corte em duas ou mais respostas positivas para as quatro questões do teste. Apresenta alta sensibilidade, especificidade e valores preditivos tanto na sua versão em inglês, como na versão em português. Os indivíduos com o escore $\geq 02$ respostas positivas foram consideradas positivos ao teste $\mathrm{CAGE}^{\left({ }^{8}\right)}$.

O SRQ-20 foi desenvolvido por Harding et al. (1980) (9), sob a coordenação da Organização Mundial de Saúde (OMS), com finalidade de estudar morbidade psiquiátrica em instituições de saúde. A versão atual do SRQ-20 é a mais utilizada em estudos de base populacional, sendo composta de 20 questões: 04 sobre sintomas físicos e 16 sobre sintomas psíquicos. As respostas são do tipo "sim" ou "não", atribuindo-se, respectivamente, valores de " 1 " e " 0 ". 0 ponto de corte sugerido pelos autores para a suspeita de DPM é o de 07 respostas positivas. 0 trabalhador que apresentou escore $\geq 07$ respostas positivas foi considerado positivo ao SRQ-20.

Um estudo piloto foi realizado no mês de junho de 2016, com dez enfermeiros trabalhadores de uma unidade de urgência de um hospital público do mesmo município, com a finalidade de verificar o tempo aproximado de preenchimento, a clareza do instrumento e a estratégia definida para a coleta de dados. Para o estudo principal, foi solicitada das Direções dos hospitais, a lista dos trabalhadores que atuavam nas UTIs e a distribuição desses entre os turnos de trabalho. Realizou-se ampla divulgação da pesquisa, por meio de cartazes e folhetos, para despertar o interesse da população alvo.

Os questionários, devidamente numerados, foram entregues aos profissionais nos respectivos locais de trabalho acompanhados do TCLE. Os pesquisadores esclareceram sobre os objetivos do estudo e as instruções gerais sobre o preenchimento. Os trabalhadores que consentiram em participar do estudo e assinaram o TCLE, preencheram o questionário no seu próprio local de trabalho. Para atender ao trabalhador que, por razões relacionadas à dinâmica do serviço, não podia interromper suas atividades para o preenchimento do instrumento, em comum acordo com sua chefia, visando não causar transtornos, um pesquisador voltava em outra ocasião para coletar os questionários respondidos. Durante a coleta, reuniões semanais foram realizadas pela equipe de pesquisadores para entrega e revisão dos questionários.

Foi realizada dupla digitação dos dados coletados no programa EpiData versão 3.1, para minimizar possíveis erros. Utilizou-se o software Statistical Package for Science (SPSS®) para a análise estatística.

A análise descritiva dos dados foi realizada com o cálculo das frequências absolutas e relativas das variáveis categóricas e da média e do desvio padrão das variáveis numéricas, referentes às características sociodemográficas, das condições de trabalho e da situação de saúde mental dos trabalhadores. Para a análise bivariada foi utilizada a razão de prevalência (RP) como medida de associação. Por se tratar de estudo populacional, não foram realizados cálculos de significância estatística ${ }^{(10)}$.

O projeto foi submetido ao Comitê de Ética em Pesquisa da Universidade Estadual de Feira de Santana (CEP/UEFS) e aprovado com Parecer n. 1.355.188 / CAAE: 49119315.4.0000.0053, cumprindo as determinações da Resolução 466/2012 (11).

\section{RESULTADOS}

Dos 85 enfermeiros inicialmente elegíveis, 5 não foram encontrados durante a coleta de dados e 15 recusaram-se a participar do estudo, constituindo uma população de 65 trabalhadores, representando $76,5 \%$ da população inicialmente elegível. 
Entre os participantes, 45,8\% trabalhavam em UTI adulto e 54,2\% em UTI pediátrica ou neonatal. Com relação às características sociodemográficas da população estudada, 90,8\% eram do sexo feminino e 9,2\% do sexo masculino; $62,9 \%$ apresentavam idade inferior a 34 anos. A média de idade encontrada foi de 33,9 anos, com desvio padrão de $\pm 6,3$. Em relação à situação conjugal, 44,4\% eram casadas e 54,0\% não tinham filhos. Com relação à formação acadêmica, 82,5\% tinham especialização e 57,1\% informaram renda entre $\mathrm{R} \$ 6.001,00$ a $\mathrm{R} \$ 10.000,00$ (Tabela 1).

Tabela 01. Características sociodemográficas da população de enfermeiros intensivistas, Feira de Santana, Bahia, Brasil, 2016.

\begin{tabular}{|c|c|c|}
\hline Características sociodemográficas & $\mathrm{n}^{*}$ & $\%$ \\
\hline \multicolumn{3}{|l|}{ Sexo $(N=65)$} \\
\hline Feminino & 59 & 90,8 \\
\hline Masculino & 6 & 9,2 \\
\hline \multicolumn{3}{|l|}{ Faixa etária (N=62) } \\
\hline$\geq 33$ anos & 39 & 62,9 \\
\hline 34 anos ou mais & 23 & 37,1 \\
\hline \multicolumn{3}{|l|}{ Estado Civil (N=63) } \\
\hline Solteiro & 19 & 30,2 \\
\hline Casado & 28 & 44,4 \\
\hline União estável & 8 & 12,7 \\
\hline Divorciado (a) & 8 & 12,7 \\
\hline \multicolumn{3}{|l|}{ Filhos $(\mathrm{N}=63)$} \\
\hline Não & 34 & 54,0 \\
\hline Sim & 29 & 46,0 \\
\hline \multicolumn{3}{|l|}{ Formação acadêmica (N=57) } \\
\hline Especialista & 47 & 82,5 \\
\hline Mestrado & 4 & 7,0 \\
\hline Residência & 5 & 8,8 \\
\hline Doutorado & 1 & 1,8 \\
\hline \multicolumn{3}{|l|}{ Tipo de UTI (N=59) } \\
\hline Adulto & 27 & 45,8 \\
\hline Neonatal & 21 & 35,6 \\
\hline Pediátrica & 11 & 18,6 \\
\hline \multicolumn{3}{|l|}{ Renda mensal $(\mathrm{N}=63)$} \\
\hline$\leq 3.000,00$ & 13 & 20,6 \\
\hline $3.001,00-6.000,00$ & 36 & 57,1 \\
\hline $6.001,00-10.000,00$ & 20 & 31,7 \\
\hline $10.001,00-20.000,00$ & 1 & 1,6 \\
\hline
\end{tabular}

Quanto às características do trabalho, a maior parte dos enfermeiros $(58,7 \%)$ informou trabalhar em UTI há pelo menos seis anos. Entre os enfermeiros estudados, 62,3\% informaram cumprir carga horária semanal de trabalho em UTI superior a 36 horas. Considerando todas as atividades que geram renda, a jornada total de trabalho ao longo da semana apresentou uma média de 54 horas, sendo que, 48,3\% apresentavam jornada semanal de trabalho superior a 54 horas e 51,7\% apresentaram jornada de trabalho semanal inferior a 54 horas. Em relação ao plantão noturno em UTI, 71,4\% apresentavam carga horária de trabalho em plantão noturno entre 12 a 24 horas. 0 tipo de vínculo de trabalho mais frequente era como assalariado no setor privado 53,1\%. Informaram ter outro vínculo de trabalho $63,5 \%$ dos participantes e $61,0 \%$ referiram assumir o plantão na UTI vindos de outra atividade de trabalho e 55,6\% dos estudados informaram acompanhar dez ou mais pacientes por plantão (Tabela 2). 
Tabela 2. Características do trabalho da população de enfermeiros intensivistas, Feira de Santana, Bahia, Brasil, 2016

\begin{tabular}{|c|c|c|}
\hline Características do trabalho & $\mathrm{n}^{*}$ & $\%$ \\
\hline \multicolumn{3}{|c|}{ Carga horária semanal de trabalho em UTI $(\mathrm{N}=61)$} \\
\hline 6-30 horas & 23 & 37,7 \\
\hline 36-168 horas & 38 & 62,3 \\
\hline \multicolumn{3}{|c|}{ Carga horária de plantão noturno em UTI (N=56) } \\
\hline 12-24 horas & 40 & 71,4 \\
\hline 36-96 horas & 16 & 28,6 \\
\hline \multicolumn{3}{|l|}{ Carga horária total semanal $(\mathrm{N}=60)$} \\
\hline$\leq 54$ horas & 31 & 51,7 \\
\hline Maior que 56 horas & 29 & 48,3 \\
\hline \multicolumn{3}{|l|}{ Vínculo institucional $(\mathrm{N}=64)$} \\
\hline Assalariado privado & 34 & 53,1 \\
\hline Assalariado público & 18 & 28,1 \\
\hline Outros** & 12 & 18,8 \\
\hline \multicolumn{3}{|l|}{ Outra atividade laboral $(\mathrm{N}=63)$} \\
\hline Sim & 40 & 63,5 \\
\hline Não & 23 & 36,5 \\
\hline \multicolumn{3}{|l|}{$\begin{array}{l}\text { Vem de outro plantão antes do } \\
\text { plantão }(\mathrm{N}=64)\end{array}$} \\
\hline Nunca/Raramente & 45 & 70,3 \\
\hline Frequentemente & 16 & 25,0 \\
\hline Sempre & 3 & 4,7 \\
\hline \multicolumn{3}{|l|}{ Pacientes por plantão $(\mathrm{N}=63)$} \\
\hline 1-9 pacientes & 28 & 44,4 \\
\hline$\geq 10$ pacientes & 35 & 55,6 \\
\hline
\end{tabular}

* Respostas válidas, excluídas as ignoradas.

Entre os enfermeiros estudados 53,8\% informaram praticar atividade física. A maior parte dos entrevistados (95,3\%) declararam não fumar. Com relação ao consumo de bebida alcoólica, 50,8\% informaram fazer uso (Tabela 3).

Tabela 3. Hábitos de vida, consumo de bebida alcoólica das enfermeiras intensivistas, Feira de Santana, Bahia, 2016

\begin{tabular}{|l|c|c|}
\hline Hábitos de vida das enfermeiras intensivistas & n* $\%$ \\
\hline Atividade Física (N=65) & 35 & 53,8 \\
\hline Sim & 30 & 46,2 \\
Não & 61 & 93,8 \\
\hline Hábito de fumar (N=64) & 02 & 3,1 \\
\hline Nunca fumou & 01 & 1,5 \\
Ex fumante & 33 & 50,8 \\
Outras & 32 & 49,2 \\
\hline Consumo de álcool -teste CAGE- (N=65) & \multicolumn{3}{|c|}{} \\
\hline Sim & Não & \\
\hline \multicolumn{3}{|c|}{ * Respostas válidas, excluídas as respostas ignoradas. }
\end{tabular}

O DPM foi observado em 24,6\% dos enfermeiros estudados. Foi verificada associação positiva entre o DPM e as variáveis sociodemográficas - idade, ter filhos, situação conjugal, renda mensal e tempo de trabalho em UTI (Tabela 4); e entre o DPM e as características do trabalho - tipo de UTI, carga horária habitual de plantão em UTI, carga horária semanal de trabalho em UTI, carga horária de plantão noturno em UTI, carga horária total de trabalho ao longo da semana e duplo vínculo e entre DPM e hábitos de vida - o consumo de álcool e a prática de atividade física (Tabela 5). 
Tabela 4 - Associação medida pela Razão de Prevalência (RP) entre as características sociodemográficos e o Distúrbio Psíquico Menor da população de enfermeiras intensivistas, Feira de Santana, Bahia, 2016.

\begin{tabular}{|c|c|c|c|c|c|}
\hline \multirow[t]{2}{*}{ Características sociodemográficas } & \multicolumn{5}{|c|}{ Distúrbio Psíquico Menor } \\
\hline & Sim & $\%$ & Não & $\%$ & $\mathrm{RP}$ \\
\hline \multicolumn{6}{|l|}{ Idade $(n=62)^{*}$} \\
\hline$\leq 32$ anos & 12 & 30,8 & 27 & 69,2 & \multirow{2}{*}{1,77} \\
\hline 33 anos ou mais & 04 & 17,4 & 19 & 82,6 & \\
\hline \multicolumn{6}{|l|}{ Situação Conjugal $(\mathrm{n}=55)$ * } \\
\hline Solteira (a) & 07 & 36,8 & 12 & 63,2 & \multirow{2}{*}{1,47} \\
\hline Com companheiro (a) & 09 & 25,0 & 27 & 75,0 & \\
\hline \multicolumn{6}{|l|}{ Ter filhos $(n=63) *$} \\
\hline Não & 10 & 29,4 & 24 & 70,6 & \multirow{2}{*}{1,42} \\
\hline Sim & 06 & 20,7 & 23 & 79,3 & \\
\hline \multicolumn{6}{|l|}{ Renda mensal $(n=63) *$} \\
\hline Maior que $\mathrm{R} \$ 6.000,00$ & 04 & 28,6 & 10 & 71,4 & \multirow{2}{*}{1,16} \\
\hline$\leq \mathrm{R} \$ 6.000,00$ & 12 & 24,5 & 37 & 75,5 & \\
\hline \multicolumn{6}{|l|}{ Tempo em anos de trabalho $(n=63) *$} \\
\hline Menor que 6 anos & 10 & 27,0 & 27 & 73,0 & \multirow{2}{*}{1,17} \\
\hline$\geq 6$ anos & 6 & 23.1 & 20 & 76,9 & \\
\hline
\end{tabular}

* Respostas válidas excluídas as ignoradas.

Tabela 5 - Associação medida pela Razão de Prevalência entre as características do trabalho, hábitos de vida e Distúrbio Psíquico Menor dos enfermeiros intensivistas, Feira de Santana, Bahia, 2016.

\begin{tabular}{|c|c|c|c|c|c|}
\hline Características do trabalho & \multicolumn{5}{|c|}{ Distúrbio Psíquico Menor } \\
\hline & Sim & $\%$ & Não & $\%$ & $\begin{array}{c}\text { Razão de } \\
\text { Prevalência }\end{array}$ \\
\hline \multicolumn{6}{|l|}{$\mathrm{CH}^{* *}$ de plantão em UTI $(\mathrm{n}=64)^{*}$} \\
\hline $\begin{array}{l}\leq 12 \text { horas } \\
>12 \text { horas }\end{array}$ & $\begin{array}{l}12 \\
04\end{array}$ & $\begin{array}{l}30,0 \\
16,7\end{array}$ & $\begin{array}{l}28 \\
20\end{array}$ & $\begin{array}{l}70,0 \\
83,3\end{array}$ & 1,80 \\
\hline \multicolumn{6}{|l|}{$\mathrm{CH}^{* *}$ total semanal em UTI $(\mathrm{n}=61)^{*}$} \\
\hline $\begin{array}{l}>36 \text { horas } \\
\leq 30 \text { horas }\end{array}$ & $\begin{array}{l}12 \\
04\end{array}$ & $\begin{array}{l}31,6 \\
17,4\end{array}$ & $\begin{array}{l}26 \\
19\end{array}$ & $\begin{array}{l}68,4 \\
82,6\end{array}$ & 1,82 \\
\hline \multicolumn{6}{|l|}{$\mathrm{CH}^{* *}$ plantão noturno $(\mathrm{n}=56)^{*}$} \\
\hline $\begin{array}{l}>12 \text { horas } \\
\leq 12 \text { horas }\end{array}$ & $\begin{array}{l}06 \\
10 \\
\end{array}$ & $\begin{array}{l}37,5 \\
25,0\end{array}$ & $\begin{array}{l}10 \\
30\end{array}$ & $\begin{array}{l}62,5 \\
75,0\end{array}$ & 1,50 \\
\hline \multicolumn{6}{|l|}{$\mathrm{CH}^{* *}$ total semanal $(\mathrm{n}=60)^{*}$} \\
\hline $\begin{array}{l}>54 \text { horas } \\
\leq 54 \text { horas }\end{array}$ & $\begin{array}{l}10 \\
06\end{array}$ & $\begin{array}{l}34,5 \\
19,4\end{array}$ & $\begin{array}{l}19 \\
25\end{array}$ & $\begin{array}{l}65,5 \\
80,6 \\
\end{array}$ & 1,78 \\
\hline \multicolumn{6}{|l|}{ Vem de outro trabalho $(n=64)^{*}$} \\
\hline $\begin{array}{l}\text { Sim } \\
\text { Não }\end{array}$ & $\begin{array}{l}12 \\
04\end{array}$ & $\begin{array}{l}30,8 \\
16,0\end{array}$ & $\begin{array}{l}27 \\
21\end{array}$ & $\begin{array}{l}69,3 \\
84,0\end{array}$ & 1,93 \\
\hline \multicolumn{6}{|l|}{ Tipo de UTI $(n=64) *$} \\
\hline $\begin{array}{l}\text { Neonatal/pediatra } \\
\text { Adulto }\end{array}$ & $\begin{array}{l}10 \\
06\end{array}$ & $\begin{array}{l}31,3 \\
22,2\end{array}$ & $\begin{array}{l}22 \\
21\end{array}$ & $\begin{array}{l}68,7 \\
77,8\end{array}$ & 1,40 \\
\hline \multicolumn{6}{|l|}{ Atividade física $(\mathrm{N}=65)$} \\
\hline $\begin{array}{l}\text { Não } \\
\text { Sim }\end{array}$ & $\begin{array}{l}08 \\
08\end{array}$ & $\begin{array}{l}26,7 \\
22,9\end{array}$ & $\begin{array}{l}22 \\
27\end{array}$ & $\begin{array}{l}73,3 \\
77,1\end{array}$ & 1,17 \\
\hline \multicolumn{6}{|l|}{ Consumo álcool $(\mathrm{N}=65)$} \\
\hline $\begin{array}{l}\text { Sim } \\
\text { Não }\end{array}$ & $\begin{array}{l}10 \\
06\end{array}$ & $\begin{array}{l}30,3 \\
18,8\end{array}$ & $\begin{array}{l}23 \\
26\end{array}$ & $\begin{array}{l}60,7 \\
81,2\end{array}$ & 1,61 \\
\hline
\end{tabular}

\section{DISCUSSÃO}

No presente estudo, o sexo feminino foi o mais frequente entre os enfermeiros estudados. A prevalência de DPM foi de 24,6\%, corroborando com o resultado do estudo sobre a sintomatologia de Transtorno Mental Comum (TMC) em enfermeiros de UTI, que encontrou uma prevalência de 27,7\% (12). Em outro estudo com trabalhadores de enfermagem de UTI, a prevalência geral de DPM foi de 42,5\% (13). 0 resultado da prevalência de DPM neste estudo foi comparado com o de outros estudos realizados com enfermeiros que 
atuavam em unidades hospitalares, sendo encontradas prevalências de DPM que variaram de 15,8\% a 20\% (14-16).

Em outros ambientes de trabalho de atuação de enfermeiros, tais como atenção básica à saúde e docência, obtiveram-se prevalências semelhantes às encontradas neste estudo ${ }^{(17,18)}$. Pode-se refletir que os DPM fazem parte de uma realidade presente no trabalho dos enfermeiros em diferentes ambientes laborais, que podem apresentar consequências diretas para a sua saúde e para a qualidade de assistência prestada, seja na área hospitalar, na atenção básica ou na docência. Por isso, podem ser considerados um problema de saúde pública.

Neste estudo, verificou-se que a prevalência de DPM foi maior entre enfermeiros com idade igual ou inferior a 34 anos, sendo observada uma razão de prevalência de 1,77, resultado semelhante ao encontrado por outro autor (15). Estudo com enfermeiros de UTI evidenciou que a depressão atinge em maior escala grupos mais jovens desses profissionais do que aqueles com idade mais avançada, apontando que essa população pode ser considerada mais vulnerável a situações de estresse e de adoecimento, devido à pouca experiência em lidar com situações rotineiras nesse ambiente de trabalho (19).

Os enfermeiros pesquisados apresentaram elevada carga horária de trabalho semanal em regime de plantão, o que pode ser um fator desencadeante de estresse e sofrimento mental. Estudos apontam que as condições de trabalho interferem diretamente na saúde dos trabalhadores. Dessa forma, este estudo revelou que existe uma associação positiva entre a elevada carga horária de trabalho em UTI e DPM, resultado semelhante ao encontrado em outros estudos com a temática de sofrimento mental e estresse entre enfermeiros de UTI e os que atuam em unidades hospitalares ${ }^{(15,19) .}$

No que se refere ao turno de plantão, verificou-se uma prevalência maior de DPM entre enfermeiros que trabalhavam à noite, com uma razão de prevalência de 1,50, resultado semelhante ao encontrado em outros estudos sobre o estresse e burnout entre enfermeiros (15,20,21). 0 trabalho noturno está associado a níveis de estresse elevados entre profissionais de enfermagem, e isso pode potencializar a ocorrência de complicações à saúde, uma vez que o desequilíbrio do ritmo biológico provoca maiores níveis de estresse e piora a qualidade do sono. Em estudo sobre os efeitos do trabalho noturno na vida de enfermeiros que atuam em unidades hospitalares, constatou-se que, no plantão noturno, esses profissionais sentem-se mais solitários, desgastados, levando a condições desfavoráveis no estado físico e mental. Tais condições incluem sensações de cansaço, alteração do humor, falta de controle e dificuldades em realizar tarefas (22).

A maioria dos enfermeiros relataram que costumavam assumir o plantão na UTI vindos de outro trabalho, o que indica uma dupla jornada laboral. A prevalência de DPM nesses profissionais foi maior quando comparada aos demais profissionais, encontrando-se uma associação positiva entre assumir o plantão vindo de outro vínculo e DPM. A dupla jornada de trabalho é uma característica constante nos estudos sobre sofrimento mental, que abordam temas como DPM, sintomatologia de TMC e estresse, revelando que a maior parte dos enfermeiros e/ou a equipe de enfermagem apresenta um duplo vínculo e que estão mais suscetíveis a apresentarem sofrimento mental $(18,20)$.

Este estudo foi realizado em distintas UTIs que prestam atendimento a diferentes clientelas (adulto, crianças e neonatos), observando-se uma associação positiva de DPM com o tipo de UTI, sendo maior a prevalência de DPM em enfermeiros que trabalhavam nas UTIs pediátricas e neonatais. Esse resultado pode ser analisado pelo contexto que envolve o trabalho nessas unidades: cuidar de crianças ou recémnascidos em estado crítico, com risco iminente de morte. Em estudo realizado com enfermeiros e médicos de UTI pediátrica sobre a significação da morte, foi relatado pelos profissionais maior sofrimento mental diante do óbito e do agravamento do quadro do paciente menor. Tal situação pode ser relacionada com a significação da vitalidade infantil, quando a morte escapa à ordem considerada natural da existência humana. Dessa forma, a sensação para os profissionais é de que a vida não foi vivida o suficiente diante da precocidade da morte ${ }^{(23)}$.

Com relação aos hábitos de vida, a maior parte dos enfermeiros relatou prática de atividade física de forma regular. Foi observada prevalência pouco maior de DPM entre os profissionais que não tinham hábito de praticar atividade física, evidenciando, portanto, a fraca associação entre a falta de atividade física e DPM. A literatura biomédica aponta inúmeros benefícios relacionados com a prática da atividade física nos hábitos cotidianos e profissionais, tais como: melhora cognitiva, combate ao estresse, ansiedade, depressão, melhora das relações interpessoais, energia e menos cansaço durante a vida laboral (24). 0 presente estudo avaliou de maneira genérica a prática de atividade física entre os trabalhadores estudados, sem utilizar instrumento específico e validado para avaliar essa condição. Além disso, esse resultado pode sugerir viés de causalidade reversa, frequente em estudos de corte transversal. Nesse caso, os trabalhadores que informaram praticar atividade física podem ter adotado esse comportamento para 
buscar melhor qualidade de vida, quando já apresentavam algum grau de sofrimento mental. Dessa forma, o resultado obtido deve ser analisado com cautela, pois a abordagem adotada apresenta baixa precisão.

Em relação ao consumo de bebida alcoólica, foi encontrada associação positiva com DPM, apresentando uma razão de prevalência de 1,61. Resultados semelhantes foram obtidos no levantamento nacional sobre o padrão de consumo de álcool na população brasileira (50\%) (25). Além disso, a American Nurses Association (ANA) estimou que cerca de 10\% dos enfermeiros são dependentes de álcool e/ou de outras drogas, o que pode comprometer sua saúde e seu desempenho profissional, colocando em risco a segurança do paciente ${ }^{(26)}$.

Algumas considerações metodológicas são importantes. 0 estudo de corte transversal examina a relação exposição-doença em uma dada população ou amostra, em um momento particular, fornecendo um retrato de como as variáveis estão relacionadas naquele momento. Por isto, não estabelece nexo causal e apenas aponta a associação entre as variáveis estudadas. Selecionar apenas os sobreviventes ao efeito estudado (viés de prevalência) é uma limitação particularmente relevante em estudos ocupacionais, em decorrência do chamado efeito trabalhador sadio. Além disso, este estudo teve cunho exploratório, realizando apenas análises bivariadas. Outro inconveniente em estudos que utilizam questionários autoaplicáveis é que o sujeito da pesquisa pode não responder a todas as questões colocadas, dificultando o controle das perdas de informação.

\section{CONCLUSÃO}

Os resultados apontaram elevada prevalência de Distúrbios Psíquicos Menores entre os enfermeiros que atuam em Unidade de Terapia Intensiva. Observou-se associação entre DPM e as variáveis: idade, carga horária total de trabalho; carga horária de trabalho, plantão noturno, duplo vínculo e tipo de Unidade de Terapia Intensiva; e consumo de álcool. Assim, existe a necessidade de ampliar os estudos sobre as condições de trabalho na Unidade de Terapia Intensiva, buscando identificar fatores associados ao sofrimento mental desses trabalhadores e promover reflexão e discussão sobre melhores condições laborais nesse cenário, visando contribuir para adoção de medidas preventivas e incentivo de hábitos de vida saudáveis.

\section{REFERÊNCIAS}

[1] Rosado IVM, Russo GHA, Maia EMC. Produzir saúde suscita adoecimento? As contradições do trabalho em hospitais públicos de urgência e emergência. Ciência Saúde Coletiva. 2014;20(10):3021-32.

[2] Ribeiro EM, Pires D, Blank VLG. A teorização sobre processo de trabalho em saúde como instrumental para análise do trabalho no Programa Saúde da Família. Cad Saúde Pública. 2004;20(2):438-46.

[3] Nascimento Sobrinho, CL, et al. Condições de trabalho e saúde mental dos médicos de Salvador, Bahia, Brasil. Cadernos de Saúde Pública, Rio de Janeiro. 2006;22(1):131-140.

[4] Araújo ST, Silva SH, Silva MN, Coelho ACC, Pires CGS, Melo CMM. Job insecurity among nurses, nursing technicians and nursing aides in public hospitals. Rev Esc Enferm USP. 2018; 52:03411.

[5] GOLDBERG, D.; HUXLEY, P. Common mental disorders: a biossocial model. 2 ed. London: Tavistock/ Routledge: 1993.

[6] COUTINHO, E. S. F.; ALMEIDA-FILHO, N.; MARI, J. Fatores de risco para morbidade psiquiátrica menor: resultado de um estudo transversal em três áreas urbanas do Brasil. Revista de Psiquiatria Clínica. 1999;26(5):246256.

[7] PORTO, D. R.; PAULA, N. V. K. Estratégias de recursos humanos relacionados com o absenteísmo profissionais de enfermagem. Revista Saúde e Pesquisa. 2010;3(3):375-370.

[8] Masur, J, Monteiro, M. Validation of the CAGE alcoholism screening test in Brazilian Psychiatry inpatient hospital setting. J Biol Res, 1983; 16: 215-8.

[9] HARDING, T. W. et al. Mental disorders in primary health care: a study of their frequency and diagnosis in four developing countries. Psychological Medicine. 1980;10(2):231-241.

[10] Dancey CP. Estatística sem matemática para psicologia. 5a ed. Porto Alegre: Penso; 2013.

[11] Brasil. Ministério da Saúde. Conselho Nacional de Saúde. Resolução n. 466, de 12 de dezembro de 2012. Aprova as diretrizes e normas regulamentadoras de pesquisas envolvendo seres humanos [Internet]. Brasília; 2013. 
[12] Silva JLL, Soares RS, Costa FS, Ramos AS, Lima FB, Teixeira LR. Psychosocial factors and prevalence of burnout syndrome among nursing workers in intensive care units. Rev Bras Ter Intensiva. 2015;27(2):125-33.

[13] Amaral TR. Dimensões psicossociais do trabalho da enfermagem e os distúrbios psíquicos menores em unidades críticas [dissertação]. [Florianópolis]: Universidade Federal de Santa Catarina; 2006. 115 f.

[14] Araujo TM, Aquino E, Menezes G, Santos CO, Aguiar L. Aspectos psicossociais do trabalho e distúrbios psíquicos entre trabalhadoras de enfermagem. Rev Saúde Pública [online]. 2003.

[15] Kirchhof ALC, Magnago TSBS, Camponocara S, Griep RH, Tavares JP, Prestes FC, et al. Condições de trabalho e características sociodemográficas relacionadas à presença de distúrbios psíquicos menores em trabalhadores de enfermagem. Texto Contexto Enferm [online]. 2009.

[16] Rodrigues EP, Rodrigues US, Oliveira LMM, Laudano RCS, Nascimento Sobrinho CL. Prevalência de transtornos mentais comuns em trabalhadores de enfermagem em um hospital da Bahia. Rev Bras Enferm. 2014;67(2):296-301.

[17] Barbosa GB, Correia AKS, Oliveira LMM, Santos VC, Ferreira SMS, Martins DFJ, et al. Trabalho e saúde mental dos profissionais da Estratégia Saúde da Família em um município do Estado da Bahia, Brasil. Rev Bras Saúde Ocup. 2012;37(126):306-15.

[18] Tavares JP, Magnago TSBS, Beck CLC, Silva RM, Prestes FC, Lautert L. Prevalência de distúrbios psíquicos menores em enfermeiros docentes. Esc Anna Nery. 2014;18(3):407-14.

[19] 19. Vasconcelos EM, Martino MMF. Preditores da sintomatologia depressiva em enfermeiros de unidade de terapia intensiva. Esc Anna Nery. 2017;21(3):17-31.

[20] 20. Inoue KC, Versa GLGS, Murassaki ACY, Melo WA, Matsuda LM. Estresse ocupacional em enfermeiros intensivistas que prestam cuidados diretos ao paciente crítico. Rev Bras Enferm. 2013;66(5):722-9.

[21] Andolhe R, Barbosa RL, Oliveira EM, Costa ALS, Padilha KG. Stress, coping and burnout among Intensive Care Unit nursing staff: associated factors. Rev Esc Enferm USP. 2015;49(spe):58-64.

[22] Girondi JBR, Gelbcke FL. Percepção do enfermeiro sobre os efeitos do trabalho noturno em sua vida. Enferm foco. 2011;2(3):191-4.

[23] Cherer EQ, Quintana AM, Pinheiro UMS. A morte na perspectiva de enfermeiros e médicos de uma Unidade de Terapia Intensiva pediátrica. Estud psicol. 2015;32(4):685-94.

[24] Freire CB, Dias RF, Schwingel PA, França EET, Andrade FMD, Costa EC, et al. Qualidade de vida e atividade física em profissionais de terapia intensiva do submédio São Francisco. Rev Bras Enferm. 2015;68(1):26-31.

[25] Instituto Nacional de Ciência e Tecnologia para Políticas Públicas do Álcool e outras Drogas; Universidade Federal de São Paulo. II LENAD - Levantamento Nacional de Álcool e Drogas - Relatório 2012.

[26] Kunyk D. Substance use disorders among registered nurses: prevalence, risks and perceptions in a disciplinary jurisdiction. J Nurs Manag. 2015;23(1):54-64. 


\section{Capitulo 14}

\section{Metodologia ativa incorporada ao ensino médico: Contribuições da monitoria em laboratório de habilidades}

Ádria Rodrigues da Silva

David José Oliveira Tozetto

Cláudia Dizioli Franco Bueno

Maria Alice Alves Fernandes de Souza

Andressa Costa de Sousa

Resumo:Segundo o Ministério da Educação, um curso de Medicina devidamente adequado deve dispor de laboratório com equipamentos e instrumento suficientes para uma excelente capacitação dos estudantes. A partir deste ponto, destaca-se a importância da constituição de uma equipe direcionada aos cuidados de manutenção de laboratórios e desenvolvimento de atividades de ensino e pesquisa nesta área. Sendo assim, o objetivo deste estudo foi relatar as atividades de ensino, pesquisa e extensão desenvolvidas através da monitoria do Laboratório de Habilidades Clínicas. Trata-se de um estudo descritivo e observacional, composto por informações retrospectivas e qualitativas, obtidas diretamente a partir de relatórios oficiais do laboratório. No período de sua vigência, o monitor realizou levantamento de aquisições do espaço de atuação, auxílio em aulas práticas e aplicação de provas dos professores da disciplina e manutenção dos materiais. A fim de contribuir ao processo de aprendizagem dos alunos, reduzindo a evasão escolar, foi criado o I Curso de Extensão de Semiologia Médica do campus, com total de 15 semanas, incluindo 9 aulas teóricas, 6 aulas práticas e 30 alunos participantes. Ao final do curso, os estudantes demonstraram preferência por métodos de ensino mais ativos e julgaram positivamente o curso, em todos os parâmetros de avaliação. Verificou-se que que é essencial a atividade do monitor para a organização das atividades desenvolvidas no laboratório de sua responsabilidade. As atribuições de ensino e extensão são importantes para a implementação de novas metodologias pedagógicas ativas, assim como para a complementação às atividades curriculares dos alunos, contribuindo para um melhor desempenho na disciplina.

Palavras-chave: Habilidades clínicas, semiologia, laboratório de habilidades. 


\section{INTRODUÇ̃̃OO}

A Universidade do Estado do Pará (UEPA) ofereceu o curso de Medicina em Marabá, um município no interior paraense com cerca de 285 mil habitantes, a fim de não só proporcionar o conhecimento das práticas médicas na Amazônia, mas também ampliar a assistência médica no interior do estado (PRESTES et al., 2015), já que esta apresentava desafios quanto ao número de profissionais disponíveis em contraste com o crescimento acelerado da população no sudeste paraense.

A UEPA foi a primeira instituição pública de ensino superior do Pará a interiorizar um curso de Medicina e a adotar o ensino baseado em problemas, o PBL (Problem Based Learning) (PRESTES et al., 2015). Este constitui-se como um método de aprendizagem inovador, centrada no estudante, sendo os educadores meros facilitadores do processo de produção do conhecimento (SOUZA e DOURADO, 2015).

O PBL enquadra-se em uma das metodologias ativas atualmente relevantes no contexto do ensino em saúde. Nesse sentido, para que um método ativo seja considerado bom, é necessário agregar algumas características em seu projeto, tais como: construtivista - se basear em aprendizagem significativa; colaborativo - favorecer a construção do conhecimento em grupo; interdisciplinar - proporcionar atividades integradas a outras disciplinas; contextualizado - permitir que o educando entenda a aplicação deste conhecimento na realidade; reflexivo - fortalecer os princípios da ética e de valores morais; crítico estimular o educando a buscar aprofundamento de modo a entender as limitações das informações que chegam até ele; investigativo - despertar a curiosidade e a autonomia, possibilitando ao educando a oportunidade de aprender a aprender; humanista - ser preocupado e integrado ao contexto social; motivador -trabalhar e valorizar a emoção; e desafiador - estimular o estudante a buscar soluções (FARIAS et al., 2015).

Apesar de parecer novo, o PBL surgiu na década de 1960, inicialmente aplicada ao estudo da psicologia comportamental. Posteriormente, passou a ser aplicada em escolas médicas e pela primeira vez na Universidade McMaster, no Canadá. Em 1987, concluiu-se que o emprego dessa metodologia apresenta oito características, que foram agrupadas e ordenadas obedecendo ao acrônimo PROBLEM da seguinte forma: problem (problema) - a unidade fundamental para o estudante é o problema; resource (recursos) a provisão adequada dos recursos permite que ocorra autoaprendizagem (ex.: instruções, literatura, internet); objectives (objetivos) - os objetivos de aprendizagem devem ser planejados pelos educadores; behaviour (comportamento) - o comportamento dos estudantes evolui progressivamente; learning (aprendizagem) - a aprendizagem é ativa e monitorada pelos pares e pelo facilitador; examples (exemplos) - o facilitador favorece o uso de habilidades cognitivas de ordem superior por meio do uso de exemplo; motivation (motivação) - a abordagem da PBL deve ser concebida para estimular o interesse em determinados tópicos e na motivação da aprendizagem (JONES, 2006).

Ademais, segundo o Ministério da Educação, um curso de Medicina devidamente adequado deve dispor de laboratório com equipamentos e instrumento suficientes para uma excelente capacitação dos estudantes. A partir deste ponto, destaca-se a importância da constituição de uma equipe direcionada aos cuidados de manutenção de laboratórios e desenvolvimento de atividades de ensino e pesquisa nesta área (BRASIL,2010).

Além do espaço físico, o treinamento de habilidades faz parte de um programa educativo estruturado ao longo dos seis anos do curso. Do primeiro ao oitavo períodos terá a denominação de Habilidades Profissionais, e seu planejamento deve prever o desenvolvimento dos conhecimentos, habilidades clínicas, cirúrgicas e atitudes necessárias ao bom desempenho profissional. Para tanto, são utilizadas estações do Laboratório de Habilidades, os ambulatórios, os hospitais e outros serviços de saúde (PRESTES et al., 2015).

Nos dois primeiros semestres, aplica-se a propedêutica e os procedimentos médicos, constituindo, a história clínica, realização de exame físico, de procedimentos médicos, de exames laboratoriais e das técnicas de comunicação. A partir do terceiro período, as habilidades profissionais fazem parte das atividades práticas de cada módulo e os estudantes são distribuídos pelos diversos cenários existentes e/ou conveniados da instituição (PRESTES et al., 2015).

Os cenários também são diversificados e ocorrem segundo a complexidade e competências necessárias à cada série. Primeiramente, o estudante realiza as atividades práticas no Laboratório de Habilidades, treinando com modelos, simuladores e pacientes atores. A partir da terceira série, os docentes iniciam as práticas nas unidades de saúde, nos ambulatórios de especialidades existentes na universidade ou em órgãos conveniados. A partir da quarta série, os docentes frequentarão as unidades hospitalares parceiras da universidade (PRESTES et al., 2015). 
Nesse contexto, a monitoria do Laboratório de Habilidades Profissionais objetiva propiciar formação acadêmica mais ampla e aprofundada ao aluno universitário, proporcionando sua participação nas atividades acadêmicas e incentivando-o ao interesse e dedicação à docência, à pesquisa e à extensão com orientação docente, contribuindo para o desenvolvimento de sua capacidade didática e científica (UEPA 2018).

Ademais, esta atividade também visa colaborar para a redução de problemas de repetência e evasão; além contribuir para o aprimoramento do ensino através do desenvolvimento de novas práticas e experiências pedagógicas no processo ensino-aprendizagem-avaliação, voltadas para a melhoria do ensino no componente curricular objeto da monitoria (UEPA, 2015).

Destina-se ao monitor, desenvolver atividades que busquem aproximar os alunos aos instrumentos de aprendizagem do laboratório, auxiliar o coordenador na elaboração de aulas e avaliações, zelar pela integridade dos materiais e elaborar pesquisa científica. Aliado à isto, observa-se a intensa necessidade de condicionar o aproveitamento do laboratório pelos alunos dos primeiros semestres do curso. É nesse período que exige-se maior carga horária dentro do laboratório, a fim de que o aluno aprenda os princípios básicos da semiologia, primeiro em simuladores, para que posteriormente, possa aplica-los nos pacientes.

Na UEPA Campus Marabá, após identificar desafios e áreas de atuação do monitor de habilidades, tornouse evidente a contribuição de um grupo de estudos pautado na ampliação dos conhecimentos em semiologia para a construção de profissionais devidamente capacitados. Esta estratégia também complementa as teorias ministradas pelos professores da disciplina, proporciona melhor aplicabilidade prática, instiga questionamentos e hipóteses e permite a troca de informações e experiências entre os alunos.

Ademais, uma problemática visualizada atualmente é a dificuldade em contratar médicos professores, visto que ainda há poucos profissionais da área no município paraense e os salários para tal cargo são pouco atraentes em face às boas remunerações oferecidas por consultórios, clínicas e hospitais. Consequente a isto, os professores da instituição são responsabilizados em ministrar disciplinas para muitas turmas, tornando os horários entre monitor e professor pouco compatíveis. Dessa forma, as oportunidades de utilização dos materiais de forma eficiente são minimizadas.

Pelos fatos descritos, evidenciou-se que a contribuição da monitoria em áreas de ensino e extensão em uma universidade paraense interiorizada deve ser discutida e valorizada em face aos desafios metodológicos e administrativos presentes na instituição. Relatar o trabalho realizado no contexto do ensino médico por metodologia ativa abrirá discussões sobre o papel dos alunos e monitor em identificar as problemáticas do ensino e propor soluções dentro de um curso de semiologia, o qual foi proposto pela união entre monitor, coordenador e alunos interessados.

\section{OBJETIVOS}

\subsection{OBJETIVO GERAL}

O objetivo deste estudo foi relatar as atividades de ensino, pesquisa e extensão desenvolvidas através da monitoria do Laboratório de Habilidades Clínicas.

\subsection{OBJETIVOS ESPECÍFICOS}

a) Analisar os métodos de ensino que os alunos mais aprovaram.

b) Reconhecer os materiais mais utilizados durante as atividades.

c) Identificar dificuldades durante o exercício do ensino.

d) Comparar as experiências vivenciadas com outros relatos de monitoria.

\section{METODOLOGIA}

A pesquisa iniciou após o consentimento do coordenador do Laboratório de Habilidades Profissionais, Prof. David José Oliveira Tozetto, e da coordenador geral a da UEPA Campus VIII - Marabá, Danielle Rodrigues Monteiro da Costa; assim como após a aprovação do protocolo de estudo pelo Comitê de Ética 
em Pesquisa (CEP) desta instituição (CAAE 09087519.2.0000.5174 e número de parecer 3.407.541) e pelo colegiado do campus, respeitando-se a Resolução № 466/2012 do Conselho Nacional de Saúde, o Código de Nuremberg e a Declaração de Helsinque.

Trata-se de um estudo descritivo e observacional, composto por informações retrospectivas e qualitativas, obtidas diretamente a partir de relatórios elaborados pelo primeiro monitor e pelo coordenador do laboratório. A partir das práticas de ensino e extensão desenvolvidas neste ambiente universitário, foram definidos os materiais mais utilizados pelos alunos e professores e as propostas de desenvolvimento para a aplicabilidade dos conhecimentos práticos. Estas informações foram relatadas pelos responsáveis do laboratório, em documentos oficiais de monitoria.

0 estudo ofereceu riscos referente à perda de sigilo de informações institucionais da universidade, visto que os materiais e serviços mencionados ficam restritos ao ambiente da instituição. Para minimizá-los, ressalta-se que as atividades desenvolvidas foram aprovadas pela extensão universitária. Ademais, a instituição e os pesquisadores não obtiveram nenhum ônus com o estudo.

É importante frisar que as atividades foram desenvolvidas no período entre setembro de 2018 à novembro de 2019, anterior à pandemia atualmente vigente da Covid-19.

\section{RESULTADOS E DISCUSSÃO}

O Laboratório de Habilidades Clínicas da UEPA Campus VIII foi inaugurado junto à liberação do prédio destinado ao curso de Medicina, em 2018. A estrutura compõe-se de uma secretaria e onze salas, designadas conforme os materiais inclusos. Um relatório anual é redigido pelo coordenador e pelo monitor, informando as atividades realizadas, as dificuldades e a situação dos materiais.

A monitoria foi disponibilizada em setembro de 2018. As primeiras atividades consistiram no levantamento digitado das aquisições do laboratório, além do treinamento acerca do funcionamento e manutenção dos instrumentos, do auxílio em aulas práticas de professores e do esclarecimento de dúvidas dos alunos em relação aos simuladores.

Em setembro de 2019, iniciaram as atividades de ensino e extensão através do I Curso de Extensão de Semiologia Médica do campus, com total de 15 semanas e uma carga horária de 50 horas. Como parte deste montante, houveram 9 aulas teóricas e 6 aulas práticas, incluindo assuntos como exame físico geral, de cabeça e pescoço, de tórax e abdome, de órgãos genitais e exame neurológico.

Foram selecionados 30 alunos interessados em participar. Para tanto, em maio de 2019, foi divulgada uma nota nas redes sociais e no mural da instituição visando informar sobre as propostas do grupo de estudo e listar os interessados. Não houve processo seletivo e, em vez disso, foi realizado um sorteio devido à maior proporção de interessados em relação ao número de vagas disponibilizadas, pois não houve prioridade por turma, visto que a semiologia básica é melhor aplicada aos primeiros anos de curso, mas também não se pôde excluir alunos em períodos mais avançados.

Sendo assim, foram incluídos como participantes os alunos do curso de Medicina da UEPA Campus VIII Marabá que possuíam 18 anos ou mais e que estavam dispostos à acompanhar semanalmente o grupo de estudos, independentemente do período em que esivessem cursando. Não foi exigido qualquer custo e a única exigência era a utilização de jaleco próprio. Por ter sido uma atividade desenvolvida em período prolongado e fora da programação curricular do curso, o grupo de estudo foi classificado como atividade complementar e ofereceu certificação de 50 horas de carga horária. Para tanto, foi exigido a presença do participante em $75 \%$ das atividades, ou seja, em doze reuniões, no mínimo.

Por ser um assunto essencial no estudo da Medicina e pela limitada capacidade física do Laboratório de Habilidades, serão excluídos da pesquisa alunos de outros cursos do campus, assim como os estudantes com menos de 18 anos de idade.

A princípio, verificou-se grande procura dos alunos em participar do curso, desde calouros até estudantes do estágio obrigatório (internos). Muitos estudantes justificaram o ato pelo desejo de agregar mais conhecimentos, uma vez que pouco frequentaram o laboratório e tiveram poucas aulas práticas com total supervisão dos professores. Assim, na primeira semana, foi feita uma reunião composta pelo monitor, coordenador e participantes, a fim estabelecer as prioridades do curso por meio de um diálogo crítico, identificando as principais dificuldades dos alunos e quais pontos na metodologia utilizada pelos professores precisariam ser reformulados. 
As aulas teóricas eram ministradas pelo monitor e apresentadas através dos recursos do PowerPoint 2013. Os conteúdos foram selecionados conforme o mais discutido nas aulas da disciplina Habilidades Profissionais, sendo abordados capítulos dos livros Semiologia Médica, 7a edição, de Celmo Celeno Porto e Arnaldo Lemos Porto e Propedêutica Médica, 10a edição, de Lynn S. Bickley e Peter G.Szilagyi. Observou-se menor interação e interesse dos alunos neste tipo de método tradicional, assim como maior cansaço e satisfação do monitor em ministrar as aulas.

As aulas práticas foram realizadas nos diferentes setores do laboratório de habilidades e integravam um questionário sobre conhecimentos adquiridos no assunto, casos clínicos acerca do exame físico estudado, treinamentos em trios e descrição do exame em prontuário simulado. 0 método das reuniões era sempre discutido juntamente aos alunos, a fim de estabelecer o que foi eficaz e o que poderia ser feito para melhorar.

Assim, o formulário confeccionado pelo monitor era aplicado por um aplicativo de celular, o Socrative student, contendo perguntas e feedbacks espontâneos, com cálculo de rendimento da turma ao final da aplicação. Para a resolução dos formulários, só era necessário ter um celular ou computador e acesso à internet, o que não demonstrou-se problema em nenhum momento. Ademais, o nome do aluno não era exigido. Verificou-se que todos os alunos interessaram-se em resolver as questões, que poderiam ser aplicadas após aula teórica, discussão ou aula prática simulada, ficando a critério do assunto abordado.

Os casos clínicos eram elaborados pelo monitor a partir do estudo das literaturas citadas, além de outros livros de clínica médica. A discussão dos casos eram realizadas em uma mesa redonda, dividindo-se a turma em duas partes, conforme a metodologia das sessões tutoriais elaborada pela coordenação do curso de Medicina da UEPA e já utilizada por diversas faculdades. Por ser uma discussão breve, foi intitulada, pelos alunos, de "mini-tutoria".

As sessões eram baseadas nos preceitos do PBL, partindo-se de sete passos direcionados: 1) identificar e esclarecer termos desconhecidos apresentados no cenário; 2) definir o(s) problema(s) a ser(em) discutido(s); 3) realizar uma sessão de brainstorming para discutir o(s) problema(s), sugerindo possíveis explicações com base no conhecimento prévio; 4) revisar as etapas 2 e 3 e disponibilizar explicações como tentativas de solução; 5) formular objetivos de aprendizagem; 6) estudo individual; e 7) discussão coletiva a partir dos resultados.

Já os treinamentos eram simulados por trios de alunos atores, que se dividiam em paciente, médico e avaliador, o qual portava um checklist com nota total 10, também previamente elaborado pelo monitor. Os trios eram definidos previamente, visando mesclar os alunos de diferentes turmas, a fim de haver melhor trabalho em equipe e troca de conhecimentos. 0 checklist avaliava desde a apresentação inicial do médico ao paciente até a empunhadura dos materiais. À cada treinamento, os atores trocavam de papel.

Por último, a descrição do exame físico em prontuário simulado visava estimular a escrita com termos técnicos, raciocínio clínico organizado e identificação das características mais importantes do exame, a fim de obter-se um registro completo e detalhado respeitando-se a descrição no sentido crânio-caudal e a ordem do exame: inspeção, palpação, percussão e ausculta (a variar segundo seguimento corporal).

Os materiais mais utilizados durante o curso foram: estetoscópio, esfingmomanômetro, abaixador de língua, espéculo nasal, otoscópio, balança antropométrica, painel de papéis, martelo de exame neurológico, diapasão para sensibilidade vibratória, caneta com foco de luz e câmeras de vídeo. Como insumos: papéis, algodão, álcool em gel, luvas de procedimento, álcool à 70\%, espéculos vaginais, escova e espátula de Ayre, gel lubrificante e talco. Os bonecos mais utilizados foram o de ausculta cardiopulmonar, de ginecologia e obstetrícia e de urologia.

Observou-se dificuldade na realização de exame neurológico, pois ainda não há simuladores sensíveis aos testes verificados na semiologia desta área, que incluem reflexos, tonicidade muscular e reação pupilar. Além disso, o exame físico do abdome ficou comprometido, uma vez que as provas para averiguar pontos dolorosos necessitariam de bonecos com sensibilidade tátil profunda, sendo estes ainda inviáveis. Ademais, verificou-se que alguns materiais destinados ao estudo de casos clínicos, como o negatoscópio, não foram utilizados.

Ao final do curso, um questionário final foi aplicado com o objetivo de reconhecer a opinião dos alunos quanto à ao ensino da Semiologia Médica, à metodologia utilizada, aos métodos de ensino mais eficientes, à estimulação ao trabalho em equipe e ao raciocínio clínico e ao trabalho do monitor. Para cada item citado, constava-se uma pergunta objetiva, conforme o Gráfico 1. Quanto os métodos de ensino, o Gráfico 2 representa as opções e preferências dos participantes, sendo que todas as alternativas poderiam ser assinaladas. E, por último, uma questão subjetiva para críticas e sugestões à próxima edição do curso. 
Gráfico 1: Avaliação do curso pelos participantes

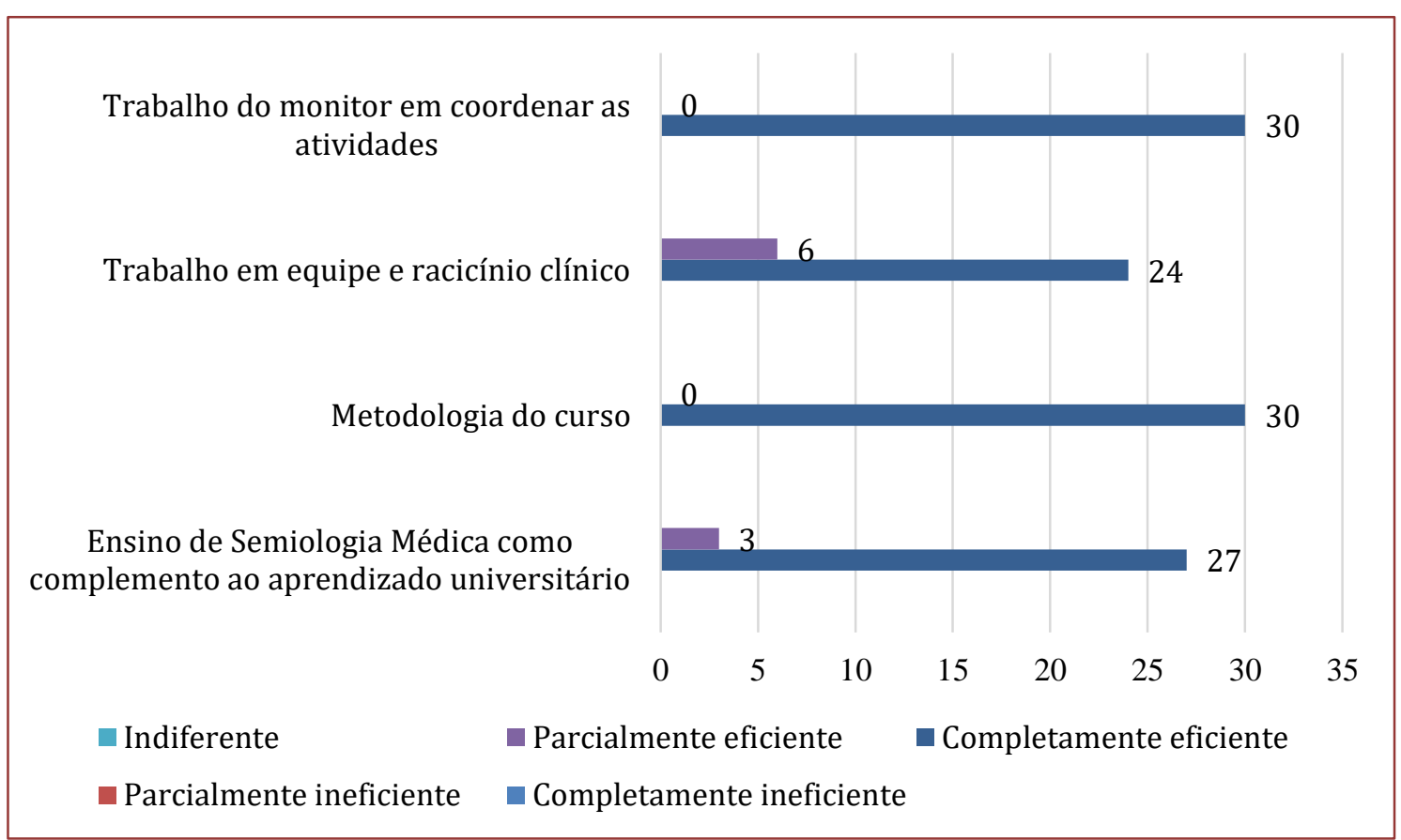

Fonte: SILVA, 2019.

Gráfico 2: Preferência dos alunos por métodos de ensino

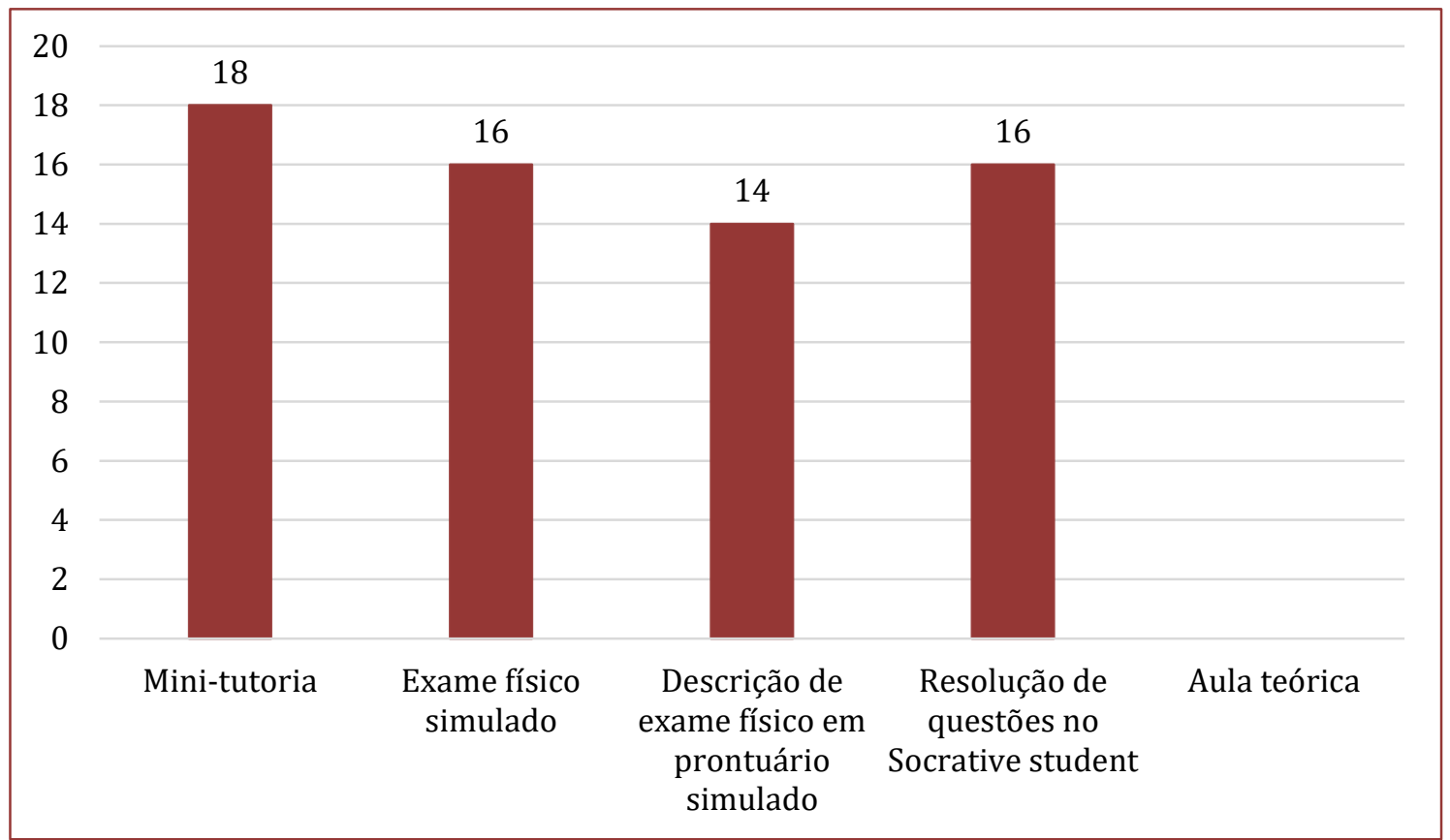

Fonte: SILVA, 2019.

Nesse contexto, Morais et al. (2014) também relataram o desenvolvimento de atividades práticas com docentes e auxílio a acadêmicos com baixo rendimento, ressaltando o enriquecimento do processo ensinoaprendizagem por parte de todos os envolvidos. Jreige et al. (2014) frisam o despertar do interesse do monitor pela docência, o que também foi observado neste caso, especialmente pelo entusiasmo na elaboração de métodos mais envolventes aos demais alunos. 


\section{CONCLUSÃO}

Conclui-se que é essencial a atividade do monitor para a organização das atividades desenvolvidas no laboratório de sua responsabilidade. As atribuições de ensino e extensão são importantes para a implementação de novas metodologias pedagógicas ativas, assim como para a complementação às atividades curriculares dos alunos, contribuindo para um melhor desempenho na disciplina.

Quanto aos métodos de ensino, as aulas teóricas configuram-se como artifício de pouca eficiência no processo de aprendizagem. Entretanto, não se pode negar que esta avaliação é relativa, pois deve-se considerar a experiência e técnica do professor. Por outro lado, é visível que as novas práticas de ensino, como as discussões de casos clínicos e simulações de exame físico, tomam lugar nesse contexto, tornando o ensino médico mais palpável, eficaz e protagonizado pelos alunos.

Nesse sentido, os relatórios sobre materiais utilizados e práticas bem aceitas pelos alunos apontam para quais instrumentos podem ser economizados e quais precisam ser implementados para um melhor desempenho coletivo.

Por fim, a monitoria permite reconhecer as dificuldades de aprendizado dos alunos e traçar um plano de ação em conjunto com os mesmos, visto que a flexibilização dos métodos de ensino é exigida constantemente no método PBL e ainda se constitui um desafio para os professores formados no ensino tradicional.

\section{REFERÊNCIAS}

[1] BRASIL. Ministério da Educação. Sistema Nacional de Avaliação da Educação Superior - SINAES. Instrumento de avaliação do curso de Medicina. Brasília: 2010.

[2] FARIAS, P.A.M.; MARTIN, A.L.A.R.; CRISTO, C.S. Aprendizagem ativa na educação em saúde: percurso histórico e aplicações. Revista brasileira de educação médica. 39 (1): 143-158; 2015.

[3] MORAIS, A.L.G.; KASUYA, A.V.B.; ALMEIDA, L.N. et al. Monitoria na disciplina de pré-clínica II: relato de experiência. In: CONGRESSO DE PESQUISA, ENSINO E EXTENSÃO, 11, 2014, Goiás. Anais. Conpeex, 2014. p. 38153819.

[4] DOURADO, L. Aprendizagem Baseada em Problemas (ABP): um método de aprendizagem inovador para o ensino educativo. Revista HOLOS, Ano 31, Vol. 5, 2015.

[5] JONES, R.W. Problem-based learning: description, advantages, disadvantages, scenarios and facilitation. Anaesth Intensive Care. 2006;34(4):485-8.

[6] JREIGE, S.K.S; FONSECA, R.B.; BARATA, T.J.E. et al. Relato de vivência na monitoria da disciplina de Clínica de Atenção Básica I. In: CONGRESSO DE PESQUISA, ENSINO E EXTENSÃO, 11, 2014, Goiás. Anais. Conpeex, 2014. p. 4181-4184.

[7] Universidade do Estado do Pará. Projeto Político Pedagógico do Curso de Medicina da Universidade do Estado do Pará (UEPA) no Município de Belém- Pará. Belém, 2015. f, il. Autores: PRESTES, Elaine Xavier et.al.

[8] Universidade do Estado do Pará. Centro de Ciências Biológicas e da Saúde. Edital no 052/2018-UEPA: processo seletivo de monitoria bolsista e voluntária/CCBS. Belém: 2018.

[9] Universidade do Estado do Pará. Conselho Universitário. Resolução 2808/15-CONSUN/UEPA. Belém: 2015. 


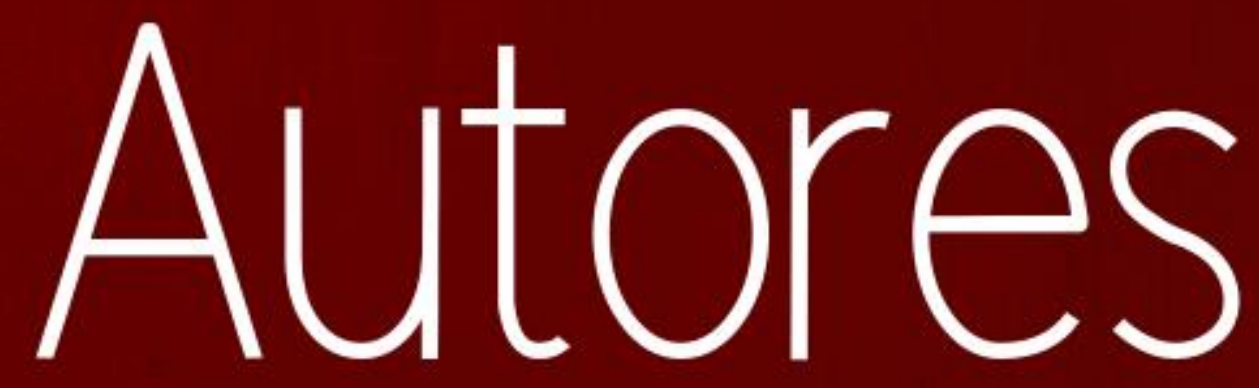




\section{GLEICA SOYAN BARBOSA ALVES (ORGANIZADORA)}

Farmacêutica (UFAM - 2013), mestre em Saúde, Sociedade e Endemias na Amazônia (UFAM - 2016) professora assistente da Universidade Federal do Amazonas (UFAM) e Coordenadora do Curso de Engenharia Sanitária do Instituto de Ciências Exatas e Tecnologia (ICET). Tem experiência na área de Microbiologia, Epidemiologia, Biologia Molecular e Controle de Qualidade de Alimentos e Medicamentos.

\section{ELIENE DE OLIVEIRA (ORGANIZADORA)}

Graduada em Odontologia pela Universidade Estadual de Montes Claros - Unimontes (2017) e em Enfermagem pelas Faculdades Unidas do Norte de Minas - FUNORTE (2011). Especialista em Saúde da Família. Especialista em Educação a Distância. Servidora pública efetiva no cargo de Odontológo na Prefeitura Municipal de Montes Claros/MG. Docente na Escola Técnica de Saúde do Centro de Educação Profissional e Tecnológica da Unimontes. Professora supervisora do Estágio em Saúde da Família do curso de Odontologia da FUNORTE. Possui experiência em Saúde Coletiva/Saúde da Família.

\section{ÁDRIA RODRIGUES DA SILVA}

Médica pela Universidade do Estado do Pará (UEPA). Ex-diretora científica (2017-2019) da Liga Acadêmica de Endocrinologia e Metabologia de Marabá (LAEMM). Ex-Monitora do Laboratório de Habilidades Clínicas da UEPA (2018-2019). Ex-bolsista (2020-2021) do Programa Institucional de Bolsas de Iniciação Científica (PIBIC) da Fundação Amazônia de Amparo a Estudos e Pesquisas (FAPESPA). Atualmente atua em serviços de Urgência e Emergência e Medicia Legal.

\section{ÁGDA BRAGA TEIXEIRA}

Cirurgiã-Dentista (graduada pela Universidade Estadual de Feira de Santana - UEFS - 2014 -2019); bolsista do núcleo de câncer oral (uefs) 2016-2017, bolsista do programa institucional de bolsa de iniciação científica na modalidade PIBIC/FAPESB (2015-2016), PROBIC/UEFS (2016-2019), aperfeiçoamento em cirugia oral menor (ABO- Feira), prótese fixa (Iapeem).

\section{ALEXANDRE BEZERRA SILVA}

Mestre em Saúde da Família. Enfermeiro da Secretaria de Saúde Pública do Estado do Rio Grande do Norte (SESAP/RN)

\section{ALISSON JUNIOR DOS SANTOS}

Enfermeiro, Mestre em Ciências pelo Programa de Pós-Graduação Mestrado Profissional Tecnologia e Inovação em Enfermagem pela Escola de Enfermagem de Ribeirão Preto/Universidade de São Paulo - EERP/USP (2020), Licenciatura em Educação Profissional e Tecnológica pelo Instituto Federal de Educação, Ciência e Tecnologia do Sul de Minas Gerais - IFSULDEMINAS Campus Muzambinho (2021), Especialização em Epidemiologia e Vigilâncias em Saúde pela Faculdade Unyleya (em andamento), Controle de Infecção Hospitalar pela AVM - Faculdades Integradas (2015), Urgência e Emergência pela Fundação de Ensino Superior de Passos/Universidade do Estado de Minas Gerais - FESP/UEMG (2012) e Bacharelado em Enfermagem pela Fundação de Ensino Superior de Passos/Universidade do Estado de Minas Gerais - FESP/UEMG (2010). Docente do Curso de Bacharelado em Enfermagem da Universidade do Estado de Minas Gerais - UEMG Unidade Passos desde 2015.

\section{ANA CAROLINE SANTOS MARIANO}

Acadêmica extensionista; Universidade Estadual de Ponta Grossa (UEPG); Odontologia. 


\title{
ANA FLÁVIA DE LIMA ROCHA CRUZ
}

\author{
Enfermeira
}

\section{ANA KAROLINE BRITO DOS SANTOS}

Enfermeira pela Universidade Estadual de Feira de Santana, Pedagoga pelo Centro Universitário Leonardo da Vinci, especialista em Enfermagem na Urgência, Emergência e UTI pela Faculdade de Tecnologia e Ciências e mestranda em Saúde Coletiva pela Universidade Estadual de Feira de Santana. Com vasta experiência em Extensão na graduação, já esteve vinculada ao Projeto "Promovendo a saúde no cotidiano das feiras livres de Feira de Santana- Ba" do Núcleo Integrado de Estudos e Pesquisas sobre o Cuidar/Cuidado (NUPEC), ao Projeto "Implantação da Sistematização da Assistência de Enfermagem no Hospital Clériston Andrade" do Núcleo Interdisciplinar de Estudos sobre Desigualdades em Saúde" (NUDES) e ao PET (Programa de Educação pelo Trabalho)/ Rede de Atenção às Urgências e Emergências, na qual atuava no Serviço de Atendimento Móvel de Urgência (SAMU). Atualmente, pesquisadora vinculada ao Núcleo Interdisciplinar de Estudos sobre Vulnerabilidade em Saúde (NIEVS) e à Fundação de Amparo à Pesquisa do Estado da Bahia (FAPESB), com ênfase na saúde da mulher.

\section{ANA PAULA EUFRÁZIO DO NASCIMENTO}

Cirurgiã-Dentista (graduada pela Universidade Estadual de Feira de Santana - UEFS - 2009 -2014); Sócia proprietária da Custmar Clínica Odontológica LTDA ME e APEN Odontologia e Saúde Integrada. Mestre em Saúde Coletiva pelo Programa de Pós-Graduação em Saúde Coletiva - Mestrado acadêmico- UEFS (2014-2016). Especialização em andamento em Implantodontia e Prótese dentária. Atuou como professora no Curso de Odontologia da Soberana - Faculdade de Saúde de Petrolina (2017-2019.2) e na Especialização de Saúde Coletiva da Faculdade Maria Milza (FAMAM: 2015-2017). Desenvolveu tirocínio docente na disciplina de Bioestatística e Epidemiologia (E.I. III), componente curricular do Curso de Odontologia da UEFS (2015.1). Possui formação em Odontologia pela UEFS (2013.2). Pesquisadora-Bolsista CAPES. Pesquisadora voluntária do Núcleo de Pesquisa em Câncer de Cabeça e Pescoço (NUPESCAP) da Unidade de alta Complexidade em Oncologia (UNACON), do Hospital Dom Pedro de Alcântara (2015 - 2018). Pesquisadora voluntária do Núcleo de Câncer Oral - NUCAO/UEFS (2013-2016). Atuou como monitora (bolsista) nas Disciplinas Odontologia Preventiva e Social II (OPS II) e Odontologia Preventiva e Social IV (OPS IV). Realizou atividades de extensão voluntária no PET- Saúde da Família e no Programa Laboratório de Comunidade (PROLAC/ 3 anos). Participou como Estagiária e Mediadora de Aprendizagem no Estágio de Vivência do SUS, nas terceira e quarta edição. Foi bolsista do Programa de extensão da UEFS (PROEXT) e monitora (voluntária) da Disciplina Odontologia Preventiva e Social IV (OPS IV). Participou como membro do Diretório Acadêmico (3 anos) do Curso de Odontologia (DIRACO), do Colegiado do Curso de Odontologia-UEFS (2 anos) e do Mestrado Acadêmico em Saúde ColetivaUEFS ( 1 ano) na qualidade de representante discente.

\section{ANDRESSA COSTA DE SOUSA}

Médica pela Universidade do Estado do Pará (UEPA). Enfermeira pela Universidade Federal do Pará (UFPA). Ex-diretora da Liga Acadêmica de Endocrinologia e Metabologia de Marabá (LAEMM). Exmonitora bolsista do Laboratório Morfofuncional. Possui estágio extracurricular em Cardiologia pelo Hospital de Clínicas Gaspar Vianna e em Radioterapia pelo Hospital Porto Dias e Hospital Ophir Loyola. Atualmente atua em serviços de Urgência e Emergência e Medicina de Família e Comunidade.

\section{BENVINDA MATIAS DANTAS NETA}

Graduada em Medicina pela Universidade Estadual de Feira de Santana(UEFS), bolsista do Programa Institucional de Iniciação Científica 2017-2018. Médica formada pela Universidade Estadual de Feira de Santana. 


\section{BRENDA HELEN FREIRE BARBOSA}

Enfermeira. Esp. em Urgência e Emergência.

\section{CARLITO LOPES NASCIMENTO SOBRINHO}

Médico Sanitarista, Doutor em Medicina e Saúde, Professor Pleno de Epidemiologia do Departamento de Saúde, Universidade Estadual de Feira de Santana. Professor Permanente do Programa de Pós-Graduação em Saúde Coletiva e do Programa de Pós-Graduação em Enfermagem, Departamento de Saúde, Universidade Estadual de Feira de Santana, Feira de Santana-BA, Brasil

\section{CLÁUDIA DIZIOLI FRANCO BUENO}

Médica especialista em Pediatria e Infectologia Pediátrica pela Universidade de São Paulo (USP), em Ribeirão Preto. Especialista em Emergências Pediátricas pela Faculdade Israelita de Ciências da Saúde Albert Einstein. Possui título de especialista em Pediatria pela Sociedade Brasileira de Pediatria (SBP), assim como em Medicina Intensiva Pediátrica e Emergências Pediátricas pela AMB (Associação Médica Brasileira). Instrutora do curso de Reanimação Neonatal da SBP. Coordenadora do Departamento de Emergências Pediátricas da SOPAPE. Docente efetiva do curso de Medicina da Universidade do Estado do Pará Campus Marabá. Membro da equipe de Unidade de Terapia Intensiva Pediátrica do Hospital Santa Helena Rede Dór.

\section{CLEIDE LUCILLA CARNEIRO SANTOS}

Licenciada em Normal Superior pela Universidade Norte do Paraná (2007). Graduada em Fisioterapia pela Faculdade Nobre (2010). Pós-Graduação em Saúde Pública pela Faculdade Nobre (2009). Pós-Graduação em Fisioterapia Cardiopneumofuncional (2011). Formação em Pilates pela Active Pilates Brasil/ Bahia (2010). Mestrado Acadêmico do Programa de Pós-graduação em Saúde Coletiva da Universidade Estadual de Feira de Santana (2015 - 2017). Pesquisadora da Sala de Situação e Análise Epidemiológica e Estatística do Departamento de Saúde da Universidade Estadual de Feira de Santana (SSAEE/DSAU/UEFS). Atua nas Áreas de Reabilitação Muscular, Pilates, Respiratória, Neurologia (atendimento domiciliar), no Núcleo Ampliado de Saúde da Família do município de Riachão do Jacuípe - BA, membro do Núcleo Responsável de Implantação das Práticas Integrativas e Complementares no município de Riachão do Jacuípe - BA, multiplicadora da Temática do Envelhecimento, elaboração do Plano de Ação de Saúde da Pessoa Idosa e na Capacitação em Atenção Integral de Saúde da Pessoa Idosa no município de Riachão do Jacuípe, Tutora da Estratégia Nacional para Promoção do Aleitamento Materno e Alimentação Complementar no Sistema Único de Saúde.

\section{DANIELA HULLER}

Pós-graduanda extensionista; Universidade Estadual de Ponta Grossa (UEPG); Doutoranda do Programa de Pós-Graduação em Odontologia.

\section{DAVID JOSÉ OLIVEIRA TOZETTO}

Médico especialista em Clínica Médica, Cardiologia e Ecocardiografia pelo Hospital das Clínicas da Faculdade de Medicina de Ribeirão Preto - Universidade de São Paulo (USP). Especialista em Medicina Intensiva pelo Hospital São Francisco. Mestrado em Ciências Médicas pela USP. Docente efetivo e coordenador pedagógico do curso de Medicina da Universidade do Estado do Pará (UEPA) Campus VIII. Doutorando em Ensino em Saúde na Amazônia pela UEPA. Coordenador das áreas de Cardiologia e Medicina Intensiva Adulto do Hospital Regional do Sudeste do Pará.

\section{DAVI FÉLIX MARTINS JÚNIOR}

Graduação em Geografia pela Universidade Federal da Bahia (UFBa) (1992), Mestrado em Saúde Comunitária pelo Instituto de Saúde Coletiva ISC/UFBa (1997) e Doutorado pelo Programa de Pósgraduação em Medicina e Saúde PPgMS/UFBa (2018). Atualmente é professor Adjunto na 
Universidade Estadual de Feira de Santana (UEFS). Tem experiência na área de Saúde Coletiva, com ênfase em epidemiologia, atuando principalmente nos seguintes temas: envelhecimento populacional, causas externas (suicídio), neoplasias e óbitos por causas mal definidas.Membro pesquisador do Nnepa/UEFS e SSAEEUEFS.

\section{DEISE DOS SANTOS SILVA NASCIMENTO}

Enfermeira, Pós-Graduação em Enfermagem do Trabalho, Mestre em Enfermagem pelo Departamento de Saúde da Universidade Estadual de Feira de Santana - BA.

\section{DOMINIQUE ELLEN CARNEIRO}

Pós-graduanda extensionista; Universidade Estadual de Ponta Grossa (UEPG); Doutoranda do Programa de Pós-Graduação em Odontologia

\section{ÉDER PEREIRA RODRIGUES}

Enfermeiro, Doutor em Processos Interativos dos Órgãos e Sistemas, Mestre em Saúde Coletivo. Professor Adjunto da Universidade Federal do Recôncavo da Bahia.

\section{EDUARDA CRISTINA SANTOS}

Acadêmica extensionista; Universidade Estadual de Ponta Grossa (UEPG); Odontologia.

\section{ELIZABETH MATILDA OLIVEIRA WILLIAMS}

Fonoaudióloga Mestre em Educação (UFAM) e Professora do Programa de Graduação do Centro Universitário Fluminense (UNIFLU) Especialista em Linguagem e Motricidade Orofacial (CEFAC) Aprimoramento em Linguagem pela TK-TechKnowledge (TK), Processamento Auditivo Central (PAC-CEFAC) e Programa de Conserção Auditiva (CEFAC) Pós- graduada em Audiologia Educacional

\section{FÁBIO ANDRÉ DOS SANTOS}

Coordenador; Departamento de Odontologia da Universidade Estadual de Ponta Grossa (UEPG); Professor Associado.

\section{FLÁVIA GOMES MATOS}

Pós-graduanda extensionista; Universidade Estadual de Ponta Grossa (UEPG); Doutoranda do Programa de Pós-Graduação em Odontologia.

\section{GABRIELLA BENÉ BARBOSA}

Especialização em Gestão em Saúde (FIOCRUZ/ENSP); Mestrado e Doutorado em Saúde Coletiva (UEFS/BA), Epidemiologia / Saúde, Trabalho e Ambiente.

\section{IANDRA SARA DOS SANTOS FERREIRA}

Graduada em Enfermagem, pela Universidade Estadual de Feira de Santana-UEFS. Pesquisadora no Núcleo Interdisciplinar de Estudos sobre Vulnerabilidades e Saúde-NIEVS/UEFS, foi bolsista de Iniciação Científica de 2016-2018, e bolsista de extensão no ano de 2019.

\section{ILMA ALESSANDRA LIMA CABRAL RODRIGUES}

Fonoaudióloga Especialista em Audiologia Clínica (CEFAC) e Coordenadora/Professora do Curso de Fonoaudiologia do Centro Universitário Fluminense (UNIFLU) 


\section{IRACEMA LUA}

Pós-doutoranda vincula ao Instituto de Saúde Coletiva (ISC-UFBA) e ao Centro de Integração de Dados e Conhecimentos para Saúde (CIDACS-FIOCRUZ). Doutora, Mestra em Saúde Coletiva e Graduada em Enfermagem pela Universidade Estadual de Feira de Santana (UEFS). Com experiência na docência do ensino superior e na pesquisa. Pesquisadora do Núcleo de Epidemiologia da UEFS atuando nas linhas de pesquisa: Gênero, Saúde e trabalho; Vigilância em saúde; Saúde, Trabalho e Ambiente; Vigilância em Saúde Mental e Trabalho; Saúde dos Trabalhadores da Saúde e Desempenho de Instrumentos de Pesquisa.

\section{JOSÉ DEUSVANDO FREIRE CAMPOS}

Enfermeiro. Esp. Enfermagem em Dermatologia.

\section{JOSIVAN FELIX DA SILVA}

Enfermeiro. Esp. em Gestão e Auditoria em Serviços de Saúde

\section{LAURA CRISTINA ANDRADE BUBNA}

Acadêmica extensionista; Universidade Estadual de Ponta Grossa (UEPG); Odontologia.

\section{LAURO TAQUES NETO}

Pós-graduando extensionista; Universidade Estadual de Ponta Grossa (UEPG); Mestrando do Programa de Pós-Graduação em Odontologia.

\section{LEOMAR EMANUEL ALMEIDA MECCA}

Pós-graduando extensionista; Universidade Estadual de Ponta Grossa (UEPG); Doutorando do Programa de Pós-Graduação em Odontologia.

\section{LEONARDO DE JESUS COSTA SANTOS}

Cirurgião-dentista, graduado na Universidade Estadual de Feira de Santana (2019); foi bolsista do PET-Odonto da UEFS (2014-2015).

\section{LORENA PACHECO CORDEIRO LISBOA}

Fisioterapeuta, Mestre em Saúde Coletiva pelo Departamento de Saúde da Universidade Estadual de Feira de Santana - BA.

\section{LOURDES ZEBALLOS LÓPEZ}

Pós-graduanda extensionista; Universidade Estadual de Ponta Grossa (UEPG); Doutoranda do Programa de Pós-Graduação em Odontologia

\section{LUCIANA MAIA SANTOS}

Graduada em Enfermagem pela Universidade Estadual de Feira de Santana (2009).Pós-Graduada em urgência e emergência pelo Centro Universitário Internacional (2010). Foi Bolsista de Iniciação científica PIBIC/CNPq e FAPESB atuando na área de Saúde da Criança e adolescente no Núcleo de Estudos e Pesquisas na Infância e Adolescência (NNEPA).Foi Enfermeira do Hospital EMEC, Coordenadora do Centro Cirúrgico do Hospital São Matheus em Feira de Santana e Enfermeira da Secretaria Municipal de Saúde de Feira de Santana. Mestre em Saúde Coletiva (2017) pelo Programa de Pós Graduação em Saúde Coletiva da Universidade Estadual de Feira de Santana. Foi Docente das 
Faculdades Faresi na cidade de Conceição do Coité e Pitágoras de Feira de Santana . Doutoranda em Saúde coletiva pelo Programa de Pós Graduação em Saúde Coletiva da Universidade Estadual de Feira de Santana, atuando nas áreas de saúde da mulher, adolescente, criança, violência por parceiro íntimo. Pesquisadora no Núcleo Interdisciplinar de Estudos sobre Vulnerabilidades e SaúdeNIEVS/UEFS.

\section{LUIZ RICARDO MARAFIGO ZANDER}

Possui graduação em Odontologia pela Universidade Estadual de Ponta Grossa (2018), Residência em Neonatologia pelo Programa de Residência Multiprofissional em Neonatologia do Hospital Universitário da Universidade Estadual de Ponta Grossa (HU/UEPG) e Pós-graduação em Aromaterapia pelo IBRA. Atualmente é mestrando do Programa de Pós-graduação em Ciências da Saúde (UEPG). Tem experiência na área de Odontologia, com ênfase em Odontologia Hospitalar, Odontologia Neonatal e Odontopediatria, atuando principalmente nos seguintes temas: saúde bucal materno-infantil, aleitamento materno, anquiloglossia, Unidade de Terapia Intensiva (UTI) Neonatal, UTI Pediátrica e odontopediatria na primeira infância. Integrante de pesquisas sobre a temática materno-infantil.

\section{LUZIMARA GOMES MELO}

Enfermeira formada pela Universidade Estadual de Feira de Santana (UEFS) - BA e especialista em Saúde da Família pelo Programa de Residência Multiprofissional em Saúde da Família FIOCRUZ/FESF-SUS. Especialização em Gestão de Redes de Atenção à Saúde pela Escola Nacional de Saúde Pública Sérgio Arouca - ENSP/FIOCRUZ e pós-graduação em Auditoria em Saúde pela UNINTER. Mestrado em andamento em Saúde Coletiva pelo Programa de Pós-Graduação em Saúde Coletiva da UEFS. Membro do Núcleo Interdisciplinar de Estudos sobre Vulnerabilidade em Saúde (NIEVS).

\section{MARCIO CAMPOS OLIVEIRA}

Possui graduação em Odontologia (1993) e Especialização em Odontologia em Saúde Coletiva (1999) pela Universidade Estadual de Feira de Santana (UEFS), Mestrado (2001) e Doutorado (2005) em Patologia Oral pela Universidade Federal do Rio Grande do Norte (UFRN). Atualmente é Coordenador do Laboratório de Patologia Bucal e Professor Titular Pleno da Universidade Estadual de Feira de Santana, no Curso de graduação em Odontologia, no Programa de Pós-graduação em Saúde Coletiva (Mestrado e Doutorado) e no Mestrado Profissional em Saúde Coletiva. Tutor egresso do PET Odontologia UEFS. Tem experiência na área de Odontologia, com ênfase em Patologia Oral e Estomatologia, atuando principalmente nos seguintes temas: Epidemiologia das doenças bucais, câncer oral e desordens orais potencialmente malignas.

\section{MARIA ALICE ALVES FERNANDES DE SOUZA}

Médica pela Universidade do Estado do Pará (UEPA). Ex-presidente da Liga Acadêmica de Endocrinologia e Metabologia de Marabá (LAEMM) e da Liga Acadêmica Marabaense de Pediatria (LAMPED). Atualmente atua em serviços de Urgência e Emergência e Medicina de Família e Comunidade.

\section{MARIA EDUARDA SCHIMANSKI}

Acadêmica do segundo do curso de Bacharel em Odontologia pela Universidade Estadual de Ponta Grossa (UEPG).

\section{MARIANE APARECIDA SANSON WAYAR}

Professora Colaboradora da UEPG nas disciplinas de Mecanismos das doenças (Microbiologia, Imunologia e Patologia Oral), Clínica Integrada e Microbiologia Experimental (2019-atual). Atua como cirurgiã-dentista em UBS na Prefeitura Municipal de Ponta Grossa. Possui Mestrado (2016) e 
Doutorado (2020) em Clínica Integrada e graduação em Odontologia pela UEPG. Especialista em Gestão em Saúde pela UEPG juntamente com a UAB. Atuação em consultório odontológico particular (2016, 2018-2019). Atua na área de pesquisa nos seguintes temas: ensaios in vitro de citotoxicidade, fluxometria pulpar por laser Doppler, cultivo celular, células indiferenciadas de polpa dental humana, modulação de resposta inflamatória, pesquisa em animais, pesquisa clínica e doença periodontal.

\section{MARIANNE GROLLMANN}

Acadêmica extensionista; Universidade Estadual de Ponta Grossa (UEPG); Odontologia.

\section{MILLA FERREIRA COURI STERNBERG}

Fonoaudióloga Especialista em Audiologia pelo Centro de Especialização em Fonoaudiologia Clínica (CEFAC) / Especialista em Motricidade Oral pelo Centro de Especialização em Fonoaudiologia Clínica (CEFAC). Secretaria Municipal de Saúde na função de Fonoaudióloga responsável pelo Programa Saúde Auditiva da microrregião de Muriaé.

\section{MÔNICA DE ANDRADE NASCIMENTO}

Médica Psiquiatra, Doutora em Medicina e Saúde (UFBA), Professora Adjunta do Curso de Medicina, Departamento de Saúde, Universidade Estadual de Feira de Santana, Feira de Santana-BA, Brasil

\section{MONIKI AGUIAR MOZZER DENUCCI}

Fonoaudióloga Doutoranda do Programa de Pós-graduação da Universidade Estadual do Norte Fluminense (UENF) e Professora do Programa de Graduação do Centro Universitário Fluminense (UNIFLU).

\section{NÚBIA SAMARA CARIBÉ DE ARAGÃO}

Enfermeira. Mestre em Saúde Coletiva - Universidade Estadual de Feira de Santana. Especialista em Enfermagem do Trabalho e Urgência/ Emergência. Especialista em Docência do Ensino Superior Universidade Cândido Mendes. Doutoranda em Saúde Coletiva - Universidade Estadual de Feira de Santana (em andamento).

\section{PALOMA DE SOUSA PINHO}

Professora Adjunta III da Universidade Federal do Recôncavo da Bahia. Doutora em Saúde Pública pelo Instituto de Saúde Coletiva da UFBA (2018). Mestre em Saúde Coletiva (2006) e Graduada em Enfermagem (2001) pela Universidade Estadual de Feira de Santana. Líder e Pesquisadora do Núcleo Saúde, Educação e Trabalho (NSET) da UFRB e Vice-Líder do Núcleo de Epidemiologia (NEPI) da UEFS. Atualmente compõe o Comitê de Acompanhamento e Enfrentamento à Covid-19 da UFRB. Representante da universidade na Comissão Intersetorial em Saúde do Trabalhador (CIST/SAJ). Tem experiência no campo da Saúde Coletiva nas linhas de Epidemiologia, Saúde do Trabalhador e da Trabalhadora, Gênero, Docência, Saúde Mental e Imunização.

\section{PATRÍCIA HELENA RIBEIRO CAIXÃO DE SIQUEIRA BARRETO}

Graduação em Fonoaudiologia pelo Centro Universitário Fluminense (UNIFLU)

\section{ROSELY CABRAL DE CARVALHO}

Possui graduação em Enfermagem Obstétrica pela Escola Paulista de Medicina (1978), mestrado em Saúde Pública pela Universidade Federal da Bahia (1998) e doutorado em Saúde Pública pela Universidade de São Paulo (2003). Estágio Pós Doutoral na UNIVERSIDADE CATÓLICA DO SALVADOR- UCSal (2016-2017 ), no Programa de Pós- graduação em Família na Sociedade 
Contemporânea , com a proposta de trabalho interdisciplinar cooperativo e compartilhado de dois núcleos de pesquisa da pós graduação na área de enfermagem NÚCLEO INTERDISCIPLINAR DE ESTUDOS SOBRE VULNERABILIDADE E SAÜDE (NIEVS) e SALA DE SITUAÇÃO E ANÁLISE EPIDEMIOLÓGICA E ESTATÍSTICA (SSAEE) da Universidade Estadual de Feira de Santana -UEFS, sob a supervisão de Profa. Dra Ana Cecília Sousa Bittencourt e Profa. Dra. Isabel Maria Sampaio Oliveira Lima dos Bastos dos grupos de pesquisa Família e Desenvolvimento Humano e Direito à Saúde e Família. Atualmente é professora titular aposentada da Universidade Estadual de Feira de Santana-UEFS. Atualmente docente do Mestrado Acadêmico de Saúde Coletiva e Mestrado Profissional da UEFS. Pesquisadora na área de Saúde Coletiva , Epidemiologia, Práticas de EnsinoServiço e Comunidade, com ênfase em vigilância a saúde e estudos de prevalência, atuando principalmente nos seguintes temas: família , infância, adolescência, juventude, violências, álcool e drogas, estilos parentais, distúrbios psicomenores, hipertensão, estudo das populações em risco e vulnerabilidade e sistema de informação. Pesquisadora da Sala de Situação e Análise Epidemiológica e Estatística (SSAEE) e Núcleo Interdisciplinar de Estudos sobre Vulnerabilidade e Saúde (NIEVS). Coordena o Projeto ADOLESCÊNCIA E JUVENTUDE RISCOS E FATORES DE PROTEÇÃO DO USO ABUSIVO DE ÁLCOOL E OUTRAS DROGAS.

\section{STELLA KOSSATZ}

Possui graduação em Odontologia pela Universidade Estadual de Ponta Grossa (1991), Mestrado em Dentística Restauradora pela Universidade Estadual Paulista Júlio de Mesquita Filho (1995) e Doutorado em Dentística Restauradora pela Universidade Estadual Paulista Júlio de Mesquita Filho (1999). Atualmente é Professora Associada do Departamento de Odontologia da Universidade Estadual de Ponta Grossa, no Paraná e Chefe do Departamento de Odontologia desta mesma instituição. Tem experiência na área de pesquisa em Odontologia, com ênfase em Dentística Restauradora, atuando principalmente nos seguintes temas: resina composta, aparelhos fotoativadores, clareamento dental, sensibilidade dental e estudos clínicos randomizados.

\section{TAMARA CRISTINA ALVES}

Acadêmica do segundo do curso de Bacharel em Odontologia pela Universidade Estadual de Ponta Grossa (UEPG).

\section{TÂNIA MACHADO DE CARVALHO}

Especialista em Psicopedagogia Clínica e Institucional (Institutos Superiores de Ensino do Censa) e graduanda do Curso de Fonoaudiologia do Centro Universitário Fluminense (UNIFLU), Professora da rede pública do estado do Rio de Janeiro (SEEDUC)

\section{TÂNIA MARIA DE ARAÚJO}

Graduada em Psicologia pela Universidade Federal de Minas Gerais (1990), Mestra em Saúde Comunitária pela Universidade Federal da Bahia (1994), Doutora em Saúde Pública pela Universidade Federal da Bahia (1999), Pós-doutorado na University of Massachusetts, Estados Unidos (2004) e Pós-doutorado na Heinrich-Heine-Universität Düsseldorf (HHU) (2019). Professora Visitante da Heinrich-Heine-Universität Düsseldorf (HHU), Alemanha (2018-2019). Atualmente, Professora Titular Pleno da Universidade Estadual de Feira de Santana. Coordenadora do Núcleo de Epidemiologia da UEFS. Docente dos Programas de Pós-Graduação em Saúde Coletiva (UEFS) e de Saúde, Ambiente e Trabalho (UFBA).

\section{THAIS REGINA KUMMER FERRAZ}

Possui graduação em Odontologia pela UEPG (2002), Mestrado em Odontologia (ênfase em Odontopediatria) pela UFSC (2006) e Doutorado em Odontologia (ênfase em Odontopediatria) pela UFSC (2009). Possui Especialização Multiprofissional em Saúde da Família pelo Departamento de Saúde Pública da Universidade Federal de Santa Catarina (2014). Atuou de 2008-2019 como cirurgiã-dentista da ESF do município de São Mateus do Sul-PR. Atualmente é professora adjunta da UEPG e da UNIUV-PR, Professora do Curso de Odontologia da Faculdade UniCesumar (Ponta 
Grossa). Ministra as disciplinas de Odontopediatria, Clínica Integrada Infantil, Práticas de Saúde Bucal e Saúde Coletiva . Têm experiência na área de Odontologia, com ênfase em Odontopediatria e Saúde Coletiva(Saúde da Família).

\section{VINICIUS SILVA BASTOS DE JESUS}

Cirurgião-dentista, graduado na Universidade Estadual de Feira de Santana (2019); MBA em Gestão Hospitalar e Serviços de Saúde, na Faculdade Atualiza (2021); fez aperfeiçoamento em cirurgia oral menor na ABO de Feira de Santana-Ba (2016-2017); bolsista de iniciação científica e extensão pelo NUCAO-UEFS (2014-2016); atualmente, atua como cirurgião-dentista junto à prefeitura de Antônio Cardoso-BA. 
